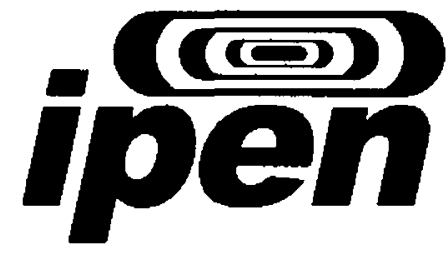

AUTARQUIA ASSOCIADA A UNIVERSIDADE DE SAO PAULO

INTERCOMPARAÇÃO DE COLIMADORES DE MÚLTIPLAS LÂMINAS PARA IMPLEMENTAÇÃO DE TERAPIA DE FEIXES DE INTENSIDADE MODULADA

\author{
JUAN FERNANDO DELGADO VITERI
}

Dissertação apresentada como parte dos requisitos para obtenção do Grau de Mestre em Ciências na Area de Tecnologia Nuclear - Aplicações.

Orientadora:

Dra. Laura Natal Rodrigues

São Paulo

2006 


\section{INSTITUTO DE PESQUISAS ENERGÉTICAS E NUCLEARES AUTARQUIA ASSOCIADA À UNIVERSIDADE DE SÃO PAULO}

\section{INTERCOMPARAÇÃO DE COLIMADORES DE MÚLTIPLAS LÂMINAS PARA IMPLEMENTAÇÃO DE TERAPIA DE FEIXES DE INTENSIDADE MODULADA}

JUAN FERNANDO DELGADO VITERI

Dissertação apresentada como parte dos requisitos para obtenção do Grau de Mestre em Ciências na Área de Tecnologia Nuclear - Aplicações.

Orientadora:

Dra. Laura Natal Rodrigues 
Este trabalho é dedicado à minha esposa Maria Alexandra e à minha filha Camila Isabella por elas serem a motivação para continuar, e nas horas dificeis me fizeram acreditar que era possivel culminar este projeto.

Aos meus pais, Fernando e Teresa, às minhas irmãs María Teresa e Maria Laura, ao César Vicente e aos seus pequenos, por terem acreditado em mim este tempo tudo.

Aos meus sogros e a todos os familiares e amigos que me apoiaram e dessa forma me ajudaram a conquistar este objetivo. 


\section{AGRADECIMENTOS}

À Dra. Laura Natal Rodrigues de forma muito especial pela orientação, dedicação, as experiências, os conselhos e a amizade que permitiram não desmaiar até chegar no final deste objetivo.

Ao Dr. José Carlos Cruz, Coordenador de Fisica Medica do Serviço de Radioterapia do Hospital Israelita Albert Einstein de São Paulo, minha eterna gratidão pela experiência e conhecimento transmitidos, pela paciência, a sábia orientação e por permitir-me acompanhar o seu trabalho no HIAE.

Ao Dr. Ken Shortt, Chefe da Seção de Fisica Médica e Dosimetria (DMRP) da Agência Internacional de Energia Atômica, por ter confiado em mim e por sua preocupação com o desenvolvimento da Fisica Médica na América Latina.

Meus agradecimentos também ao Serviço de Radioterapia Hospital Israelita Albert Einstein de São Paulo, pela oportunidade de desenvolver este trabalho. Agradeço à equipe, aos Médicos, às Biomédicas, pessoal de Enfermagem e Administrativo. De forma especial, agradeço aos Físicos Paulo, Lourenço e Roberto, e às Dosimetristas Adriana e Lidiane. Obrigado pela ajuda, a paciência e pela oportunidade de crescer profissionalmente junto a vocês.

Agradeço profundamente ao Hospital Oncológico SOLCA - Núcleo de Quito, ao seu Presidente o Gral. Sólon Espinosa Ayala; ao Diretor Médico, Dr. Fausto Tafur; ao Diretor Executivo, Coronel Benjamin Núñez, por ter me oferecido à oportunidade de obter este Grau e de adquirir experiência profissional como Fisico Médico, representando ao Hospital e ao nosso querido Equador.

A toda a equipe do Departamento de Radioterapia do Hospital Oncológico SOLCA - Núcleo de Quito dirigidos pelo Dr. César Bueno, aos Médicos, Dosimetristas, Técnicos, pessoal de Enfermagem e Secretaria. 
Aos meus colegas os Fisicos do Departamento de Radioterapia do Hospital Oncológico SOLCA - Núcleo de Quito, Yolanda Défaz, Jorge García e William Espinoza por apoiar-me neste projeto.

Aos meus colegas de Pos Graduação, Eduardo, Priscilla, Patricia, Cristiane, Márcio por ter compartilhado todos esses momentos com este estranho; agradeço ainda de forma especial ao André M. M. Vieira pela amizade e a oportunidade de discutir o desenvolvimento deste trabalho ao longo destes dois anos, estarei agradecido para sempre.

Ao IPEN e ao Centro de Metrologia das Radiações pela oportunidade de desenvolver este trabalho.

Meu agradecimento à Agência Internacional de Energia Atômica pelo suporte financeiro para o desenvolvimento do presente trabalho.

Agradeço novamente à minha familia e aos meus amigos lá no distante Equador, saibam que cada coisa feita durante o desenvolvimento deste trabalho teve um esforço dobrado (pela língua e pela distância), mas tudo isso é pouco diante do orgulho de ter nascido nessa nossa terra e de tentar fazê-la crescer. Espero sinceramente, não tê-los defraudado.

Por fim, quero agradecer a todas as pessoas, que eu esqueci de nomear acima e que de alguma forma colaboraram e me ajudaram a conseguir este objetivo. Muito obrigado. 


\title{
INTERCOMPARAÇÃO DE COLIMADORES DE MÚLTIPLAS LÂMINAS PARA IMPLEMENTAÇÃO DE TERAPIA DE FEIXES DE INTENSIDADE MODULADA
}

\author{
Juan Fernando DELGADO VITERI
}

\begin{abstract}
RESUIO
Neste trabalho é apresentada uma intercomparação das caracteristicas dosimétricas entre três sistemas de colimadores multi-låminas: Varian Millenium com 120 lâminas, mMLC $m_{3}$ Brainlab e Varian Mark II ambos com 52 lâminas. A largura da projeção das lâminas no isocentro e na regiâo central do campo é de $0,5 \mathrm{~cm} ; 0,35 \mathrm{~cm}$ e $1,0 \mathrm{~cm}$ respectivamente. Foram comparadas caracteristicas dosimétricas comuns aos três sistemas em modo estático e, no modo dinâmico, 0 trabatho limitou-se aos dois primeiros

Em modo dinâmico, foram realizados testes que avaliam o funcionamento através da irradiaçăo em filme de figuras padrăo, como a reprodutibilidade e estabilidade do MLC. Foi testada a linearidade das UM, sensibilidade a interrupçáo de tratamentos, a constáncia na velocidade das láminas encontrando-se em todos os casos dentro do $\pm 3 \%$. Na linearidade da taxa de dose existem diferenças quando este parâmetro diminui. Encontrou-se que o desvio médio da dose é inversamente proporcional à abertura média dos campos dinâmicos. $O$ fator de rendimento em modo dinámico apresentou variaçōes de até $1 \%$ quando 0 sistema suporte funcional se encontrava em posiçőes laterais
\end{abstract}

Para os trés sistemas de MLC, nos perfis para um mesmo tamanho de campo foi observada uma inclinação maior na região de penumbra para o $\mathrm{mMLC}$; nos fatores de rendimento existem também pequenas diferenças de um sistema para outro.

A abertura dosimétrica entre pares de lâminas foi determinado para o MLC 120, mMLC e MLC 52 , os valores obtidos para $6 \mathrm{MV}$ foram: $(0,202 \pm 0,054) \mathrm{cm} ;(0,157 \pm 0,070) \mathrm{cm}$ e $(0,189 \pm 0,081) \mathrm{cm}$ respectivamente. A transmissão apresentou um comportamento crescente com a profundidade e 0 tamantio de campo para $6 \mathrm{MV}$ nos trés sistemas. Os valores médios determinados com cămara de ionizaçăo para $6 \mathrm{MV}$ foram os seguintes: $(1,630 \pm 0,018) \%$ para o MLC $120 ;(1,291 \pm 0,029) \%$ para o mMLC e $(1,638 \pm 0,010) \%$ para o MLC 52 . Quando testada com filme, a transmissåo entre as làminas $\mathrm{e}$ intralâminas apresentou dependéncia com a posição fora do eixo central tanto no MLC 120 quanto no mMLC. A porcentagem de espalhamento produzido pelo MLC, com relaçáo a um campo aberto de referencia de $6 \mathrm{MV}$ foi: $(0,297 \pm 0,024) \%$ para o MLC $120 ;(0,239 \pm 0,052) \%$ para o mMLC e $(0,202 \pm 0,028) \%$ para o MLC 52. A penumbra $(80-20 \%)$ em funçăo do deslocamento fora do eixo não apresentou variações significativas nos três sistemas. Para todos os MLCs, a penumbra apresentou um comportamento crescente em função do tamanho de campo definido pelas lâminas. Em função da profundidade em $6 \mathrm{MV}$, a penumbra apresentou o menor valor para o mMLC em $d_{\max }: 2,59 \mathrm{~mm}$ e o maior é $6,74 \mathrm{~mm}$ para o MLC Mark 11 a $10 \mathrm{~cm}$ de profundidade. A penumbra em função do ángulo que as lâminas formam com o seu eixo de movimento, para o ângulo de $10^{\circ}$ no $\mathrm{mMLC}$ apresentou um valor $3,74 \mathrm{~mm}$; já para os ângulos maiores, os maiores valores foram os obtidos para o Mark II.

A série de testes descrita no presente trabalho permite estabelecer uma rotina no comissionamento de sistemas de MLC que pode ser aplicada nos serviços de Radioterapia que vão comissionar sistemas de MLC para IMRT em modo dinâmico. Os resultados descritos permitem caracterizar cada um dos sistemas de MLC estudados. Nâo é possivel dizer que um sistema é melhor que outro, mas é possivel, a partir da escolha de um deles, identificar as possiveis vantagens e desvantagens que cada um vai apresentar. 


\title{
MULTILEAF COLLIMATOR INTERCOMPARISON FOR INTENSITY MODULATED RADIATION THERAPY IMPLEMENTATION
}

\author{
Juan Fernando DELGADO VITERI
}

\begin{abstract}
In this work a dosimetric comparison between three multileaf collimator systems is presented: a Varian Millenium with 120 leaves, Brainlab $\mathrm{mMLC}_{3}$ and Varian Mark II both with 52 leaves. The width projection at isocenter level in field's central region are: $0.5 \mathrm{~cm} ; 0,35 \mathrm{~cm}$ e $1.0 \mathrm{~cm}$ respectively. Common dosimetric characteristics for the three systems in static mode and dynamic capabilities for the two first were compared

In dynamic mode, tests validating proper MLC function through film irradiation were done, such MLC stability, MU linearity, treatment interruptions sensitivity, stability of MLC in dynamic mode, leaf speed stability, were found within $\pm 3 \%$ deviation in all cases. Dose rate linearity showed differences when this parameter decreases in dynamic mode. Average dose errors for fixed width gaps moving at constant speed were found to be proportional to gap errors and inversely proportional to the gap width. Output factors differences delivered through a sweeping gap were found less than $\pm 1 \%$ when the gantry was in a lateral position.

For the three MLC systems, when comparing beam profiles for the same field was observed that for $\mathrm{mMLC}$ presents the sharpest dose gradient region. In the output factors small differences where observed in every MLC system.

Dosimetric leaf gap was determined for MLC 120, mMLC and MLC 52, obtained values for a $6 \mathrm{MV}$ beam are: $(0,202 \pm 0,054) \mathrm{cm} ;(0,157 \pm 0,070) \mathrm{cm}$ e $(0,189 \pm 0,081) \mathrm{cm}$ respectively. The transmission showed an increase with depth and field width for $6 \mathrm{MV}$ in all the three systems. Average values obtained with ionization chamber for this energy were: $(1,630 \pm 0,018) \%$ for MLC 120; $(1,291 \pm 0,029) \%$ for $\mathrm{mMLC}$ and $(1,638 \pm 0,010) \%$ for MLC 52 . When obtained through film irradiation, inter and intra leaf transmission showed an off axis dependent behavior for MLC 120 and $\mathrm{MMLC}$. Scatter produced by MLC as a $6 \mathrm{MV}$ open reference field ratio was: $(0,297 \pm 0,024) \%$ for MLC 120; $(0,239 \pm 0,052) \%$ for mMLC and $(0,202 \pm 0,028) \%$ for MLC 52. It was verified that penumbra width $(80-20 \%)$ as a function of off axis leaf position do not showed significant differences in all systems. As a function of field width defined by MLC leaves, penumbra width presented an increasing behavior. When tests as a depth function in a $6 \mathrm{MV}$ field, penumbra showed the smallest value for the $\mathrm{mMLC}$ at $d_{\text {max }}: 2,59 \mathrm{~mm}$ and the biggest was $6,74 \mathrm{~mm}$ for the MLC Mark II AT $10 \mathrm{~cm}$ depth. Penumbra dependence with leaf movement axis showed that for $10^{\circ}$, the $\mathrm{mMLC}$ presented a $3,74 \mathrm{~mm}$ value, for larger angles, the higher values were obtained for MLC Mark II.

Described series of tests described in the present investigation allows to establish a commissioning routine for MLC systems, that could be applied in a Radiotherapy Department that will commission those systems for dynamic IMRT. Obtained results allow to characterize every MLC studied system. It is not possible to establish which system is better, but when one is chosen it is feasible to identify vantages and disadvantages that everyone will present.
\end{abstract}




\section{SUMÁRIO GERAL}

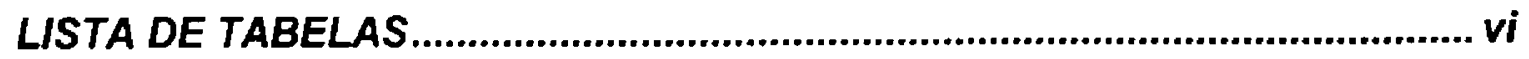

LISTA DE FIGURAS..................................................................................... vii

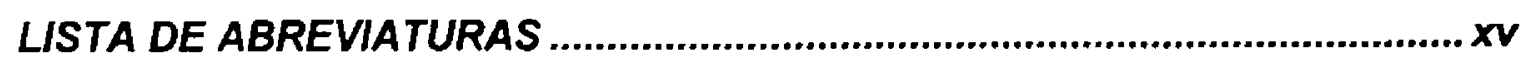

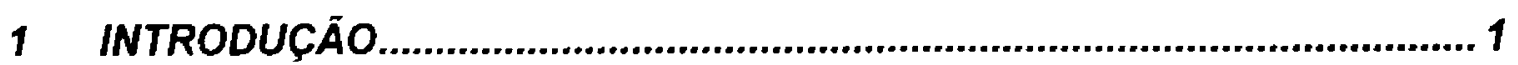

1.1 HISTÓRICO. O PERCURSO ATÉ A MODULAÇÃO DO FEIXE............... 4

1.2 SISTEMA DE MICRO COLIMADOR MULTI-LÂMINAS ....................... 5

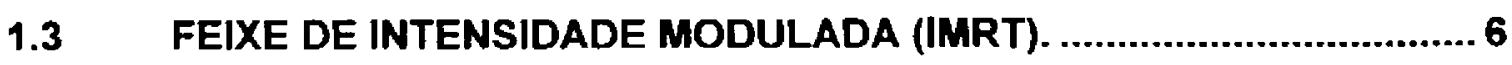

1.3.1 FEIXES DE FÓTONS E ELÉTRONS COM INTENSIDADE MODULADA ... 6

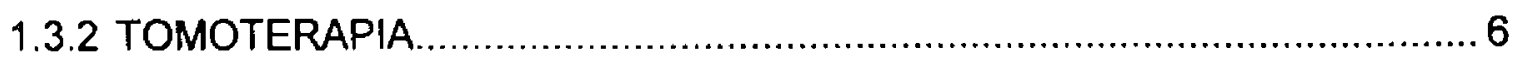

1.3.3 INTENSIDADE MODULADA COM COLIMADORES MULTI-LÂMINAS ....... 8

1.3.3.1 MODO DINÂMICO DE MOVIMENTO DAS LÂMINAS DO MLC. JANELA

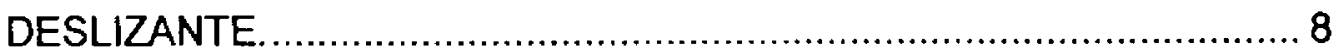

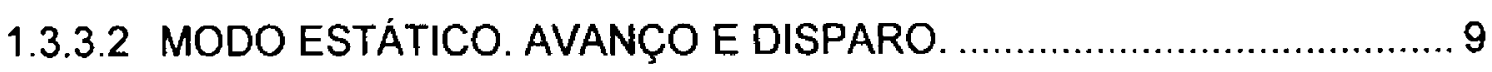

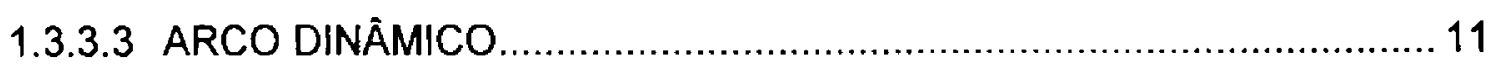

1.3.4 INTENSIDADE MODULADA COM MODULADORES FISICOS ............... 11

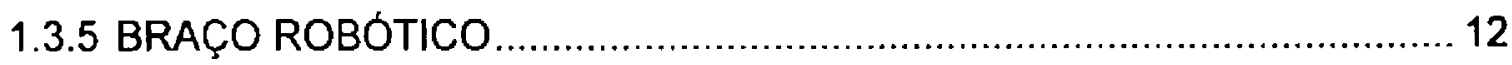

1.4 SISTEMAS DE PLANEJAMENTO ...................................................... 12

1.4.1 ALGORITMOS DE PLANEJAMENTO. PLANEJAMENTO DIRETO E

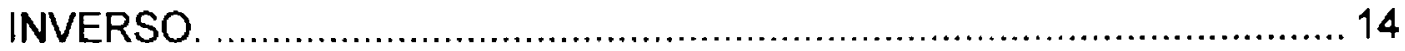

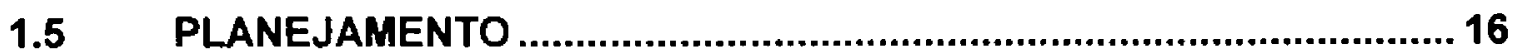

1.6 FUNDAMENTOS DE DOSIMETRIA. ................................................ 17

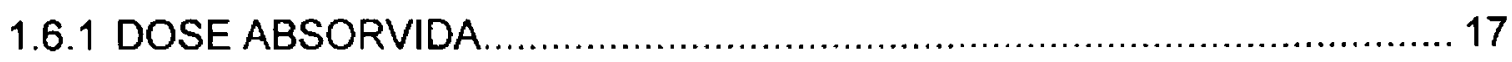

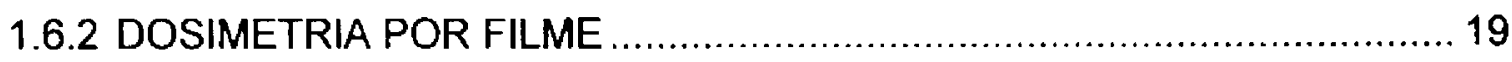

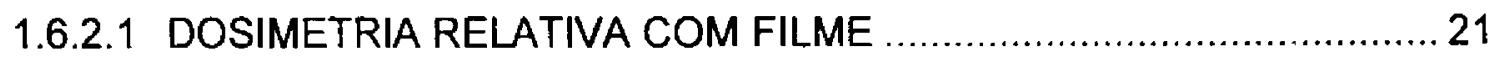

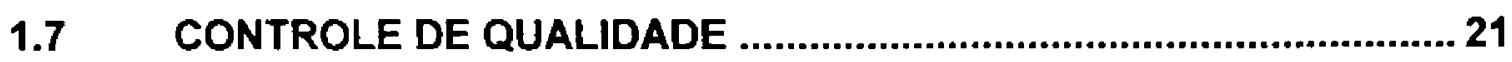

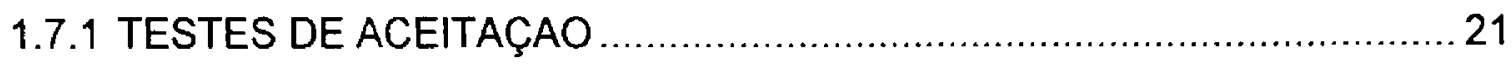

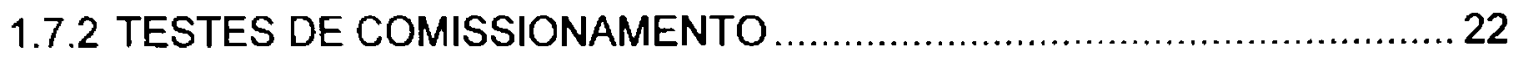

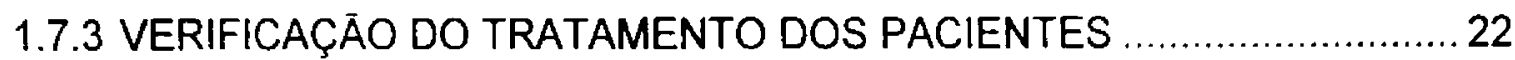

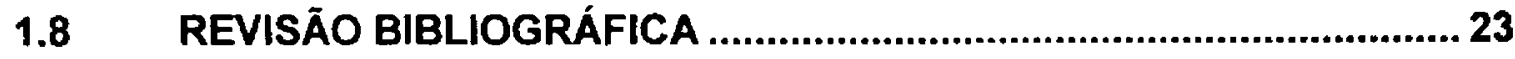

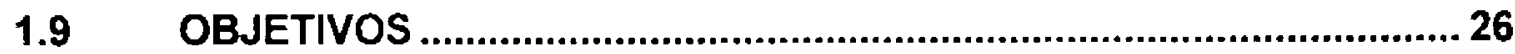

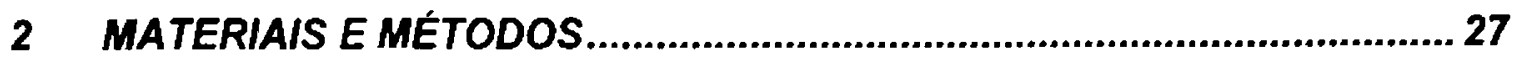

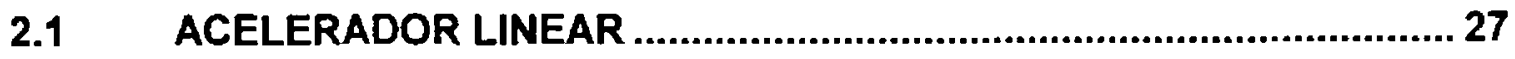

2.2 SISTEMA DE COLIMADOR MULTI-LÂMINAS..................................... 28 
2.2.1 COLIMADOR MULTI-LÂMINAS. VARIAN -MODELO MARK $\| \ldots \ldots \ldots \ldots . . . . .28$

2.2.2 COLIMADOR MULTI-LÂMINAS. VARIAN -MODELO MILLENIUM. ......... 29

2.2.3 COLIMADOR MICRO MULTI-LÂMINAS. BRAINLAB -MODELO $m_{3} \ldots \ldots . . .30$

2.3 EQUIPAMENTO DOSIMÉTRICO.................................................... 31

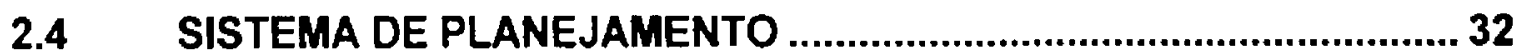

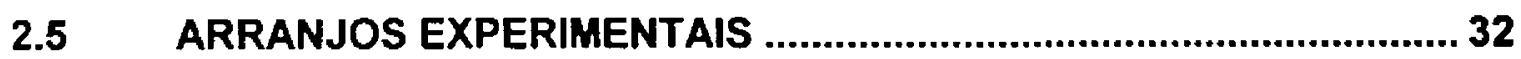

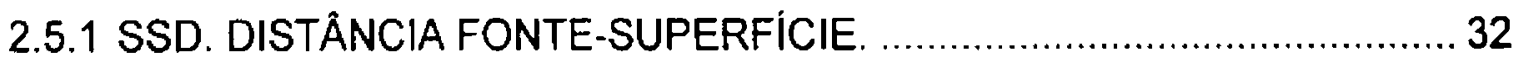

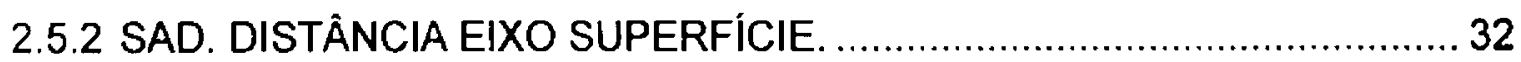

2.6 TESTES DE ACEITAÇÃO E COMISSIONAMENTO ............................. 33

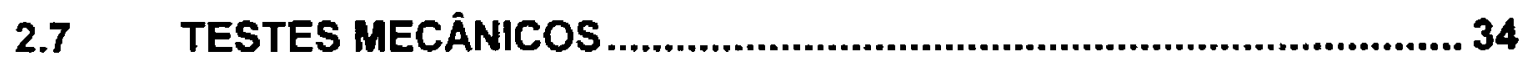

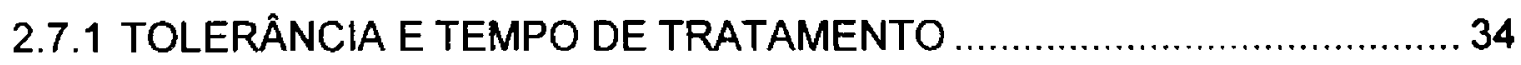

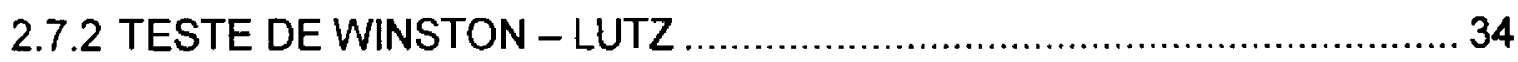

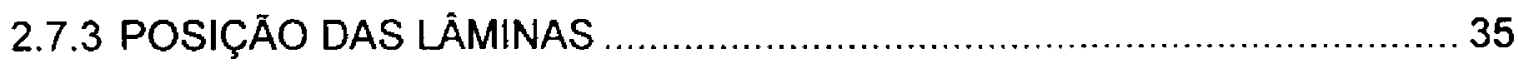

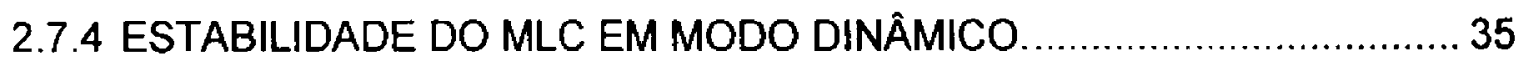

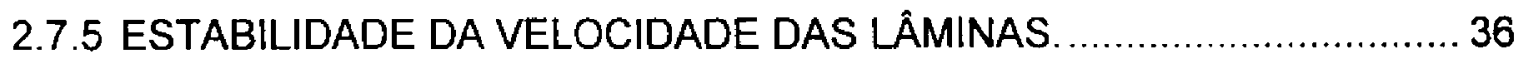

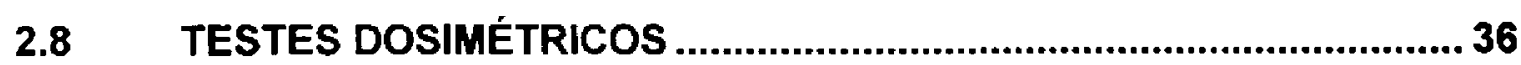

2.8.1 SENSIBILIDADE À INTERRUPÇĀO DE TRATAMENTOS.......................... 36

2.8.2 ESTABILIDADE DO FATOR DE RENDIMENTO COM O DMLC. ...............36

2.8.3 LINEARIDADE COM AS UNIDADES MONITORAS................................ 37

2.8.4 LINEARIDADE DE DOSE EM FUNÇÃO DA TAXA DE DOSE ..................37

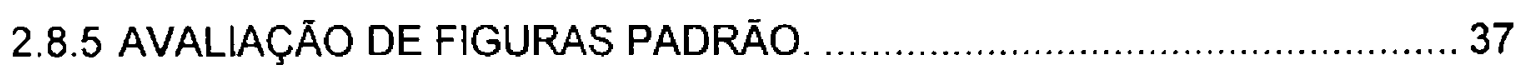

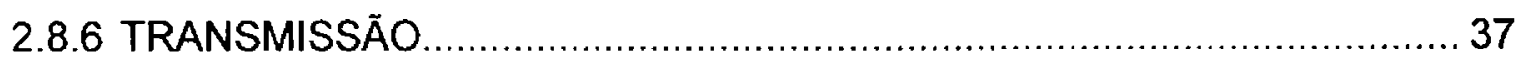

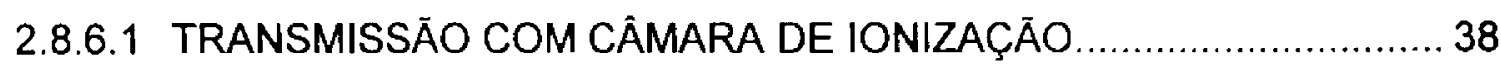

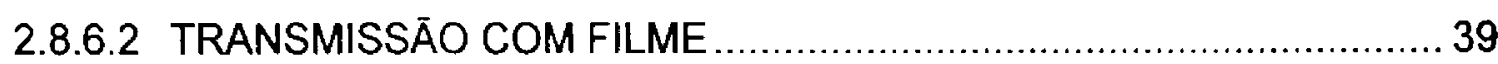

2.8.7 ESPALHAMENTO DE RADIAÇÃO PRODUZIDO PELO MLC .................. 39

2.8.8 EFEITO DA BORDA ARREDONDADA E ABERTURA DOSIMÉTRICA ENTRE PARES DE LÂMINAS.................................................... 40

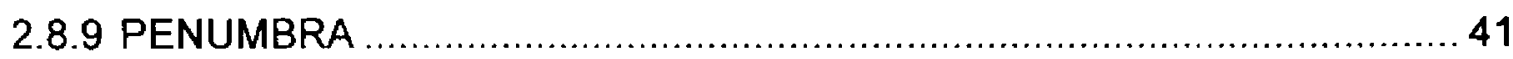

2.8.9.1 PENUMBRA EM FUNÇĀO DO DESLOCAMENTO FORA DO EIXO

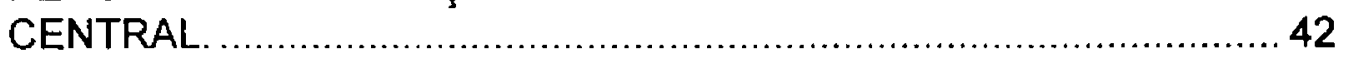

2.8.9.2 PENUMBRA EM FUNÇÃO DO TAMANHO DE CAMPO ….................43

2.8.9.3 PENUMBRA EM FUNÇÃO DA PROFUNDIDADE .............................. 43

2.8.9.4 PENUMBRA EM FUNÇÄO DO ÂNGULO COM AS BORDAS ............. 43

2.9 ANÁLISE DOS ARQUIVOS "DYNALOG".......................................4 44

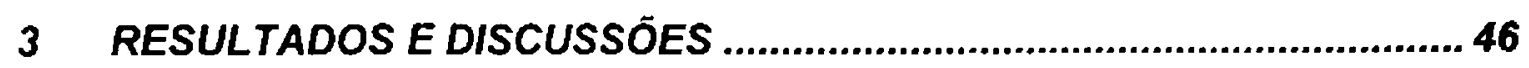

3.1 COLIMADOR MULTI-LÂMINAS VARIAN MODELO MILLENIUM....... 46 
3.1.1 TESTES MECÂNICOS . 46

3.1.1.1 POSIÇÃO DAS LÂMINAS NO ISOCENTRO ……............................ 47

3.1.1.2 ESTABILIDADE DO MLC EM MODO DINÂMICO ............................48

3.1.1.3 ESTABILIDADE DA VELOCIDADE DAS LÂMINAS. ........................... 49

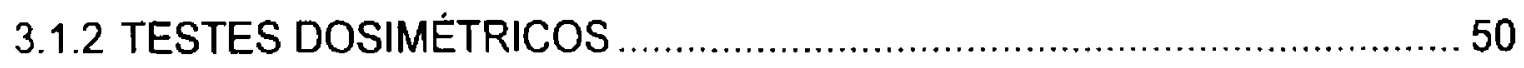

3.1.2.1 SENSIBILIDADE Ȧ INTERRUPÇĀO DE TRATAMENTOS ................. 50

3.1.2.2 ESTABILIDADE DO FATOR DE RENDIMENTO COM O DMLC..........51

3.1.2.3 LINEARIDADE DAS UNIDADES MONITORAS .............................. 52

3.1.2.4 LINEARIDADE DE DOSE EM FUNÇÃO DA TAXA DE DOSE .............52

3.1.2.5 AVALIAÇÃO DE FIGURAS PADRÃO........................................... 53

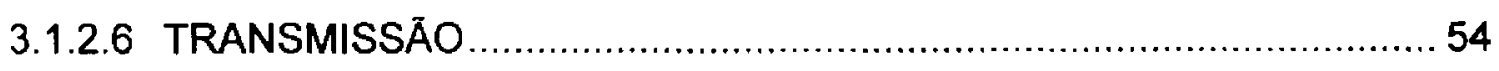

3.1.2.6.1 TRANSMISSĀO COM CÂMARA DE IONIZAÇĀO …….................54

3.1.2.6.2 TRANSMISSÃO COM FILME................................................56

3.1.2.7 ESPALHAMENTO DE RADIAÇÃO PRODUZIDO PELO MLC $120 \ldots . . .57$

3.1.2.8 EFEITO DA BORDA ARREDONDADA E ABERTURA DOSIMÉTRICA

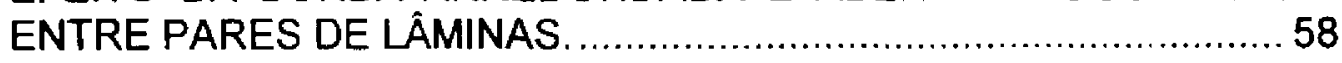

3.1.2.9 PENUMBRA

3.1.2.9.1 PENUMBRA EM FUNÇÃO DO DESLOCAMENTO FORA DO EIXO

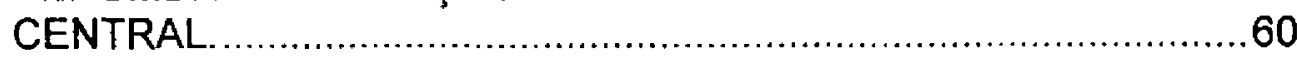

3.1.2.9.2 PENUMBRA EM FUNÇÃO DO TAMANHO DE CAMPO .................61

3.1.2.9.3 PENUMBRA EM FUNÇÃO DA PROFUNDIDADE. .......................61

3.1.2.9.4 PENUMBRA EM FUNÇÃO DO ÂNGULO COM AS BORDAS. .........62

3.1.2.10 ANÁLISE DOS ARQUIVOS "DYNALOG". ....................................63

3.2 MICRO COLIMADOR MULTI-LÂMINAS BRAINLAB m3....................65

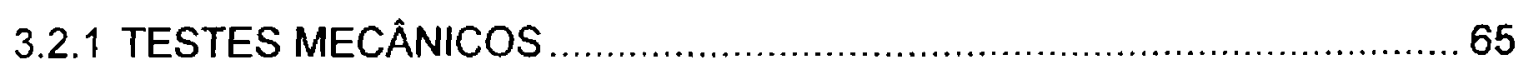

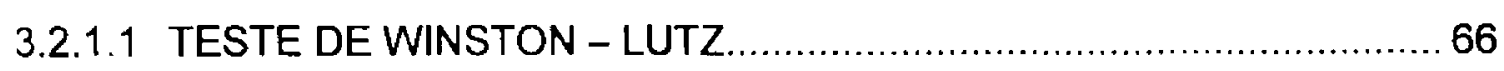

3.2.1.2 POSIÇĀO DAS LÂMINAS NO ISOCENTRO …...............................6 66

3.2.1.3 ESTABILIDADE DO SISTEMA MMLC EM MODO DINÂMICO ...........67

3.2.1.4 ESTABILIDADE DA VELOCIDADE DAS LÂMINAS. .........................67

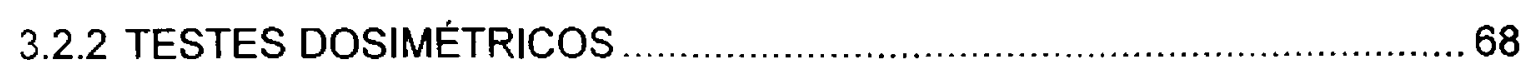

3.2.2.1 SENSIBILIDADE À INTERRUPÇÃO DE TRATAMENTOS .................68

3.2.2.2 ESTABILIDADE DO FATOR DE RENDIMENTO COM O mMLC EM

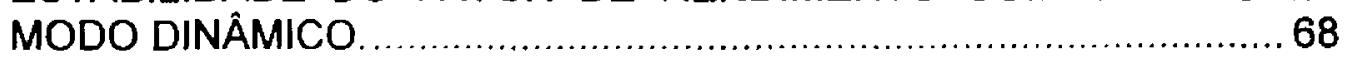

3.2.2.3 LINEARIDADE COM AS UNIDADES MONITORAS..........................69

3.2.2.4 LINEARIDADE DE DOSE EM FUNÇĀO DA TAXA DE DOSE.............70

3.2.2.5 AVALIAÇĀO DE FIGURAS PADRĀO......................................... 71 


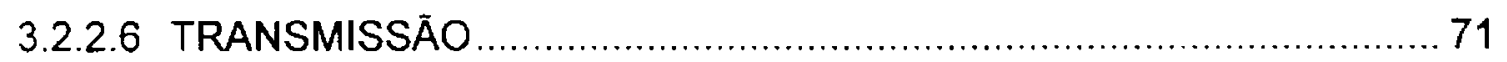

3.2.2.6.1 TRANSMISSĀO COM CÂMARA DE IONIZAÇĀO ……...................71

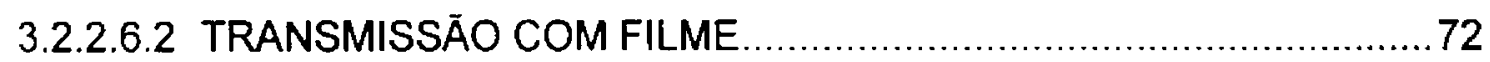

3.2.2.7 ESPALHAMENTO DE RADIAÇĀO PRODUZIDO PELO MMLC ..........73

3.2.2.8 EFEITO DA BORDA ARREDONDADA E ABERTURA DOSIMÉTRICA

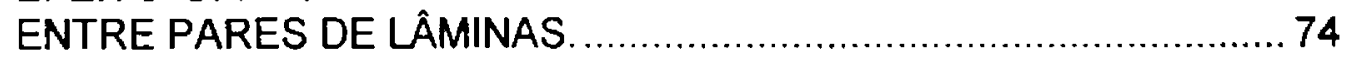

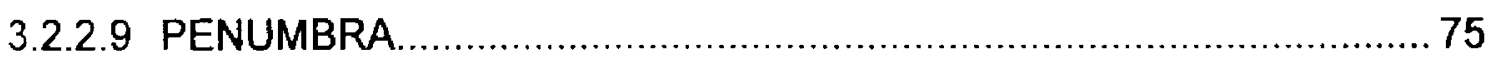

3.2.2.9.1 PENUMBRA EM FUNÇĀO DO DESLOCAMENTO FORA DO EIXO

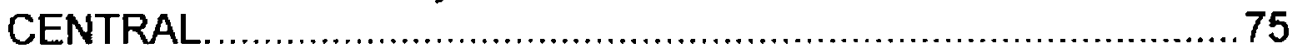

3.2.2.9.2 PENUMBRA EM FUNÇÃO DO TAMANHO DE CAMPO...................76

3.2.2.9.3 PENUMBRA EM FUNÇĂO DA PROFUNDIDADE. ..........................77

3.2.2.9.4 PENUMBRA EM FUNÇĀO DO ÂNGULO COM AS BORDAS. .........78

3.2.2.10 ANÁLISE DOS ARQUIVOS "DYNALOG"........................................78

3.3 COLIMADOR MULTI-LÂMINAS VARIAN MODELO MARK II..............79

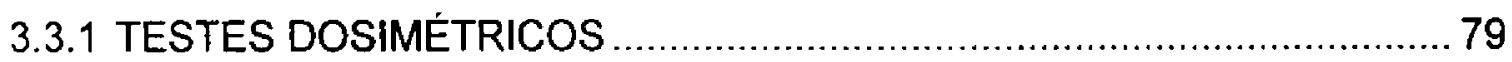

3.3.1.1 TRANSMISSÃO

3.3.1.1.1 TRANSMISSÃO COM CÂMARA DE IONIZAÇÃO ……....................79

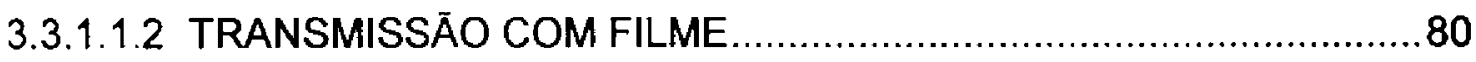

3.3.1.2 ESPALHAMENTO PRODUZIDO PELO MLC 52 - MARK $11 \ldots \ldots \ldots \ldots \ldots . . . . . . .82$

3.3.1.3 EFEITO DA BORDA ARREDONDADA E ABERTURA DOSIMETRICA ENTRE PARES DE LÂMINAS ...................................................... 83

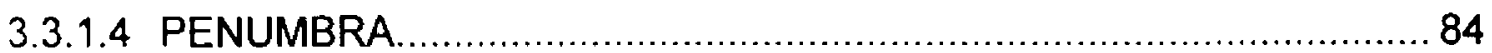

3.3.1.4.1 PENUMBRA EM FUNÇÃO DO DESLOCAMENTO FORA DO EIXO

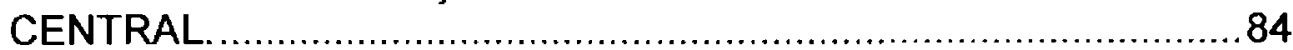

3.3.1.4.2 PENUMBRA EM FUNÇÃO DO TAMANHO DE CAMPO …..............85

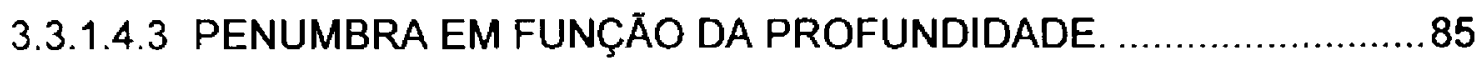

3.3.1.4.4 PENUMBRA EM FUNÇĀO DO ÂNGULO COM AS BORDAS. .........86

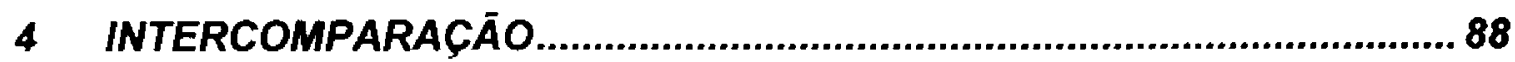

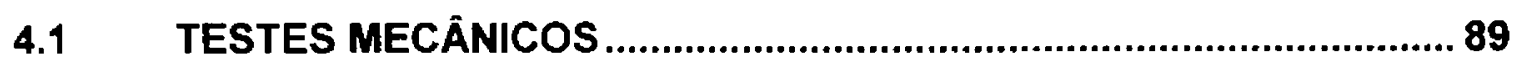

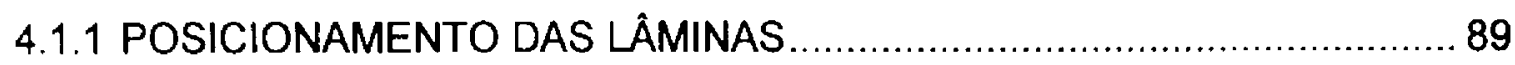

4.2 DADOS DOSIMÉTRICOS PARA USO CLÍNICO ..................................90

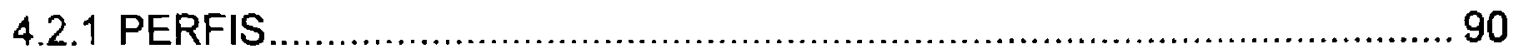

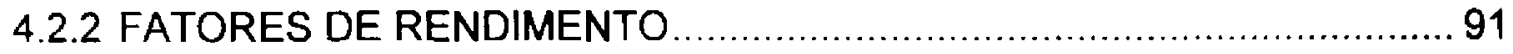

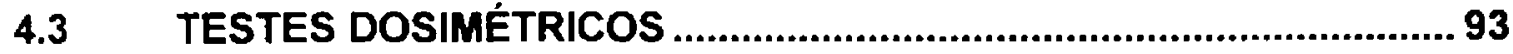

4.3.1 LINEARIDADE DE DOSE EM FUNÇÃO DA TAXA DE DOSE …..............93

4.3.2 SENSIBILIDADE À INTERRUPÇĀO DE TRATAMENTOS …................... 94 
4.3.3 ESTABILIDADE DO FATOR DE RENDIMENTO COM O DMLC .............. 95

4.3.4 TRANSMISSÃO MÉDIA COM CÂMARA DE IONIZAÇÃO .....................96

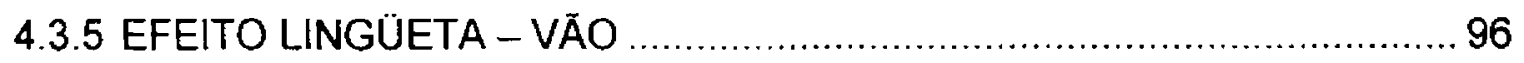

4.3.6 TRANSMISSĀO ENTRE AS LÂMINAS E INTRALÂMINAS .................... 97

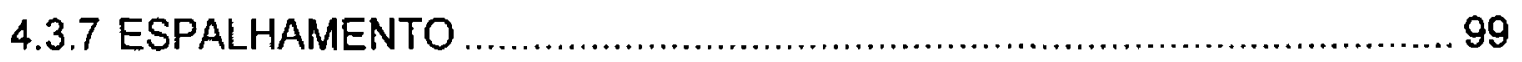

4.3.8 ABERTURA DOSIMÉTRICA ENTRE PARES DE LÂMINAS .................. 100

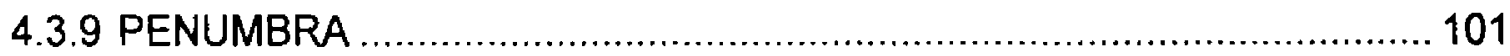

4.3.9.1 PENUMBRA EM FUNÇÃO DA PROFUNDIDADE.......................... 101

4.3.9.2 PENUMBRA EM FUNÇÃO DA POSIÇÃO FORA DO EIXO .............. 102

4.3.9.3 PENUMBRA EM FUNÇÃO DO TAMANHO DE CAMPO ................... 104

4.3.9.4 PENUMBRA EM FUNÇĀO DO ÂNGULO QUE FORMA COM O EIXO DE MOVIMENTO DAS LAMINAS ....................................... 105

5 CONCLUSŌES E RECOMENDAÇŌES............................................ 108

6 REFERÊNCIAS BIBLIOGRÁFICAS ............................................ 111 


\section{LISTA DE TABELAS}

Tabela 1. Resultados da transmissão medida com filme, analisados no eixo central.

Tabela 2. Resultados do cálculo de espalhamento produzido pelas lâminas do MLC Millenium 120, para um campo de $10 \times 10 \mathrm{~cm}^{2}$.

Tabela 3. Resultados obtidos da penumbra em função da profundidade comparada com os descritos na literatura.

Tabela 4. Resultados da penumbra $80-20 \%$ em funçäo do ângulo que formam as bordas do MLC.

Tabela 5. Resultados do cálculo de espalhamento produzido pelas lâminas do mMLC $\mathrm{m}_{3}$, para um campo de $9,8 \times 9,8 \mathrm{~cm}^{2}$.

Tabela 6. Resultados da dependência da penumbra em função do ângulo que formam as lâminas com seu eixo de movimento.

Tabela 7. Resultados da transmissão medida com filme, analisados no eixo central para o MLC 52

Tabela 8. Resultados do cálculo de espalhamento produzido pelas lâminas do MLC 52, para um campo de $10 \times 10 \mathrm{~cm}^{2}$.

Tabela 9. Resultados obtidos da penumbra em função da profundidade comparados com os descritos na literatura. .86

Tabela 10. Resultados da dependência da penumbra em função do ângulo que formam as lâminas do MLC Mark II com seu eixo de movimento. 87

Tabela 11. Comparação dos valores de transmissão medidos com câmara de ionização. 96

Tabela 12. Resultados comparativos do espalhamento produzido pelos três sistemas de MLC estudados. 99

Tabela 13. Resultados comparativos da abertura dosimétrica entre pares de lâminas nos três sistemas de MLC estudados 100 
Tabela 14. Resultados comparativos da penumbra $(80-20) \%$ em função da profundidade nos três sistemas de MLC para $6 \mathrm{MV}$ 101 


\section{LISTA DE FIGURAS}

Figura 1. Esquema de uma lâmina que forma parte de um sistema MLC. 5

Figura 2. Vista frontal de vários sistemas comerciais de MLC, com o respectivo projeto do efeito lingüeta - vão ("tongue and groove").

Figura 3. (a) Sistema de colimaçāo para IMRT MIMiC @ acoplado no acelerador. (b) Fotografia do MIMiC $B$. Tomado de Purdy e colaboradores [2]......7

Figura 4. Esquema de liberação com IMRT em modo dinâmico (DMLC) de um perfil de intensidade modulado. $O$ ponto $P$ do padrão está em exposição direta à radiação no intervalo de tempo entre os pontos b e c [1]. 8

Figura 5. Esquema de liberação com IMRT em modo estático (SMLC) de um perfil de intensidade modulado. $O$ ponto $P$ do padrāo está coberto pela lâmina direta no intervalo de tempo entre os pontos a e b [1]

Figura 6. BEV de um campo de tratamento com as respectivas distribuições de dose depois da otimização do tratamento. As regiōes em vermelho são as de maior dose.

Figura 7. Exemplo de distribuição de dose obtida a partir de um planejamento inverso de IMRT para um paciente com câncer de próstata.

Figura 8. Objeto simulador sólido equivalente à água, para verificações pré tratamento (dosimetria absoluta e relativa). Pode-se observar a distribuição de dose exportada nele e normalizada no centro da câmara de ionização.

Figura 9. Acelerador linear Varian modelo 23EX do Departamento de Radioterapia do Hospital Israelita Albert Einstein. .28

Figura 10. Colimador multi-lâminas marca Varian; pode-se observar o motor responsável pelo movimento acoplado à lâmina 29

Figura 11. Esquema dos arranjos de distância fonte superfície fixa (SSD) e eixosuperficie (SAD) para medição de dose no ponto $Q$ na profundidade $d$ para um feixe com dose máxima no ponto $P$ 33 
Figura 12. Figuras padrão utilizadas para definir a dependência da penumbra em funçäo do ângulo com as bordas. (a) Para os ângulos de $15^{\circ}, 30^{\circ} \mathrm{e}$ $75^{\circ}$. (b) Para os ângulos de $10^{\circ}, 45^{\circ}$ e $60^{\circ}$.

Figura 13. Variaçāo do tempo de tratamento de um campo dinâmico em função da tolerância entre as posiçōes programadas e reais das lâminas em modo dinâmico para o MLC 120.

Figura 14. Efeito da tolerância na posição das lâminas na dose relativa para um campo de tratamento dinâmico para o MLC 120.

Figura 15. Resultados que relacionam o erro na dose liberada com o erro na abertura desizante para 6MV liberado com o MLC 120.

Figura 16. Resultados do teste de estabilidade do MLC 120 (jardineira - "garden fence"). O último pico apresenta uma intensidade menor, o que representa um erro na posição de uma das làminas. 49

Figura 17. Resultados do teste de velocidade das lâminas do MLC 120. Para o fabricante Varian, este teste è denominado X-WEDGE e Y-WEDGE. 50

Figura 18. Efeito da interrupção do feixe durante um tratamento com o MLC 120 em modo dinâmico (DMLC). 50

Figura 19. Resultados de mediçöes para verificar a estabilidade do fator de rendimento com o MLC 120 em modo dinâmico (DMLC). 51

Figura 20. Resultados dos testes de linearidade das unidades monitoras para um tratamento de IMRT, liberado com o MLC 120, mantendo constante a taxa de dose.

Figura 21. Resultados dos testes da constância da dose em função da taxa de dose para um número fixo de unidades monitoras em um tratamento de IMRT. 53

Figura 22 Figuras padrão disponibilizadas pelo fabricante. (a) Fatias segmentadas. (b) Padrāo complexo. (c) Pirâmide.

Figura 23. Transmissão do MLC 120 em função da profundidade para vários tamanhos de campo para um feixe de $6 \mathrm{MV}$. 54 
Figura 24. Transmissão do MLC 120 em função da profundidade para vários tamanhos de campo para um feixe de $15 \mathrm{MV}$. 55

Figura 25. Transmissāo entre as lâminas e intralâminas para um feixe de $15 \mathrm{MV}$ no MLC 120. 56

Figura 26. Transmissão entre as lâminas e intralâminas um feixe de $6 \mathrm{MV}$ no MLC 120. 56

Figura 27. Transmissāo vs. largura do campo para o MLC Millenium $120 \mathrm{em}$ um feixe de 6 e $15 \mathrm{MV}$. .58

Figura 28. Gráfico da dose relativa em função da abertura nominal para o MLC 120. 59

Figura 29. Gráfico da dose relativa em função da abertura nominal para o MLC 120 . 59

Figura 30. Penumbra (80-20\%) em função da posição das lâminas em relação ao eixo central para o MLC 120 . 60

Figura 31. Variação da penumbra em função do tamanho de campo nos sentidos paralelo e perpendicular ao movimento do MLC 120.

Figura 32. Variação da penumbra em função da profundidade para campos de referência $10 \times 10 \mathrm{~cm}^{2}$ definidos pelo MLC Millenium para $6 \mathrm{MV}$.

Figura 33. Histograma fornecido pelo arquivo "dynalog" com o número de desvios das posiçōes das lâminas durante um tratamento dinâmico no MLC 120. 63

Figura 34. Gráfico do erro quadrático médio para cada uma das 120 lâminas do MLC. O maior pico indica um erro acima da tolerância do sistema para a lâmina A39 diagnosticado com o arquivo "dynalog". 64

Figura 35. Gráfico do estado do feixe (ligado ou desligado) em função do tempo de tratamento para um tratamento dinâmico liberado com o MLC 120. A existência de vários picos indica que o feixe foi desligado várias vezes durante o tratamento quando as lâminas não atingiram a posição programada 
Figura 36. Variaçāo do tempo de tratamento de um campo dinâmico em função da tolerância entre as posiçōes programadas e reais das lâminas em modo dinâmico para o mMLC

Figura 37. Efeito da tolerância na posição das lâminas na dose relativa para um campo de tratamento dinâmico para o mMLC. 65

Figura 38. Gráfico do deslocamento do isocentro em função do ângulo de rotaçāo do sistema de suporte funcional, realizado pelo método de Winston Lutz no mMLC. 66

Figura 39. Resultados que relacionam o erro na dose liberada com o erro na abertura deslizante para $6 \mathrm{MV}$ no mMLC 67

Figura 40. Efeito da interrupção do feixe durante um tratamento dinâmico com o mMLC 68

Figura 41. Resultados de medições para verificar a estabilidade do fator de rendimento em modo dinâmico do $\mathrm{mMLC}$. 69

Figura 42. Resultados dos testes de linearidade das unidades monitoras para um tratamento de IMRT liberado como o mMLC, mantendo constante a taxa de dose. 70

Figura 43. Resultados dos testes da constância da dose em função da taxa de dose para um número fixo de unidades monitoras em um tratamento de IMRT liberado como o mMLC .70

Figura 44. Figura padrão (PIRÂMIDE) que fornece informaçāo qualitativa da posiçăo das lâminas e do movimento das lâminas. 71

Figura 45. Transmissão em função da profundidade para vários tamanhos de campo definidos pelo mMLC para um feixe de $6 \mathrm{MV}$. .72

Figura 46. Filme de verificação dosimétrica testando a transmissão .72

Figura 47. Transmissão entre as lâminas e intralâminas obtida através de filme de verificação dosimétrica. 73

Figura 48. Transmissão vs. largura do campo para o mMLC em um feixe de $6 \mathrm{MV}$. 
Figura 49. Gráfico da abertura dosimétrica entre pares de lâminas obtida com càmara de ionização para o mMLC .75

Figura 50. Penumbra (80-20\%) em função da posição das lâminas com respeito ao eixo central para o mMLC .76

Figura 51. Gráfico da penumbra vs. Tamanho de campo para campos definidos pelo mMLC em sentido paralelo e perpendicular ao movimento das lâminas .77

Figura 52. Variação da penumbra em função da profundidade para campos de referência $10 \times 10 \mathrm{~cm}^{2}$ definidos pelas lâminas do $\mathrm{mMLC}$.

Figura 53. Transmissão do MLC 52 em função da profundidade para vários tamanhos de campo para um feixe de $6 \mathrm{MV}$ .79

Figura 54. Transmissão do MLC 52 em função da profundidade para vários tamanhos de campo para um feixe de $18 \mathrm{MV}$ 80

Figura 55. Transmissão entre as lâminas e intralâminas para a energia de $6 \mathrm{MV}$ no MLC Mark II de 52 lâminas

Figura 56. Transmissão entre as lâminas e intralâminas para a energia de $18 \mathrm{MV}$ no MLC Mark II de 52 lâminas

Figura 57. Transmissão vs. largura do campo para o MLC Mark II em feixes de 6 e $18 \mathrm{MV}$

Figura 58. Gráfico da abertura dosimétrica entre pares de lâminas obtida com câmara de ionizaçāo para o MLC 52

Figura 59. Penumbra (80-20\%) em função da posição das lâminas com respeito ao eixo central para o MLC Mark II.

Figura 60. Gráfico da penumbra vs. tamanho de campo para campos definidos pelo MLC Mark II em sentidos paralelo e perpendicular ao movimento das lâminas. .85

Figura 61. Variação da penumbra em funçāo da profundidade para campos de referência $10 \times 10 \mathrm{~cm}^{2}$ definidos pelas lâminas do MLC Mark 11 . .86

Figura 62. Comparação de perfís para campos $8 \times 8 \mathrm{~cm}^{2}$ definidos pelos três sistemas de MLC estudados 
Figura 63. Resultados comparativos dos fatores de rendimento para campos quadrados definidos pelos MLC's.

Figura 64. Fatores de rendimento para o MMLC realizados com diferentes ferramentas dosimétricas.

Figura 65. Comportamento da dose relativa nos sistemas com capacidade de liberação de feixes modulados dinamicamente quando a taxa de dose varia. .94

Figura 66. Comparação do efeito de interrupção em tratamentos de IMRT dinâmico liberado pelos dois sistemas de MLC habilitados para esta técnica. .94

Figura 67. Comparação do fator de rendimento em modo dinâmico em função do ângulo do sistema de suporte funcional nos dois sistemas que permitem a liberaçāo de feixes modulados. 95

Figura 68. Resultados comparativos do efeito lingüeta - vão dos três sistemas de MLC estudados.

Figura 69. Comparação da transmissão para $6 \mathrm{MV}$ dos três sistemas de MLC do HIAE, no eixo central. .98

Figura 70. Comparação da transmissão para $6 \mathrm{MV}$ dos três sistemas de MLC do HIAE, os perfis foram obtidos a $3 \mathrm{~cm}$ de deslocamento do eixo central em sentido oposto à junção das lâminas opostas. .98

Figura 71. Resultados comparativos da penumbra $(80-20) \%$ em função do deslocamento fora do eixo central na profundidade de $1,5 \mathrm{~cm}$. 103

Figura 72. Resultados comparativos da penumbra $(80-20) \%$ em função do deslocamento fora do eixo central na profundidade de $5,0 \mathrm{~cm}$. 103

Figura 73. Resultados comparativos da penumbra $(80-20) \%$ em função do deslocamento fora do eixo central na profundidade de $10,0 \mathrm{~cm}$...... 104

Figura 74. Resultados comparativos da penumbra $(80-20) \%$ em função do tamanho de campo definido pelos três sistemas de MLC no sentido paralelo ao movimento das lâminas. 105 
Figura 75. Resultados comparativos da penumbra $(80-20) \%$ em função do tamanho de campo definido pelos três sistemas de MLC no sentido perpendicular ao movimento das lâminas. 105

Figura 76. Resultados comparativos da dependência da penumbra $80-20 \%$ em função do ângulo que formam as lâminas com seu eixo de movimento. 106

Figura 77. Resultados comparativos da dependência da penumbra $(80-20) \%$ em função do ângulo que formam as lâminas com seu eixo de movimento para o mMLC 106 


\section{INTRODUÇÃO}

Um dos itens mais importantes na aplicação da Radioterapia com Intensidade Modulada de Feixe (IMRT) è sem dúvida o colimador multi-lâminas. Há pouco tempo, e em muitos centros de Radioterapia na atualidade, os aceleradores lineares possuiam sistemas de colimação simples, com sistemas de colimação secundária que permitiam aberturas de campo simétricas (quadradas ou retangulares).

A maior limitação à eficiência do tratamento de Radioterapia è a produção de complicações não desejadas pela irradiação de tecidos sadios em uma determinada técnica radioterápica. Muitos órgãos são relativamente sensíveis aos danos de radiação e devem receber atenção especial durante o planejamento do tratamento. Em geral, quem é encarregado de planejar tenta otimizar as distribuições de dose seguindo uma dada estratégia para liberar uma dose tumoricida no alvo, minimizando assim a dose nos tecidos normais circundantes.

Os tratamentos convencionais usam um nümero limitado de campos de tratamento e restringem suas orientaçōes a um número limitado de feixes coplanares. Um aparetho de tratamento convencional delimita o tamanho do campo de tratamento por meio de um conjunto de colimadores secundários construídos de metal denso. Estes colimadores são posicionados no cabeçote do acelerador, abaixo dos colimadores secundários e permanecem estáticos durante - tratamento. Para reduzir o volume do tecido sadio irradiado, devem ser elaboradas proteções e o alvo também deve ser conformado para poupar estas regiōes anatômicas, assim como o uso de feixes múltiplos de tratamento. Para isto, foram desenvolvidas ligas de chumbo com baixo ponto de fusão para a elaboração de proteçōes personalizadas, de acordo com o volume tumoral a ser tratado em cada paciente. Estes blocos são personalizados e construidos a partir das imagens de simulação do paciente feitas no próprio simulador ou reconstruções digitais das imagens de tomografia computadorizada (CT). Estas proteções permitem que a radiação passe pelas regiōes não protegidas atingindo o volume a ser tratado. 
Os colimadores multi-lâminas (MLC) estão sendo disponibilizados em muitos serviços de Radioterapia, utilizando-os para substituir técnicas convencionais de conformação, melhorando assim a eficiência do tratamento convencional de radioterapia. Os colimadores multi-lâminas ou colimadores de múltiplas lâminas (MLC) apresentam a possibilidade de substituir os blocos de proteção para conformaçāo do feixe. Os MLCs têm lâminas com a capacidade de se movimentar até uma posição pré-definida para bloquear a irradiação em uma certa regiāo.

O processo de conformar os feixes de acordo com a forma do alvo e poupando os tecidos sadios, dá origem à Radioterapia Conformada (3DCRT). Este é um processo mais rápido e com menor custo operacional que é a fabricação dos blocos. É de muita utilidade no caso em que há necessidade de correções durante o tratamento, devido ao fato de que o bloco não deve ser refeito, mas pode ser reconformado com as lâminas.

Quando um volume tumoral é definido em uma imagem CT ou de ressonància magnética (RM) pelo Radioterapeuta, a partir desta definição dos volumes, é realizado o planejamento do tratamento. Uma vez terminado o planejamento de um tratamento este é revisado e discutido conjuntamente entre Físico e Radioterapeuta para sua aprovaçăo. Uma vez aceito, os dados do plano de tratamento são enviados pela rede de registro e verificação para o acelerador. Estes dados incluem a posição das lâminas do MLC, os dados do tratamento, posicionamento do sistema de suporte funcional ("gantry"), colimador, mesa, etc. Um controlador ordena as lâminas do MLC para se posicionarem na posição preconizada. Existem vários modelos de colimadores multi-lâminas com um maior ou menor número de lâminas e com larguras diferentes para se obter um maior ou menor grau de conformação.

$\mathrm{Na}$ técnica de tratamento conformacional (3DCRT), as lâminas ficam estáticas na posiçāo programada para cada campo e o feixe de radiação é liberado. Uma vez terminado um campo de tratamento, são colocados os parâmetros do novo campo (sistema de suporte funcional - "gantry", colimador, lâminas, unidades monitoras, etc.) e o paciente é irradiado novamente.

Outra aplicação possivel dos MLCs é a modulação da intensidade do feixe. Esta técnica é uma variação da terapia conformada (3DCRT), e requer 
compensação ou modulação a qual pode ser atingida utilizando o movimento das lâminas do MLC durante a irradiação ou da posição das lâminas para certas posiçōes do sistema de suporte funcional. Assim, o MLC é um dos itens mais importantes na aplicação da Radioterapia com Intensidade Modulada de Feixe (IMRT).

Pelo fato do MLC ser um sistema adicional ao acelerador, e que modifica a geometria do feixe, requer um controle da qualidade exaustivo, para o qual devem ser elaborados testes rotineiros.

A partir do uso de colimadores multi-lâminas para substituir os blocos em 3DCRT, iniciou-se a pesquisa para a utilização dos MLCs para modular os feixes de tratamento. Nestes últimos anos, a maior parte de esforços tem sido focalizados nos algoritmos de otimização dos planos de tratamento e no aperfeiçoamento dos sistemas de planejamento computadorizados e de liberação de feixes modulados.

Devido à crescente implementação da técnica de modulação de feixe no mundo inteiro é de interesse atual estabelecer procedimentos de aceitação e comissionamento dos sistemas de colimador multi-lâminas ou de múltiplas lâminas. Cabe ao Fisico responsável pela implementação da técnica, além dos testes de aceitação básicos estipuladas pelo fabricante, realizar os testes de tal forma que garantam o ótimo funcionamento do sistema. Outro objetivo fundamental desses testes é fazer o levantamento dos dados que permitam à equipe multidisciplinar da Radioterapia (Físico, Radioterapeuta e Dosimetristas) a perfeita compreensão do equipamento que está sendo utilizado. No caso de existir mais de um sistema de MLC em um serviço de Radioterapia, é recomendável a intercomparação deles após o levantamento dos dados.

Em geral os testes de aceitação realizados e recomendados pelo fabricante provêem uma informação limitada, e muitos deles foram refeitos na realizaçăo deste trabalho. A maioria de testes apresentados neste trabalho constituiu as seguintes etapas: avaliar o comportamento do sistema multi-lâminas em certas condições de interesse clínico e levantar dados úteis nessas condições. 


\subsection{HISTÓRICO. O PERCURSO ATÉ A MODULAÇÃO DO FEIXE.}

Os primeiros conceitos de Radioterapia Conformada apareceram em 1965, quando o primeiro sistema de colimaçāo de múltiplas lâminas foi desenvolvido e implementado. Ele era controlado mecanicamente para conformar o feixe de acordo com a forma do volume alvo ao mesmo tempo em que o cavalete ("gantry") do equipamento girava ao redor do paciente. Este sistema foi desenvolvido no Japão pelo grupo de pesquisa do Dr. Shinji Takahashi em Nagoya no Japão. Um dispositivo com principio similar foi desenvolvido independentemente pela Clínica Lahy do Instituto de Tecnologia de Massachusetts [1].

Outros desenvolvimentos ocorreram na Inglaterra utilizando um equipamento de Cobalto-60, no qual o paciente era irradiado pelo movimento da mesa e do cavalete ("gantry") que girava durante o tratamento, usando sistemas eletromecânicos. O objetivo desta técnica era conformar a dose ao redor das vias de disseminação da doença e a conseqüente conformação da distribuição da dose [1].

Outros esforços foram desenvolvidos no Karolinska Intitutet na Suécia, nos quais se relatou o uso de distribuições de intensidade não uniformes, e se discutiram aspectos relacionados com o planejamento e otimização. Muitos desses conceitos estiveram envolvidos no projeto do MM50 Racetrack Microtron System $(8)$ da Scanditronix, que será mencionado posteriormente [1].

Um avanço significativo no caminho da modulação do feixe foram os filtros dinâmicos, nos quais o movimento de uma das mandibulas ("jaws") do colimador do acelerador, junto com a variação na taxa de dose gerando assim uma distribuição de dose similar a de um filtro fisico.

A partir do uso de colimadores multi-lâminas para substituir os blocos em 3DCRT, iniciou-se a pesquisa para a utilização dos MLC para modular os feixes de tratamento. Nestes últimos anos, a maior parte de esforços tem sido focalizados nos algoritmos de otimização dos planos de tratamento e no melhoramento dos sistemas de planejamento computadorizados e de liberação de feixes modulados. 
Os valores dos parâmetros, tais como as transmissōes de meia-lâmina e intra-lâminas, calibração das variações da posição de lâminas, fatores de rendimento para campos pequenos, e geralmente medidas com campos estáticos ao se comissionar o MLC; a intercomparação dos MLCs é uma conseqüência de tais medidas.

\subsection{SISTEMA DE MICRO COLIMADOR MULTI-LÂMINAS}

Para caracterizar um sistema de colimadores multi-lâminas, é preciso ter as seguintes informaçōes:

- número de pares de lâminas;

- largura das lâminas (projetada no isocentro);

- tamanho de campo máximo;

- distância máxima de ultrapassagem com relação ao eixo central.

Na Figura 1 encontra-se um diagrama de uma lâmina e a denominação de cada uma das suas partes, discutidas no presente trabalho.

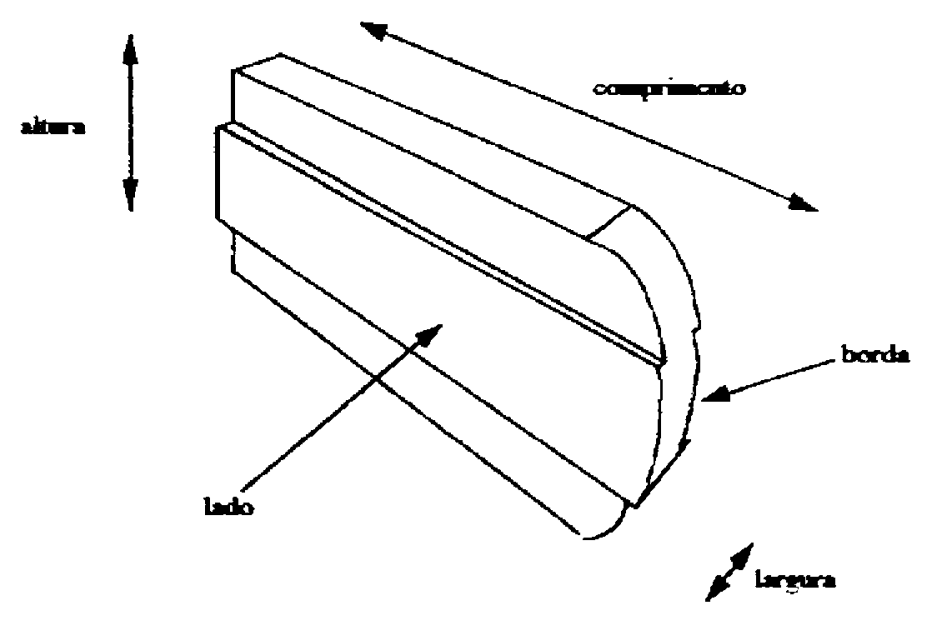

Figura 1. Esquema de uma lâmina que forma parte de um sistema MLC.

Todos os sistemas de colimadores multi-lâminas apresentam em seu projeto uma forma irregular pela vista frontal. Este efeito é conhecido como efeito lingüeta - vão ("tongue and groove"), que permite a movimentação das lâminas contíguas tentado minimizar o efeito de transmissão da radiação entre as lâminas. O efeito está ilustrado na Figura 2. 


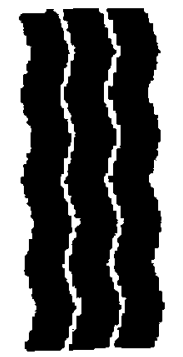

Git:

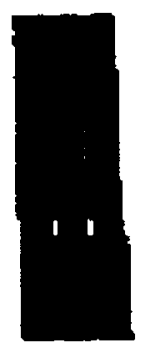

Sinditronis

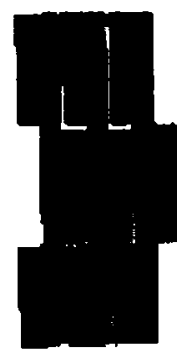

Siding

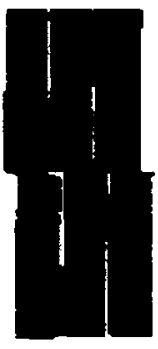

rtilim

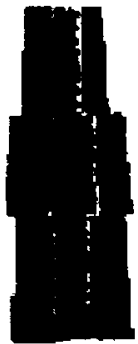

Sirtak

Figura 2. Vista frontal de vários sistemas comerciais de $M L C$, com o respectivo projeto do efeito lingüeta - vão ("tongue and groove").

\subsection{FEIXE DE INTENSIDADE MODULADA (IMRT).}

A Radioterapia por intensidade modulada de feixe (IMRT) é uma parte da modalidade de tratamento que tem sido conhecida tradicionalmente como Radioterapia Conformada (3DCRT); a diferença encontra-se na utilização de feixes com intensidades não uniformes, obtidas a partir de técnicas de otimização nos sistemas de planejamento computadorizados [1][2][3][4]. Na prática, existem algumas formas e sistemas que permitem esta modulação e que serão descritos em seguida.

\subsubsection{FEIXES DE FÓTONS E ELÉTRONS COM INTENSIDADE MODULADA.}

O sistema Microtron Racetrack System® da Scanditronix foi o primeiro sistema de modulação de intensidade do feixe [1]. O principio de funcionamento deste sistema é controlar o ângulo e a intensidade com que o feixe de elétrons atinge $o$ alvo de produção de raios- $X$, formando assim raios- $X$ por freamento ("bremsstrahlung") que podem ser posicionados em qualquer posição dentro do campo de radiação, usando um padrāo de intensidades que guia o posicionamento.

\subsubsection{TOMOTERAPIA}

A Tomoterapia é baseada na utilização de um feixe estreito colimado por micro colimadores multi-lâminas que são montados no sistema de suporte funcional de um acelerador linear convencional. Denomina-se tomoterapia serial, 
pela semelhança com a tomografia axial computadorizada. Existe também a tomoterapia em espiral, na qual os erros potenciais devido ao movimento da mesa săo reduzidos, e a semelhança é desta vez com um exame de tomografia helicoidal [1][2].

Neste tipo de feixe de tratamento é produzido um campo de aproximadamente $20 \mathrm{~cm}$ de largura e de 1 a $4 \mathrm{~cm}$ de comprimento. Este feixe estreito irradia uma seç̧ão pequena do paciente ao mesmo tempo em que o sistema funcional de suporte gira ao redor do seu eixo. Durante a rotação, as lâminas do MLC se movimentam entrando e saindo, sendo controladas por um sistema computadorizado ("MLC Controller"), modulando a fraçāo de tempo que cada segmento da rotação está bloqueada ou desbloqueada. As secçōes (definidas pela largura do campo) são irradiadas seqüencialmente de forma que toda a área de tratamento é irradiada [1].

As seç̧ões (definidas pela largura do campo) são irradiadas seqüencialmente de forma que toda a área de tratamento é irradiada. É imperativo e preciso a movimentação exata da mesa de tratamento para garantir um tratamento correto. Comercialmente, o sistema de tomoterapia é o Peacock ® e é desenvolvido pela Nomos Corporation. O colimador adicional que é montado no acelerador é o MIMiC 8 e está ilustrado na Figura 3 [1][2].
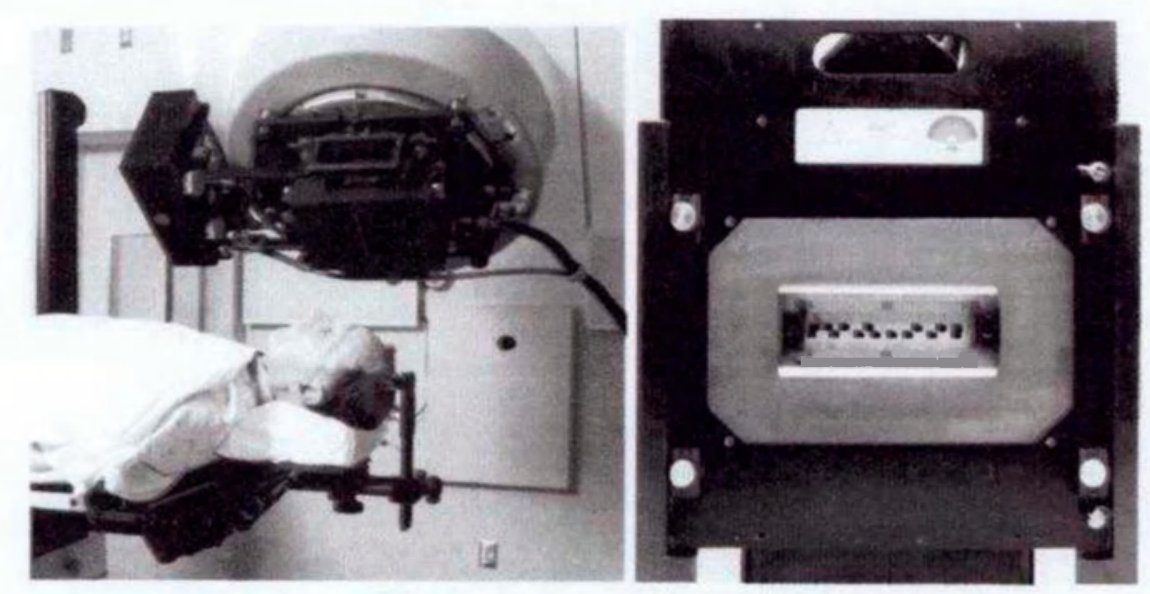

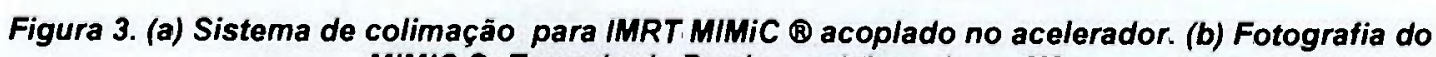
MIMiC (8. Tomado de Purdy e colaboradores [2]. 


\subsubsection{INTENSIDADE MODULADA COM COLIMADORES MULTI-LÃMINAS}

Estes são os métodos mais usados de tratamento por IMRT, na prática clínica e que vão ser estudados mais detalhadamente.

\subsubsection{MODO DINÂMICO DE MOVIMENTO DAS LÂMINAS DO MLC. JANELA DESLIZANTE.}

Os sistemas convencionais de MLC sendo controlados por computador podem liberar feixes de intensidade modulada. Para uma posição fixa do sistema de suporte funcional ("gantry"), uma abertura formada entre pares de lâminas opostas dos bancos do MLC se movimenta em um sentido único através do campo a ser tratado, quando o feixe está sendo liberado, produzindo assim o padrão de fluência desejado. Esta técnica de IMRT é comumente chamada como janela deslizante ("sliding window") ou simplesmente como DMLC (Dynamic MLC).

IMRT EM MODO DINĀMICO

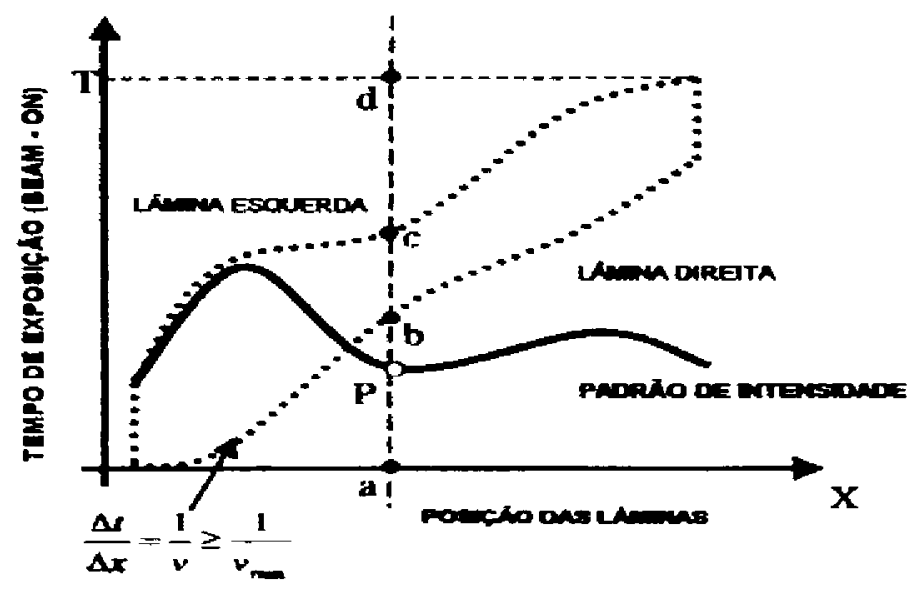

Figura 4. Esquema de liberação com IMRT em modo dinâmico (OMLC) de um perfil de intensidade modulado. $O$ ponto $P$ do padrão está em exposição direta à radiação no intervalo de tempo entre os pontos b e c [1].

Na Figura 4, o perfil de intensidade a ser liberado encontra-se em linha continua. Os caminhos a serem "percorridos" pelas lâminas esquerda e direita são mostrados em linhas tracejadas. O eixo horizontal representa a posição das lâminas e o eixo vertical o tempo de irradiação em termos de unidades monitoras. Em um ponto fixo, o intervalo de tempo entre as duas linhas de pontos representa o tempo de exposição direta da radiação. Os intervalos de tempo sob a lâmina direita e sobre a lâmina esquerda representam o tempo em que o campo de 
tratamento está bloqueado por cada uma das respectivas lâminas. Se considerarmos o ponto $\mathrm{P}$ no padrão de intensidade, este ponto está em exposição direta ao feixe entre os tempos de exposição $b$ e $c$, e bloqueado pela lâmina direita e esquerda respectivamente entre os pontos a e $b$, e entre os pontos $c$ e $d$.

A inclinação $\Delta t / \Delta x$ ao longo do movimento da lâmina é o inverso da velocidade $\Delta x / \Delta t$. Cada lâmina possui uma velocidade máxima, e a inclinação deve, como restrição, ter o valor minimo de $1 / v_{\max }$. O tempo total de exposição é $T$, que depende do comportamento da inclinação. Quando menor for a inclinação permitida, maior será a velocidade das lâminas e menor o tempo total de irradiação.

O movimento das lâminas é controlado por um sistema computadorizado (controlador). A abertura de cada par de lâminas e sua velocidade se ajustam continuamente durante o movimento, e são funçōes dependentes do tempo. Neste modo de tratamento, a posição e velocidade das lâminas, as unidades monitoras administradas e a taxa de dose interagem entre si.

Uma vez implementado o sistema para uso clínico, é imperativo realizar a verificação pré-tratamento para cada paciente com a medição da dose absoluta com uma câmara de ionização em um objeto simulador sólido equivalente à água, assim como a determinação da distribuição de dose através de dosimetria por filme ou por ferramentas mais sofisticadas como matrizes de detectores ou sistemas eletrônicos de imagem portal, com a posterior análise em um "software" adequado desta natureza.

\subsubsection{MODO ESTÁTICO. AVANÇO E DISPARO.}

Um segundo método de tratamento por IMRT com MLC é aquele que emprega segmentos múltiplos de campo para conformar um determinado padrão de intensidade. Cada campo de tratamento (em uma orientação do sistema de suporte funcional definida) é constituído por segmentos ou sub-campos definidos por aberturas do MLC; a soma destes segmentos constitui um campo de tratamento, e desta forma é obtida a modulação da intensidade do feixe de 
radiação. O feixe é liberado quando as lâminas terminam seu posicionamento, a dose do segmento é liberada e o feixe é então desligado. Depois disso, a configuraçāo das lâminas muda para o segmento seguinte; uma vez as lâminas posicionadas novamente, o feixe é liberado. O processo se repete para todos os segmentos de um campo de tratamento e posteriormente para os campos restantes. Este método é conhecido como avanço e disparo ("step and shoot"), ou simplesmente SMLC (Static MLC).

No método de liberação de radiação SMLC, existem muitos algoritmos de otimizaçăo para a obtenção do feixe modulado, sendo que alguns visam minimizar o número de segmentos, enquanto que outros o tempo de exposiçăo à radiação.

IMRT EM MODO AVANÇO E DISPARO

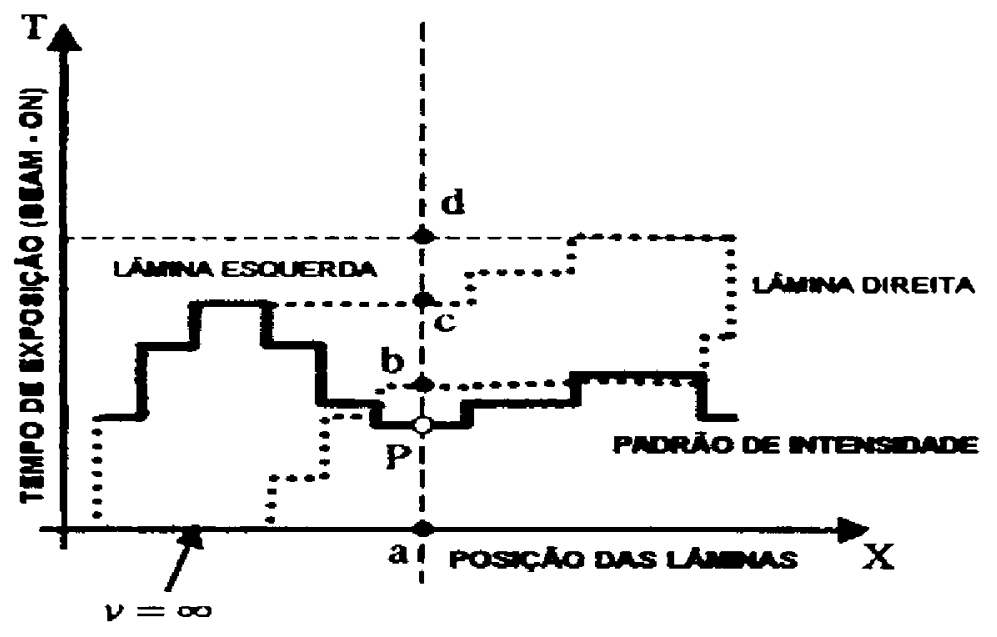

Figura 5. Esquema de liberaçāo com IMRT em modo estático (SMLC) de um perfil de intensidade modulado. $O$ ponto $P$ do padrão está coberto pela lámina direta no intervalo de tempo entre os pontos $a$ e $b[1]$.

A Figura 5 mostra uma distribuição de intensidade em cinco niveis comparável com a distribuição continua do modo DMLC. O padrão de intensidade discreto encontra-se em linha contínua e as trajetórias de cada uma das lâminas (esquerda e direita), estāo em linhas pontilhadas. Os segmentos horizontais são o tempo de parada no qual as lâminas estão mudando até a posição pré-definida $(\Delta x>0)$ e o feixe desligado $(\Delta t=0)$. Os segmentos verticais são o "disparo" ("shoot") durante o qual as lâminas permanecem estáticas $(\Delta x=0)$ e a radiação está sendo liberada $(\Delta t>0)$. As lâminas da esquerda e da direita podem-se 
movimentar de maneira simultânea durante o tempo de "parada" para encontrar suas novas posições.

Este método em particular de modulação da intensidade por múltiplos segmentos, pode ser visto sob a perspectiva de uma aproximaçāo do caso descrto de DMLC quando a velocidade das lâminas $\Delta x / \Delta t$ é infinita [2].

\subsubsection{ARCO DINÂMICO}

Existe também a técnica conhecida como arco terapia de intensidade modulada, que emprega campos múltiplos irregulares definidos pelas lâminas do MLC ao mesmo tempo em que o cavalete ("gantry") gira ao redor do paciente. Esta técnica é planejada como uma seqüência de campos estáticos com 5 a $10^{\circ}$ de separação, liberados com arcos múltiplos superpostos. Em cada arco, os MLCs mudam sua configuração continuamente em função da angulação do cavalete ("gantry") com base nos resultados da otimização, adaptando-se ao volume alvo em cada projeção, de forma que a acumulação de distribuiçōes de intensidade leva à distribuição de dose [1].

Esta técnica de tratamento é utilizada também em Radiocirugia Estereotáxica e é conhecida também com arco dinâmico (AD). O principio è a conformação do volume alvo para liberar nele uma dose alta poupando os tecidos sadios circundantes.

\subsubsection{INTENSIDADE MODULADA COM MODULADORES FISICOS}

Existem sistemas nos quais a modulação da intensidade de feixe é realizada através de moduladores físicos, sendo que o efeito deles é compensar as diferenças pela falta ou excesso de tecido em certas regiões, a partir da visualização dos cortes tomográficos de simulação do paciente [1]. Com o advento dos sistemas de planejamento computadorizados, as heterogeneidades no interior do contorno do paciente também podem ser compensadas. Os compensadores são delineados ao longo do feixe de radiação, sendo que sua construção é feita com ligas de chumbo com baixo ponto de fusão ("Lipovitz","cerrobend"). A informação do planejamento, tal como a fluência, é 
enviada para fresas automatizadas que fazem esta tarefa com a precisão requerida para este fim. Nesta técnica um dos principais fatores a serem levados em conta é o endurecimento do feixe e a radiação espalhada pela presença dos filtros.

\subsubsection{BRAÇO ROBÓTICO}

Este conceito foi inicialmente desenvolvido para tratamentos de Radiocirurgia estereotáxica, no qual um braço robótico é capaz de gerar feixes muito estreitos ("beamlets") em qualquer orientaçäo relativa ao volume alvo, conseguindo assim flexibilidade para obter modulação na intensidade do feixe [1].

\subsection{SISTEMAS DE PLANEJAMENTO}

As primeiras publicações a respeito de sistemas de planejamento computadorizados datam de mais de quarenta anos. Os primeiros sistemas dependiam de contornos bidimensionais e doses calculadas em modelos simples. A partir de então, existiram algumas tentativas para se dispor de sistemas de planejamento tridimensional, mas o estado da arte na época dos sistemas computacionais baseados em imagens não permitia o seu desenvolvimento. A primeira aproximaçāo do grupo de Sterling e colaboradores entre 1965 e 1974, gerava uma seqüência de imagens da distribuição de dose que dava uma visão 3D da anatomia irradiada [1][2].

Em 1978, foi desenvolvida na universidade de Brown - Estados Unidos, uma ferramenta muito utilizada na atualidade nos sistemas de planejamento tridimensional, o "beam-eyes-view" (BEV), uma ferramenta de visualização que posiciona o usuário na posiçăo da fonte de radiação, olhando abaixo os raios divergentes do feixe, resultando em uma visão semelhante à de uma imagem de raios- $X$ convencional. $A$ introdução posterior da tomografia axial computadorizada na rotina dos serviços de Radioterapia permitiu a inclusão de algoritmos de reconstrução até chegar na utilizaçăo completa do BEV a partir das imagens reconstruidas a partir dos cortes tomográficos, trazendo a possibilidade de conformar os feixes a partir das imagens radiográficas de reconstrução digital 
(DRR) [1][2]. Um exemplo de um BEV de um campo de tratamento está na Figura 6.

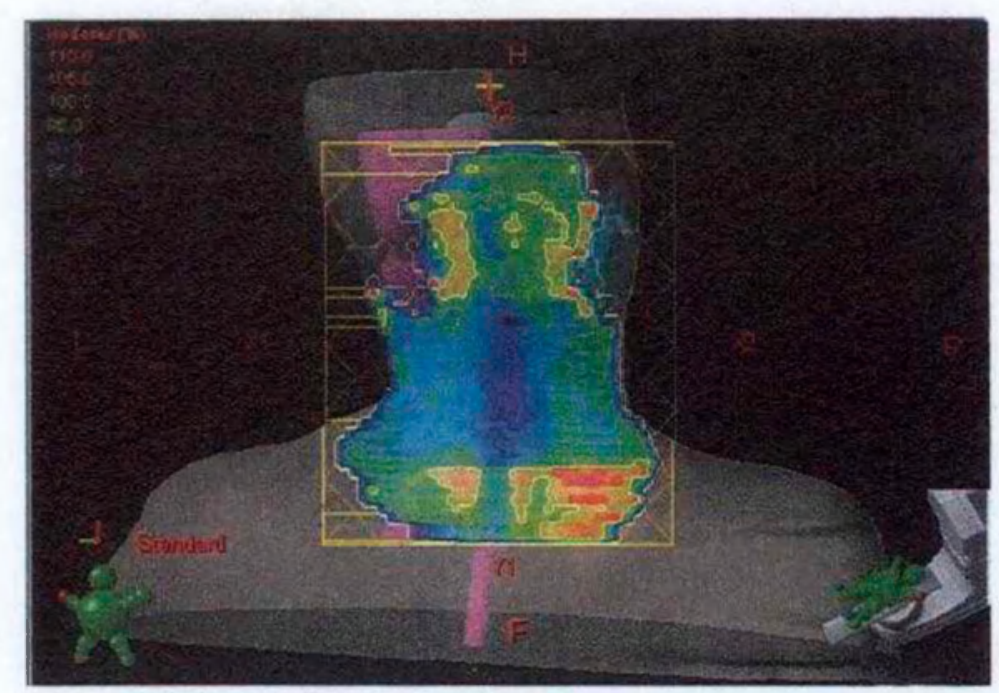

Figura 6. BEV de um campo de tratamento com as respectivas distribuiçóes de dose depois da otimizaçáo do tratamento. As regióes em vermelho sáo as de maior dose.

Já no final da década dos anos oitenta, sistemas tridimensionais confiáveis desenvolvidos em Universidades começaram a ser implementados para uso clínico. Nos anos 90 até os nossos dias estes sistemas têm sido implementados em todos os centros oferecendo cada vez mais ferramentas no cálculo (algoritmos), no desenho de estruturas, na velocidade de cálculo e no próprio desempenho dos sistemas [1][3].

A partir do uso de colimadores multi-lâminas para substituir os blocos em 3DCRT, iniciou-se a pesquisa para a utilização dos MLC para modular os feixes de tratamento. Para 3DCRT, é possivel visualizar a distribuiçăo exata das curvas de isodose em cada plano definido pelas imagens de CT. O cálculo de 3DCRT é possivel através da utilização do sistema de planejamento computadorizado.

Este sistema é alimentado com os dados obtidos no aceite e comissionamento do acelerador. Devido a este fato, esta tarefa deve ser realizada com muita precisão devido ao fato de que algum erro na tomada de dados será refletido nos futuros cálculos já com pacientes. São mandatórias, também, a elaboração e a execução de um programa de controle da qualidade rigoroso.

No caso das técnicas mais modernas, como o IMRT ou o arco dinâmico, além da eficiência no tratamento, e pelo fato dos MLCs serem 
fundamentais nelas, o resultado clínico depende da exatidão e do controle da qualidade continuo das várias etapas do processo.

\subsubsection{ALGORITMOS DE PLANEJAMENTO. PLANEJAMENTO DIRETO E INVERSO.}

Em IMRT a distribuição de dose é calculada dividindo-se o feixe em pequenos raios ("beamlets') que por sua dimensāo dificilmente atingem o equilibrio eletrōnico entre eles; isto produz assim a utilizaçāo de técnicas que integrem os feixes ("dose kernels') ou técnicas de Monte Carlo. Em IMRT modulado com MLC, as intensidades dos feixes variam com o movimento das lâminas através do campo de radiação, por isso é preciso que o sistema modele de maneira adequada a penumbra, a transmissão e a forma das bordas pelo sistema de planejamento.

Uma vez otimizado um plano de tratamento, deve ser obtida a seqüência das lâminas para serem liberadas no acelerador. Isto é conseguido através de algoritmos para dispor em seqüência o posicionamento das lâminas. Mas devido ao fato de que os parâmetros citados no parágrafo anterior são modelados, a liberação de radiação não será exata, mas tentando sempre liberar um feixe o mais parecido com o planejado. Existem sistemas de planejamento computadorizados que incluem este processo no planejamento inverso aumentando o tempo de cálculo. Por ocasiảo do comissionamento todos estes detalhes começam a serem determinados para a implementação clinica [1][2].

Os termos planejamento "inverso" e "direto" têm sido muito utilizados desde o uso do IMRT. O planejamento "direto" ("forward planning") é aquele no qual o planejador decide a configuração dos feixes e ele mesmo avalia a conveniência do plano desenvolvido e, se for o caso, efetua as mudanças necessárias. Muitas vezes, se não a maioria delas, estas mudanças sāo o produto da experiência adquirida pelo planejador, seja este o Físico ou o Dosimetrista. Este tipo de planejamento é utilizado pelos sistemas de planejamento tridimensionais.

O planejamento inverso divide o feixe em múltiplos raios ("beamlets") e determina a intensidade de cada um deles, e, devido ao grande número de raios 
assim gerados, a solução só é possivel computacionalmente. Quem planeja especifica as orientações dos feixes, a dose objetiva no volume alvo $e$ as restriçōes de dose ou limites de dose nos órgãos de risco; em seguida, o algoritmo de otimizaçāo calcula o padrão de intensidades mais próximo à descrição desejada. Se o Físico precisa mudar o resultado, os limites e as restrições devem ser alterados e deve-se proceder a uma nova otimização. $O$ sistema de planejamento agrupa os valores dos objetivos e as restrições em uma função de "custo" a ser maximizada ou minimizada pelo algoritmo de otimização. Deve sempre ser considerado que a solução do planejamento inverso não garante uma solução clinicamente ótima já que as restrições inseridas não podem ser atingidas [1][2][3][4].

Os algoritmos de otimização são esquemas heuristicos de procura de máximos e mínimos locais que nem sempre levam a uma solução clinicamente ótima para o problema em questão. Em geral, sempre é precisa mais do que uma tentativa antes de se encontrar a melhor solução. $O$ exito do planejamento inverso depende em grande parte de uma boa representação do problema clínico através da função "custo" [2].

Existem dois tipos de algoritmos de otimização para minimizar funções de custo: determinísticos e estocásticos [1][3][4]. Os determinísticos vão da solução proposta à solução seguinte, calculando as primeiras e segundas derivadas da funçāo custo. O tamanho do intervalo depende do gradiente calculado. O cálculo é feito relativamente rápido, mas não pode sair de um mínimo local; estes métodos são chamados como métodos de decréscimo de gradiente. Os algoritmos estocásticos acham a solução por mudanças aleatórias nas intensidades dos raios, isto faz possivel obter um minimo local. Eles são mais lentos no cálculo que os deterministicos, devido ao fato de que o algoritmo leva um certo tempo avaliando e rejeitando os movimentos aleatórios. O método de arrefecimento simulado ("simulated annealing") é uma técnica estocástica usada na otimização inversa do IMRT. Na prática, os métodos estocásticos e de descida de gradiente podem ser combinados [3]. A existência de um minimo local depende da função de custo e dos objetivos estipulados. Se a função é linear ou quadrática, com uma dose objetiva em cada estrutura anatômica na região de cálculo, os objetivos dose-volume podem fazer com que exista um mínimo local, 
ou se o número e orientação dos campos de tratamento é um parâmetro a se otimizar.

\subsection{PLANEJAMENTO}

O planejamento de IMRT inclui vários critérios adicionais a serem levados em consideração do que em um planejamento convencional e até em um planejamento tridimensional. A nāo uniformidade da intensidade introduz regiōes de alto gradiente de dose entre volume alvo e tecidos circundantes, devido às concavidades nos desenhos dos volumes, à proximidade entre as estruturas ou do número de campos de tratamento utilizados [1][3]

Com relação ao delineamento de estruturas, é preciso dispor de muito tempo por parte do Radioterapeuta para permitir uma definição correta das estruturas nas quais a otimização se baseará, já que esta é uma tarefa fundamental no processo como um todo. Uma vez as estruturas delineadas, devese estabelecer as margens dos órgãos seguindo os conceitos do ICRU [5][6], por exemplo volume alvo clínico (CTV) e volume alvo de planejamento (PTV). Todos os volumes dos quais se requer informação ou que sejam poupados, precisam ser desenhados nas imagens de tomografia. Com todas as estruturas delineadas, deve-se inserir no sistema as restrições (doses objetivo) dose - volume para os volumes alvo e os órgãos em risco.

O processo seguinte consiste no cálculo inverso, como foi descrito anteriormente; o sistema procura as melhores soluções para as restrições propostas. Os critérios de aceitação de um plano devem estar previamente estabelecidos para que os resultados sejam discutidos entre 0 Físico e o Radioterapeuta. Deve ser lembrado que as soluções não são sempre as melhores desde o ponto de vista clínico, porém, geralmente são mudadas algumas restriçōes para se obter uma solução mais próxima à planejada no inicio. Na Figura 7 está um exemplo de distribuição de dose obtida a partir de um planejamento inverso.

Uma vez aprovado o plano, iniciam-se as tarefas de controle da qualidade pré - tratamento que incluem a exportação do plano escolhido a um objeto simulador sólido para a verificação de dose absoluta pontual e de dose 
relativa ou distribuição de dose. Os resultados destes testes são analisados e, se os resultados são positivos, o paciente está pronto para começar o seu tratamento.

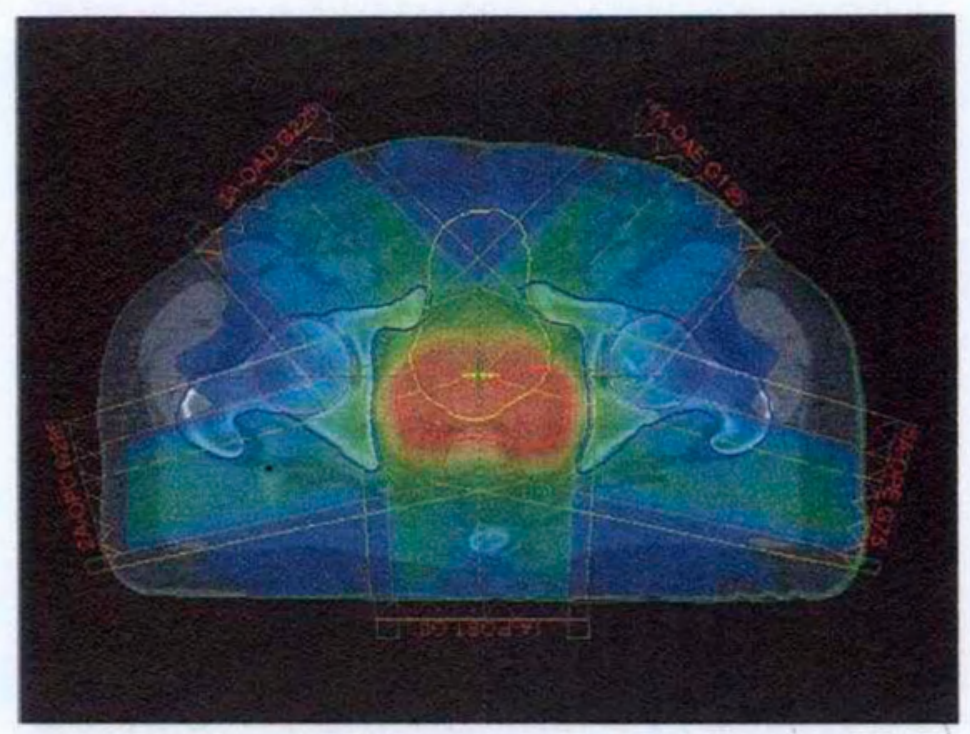

Figura 7. Exemplo de distribuição de dose obtida a partir de um planejamento inverso de IMRT para um paciente com câncer de próstata.

\subsection{FUNDAMENTOS DE DOSIMETRIA.}

\subsubsection{DOSE ABSORVIDA.}

A radioterapia moderna baseia-se na entrega exata da dose ao volume alvo prescrito. A Comissão Internacional de Unidades e Medidas de Radiação (ICRU) recomenda uma exatidão global de $\pm 5 \%$ baseada na análise dos dados da resposta da dose e em uma avaliação das incertezas envolvidas na liberação de dose ao paciente [5][6]. Considerando todas as incertezas envolvidas na liberação de dose ao paciente, a recomendação do $\pm 5 \%$ de exatidão não é de maneira alguma fácil de atingir.

Antes do uso clínico, o rendimento dos feixes de fótons e de elétrons produzidos nos equipamentos de radioterapia externa deve ser determinado. Esta calibração é sem dúvida uma das partes mais importantes do processo de liberação da dose ao paciente.

O rendimento em um equipamento de radioterapia indica-se geralmente como a taxa de dose em um ponto $P$ em uma profundidade de referência $d_{\text {ref }}$ em um objeto simulador equivalente à água a uma distância 
nominal fonte-superficie e para um tamanho de campo de referência $10 \times 10 \mathrm{~cm}^{2}$ na superficie do objeto simulador ou no isocentro. $O$ fator de rendimento para equipamentos de raios- $X$ na faixa dos $k V p$ e unidades de cobaitoterapia $\dot{e}$ expressado em Gy/min; para aceleradores clinicos está dada em Gy/UM, sendo UM unidade monitora [7].

As câmaras de ionização sāo utilizadas em radioterapia e radiodiagnóstico para a determinação da dose. Uma câmara de ionização é basicamente uma cavidade cercada de uma parede de material condutor e um eletrodo central coletor. A parede e o eletrodo estão separados por um isolante para reduzir a corrente de fuga quando é aplicada uma determinada tensão à câmara.

Os procedimentos a serem seguidos quando um feixe clínico de fótons ou elétrons é calibrado são descritos nos chamados Protocolos de Dosimetria. A escolha do uso de um determinado protocolo é responsabilidade de cada Departamento, sendo alguns deles recomendados por Organismos internacionais como a Agência Internacional de Energia Atômica (IAEA), ou por organismos regionais (p.ex. AAPM na América do Norte, NACP na Escandinávia, etc.) ou nacionais. Estes procedimentos asseguram um alto nivel de consistência na determinação da dose entre os diferentes centros de Radioterapia em um determinado pais e também entre um pais e outro [8][9].

Na prática clinica. a câmara de ionização é a ferramenta mais utilizada para a determinação da dose através da utilização de fatores que asseguram a rastreabilidade com padrões nacionais, e as câmaras de ionização são então usadas como dosimetros relativos. Antes do uso de uma câmara na calibração de um feixe clínico, deve ser escothido o protocolo de calibração apropriado para o feixe. Os protocolos fornecem o formalismo e os dados necessários para relacionar a calibração da câmara em um laboratório padrão com a medição da dose na água em condiçōes de referência no feixe clínico. Atualmente são usados os protocolos baseados em fatores de calibração de dose absorvida na água. Estes fatores sāo obtidos geralmente em feixes de Cobalto 60 nos laboratórios de calibração secundária [7].

A primeira etapa na utilização de um protocolo è a determinação do sinal da câmara corrigindo a carga da câmara pelas grandezas de influência que 
possam afetar o sinal da câmara $\left(M_{Q_{0}}\right)$. A dose absorvida na água na profundidade de referência de um feixe de qualidade $Q_{0}$ é dada por:

$$
D_{w, Q_{0}}=M_{Q_{0}} N_{O W Q_{0}}
$$

O fator $N_{D, w, Q_{0}}$ é o fator de calibração de dose absorvida na água obtido no laboratório secundário de calibração.

Seguindo este procedimento, pode ser obtida a dose absorvida e comparada com a dose em condiçōes de referência. Isto é realizado como prática rotineira como verificação pré - tratamento para todos os pacientes tratados com técnicas como IMRT e AD.

Os planos aprovados são exportados a um objeto simulador sólido equivalente à água.

\subsubsection{DOSIMETRIA POR FILME}

Os filmes radiográficos desenvolvem funções importantes em radiodiagnóstico, radioterapia e radioproteção. Servem como detector de radiação, dosímetro relativo, dispositivo de exposição e meio de arquivo de informação.

Um filme radiográfico consiste em uma base fina de plástico com uma emulsão sensivel à radiação (grãos de brometo de prata suspensos em base gelatinosa) revestida uniformemente em um ou ambos os lados da base. A ionização do $\mathrm{AgBr}$ em grãos, como resultado da interação com a radiaçāo, forma uma imagem latente no filme. A imagem é visivel (filme é escurecido) somente quando é revelado, sendo que os grãos expostos à radiação se reduzem à prata metálica. O filme é então fixado através de uma solução que dissolve o brometo de prata e a gelatina nāo expostos à radiaçāo [7][10].

A luz transmitida é função da opacidade do filme e pode ser medida em termos da densidade óptica (OD) com equipamento de medição (densitômetros).

A densidade óptica é defina como $O D=\log _{10}(/ / /)$, e é função da dose. $\mathrm{I}_{0}$ é a intensidade inicial de luz e I, a intensidade transmitida através do filme. $\mathrm{O}$ filme oferece excelente resolução espacial em duas dimensōes e em uma única 
exposição apresenta informação da distribuição espacial de radiação na área irradiada ou a atenuação de radiação por algum objeto.

A faixa na qual pode ser utilizado o filme é limitada segundo o tipo utilizado, devido ao fato de que apresenta dependência energética. Pela dependência do efeito fotoelétrico com o número atômico ao cubo, e por ter em sua composição a prata $(Z=45)$, o filme absorve radiação espalhada abaixo de $150 \mathrm{keV}$, e não é recomendável seu uso abaixo este valor [7].

Geralmente os filmes são usados como ferramentas para dosimetria qualitativa, mas com uma calibração adequada, cuidado no uso e análise, podem ser usados para se avaliar a dose. Alguns tipos de filmes sāo utilizados em radioterapia (de exposição direta, para simulação, de chassi metálico para imagens portais, etc.) [7][11][12][13].

Os filmes não expostos à radiação exibem densidade óptica de fundo ("fog"); a densidade óptica liquida é obtida pela subtração da densidade de fundo da densidade medida devido à exposição à radiação.

Como leitores de OD são utilizados os densitômetros, densitômetros a laser, digitalizadores automáticos ("scanner"), etc. Idealmente, a relação entre a dose e a OD deve ser linear, mas isto nem sempre acontece. Algumas emulsōes são lineares, outras são lineares em uma determinada faixa de dose e outras são não lineares. A curva dose vs. OD é conhecida como curva sensitométrica ou curva caracteristica H\&D, na honra a Hurter e Driffield que foram os primeiros pesquisadores desta relação. A curva mencionada deve ser estabelecida para cada tipo de filme utilizado antes de cada medida dosimétrica [7][10][12][13].

As aplicações típicas do filme radiográfico em radioterapia sāo medições qualitativas e quantitativas, incluindo dosimetria para feixes de elétrons, controle da qualidade dos equipamentos (p.ex. coincidência de campo luminoso e de radiaçāo. isocentricidade do colimador, do sistema de suporte funcional, mesa de tratamento, etc.), simetria e planura do feixe, distribuições de dose. verificação de técnicas de tratamento (controle da qualidade pré-tratamento). imagens portais e comissionamento de equipamentos $[7][10][11][12][14][15][16][17]$. 


\subsubsection{DOSIMETRIA RELATIVA COM FILME}

Uma das ferramentas mais utilizadas e de maior confiabilidade é a utilização dos filmes radiográficos de verificação (tipo Kodak X-Omat V \& ou EDR2). Com arranjos experimentais simples pode ser realizado o levantamento de dados dosimétricos para o comissionamento de um equipamento que vão ser inseridos nos sistemas de planejamento computacionais [7][10][11][12].

Este tipo de filme é também de grande utilidade nos procedimentos de controle da qualidade pré-tratamento para as técnicas de IMRT. Neste caso, as fluências do planejamento aprovado são exportadas a um objeto simulador sólido equivalente à água, um filme de verificação é posicionado e irradiado. Com um "software" de verificação dosimétrica são comparadas às distribuições obtidas tanto no filme irradiado quanto as calculadas pelo sistema de planejamento. Este sistema permite uma análise qualitativa e quantitativa que permite decidir o inicio ou não do plano de tratamento [3][4][11][12][14][17][18].

\subsection{CONTROLE DE QUALIDADE}

\subsubsection{TESTES DE ACEITAÇAO}

Os testes de aceitação asseguram que as especificaçōes estipuladas na aquisição do equipamento sejam satisfeitas. Estes testes são realizados na presença do representante do fabricante do equipamento. Geraimente possuem tolerâncias maiores que as desejadas, se bem que garantem um funcionamento adequado do equipamento, que deve ser ainda testado e os testes aprofundados para uma familiarização completa com o equipamento.

Os testes de aceitação podem ser divididos em três grupos:

- testes de segurança;

- testes mecânicos; e

- mediçōes dosimétricas [3][7][15][18]. 


\subsubsection{TESTES DE COMISSIONAMENTO}

O comissionamento de um equipamento de radioterapia inclui uma série de testes que geralmente consiste dos seguintes passos:

- aquisição de todos os dados dosimétricos necessários para o tratamento;

- organizar todos estes dados em um livro de dosimetria;

- alimentar o sistema de planejamento computadorizado com todos esses dados;

- desenvolver todas as rotinas de dosimetria, planejamento de tratamentos e procedimentos de tratamentos,

- verificação da exatidão destas rotinas:

- estabelecer os testes e procedimentos de controle da qualidade; e

- treinamento de todo o pessoal.

Geralmente, são testes que garantem um ótimo funcionamento do equipamento bem como de seu estado inicial. Muitos dos parâmetros a serem verificados rotineiramente devem ser comparados com os levantados nesta fase. Um comissionamento abreviado é requerido depois de cada manutenção significativa do equipamento [2][3][7][15].

\subsubsection{VERIFICAÇÃO DO TRATAMENTO DOS PACIENTES}

Como parte do programa de controle da qualidade dos tratamentos dos pacientes existem algumas tarefas a serem desenvolvidas pela equipe de Fisica de um Serviço que trata pacientes com IMRT, arco dinâmico, radiocirugia fracionada, etc.

Uma vez terminado o planejamento de um tratamento, este é revisado e discutido conjuntamente entre Fisico e Radioterapeuta para sua aprovação. Uma vez aceito. os dados do plano de tratamento são enviados pela rede de registro e verificação para o acelerador.

Nesse momento devem ser desenvolvidas tarefas de controle de qualidade do plano de tratamento escolhido. O sistema de planejamento permite 
exportar o plano a um objeto simulador, no qual é possivel realizar medidas de dose absoluta, com câmara de ionização, e de distribuição de dose, com filme de verificação dosimétrica. Os dados de cada campo, como ângulo de cavalete ("gantry"), ângulo de mesa, pontos de localização do isocentro, configuração do MLC, dose e UM, são então verificados. Deve-se determinar a dose absoluta a partir do plano gerado no objeto simulador seguindo os protocolos de determinação de dose absorvida, como está ilustrado na Figura 8 [8][9].

Outra etapa muito importante, como parte do programa de controle da qualidade, é a verificação das unidades monitoras calculadas pelo sistema de planejamento [19][20][21].

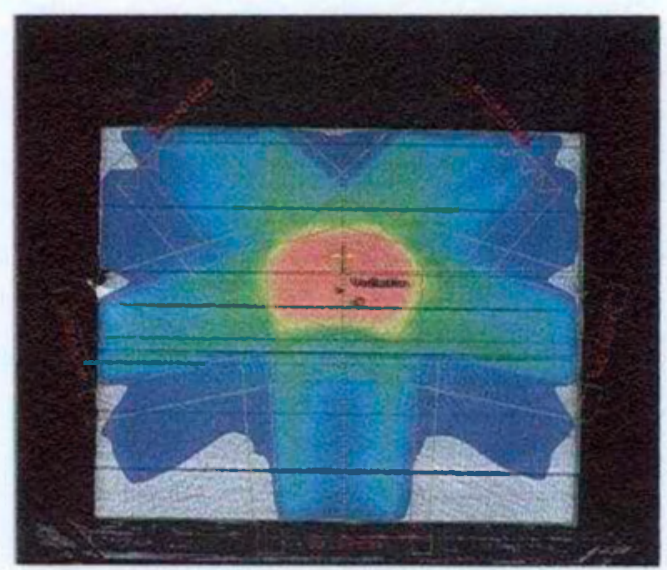

Figura 8. Objeto simulador sólido equivalente à água, para verificaçóes pré - tratamento (dosimetria absoluta e relativa). Pode-se observar a distribuição de dose exportada nele e normalizada no centro da cámara de ionizaçāo.

\subsection{REVISÃO BIBLIOGRÁFICA}

Os primeiros conceitos de Radioterapia Conformada apareceram em 1965, quando o primeiro sistema de colimação de múltiplas lâminas foi desenvolvido e implementado em Nagoya no Japão [1].

Posteriormente na Inglaterra, foi utilizado um equipamento de Cobalto60 , no qual o paciente era irradiado assim que a mesa se movimentava e o sistema de suporte funcional ("gantry") girava durante o tratamento. Com esta técnica a dose era conformada ao redor das vias de disseminação da doença [1].

No Karolinska Intitutet na Suécia, se relatou o uso de distribuições de intensidade não uniformes, no projeto do MM50 Racetrack Microtron System $®$ da Scanditronix [1][2]. 
O desenvolvimento dos sistemas de planejamento computadorizado com ferramentas tridimensionais permitiu os tratamentos conformados usando blocos de proteção de ligas de chumbo. O posterior desenvolvimento dos sistemas de colimação de multi-lâminas trouxe a possibilidade de utilizar estes para substituir os blocos de proteção [22].

A utilização em cada vez mais centros de Radioterapia dos MLCs fez com que sejam reportadas metodologias para o controle de qualidade dos sistemas, detalhado os testes e a freqüência a serem realizados [23][24][25]. Posteriormente, Boyer e colaboradores [26] compilaram informação em um único texto com aplicações e caracteristicas dos colimadores multi-lâminas comercialmente disponiveis.

A partir do uso de colimadores multi-lâminas para substituir os blocos em 3DCRT, iniciou-se a pesquisa para a utilização dos MLC para modular os feixes de tratamento. Foi assim que LoSasso e colaboradores reportaram o desenvolvimento destes sistemas para a utilização em DMLC [15] e as características dosimétricas.

Uma vez disponibilizados comercialmente sistemas de liberação de feixe por intensidade modulada, a pesquisa na área incrementou-se, começou então a serem apresentadas as experiências de diversos centros; esse foi o caso de LoSasso e colaboradores [16] no Memorial Sloan - Kettering Câncer Center em Nova Iorque nos Estados Unidos; Essers e colaboradores [14] no Hospital Universitário de Rotterdam, e Venencia e Besa [18] apresentaram o programa de controle de qualidade implementado no Hospital adjunto à Universidade Católica em Santiago no Chile. $O$ trabalho de Van Esch e colaboradores [17] apresenta a experiência de cinco centros de Radioterapia na Europa, detalhando as ferramentas dosimétricas em cada um deles para fazer a aceitação, comissionamento e controle de qualidade dos diversos sistemas envolvidos em um programa de IMRT (MLC, sistema de planejamento, acelerador, etc.). Linthout e colaboradores [27] fizeram uma descrição de alguns sistemas de liberação de feixe com intensidade modulada e as tarefas na aceitaçāo, comissionamento e controle de qualidade dos sistemas. Cosgrove e colaboradores [28] descreveram essas tarefas especificamente para o micro colimador multi-iâminas (mMLC). 
Os programas de controle de qualidade, descritos nos trabalhos citados no parágrafo anterior, levam em consideração a utilizaçāo de diversas ferramentas dosimétricas. Uma delas é a mediçāo da dose absoluta pontual como verificação pré - tratamento de um caso de IMRT; é descrita na literatura por LoSasso e colaboradores [16] para cerca de 400 pacientes e por Venencia e Besa [18] para 120 pacientes planejados com IMRT, e é sempre realizada seguindo os Protocolos de Calibração mais divulgados [8][9]. Linthout e colaboradores [29], mostram um algoritmo para verificação pré-tratamento dos cálculos realizados pelos sistemas de planejamento com IMRT e Arco Dinâmico.

No caso da realização de dosimetria relativa como verificação pré tratamento, LoSasso e colaboradores [15][16] apresentam seus resultados. Venencia e Besa [18], Van Esch e colaboradores [17], Essers e colaboradores [14] e Cosgrove e colaboradores [28] mostram sua experiência na verificação através de filmes de verificaçăo dosimétrica e a comparação destes com os planejamentos realizados. Já Bucciolini e colaboradores [11] descrevem de forma mais detalhada a metodologia utilizada para esta verificação. Como ferramenta adicional, Depuydt e colaboradores [30] apresentam o Análise Gamma para a comparação quantitativa e qualitativa entre os resultados da verificação pré tratamento realizada com filmes e o plano calculado pelo sistema de planejamento.

Todos os esforços de controle de qualidade não teriam efeito real se os sistemas de planejamento computadorizados (TPS) não tivessem o seu próprio. Testes e procedimentos rigorosos envolvendo os TPS são descritos por Fraass e colaboradores [19] e no novo documento da Agência Internacional de Energia Atômica [21].

Nestes últimos anos, a maior parte de esforços tem sido focalizada a normatizar os procedimentos na implementação de IMRT. desde o comissionamento dos sistemas de liberação (p.ex. MLC). dos sistemas de planejamento, o equipamento de dosimetria e principalmente $\circ$ treinamento e experiência requeridos pela equipe multidisciplinar (Radioterapeuta, Fisico Médico, Dosimetristas, Técnicos, etc.). Para isto existem documentos importantes que descrevem a técnica de IMRT e certos aspectos gerais a serem considerados, esse é o caso do "Collaborative Group de IMRT" [1], e dos grupos 
conjuntos da Associação Americana de Fisicos em Medicina e Associação Americana de Radiologia e Oncologia Terapêutica [3][4].

\subsection{OBJETIVOS}

Caracterizar três sistemas de MLC disponiveis no Serviço de Radioterapia do Hospitał Israelita Albert Einstein em São Paulo. Verificar suas vantagens e desvantagens, através de uma intercomparação entre eles, visando a implementação de Radioterapia de Intensidade Modulada de Feixe (IMRT). 


\section{MATERIAIS E MÉTODOS}

\subsection{ACELERADOR LINEAR}

O equipamento usado nos tratamentos de Radioterapia, Radiocirurgia e Arco Dinâmico do Hospital Israelita Albert Einstein - HIAE è um acelerador CLINAC $600 \mathrm{C}$ (Varian Medical Systems, Palo Alto) montado isocentricamente com distância fonte - eixo de rotação de $100 \mathrm{~cm}$. A energia nominal do feixe de fótons liberado é de $6 \mathrm{MV}$. A taxa de dose utilizada nos diversos testes foi de 250 $U M / m i n$. Neste acelerador é acoplado um sistema $m_{3}$ (BrainLAB, $A G$, Heimstetten, Alemanha) de micro colimadores multi-lâminas ( $m M L C)$. O sistema tem a capacidade de tratar campos conformados, campos de intensidade modulada em modo dinâmico e estático, e arco dinâmico.

O equipamento usado nos tratamentos de Radioterapia de Intensidade Modulada de Feixe no Hospital Israelita Albert Einstein - HIAE é um acelerador Varian, modelo 23EX (Varian Medical Systems, Palo Alto) montado isocentricamente com distância fonte - eixo de rotação de $100 \mathrm{~cm}$. Tem a capacidade de liberar feixes de fótons de 6 e $15 \mathrm{MV}$, e de 4, 6, 9, 12, 16 e $20 \mathrm{MeV}$ de elétrons. A taxa de dose padrão utilizada nos diversos testes foi de 300 $\mathrm{UM} / \mathrm{min}$, sendo que este equipamento pode tratar com taxas de dose entre $100 \mathrm{e}$ $600 \mathrm{UM} / \mathrm{min}$. O sistema tem a capacidade de tratar campos conformados, campos de intensidade modulada em modo dinâmico e estático, e arco dinâmico. Uma fotografia deste equipamento está na Figura 9.

Para a elaboração do presente trabalho e seguindo a rotina do HIAE, os testes foram realizados para avaliar parâmetros envolvidos nos tratamentos de IMRT em modo dinâmico.

O acelerador que foi utilizado, para os testes com o MLC Mark II. é marca Varian, modelo $2100 \mathrm{C}$. Libera feixes de fótons de 6 e $18 \mathrm{MV}$, e de 4, 6, 9 , 12 e $16 \mathrm{MeV}$ de elétrons. Ele está montado isocentricamente com distância fonte - eixo de rotação de $100 \mathrm{~cm}$. 


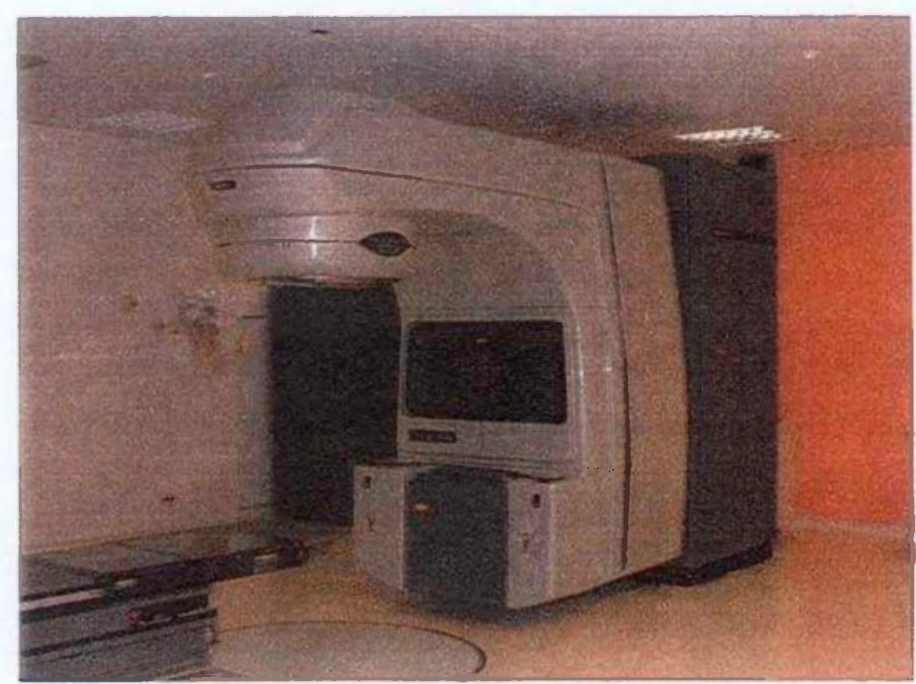

Figura 9. Acelerador linear Varian modelo 23EX do Departamento de Radioterapia do Hospital Israelita Albert Einstein.

\subsection{SISTEMA DE COLIMADOR MULTI-LÂMINAS.}

\subsubsection{COLIMADOR MULTI-LÂMINAS. VARIAN -MODELO MARK II}

O sistema de colimador multi-lâminas Varian, modelo Mark II, está montado abaixo dos coiimadores convencionais nos aceleradores Varian Série C. Possui 26 pares de lâminas de uma liga de tungstênio, de $6 \mathrm{~cm}$ de altura; cada lâmina projeta uma largura de $1 \mathrm{~cm}$ no isocentro e o ponto médio da lâmina fica a $51 \mathrm{~cm}$ da fonte. As lâminas, montadas em carrosséis possuem movimento retilineo, no mesmo sentido que os colimadores secundários.

A faixa de movimento das lâminas por si mesmas é de aproximadamente $15 \mathrm{~cm}$ no isocentro relativo ao carreto, e de $+20 \mathrm{~cm}$ a $-16 \mathrm{~cm}$ relativo ao isocentro quando combinado com o movimento do carrossel.

Dentre os colimadores secundários, existem os superiores e inferiores. Os primeiros definem os limites superiores $e$ inferiores dos campos. Os colimadores inferiores são posicionados a $0,5 \mathrm{~cm}$ de distância da posição mais retraida das lâminas em cada lado do campo. Isto acontece de igual maneira nos campos estáticos.

Para ter um valor relativamente constante de penumbra do feixe em diferentes posições, as bordas das lâminas foram projetadas arredondadas. A porção central das lâminas $(3 \mathrm{~cm})$ é circular com raio de $8 \mathrm{~cm}$. Depois dessa faixa de $3 \mathrm{~cm}$ a borda é reta formando um ângulo de $11,3^{\circ}$ relativo ao eixo vertical. 


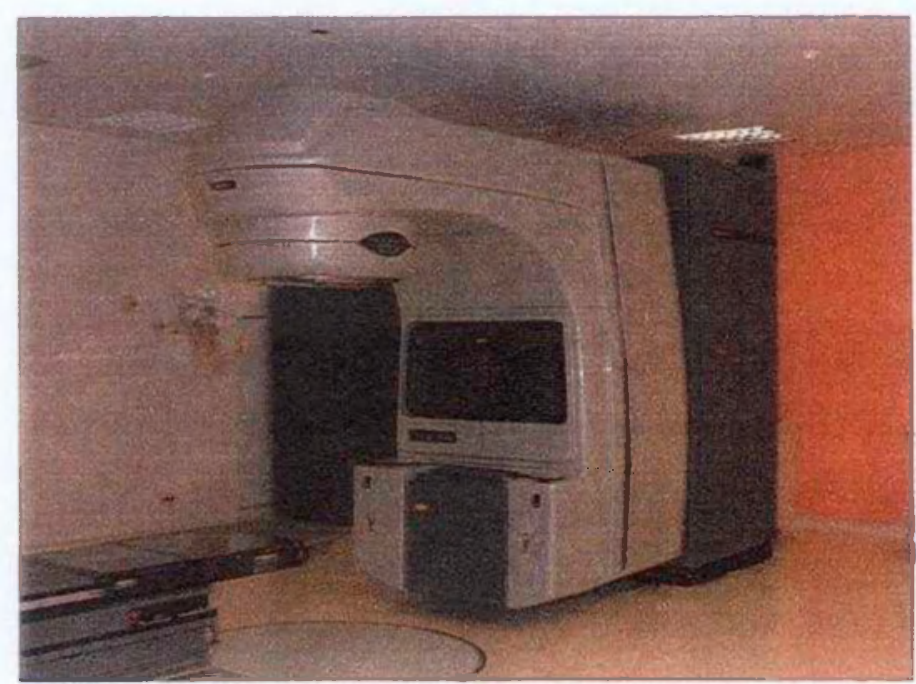

Figura 9. Acelerador linear Varian modelo 23EX do Departamento de Radioterapia do Hospital Israelita Albert Einstein.

\subsection{SISTEMA DE COLIMADOR MULTI-LÂMINAS.}

\subsubsection{COLIMADOR MULTI-LÂMINAS. VARIAN -MODELO MARK II}

O sistema de colimador multi-lâminas Varian, modelo Mark II, está montado abaixo dos colimadores convencionais nos aceleradores Varian Série C. Possui 26 pares de lâminas de uma liga de tungstênio, de $6 \mathrm{~cm}$ de altura; cada lâmina projeta uma largura de $1 \mathrm{~cm}$ no isocentro e o ponto médio da lâmina fica a $51 \mathrm{~cm}$ da fonte. As lâminas, montadas em carrosséis possuem movimento retilineo, no mesmo sentido que os colimadores secundários.

A faixa de movimento das lâminas por si mesmas é de aproximadamente $15 \mathrm{~cm}$ no isocentro relativo ao carreto, e de $+20 \mathrm{~cm}$ a $-16 \mathrm{~cm}$ relativo ao isocentro quando combinado com o movimento do carrossel.

Dentre os colimadores secundários, existem os superiores e inferiores. Os primeiros definem os limites superiores $e$ inferiores dos campos. Os colimadores inferiores são posicionados a $0,5 \mathrm{~cm}$ de distância da posição mais retraida das lâminas em cada lado do campo. Isto acontece de igual maneira nos campos estáticos.

Para ter um valor relativamente constante de penumbra do feixe em diferentes posições, as bordas das lâminas foram projetadas arredondadas. A porção central das lâminas $(3 \mathrm{~cm})$ é circular com raio de $8 \mathrm{~cm}$. Depois dessa faixa de $3 \mathrm{~cm}$ a borda é reta formando um ângulo de $11,3^{\circ}$ relativo ao eixo vertical. 
Para minimizar a fuga de radiação entre lâminas adjacentes foi projetado um intertravamento conhecido como lingüeta - vão ("tongue and groove").

O movimento retilineo e a forma arredondada da borda introduzem uma dependência não linear do tamanho de campo na posiçăo da lâmina. Quando a lâmina se encontra retraindo do eixo central, o ponto de definição do tamanho de campo na região arredondada não está mais no centro da lâmina, pois este se afasta da fonte. Quando as lâminas atravessam o eixo central, o ponto de definição do tamanho do campo muda em sentido da fonte. Um "software" do fabricante corrige esta dependência não linear do tamanho de campo com a posição da lâmina. Desta maneira, a leitura digital está relacionada com o campo luminoso e de radiação, e não com o deslocamento físico.

Através de outro "software" é controlado o alinhamento e a calibração da posição das lâminas. Isto é feito ajustando quatro parâmetros: a "obliqüidade" dos bancos (esquerdo e direito) de forma individual, a abertura dosimétrica entre lâminas opostas e a posição das lâminas no eixo central.

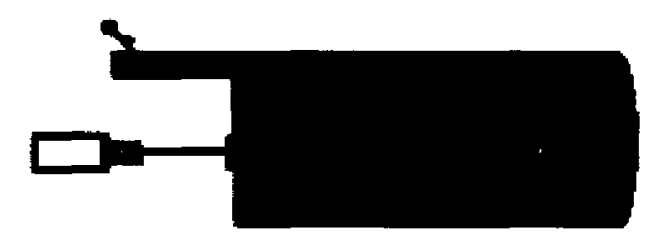

Figura 10. Colimador multi-lâminas marca Varian; pode-se observar o motor responsável pelo movimento acoplado a lámina.

\subsubsection{COLIMADOR MULTI-LÂMINAS. VARIAN -MODELO MILLENIUM.}

O sistema colimador multi-lâminas Varian, modelo Millenium, está montado abaixo dos colimadores convencionais nos aceleradores Varian Série EX. Possui 60 pares de lâminas de uma liga de tungstênio, aproximadamente de $6 \mathrm{~cm}$ de altura. Os pares $1-10$ e $51-60$ projetam $1,0 \mathrm{~cm}$ de largura; e o resto das lâminas (20 cm centrais) projetam uma largura de $0,5 \mathrm{~cm}$ no isocentro. $O$ limite inferior da lâmina fica a $53,8 \mathrm{~cm}$ da fonte. As lâminas, montadas em carrosséis possuem movimento retilineo, no mesmo sentido que os colimadores secundários. 
A faixa de movimento das lâminas por si mesmas é de aproximadamente $15 \mathrm{~cm}$ no isocentro relativo ao carrossel, e de $+20 \mathrm{~cm}$ a $-16 \mathrm{~cm}$ relativo ao eixo central quando combinado com o movimento do carrossel. $O$ tamanho de campo máximo é de $40 \times 40 \mathrm{~cm}^{2}$. A velocidade máxima da lâmina no isocentro é de $2,5 \mathrm{~cm} / \mathrm{s}$ para operação em modo dinâmico; é permitida somente a movimentaçāo das lâminas, permanecendo os carrosséis fixos durante a liberação do feixe. Para minimizar a fuga de radiaçăo entre lâminas adjacentes foi projetado um intertravamento conhecido como lingüeta - vão ("tongue and groove").

No presente trabalho os testes realizados foram desenvolvidos com finalidade de avaliar o MLC em modo dinâmico.

\subsubsection{COLIMADOR MICRO MULTI-LÂMINAS. BRAINLAB -MODELO $\mathrm{m}_{3}$}

O colimador de micro multi-lâminas (mMLC) está baseado na configuraçăo e projeto de um sistema convencional de colimador de multilâminas. Possui 26 pares de lâminas de tungstênio com movimento perpendicular ao eixo central. A diferença que existe entre o sistema $m_{3}$ com o sistema de multjlâminas convencional da Varian é que a largura das lâminas no caso do micro colimador de multi-lâminas não é a mesma nas 52 lâminas, sendo a configuração a seguinte: 7 pares com $3,0 \mathrm{~mm}$ de largura, 6 pares com $4,5 \mathrm{~mm}$ de largura e 6 pares com $5.5 \mathrm{~mm}$ de largura. Fazendo um corte transversal das lâminas pode ser observado o projeto do efeito lingüeta - vão necessário para permitir que o eixo de movimento seja inserido em cada lâmina. O movimento é realizado por um motor de $10 \mathrm{~mm}$ de diâmetro.

O sistema de micro colimador multi-lâminas pesa $30 \mathrm{~kg}$, sendo acoplado no cabeçote do acelerador. A distância livre que fica entre a base do $\mathrm{mMLC}$ e o isocentro de tratamento é de $37,9 \mathrm{~cm}$ para o acelerador utilizado neste trabalho.

A extremidade da lâmina é constituida por três bordas retas que correspondem à divergência do feixe quando a lâmina está completamente retraída (posiçāo $x=4,9 \mathrm{~cm}$ ), centralizada (posiçāo $x=0,0 \mathrm{~cm}$ ) e completamente 
extendida (posição $x=-4,9 \mathrm{~cm}$ ). O campo de radiação máximo do micro colimador multi-lâminas é $9.8 \times 9,8 \mathrm{~cm}^{2}$.

O monitoramento da posição de cada lâmina é feito por dois mètodos: o principal, em que um sinal indica a posição a partir da rotação do eixo de cada lâmina; no método secundário, o sinal vem de duas escovas montadas no plano longitudinal de cada lâmina. Estes métodos em conjunto asseguram uma precisão de $0.1 \mathrm{~mm}$ no posicionamento das micro multi lâminas.

No presente trabalho os testes realizados foram desenvolvidos com finalidade de avaliar o MLC em modo dinâmico.

\subsection{EQUIPAMENTO DOSIMÉTRICO.}

Foram utilizados filmes para verificação dosimétrica Kodak tipo X-Omat $\checkmark$ e Kodak tipo EDR-2 (Eastman Kodak Company, Rochester, NY). Os filmes irradiados foram revelados em uma processadora Kodak X-Omat 270RA, para depois serem digitalizados em um digitalizador (scanner) da marca Vidar VXR-12 Film Digitizer. O scanner tem capacidade de leitura de densidade óptica de 0 a 4 unidades de densidade (OD), uma resolução óptica de 0,01 OD e resolução geométrica de $0,1 \mathrm{~mm}$; como ferramenta para conferência da leitura óptica foi utilizado um densitômetro MacBeth TD 932, leitora de densidade óptica. A análise dos filmes foi feita a partir dos filmes digitalizados em dois "softwares" de análise dosimétrica: PTW Verisoft v.2.11 e o RFAPlus v. 5.3 da Scanditronix Medical AB.

Foram usadas, para o levantamento dosimétrico, câmaras de ionização (CI) Scanditronix modelo RK com uma cavidade de ar de $0,120 \mathrm{~cm}^{3}$ de volume; a parede externa é de polimetilmetacrilato, o material isolante é poliestireno com espessura de $0,12 \mathrm{~g} / \mathrm{cm}^{2}$, o eletrodo central e a parede interna são de uma mistura de grafite e resina epóxi, a haste é de aço inoxidável [31].

Para a determinação de dose absoluta foi usada uma micro-câmara de ionização Exradin modelo $A 16 \mathrm{com} 0,007 \mathrm{~cm}^{3}$ de volume. O material da parede é Shonka, o coletor é equivalente ao ar e o anel de guarda è de plástico C552.

Foram utilizados três eletrômetros marca Keithley, sendo dois do modelo 614 e terceiro do modelo 35617 EBS. 
Foram utilizados dois objetos simuladores, um deles equivalente à água ("Solid Water" ${ }^{\circledR}$ - SW) e o outro um objeto simulador de PMMA, desenvolvido no hospital para testar justamente campos de arco dinâmico, radiocirugia e de intensidade modulada, simulando um crânio.

\subsection{SISTEMA DE PLANEJAMENTO}

Os sistemas de planejamento utilizados para gerar os tratamentos foram:

Brainscan v. 5.3 (BrainLAB, AG, Heimstetten, Alemanha), que permite o planejamento de diversas técnicas de tratamento como Radiocirurgia Estereotáxica, Radioterapia Conformada, Radioterapia por Intensidade Modulada de Feixe (IMRT) e o Arco Dinâmico (AD);

Eclipse v. 6.5 (Palo Alto, California, USA), que permite o planejamento de Radioterapia Conformada, Radioterapia por Intensidade Modulada de Feixe (IMRT) e o Arco Dinàmico (AD).

\subsection{ARRANJOS EXPERIMENTAIS}

\subsubsection{SSD. DISTÂNCIA FONTE-SUPERFÍCIE.}

Este arranjo é denominado assim pela sigla em inglês, "Source to Surface Distance". Nesta condiçăo, a superficie do objeto simulador é posicionada a uma distância fixa, geraimente a do eixo de rotaçāo do acelerador; o detector encontra-se a uma profundidade de referência $(d)[7]$.

\subsubsection{SAD. DISTÂNCIA EIXO SUPERFÍCIE.}

Representa um arranjo no qual a distância da fonte ao detector é fixa, geralmente do eixo de rotação do cavalete ("gantry"). denominado isocentro. $O$ detector encontra-se à profundidade $(d)$. A sigla vem do inglês "Source to Axis Distance".

Na Figura 11 encontram-se esquemas dos dois tipos de arranjo. 


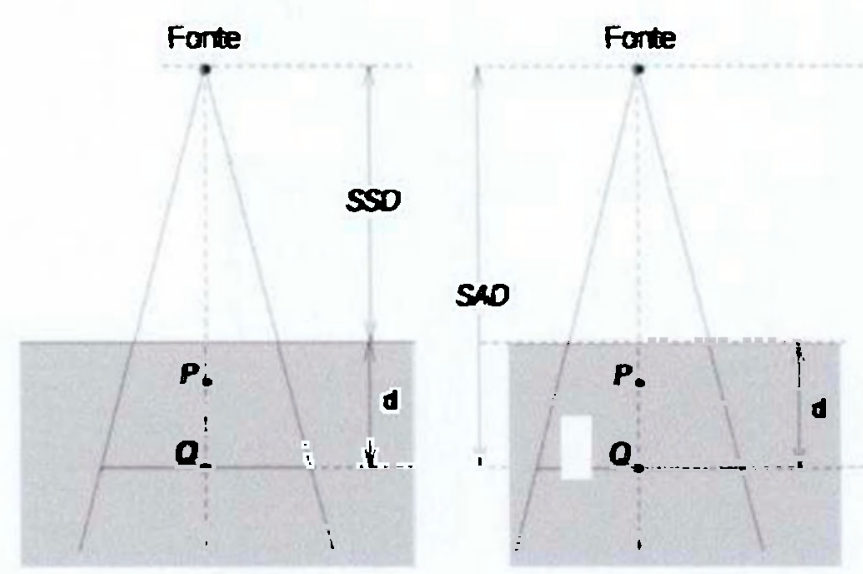

Figura 11. Esquema dos arranjos de distáncia fonte superficie fixa (SSD) e eixo-superficie (SAD) para mediçāo de dose no ponto $Q$ na profundidade d para um feixe com dose máxima no ponto $P$.

\subsection{TESTES DE ACEITAÇÃO E COMISSIONAMENTO}

Nos serviços de Radioterapia que dispõem de vários aceleradores equipados com múltiplos MLCs, é necessário estabelecer um controle de qualidade que fará a comparação dos parâmetros dos MLCs.

A exatidão no posicionamento e re-posicionamento deve ser verificada no comissionamento e no controle da qualidade, pela utilização de campos muito pequenos delimitados pelas lâminas. Deve ser testada a dependência da posição da lâmina com relação ao eixo central, em ambos os sentidos. Devem ser irradiadas seqüências em filmes nas quais possam ser verificadas a fuga de radiação entre lâminas e o efeito "lingüeta - vão". Também é importante conhecer o efeito da gravidade no posicionamento e resposta oferecidos pelo sistema, sendo que isto pode ser testado em diferentes posições do sistema de suporte funcional e colimador.

O rendimento do feixe para campos delimitados pelos MLCs deve ser verificado, em especial para campos pequenos, assim como a constância de dose por unidade monitora, e a linearidade.

É importante fazer todos estes testes, seja no modo dinâmico ou no modo estático com os dosimetros adequados e preferivelmente com mais de uma técnica dosimétrica como método de garantia da qualidade.

No comissionamento do sistema de DMLC, devem ser determinados parâmetros tais como a transmissão, abertura dosimétrica entre pares de lâminas, 
penumbra, constância da velocidade, da taxa de dose. interrupção de tratamento, e exatidão da posição das lâminas. Devem tambem ser realizados testes periódicos destes parâmetros. Todos eles devem ser realizados com a maior quantidade de ferramentas dosimétricas disponiveis no serviço, câmaras de ionização adequadas (microcâmaras), filmes, diodos [1][2].

Devem ser realizados testes por ocasião do comissionamento e do aceite do sistema de planejamento computadorizado para planejamento inverso, assim como seus testes rotineiros.

\subsection{TESTES MECÂNICOS}

\subsubsection{TOLERÂNCIA E TEMPO DE TRATAMENTO}

O sistema de liberação dinâmica do feixe dos aceleradores Varian compara a cada $55 \mathrm{~ms}$ as posições reais das lâminas e as programadas, levando em consideração uma tolerância definida pelo usuário. Foi testado o efeito do parâmetro de tolerância entre a posição programada e a posição real das lâminas dos MLC. O desligamento do feixe ocorreu mais freqüentemente quando 0 parâmetro foi diminuido pela dificuldade crescente das lâminas de atingirem a posição programada. A faixa de tolerância que pode ser testada é: $0,05 \mathrm{~cm}$ até $0,5 \mathrm{~cm}$.

\subsubsection{TESTE DE WINSTON - LUTZ}

Para o caso do micro colimador de multi-làminas, pelo fato de ser um sistema acoplado ao cabeçote do acelerador, deve ser investigada a influência dos $30 \mathrm{~kg}$ adicionais através de um possivel desvio do isocentro. Para isso, é usado um teste descrito na literatura para aplicaçōes de radiocirurgia. Uma esfera de $3 \mathrm{~mm}$ de diâmetro de tungstênio está dentro de uma haste. A esfera é fixada no isocentro de radiação definida pelos lasers da sala de tratamento. Este não é o verdadeiro isocentro de radiaçāo porque pode ser movimentado devido à instabilidade mecânica, mas é um ponto referencial a partir do qual podem ser observados os deslocamentos em função dos ângulos do cabeçote, do colimador e da mesa de tratamento. 
Este teste é realizado cada vez que o mMLC é acoplado no cabeçote do acelerador para diferentes àngulos do cabeçote $\left(90^{\circ}, 135^{\circ}, 180^{\circ}, 225^{\circ}\right.$ e $270^{\circ}$. ESCALA VARIAN).

\subsubsection{POSIÇÃO DAS LÂMINAS}

O primeiro teste mecânico a ser realizado rotineiramente é a posição das lâminas com a projeção de luz no isocentro em papel milimetrado, sendo que esta leitura tem uma incerteza espacial em torno de $0,25 \mathrm{~mm}$.

$\mathrm{Na}$ liberação de um feixe de intensidade modulada, é importante a exatidão no posicionamento. O sistema compara as posiçōes programadas e as reais a cada $55 \mathrm{~ms}$, mas o resultado final deve ser quantificado. Para isto, foram realizadas medidas de aberturas nominais, propositalmente foram introduzidos "erros" na posição das lâminas com o intuito de gerar uma familia de curvas que nos permitisse quantificar a influência destes erros nos tratamentos dinâmicos tanto para 6 e $15 \mathrm{MV}$. Criaram-se campos dinâmicos com aberturas nominais deslizantes definidas $(0,1 ; 0,5 ; 1,0 ; 2,0 ; 3,0$ e $5,0 \mathrm{~cm})$. Para cada uma destas aberturas foram criados arquivos introduzindo erros no posicionamento das lâminas de 0,$01 ; 0,02: 0,05,0,1$ e $0,2 \mathrm{~cm}$. As aberturas nominais são definidas como as leituras de referência. Desta forma, é possivel quantificar os erros em uma abertura determinada.

\subsubsection{ESTABILIDADE DO MLC EM MODO DINÂMICO.}

A verificação da estabilidade do $\mathrm{mMLC}$ em modo dinâmico e da reprodutibilidade da abertura dosimétrica entre pares de lâminas é realizada através de dois testes: estrias ("picket fence") e da jardineira ou cerca ("garden fence"), nomeados assim pelos diagramas obtidos nos filmes expostos. Estes campos testes são realizados expondo filmes tipo $\mathrm{X}$-Omat $\mathrm{V}$ a uma distância fonte superficie (SSD) de $100 \mathrm{~cm}$ sobre a mesa de tratamento e coberto com dois centimetros de acrilico para obter a condição de equilibrio eletrônico. Cada filme foi analisado visualmente e utilizando a largura na metade da altura (FWHM). 
O teste da jardineira consiste de uma faixa estreita (largura de $2 \mathrm{~mm}$ ) espaçada em intervalos de $2 \mathrm{~cm}$. É realizado em quatro angulaçōes distintas do cabeçote $\left(180^{\circ}, 90^{\circ}, 0^{\circ}\right.$ e $270^{\circ}$ - ESCALA VARIAN).

O teste das estrias consiste em oito movimentos consecutivos das lâminas em um campo de $5 \mathrm{~cm}$ de largura espaçados em intervalos de $5 \mathrm{~cm}$. A informação do campo está contida em trēs arquivos que são executados em seqüência [32].

\subsubsection{ESTABILIDADE DA VELOCIDADE DAS LÂMINAS.}

A estabilidade da velocidade das lâminas foi verificada usando um campo teste que requer que o par de laminas se movimente com sete velocidades constantes, gerando assim um padrão em etapas e homogêneo em termos de valores de dose conhecidos. Para a elaboração do arquivo que contém a informação do teste foi usado o "software" Shaper ${ }^{\mathrm{TM}}$ (Varian Medical Systems, Palo Alto, CA). A estabilidade dos diferentes niveis de velocidade foi analisada e a uniformidade de cada perfil foi comparada com um perfil de campo aberto.

\subsection{TESTES DOSIMÉTRICOS}

\subsubsection{SENSIBILIDADE Ȧ INTERRUPÇÃO DE TRATAMENTOS.}

Testar a dose parcial permite conhecer o comportamento do sistema quando ocorrem interrupções na liberação do feixe. Para a elaboração do presente trabalho estes testes foram feitos tanto quando as lâminas estavam em aceleração quanto em desaceleração em tratamentos dinâmicos. Já durante os tratamentos clinicos estas interrupçōes podem ocorrer espontaneamente. Estes testes são realizados com câmara de ionização comparando as leituras para a irradiaçāo completa e para a irradiação interrompida.

\subsubsection{ESTABILIDADE DO FATOR DE RENDIMENTO COM O DMLC.}

A estabilidade do fator de rendimento em modo dinâmico dos MLC foi verificada através de uma abertura de $1,0 \mathrm{~cm}$ que varre uma abertura fixa de 
campo, criando um padrāo homogêneo de dose. Uma câmara de ionização é posicionada no eixo central do feixe. As medidas são normalizadas para a dose de referência. Para avaliar um efeito da gravidade potencial, o teste foi realizado em quatro posições de ângulo diferentes $\left(180^{\circ}, 90^{\circ}, 0^{\circ}\right.$ e $270^{\circ}$. ESCALA VARIAN).

\subsubsection{LINEARIDADE COM AS UNIDADES MONITORAS.}

Com este teste é avaliada a sensibilidade do sistema para liberar um mesmo padrão de intensidade modulada com um número diferente de unidades monitoras, mantendo a taxa de dose constante.

\subsubsection{LINEARIDADE DE DOSE EM FUNÇÃO DA TAXA DE DOSE.}

Com este teste é avaliado o comportamento do sistema para liberar um mesmo padrão de intensidade modulada com taxas de dose diferentes, mantendo o número de unidades monitoras constante.

\subsubsection{AVALIAÇÃO DE FIGURAS PADRÃO.}

Existem testes com figuras padrāo desenvolvidas pela empresa Varian que foram realizados neste trabalho. Estes testes procuram realizar uma análise qualitativa da exatidão na posição das lâminas, propriedades cinéticas do sistema de multi-lâminas e uma avaliação dosimétrica da fração de dose liberada.

Todos estes testes foram desenvolvidos irradiando filmes e analisando os padrões de dose. Estes testes fornecem informação da constância no posicionamento das lâminas, na velocidade das lâminas e uma avaliação dosimétrica da fração de dose liberada.

\subsubsection{TRANSMISSÃO}

A radiação transmitida é definida como a razão da dose obtida entre $\circ$ campo com o acessório (bandeja, bloco, filtro, MLC, etc.) e a dose do campo de referência. No caso dos sistemas de MLC, o objetivo da medição da transmissão 
é caracterizar este parâmetro tanto entre lâminas (fuga) como também intralâminas.

É importante determinar a transmissão no eixo central e fora do eixo porque os sistemas de planejamento pedem um único valor de transmissão para ser considerado no cálculo. Porém, para ser feita uma caracterização correta deste fenômeno, é melhor inserir o valor médio, de forma que este abranja uma regiāo de interesse clínico em uma profundidade relevante. A determinação da transmissảo dos sistemas de micro colimadores multi-lâminas foi feita com câmara de ionização e com filme.

\subsubsection{TRANSMISSÃO COM CÂMARA DE IONIZAÇÃO}

Foram usados dois modelos de câmaras de ionização para este teste: uma de $0,120 \mathrm{~cm}^{3}$ de volume e outra de $0,6 \mathrm{~cm}^{3}$, sendo que as medições foram realizadas em um objeto simulador sólido equivalente à água a uma distância fonte - eixo de $100 \mathrm{~cm}$. É importante determinar a transmissão no eixo central e fora do eixo porque os sistemas de planejamento requerem apenas um único vajor de transmissão para ser considerado no cálculo, porém deve ser feita uma caracterização correta deste fenômeno. É melhor inserir o valor médio, de forma que este abranja uma regiăo de interesse clínico em uma profundidade relevante. Para a obtenção deste parâmetro é vantajosa a utilização de uma câmara de ionizaçāo pois a informação coletada representa tanto a transmissão intralâminas quanto a transmissão entre as lâminas (fuga).

As medições foram realizadas no eixo e fora do eixo central: para o primeiro caso a junção dos MLC foi programada para estar abaixo dos colimadores secundários para evitar a transmissão entre as bordas arredondadas; para os dados fora do eixo os MLC foram posicionados assimetricamente.

Para o MLC modelo Millenium $\otimes$ foi medida a transmissão para campos de $6 \times 6 \mathrm{~cm}^{2}, 10 \times 10 \mathrm{~cm}^{2}, 15 \times 15 \mathrm{~cm}^{2}$ em diferentes profundidades, desde a respectiva profundidade de máximo $\left(d_{\max }\right)$ de cada energia até $20 \mathrm{~cm}$. As mediçōes fora do eixo se limitaram a um campo de $10 \times 10 \mathrm{~cm}^{2}$. 


\subsubsection{TRANSMISSÃO COM FILME}

A obtenção da transmissão com filme permite quantificar separadamente a componente entre as lâminas e a componente intralâminas para as diversas energias. Para isto o filme de verificação dosimétrica foi colocado em um objeto simulador sólido equivalente à água a uma profundidade de $5 \mathrm{~cm}$. $\mathrm{O}$ filme foi irradiado com as lâminas fechadas e juntas como foi descrito para a obtenção da transmissão com câmara de ionização. A metodologia é irradiar tanto o filme com as lâminas fechadas como o filme de campo aberto com uma mesma densidade óptica ajustando as unidades monitoras. O filme depois é revelado e posteriormente digitalizado no scanner Vidar. As doses foram derivadas a partir da calibração feita para o tipo de filme empregado (Ready Pack X-Omat V) na profundidade de irradiação. A transmissão é determinada pela razão do perfil de dose transmitida para o perfil de dose do campo aberto depois da respectiva correção pelas unidades monitoras liberadas.

\subsubsection{ESPALHAMENTO DE RADIAÇÃO PRODUZIDO PELO MLC}

A área superficial do MLC exposto ao feixe aumenta com o tamanho de campo; por isto a contribuição de espalhamento do MLC se incrementa também. O espalhamento para um tamanho de campo pode ser determinada subtraindo a transmissāo do tamanho de campo zero da transmissão medida no tamanho de campo de interesse.

Com o intuito de estimar o espalhamento, foram medidas as transmissões para o MLC fechado (junção das lâminas a $10 \mathrm{~cm}$ do eixo central) com os colimadores secundários definindo os seguintes tamanhos de campo: 0,5 $\times 5,0 \mathrm{~cm}^{2} ; 1,0 \times 5,0 \mathrm{~cm}^{2} ; 3,0 \times 5,0 \mathrm{~cm}^{2} ; 5,0 \times 5,0 \mathrm{~cm}^{2}$ e $10,0 \times 5,0 \mathrm{~cm}^{2}$. Pode ser observado que o comprimento do campo foi mantido constante para assegurar que as mesmas superficies internas das quatro lâminas limitantes integrem a transmissão. Para esta medição utilizou-se a micro câmara de ionização Exradin modelo $A 16$ de $0,007 \mathrm{~cm}^{3}$, posicionada a $100 \mathrm{~cm}$ de distância fonte - superficie em um objeto simulador equivalente a água, a uma profundidade de $5 \mathrm{~cm}$.

A extrapolação linear das transmissões medidas dos tamanhos de campo citados, para o campo de largura zero, é denominada transmissão do 
campo zero e representa o feixe primário. A diferença na transmissão entre o campo de tamanho finito e o campo de área nula é a componente da dose devido ao espalhamento dos MLC para esse tamanho de campo determinado.

\subsubsection{EFEITO DA BORDA ARREDONDADA E ABERTURA DOSIMÉTRICA ENTRE PARES DE LÂMINAS.}

A contribuição da radiação transmitida pela borda arredondada das lâminas pode ser medida usando a medição de perfis de campos estáticos definidos pelo MLC com aberturas entre 1 e $100 \mathrm{~mm}$, e com a integração posterior sobre o perfil medido. A integração leva em conta a soma dos seguintes parâmetros:

(a) fluência transmitida através das lâminas do colimador multi-lâminas;

(b) fluência através da abertura; e

(c) fluência transmitida através da borda arredondada.

A soma de (b) e (c) deve ser proporcional à abertura efetiva, isto é, à abertura nominal mais uma compensação. A suposição de que a compensaçāo é constante independentemente da posição em que as lâminas se encontrarem é correta para distâncias de $\pm 5,0 \mathrm{~cm}$ com relação ao eixo central.

A partir do gráfico da dose liquida (fluência através da abertura somada à fluência transmitida através da borda arredondada e subtraida a transmissão), em função da abertura nominal, é possivel encontrar a abertura dosimétrica entre pares de lâminas, extrapolando para uma dose igual a zero.

Já na prática, pode ser utilizada uma câmara de ionização posicionada em um objeto simulador a $5 \mathrm{~cm}$ de profundidade, com distância eixo - superfície de $95 \mathrm{~cm}$. Devem ser medidas aberturas de $1 \mathrm{~mm}$ até $100 \mathrm{~mm}$ definidas pelas lâminas em modo dinâmico (modo de janela deslizante ou "sliding window") [33]. Deve ser subtraído da leitura obtida o valor de "transmissāo dinâmica" (TD) seguindo a seguinte relaçāo, obtendo a abertura nominal:

$$
T_{D}=\frac{T_{S}\left(1-C_{P}\right)}{C_{A V}}
$$


em que $T_{S}$ é a transmissão determinada, $C_{p}$ é a fração de unidades monitoras que o ponto de mediçāo está em baixo da abertura, $\mathrm{C}_{\mathrm{AV}}$ é a razão de unidades monitoras necessárias para liberar a mesma dose no modo dinâmico que no modo estático ("workload").

Através de um gráfico da dose relativa em funçăo da abertura nominal, e obtida a interseção quando a dose é extrapolada à zero. O valor determinado será a abertura dosimétrica entre pares de lâminas ("dosimetric gap").

\subsubsection{PENUMBRA}

Todo sistema de colimação (colimadores convencionais, blocos ou colimadores multi-lâminas) foi projetado para variar o tamanho e a forma do feixe de acordo com o requerido. A forma mais simples de colimação em um acelerador moderno são quatro blocos de metal pesado (as mandibulas) que definem o tamanho de campo (quadrado ou retangular). Estes blocos possuem as bordas internas retas e paralelas ao eixo central do feixe, sendo que a radiação que cruza estas bordas é definida como a penumbra de transmissão. Esta é a região irradiada por fótons que são transmitidos através da borda dos colimadores. A extensão desta penumbra depende do tamanho de campo, devido à maior ou menor obliqüidade dos raios com relação à borda dos colimadores. Este efeito é reduzido se o sistema de colimaçāo está projetado para que as bordas internas sejam sempre paralelas às bordas oblíquas do feixe. Nestes casos, as mandibulas do colimador são articuladas no topo da carcaça do sistema de suporte funcional garantindo desta forma que a inclinação coincida com o ângulo do feixe em cada mandibula. Esta penumbra de transmissāo pode ser minimizada pelo projeto do sistema de colimação, mas não removido completamente.

Nos casos dos sistemas de colimadores multi-lâminas, estas últimas são projetadas de forma que este efeito seja minimizado. Por isto, geralmente a borda interna das lâminas é constituída por três bordas, duas retas na região inferior e superior, e uma reta na região central. As bordas retas estão projetadas justamente para reduzir o efeito deste sistema de colimação terciário. 
O termo penumbra, em geral, significa a regiāo na borda do feixe de radiação, no qual a taxa de dose muda rapidamente em função da distância com relaçāo ao eixo central. A penumbra é a região na borda de um volume irradiado que recebe alguma quantidade de radiação, mas não a dose completa liberada pelo feixe. Existe por causa do tamanho finito da fonte e por causa da radiação espalhada.

Para efeitos práticos é definida como a distância entre os pontos definidos por $80 \%$ e por $20 \%$ da dose. Às vezes, é usada a definição de penumbra $90 \%$ - 10\%, sendo definida como as distâncias entre os pontos de dose mencionados.

\subsubsection{PENUMBRA EM FUNÇÃO DO DESLOCAMENTO FORA DO EIXO CENTRAL.}

No caso do mMLC, foi testada a penumbra em função da posição assimétrica das lâminas com relação ao eixo central. Foram criados campos retangulares definidos pelas multi-lâminas de $2 \times 10 \mathrm{~cm}^{2}$, para serem irradiados em modo estático. A abertura de $2 \mathrm{~cm}$ é paralela ao movimento das lâminas. Cada campo foi irradiado em três profundidades diferentes, $1,5 \mathrm{~cm}$ ( $d_{\text {max }}$ para o feixe de $6 \mathrm{MV}$ ), $5 \mathrm{~cm}$ e $10 \mathrm{~cm}$, à distância fonte superficie de $95 \mathrm{~cm}$ em um objeto simulador sólido equivalente à água. A configuração de campo foi deslocada em etapas de $1 \mathrm{~cm}$ assimetricamente. O último campo estará centrado a $4 \mathrm{~cm}$ de distância do eixo central, com um dos bancos de lâminas retraído completamente $(+5 \mathrm{~cm}$ ) e o outro banco ultrapassando o eixo $3 \mathrm{~cm}$. Foram irradiados cinco campos nas três profundidades citadas.

Para o MLC Millenium $\otimes$ e o Mark II $@$ os colimadores secundários foram definidos em $15 \times 15 \mathrm{~cm}^{2}$. A abertura foi também de $2 \mathrm{~cm}$. As profundidades do teste foram em todos os casos $d_{\max }(6 \mathrm{MV}=1,5 \mathrm{~cm}$; $15 \mathrm{MV}=$ $2.7 \mathrm{~cm} ; 18 \mathrm{MV}=3,2 \mathrm{~cm}), 5 \mathrm{~cm}$ e $10 \mathrm{~cm}$. A distância fonte - superficie foi $95 \mathrm{~cm}$ em um objeto simulador sólido equivalente à água. Os campos assimétricos foram deslocados de $1 \mathrm{em} 1 \mathrm{~cm}$, da mesma maneira que para o mMLC. 
Para todos os casos, foram determinados os perfis em sentido paralelo ao movimento das lâminas, em filmes de verificação dosimétrica Kodak X-Omat $V$, no programa de análise dosimétrico PTW Verisoft v.2.11.

\subsubsection{PENUMBRA EM FUNÇĀO DO TAMANHO DE CAMPO.}

Para o mMLC, foi medida a penumbra $80 \%$ a $20 \%$ em função ao tamanho de campo, para campos desde $1,8 \times 1,8 \mathrm{~cm}^{2}$ até $10 \times 10 \mathrm{~cm}^{2} \mathrm{em}$ incrementos em torno de $1 \mathrm{~cm}$ dependendo da largura das lâminas. Os filmes, de verificação dosimétrica Kodak $X$-Omat $V$, foram posicionados na profundidade de dose máxima, e distância fonte - superficie $98,5 \mathrm{~cm}$ em um objeto simulador sólido equivalente à água.

Para os MLC Millenium e Mark II, foi medida também a penumbra $80 \%$ a $20 \%$, para tamanhos de campo entre $1 \times 1 \mathrm{~cm}^{2}\left(2 \times 2 \mathrm{~cm}^{2}\right.$ para o Mark II) até 10 $\times 10 \mathrm{~cm}^{2}$ na profundidade de $5 \mathrm{~cm}$ em com distância fonte-filme $100 \mathrm{~cm}$ na profundidade de dose máxima.

Para todos os casos, foram determinados perfis tanto no sentido paralelo como perpendicular ao movimento das lâminas, no programa de análise dosimétrica PTW Verisoft v.2.11.

\subsubsection{PENUMBRA EM FUNÇÃO DA PROFUNDIDADE.}

Foi investigada a dependência da penumbra com a profundidade, para a qual foram irradiados filmes de verificação dosimétrica na profundidade de máxima dose de cada energia até $10 \mathrm{~cm}$. Foram determinados os perfis no sentido paralelo e perpendicular ao movimento das lâminas no programa de análise dosimétrica PTW Verisoft v.2.11.

\subsubsection{PENUMBRA EM FUNÇÃO DO ÂNGULO COM AS BORDAS.}

Foram desenvolvidas duas figuras padrões (Figura 12) definidas com as multi-lâminas, cujas bordas retas formam ângulos determinados com o eixo 
horizontal. As lâminas foram posicionadas de forma que o ponto médio delas interceptem a diagonal que define a borda da figura padrão.

Para a determinação desta dependência da penumbra, filmes de verificação dosimétrica Kodak $X$-Omat $V$ foram posicionados na profundidade de dose máxima, e distância fonte - superficie $98,5 \mathrm{~cm}$ em um objeto simulador sólido equivalente à água. Foi determinada a penumbra $80 \%$ a $20 \%$ no programa de análise dosimétrica PTW Verisoft v.2.11.
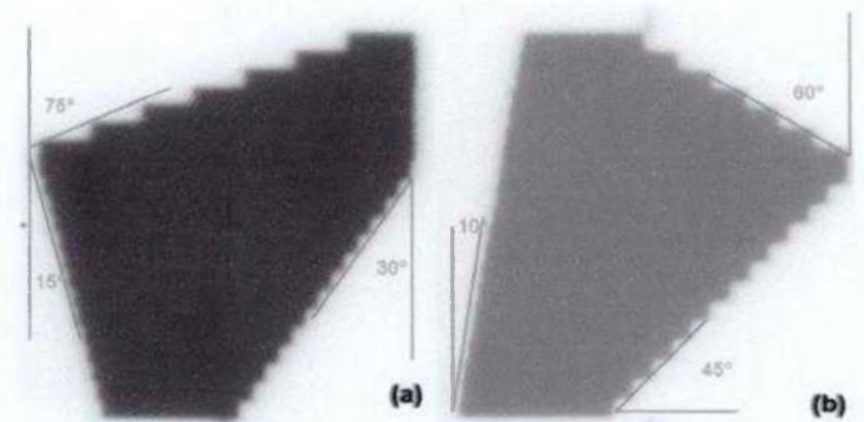

Figura 12. Figuras padrāo utilizadas para definir a dependência da penumbra em funçāo do ângulo com as bordas. (a) Para os ángulos de $15^{\circ}, 30^{\circ}$ e $75^{\circ}$. (b) Para os ángulos de $10^{\circ}, 45^{\circ}$ e $60^{\circ}$.

\subsection{ANÁLISE DOS ARQUIVOS "DYNALOG"}

Os arquivos de registro dinâmico, criados pelo controlador de MLC no final de cada tratamento de IMRT, são analisados usando o programa "Dynalog File Viewer" (Varian Medical Systems, Inc. Palo Alto, CA), que é parte do conjunto de programas da estação de trabalho do MLC. Este arquivo possui informação das posiçōes planejadas versus as posiçōes reais a cada $50 \mathrm{~ms}$ enquanto o feixe está sendo liberado. O "software" gera tabelas de dados e grafica um histograma, que mostra informação de todos os desvios das posições das lâminas. $O$ programa gera também o desvio quadrático médio (RMS - "root mean square") do desvio de cada lâmina e um gráfico que representa o desligamento do feixe ao longo do tratamento dinâmico [18][34].

Para cada campo tratado, o histograma é considerado aceitável se 95\% ou mais das contagens de erro (número de desvios das posições das lâminas) apresentam desvios menores do que $0,1 \mathrm{~cm}$ e não há contagem de erro com desvios superiores a $0,3 \mathrm{~cm}$. O maior valor quadrático médio do erro é de $0,05 \mathrm{~cm}$. O número máximo de paradas do feixe aceito é 2 . O histograma dos 
desvios e o valor quadrático médio dos desvios são armazenados para cada campo de intensidade modulada. Os dados obtidos são utilizados para prever falhas iniciais nos motores e determinar a necessidade de substituir de forma preventiva [18][34]. 


\section{RESULTADOS E DISCUSSÕES}

\subsection{COLIMADOR MULTI-LÂMINAS VARIAN MODELO MILLENIUM.}

\subsubsection{TESTES MECÃNICOS}

Foi testado o efeito do parâmetro de tolerância entre a posiçāo programada e a posição real das lâminas do MLC. O desligamento do feixe ocorreu mais freqüentemente quando o parâmetro foi diminuido pela dificuldade crescente das lâminas de atingirem a posição programada. A faixa de tolerância que pode ser testada é de $0,05 \mathrm{~cm}$ até $0,5 \mathrm{~cm}$. Determinou-se que existe um aumento no tempo de tratamento quando a tolerância diminuiu. A dose relativa apresentou variaçōes quando a tolerância foi mudada nos arquivos dinâmicos, os resultados são apresentados nas Figuras 13 e 14 :

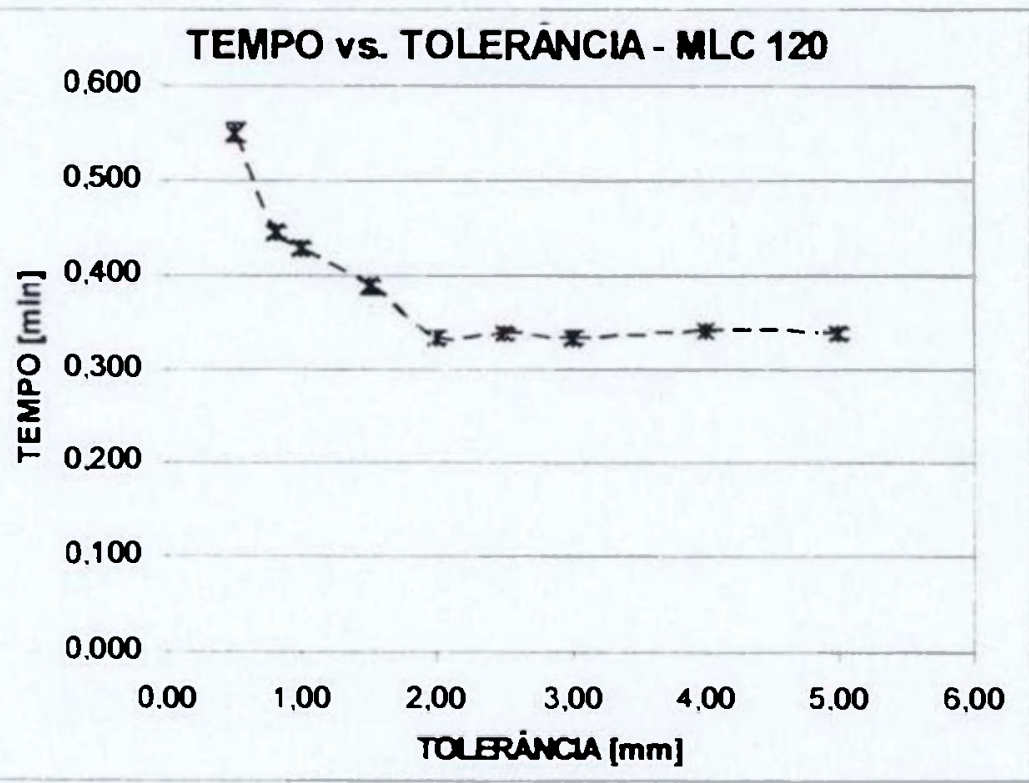

Figura 13. Variaçāo do tempo de tratamento de um campo dinàmico em funçāo da tolerància entre as posiçōes programadas e reais das làminas em modo dinàmico para o MLC 120.

A variação na dose relativa mostrada nas Figuras 13 e 14 pode ser explicada pela instabilidade do feixe causada pro desligamento do feixe quando as lâminas não atingem a posição programada. 


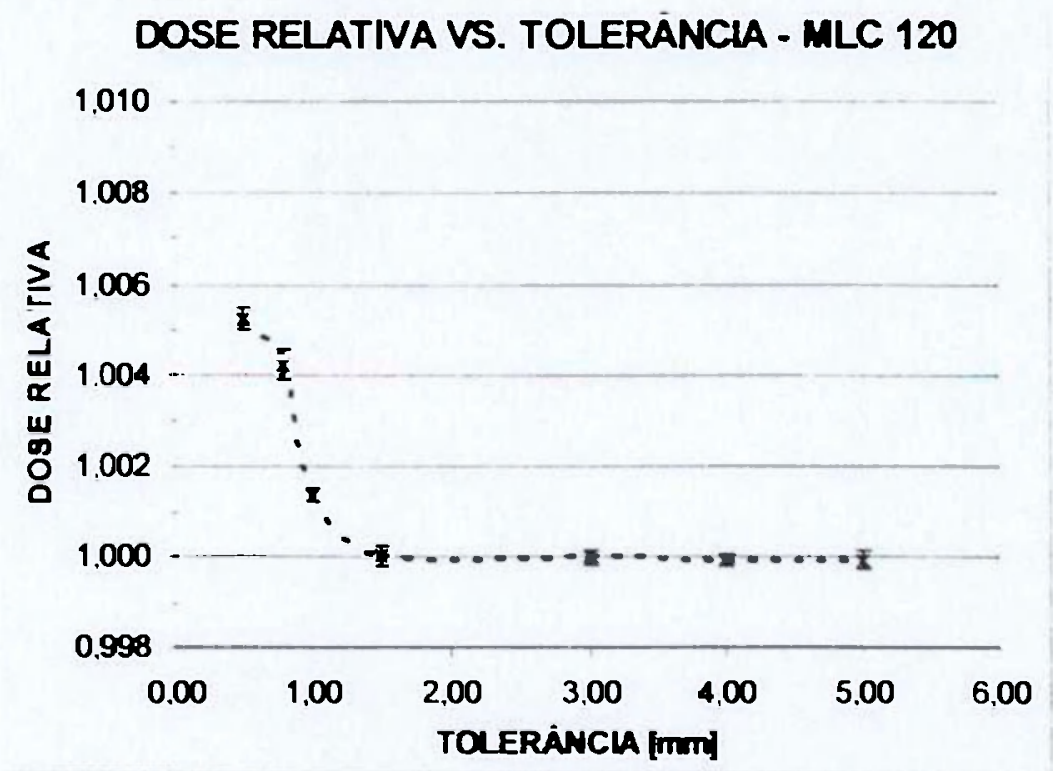

Figura 14. Efeito da tolerância na posiçāo das lâminas na dose relativa para um campo de tratamento dinâmico para o MLC 120.

Os resultados obtidos de tempo de tratamento e de dose relativa. quando a tolerância variou, apresentam a mesma tendência que os descritos por LoSasso e colaboradores [15] para o MLC Mark II de 52 lâminas

\subsubsection{POSIÇÃO DAS LÂMINAS NO ISOCENTRO}

Foram realizadas medidas de aberturas nominais, sendo que propositalmente foram introduzidos "erros" na posição das lâminas com o intuito de gerar uma familia de curvas que nos permita quantificar a influência destes erros nos tratamentos dinâmicos para 6 e $15 \mathrm{MV}$, mostrando os resultados da Figura 15.

Na Figura 15 é possivel quantificar o erro na liberação da dose quando existe uma diferença no posicionamento das lâminas na abertura dinâmica. Por exemplo, para uma abertura nominal de $2 \mathrm{~cm}$, um erro no posicionamento das lâminas de $2 \mathrm{~mm}$ representa um desvio de $10,7 \%$ na dose com respeito à abertura de $2 \mathrm{~cm}$ sem erro na posição das lâminas para $6 \mathrm{MV}$. Os resultados para $15 \mathrm{MV}$ são muito parecidos aos de $6 \mathrm{MV}$. mudando a comparação feita de $10.6 \%$ para $10,8 \%$.

As barras de erro na Figura 15 foram omitidas jà que sua magnitude é da ordem dos pontos de medida. 


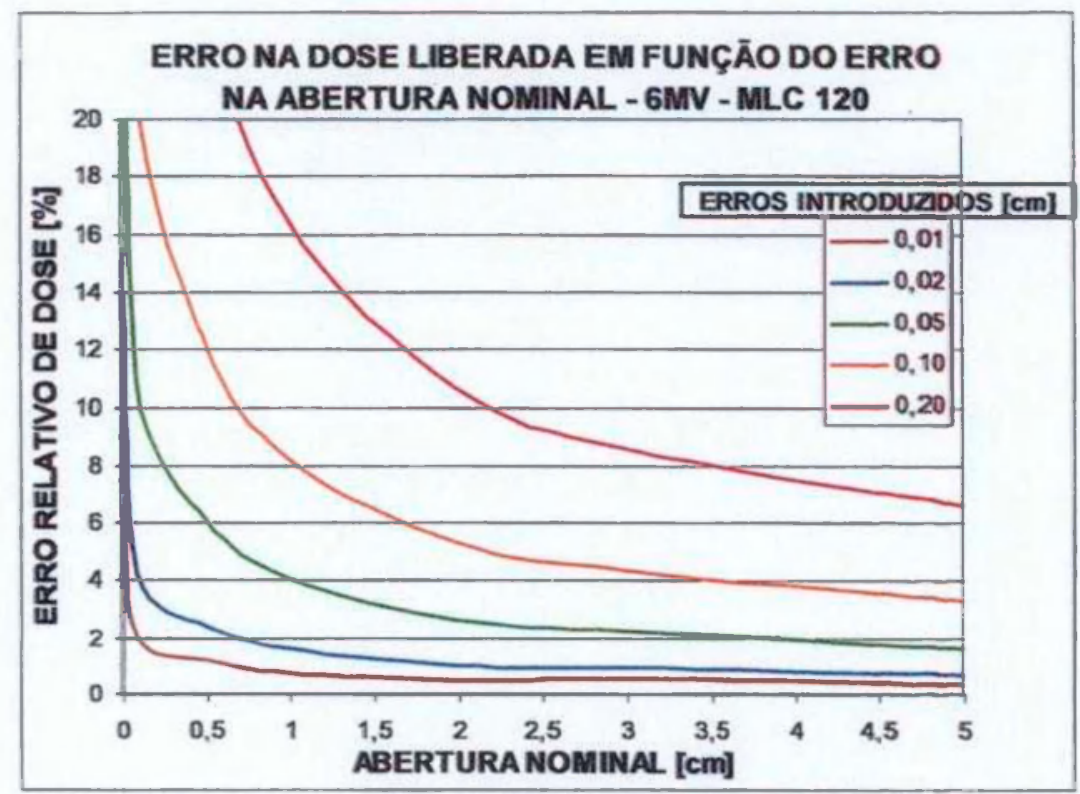

Figura 15. Resultados que relacionam o erro na dose liberada com o erro na abertura deslizante para 6MV liberado com O MLC 120.

Os valores encontrados estão de acordo com resultados publicados com metodologias semelhantes por LoSasso e colaboradores [15][35] e por Venencia e Besa [18].

\subsubsection{ESTABILIDADE DO MLC EM MODO DINÂMICO.}

Na Figura 16 está mostrado o perfil obtido para um teste com um erro em uma das lâminas, representado pelo pico de menor intensidade. $O$ teste apresentado foi realizado com o sistema de suporte funcional ("gantry") em $180^{\circ}$ (Escala Varian).

Após a irradiação do filme nos testes da jardineira e das estrias, a determinação dos desvios no posicionamento das lâminas é feita visualmente. Para quantificar estes desvios, é preciso utilizar um digitalizador de filmes com um "software" de análise associado ou um densitômetro. Em cada linha intensa de sobreposição, se formará um pico, cuja largura à meia altura representa a separação dosimétrica das lâminas do MLC. Deve ser também avaliada a distância entre picos, o que indica a reprodutibilidade no posicionamento das lâminas. 


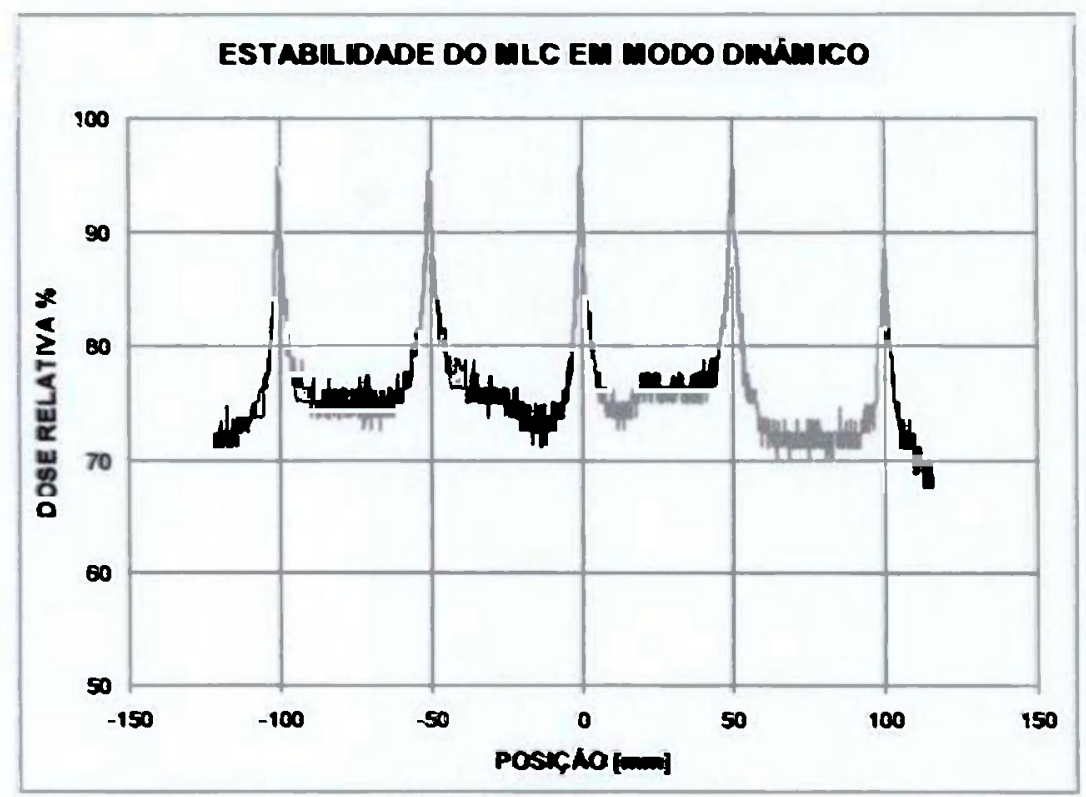

Figura 16. Resultados do teste de estabilidade do MLC 120 (jardineira - "garden fence"). O último pico apresenta uma intensidade menor, o que representa um erro na posiçáo de uma das láminas.

Em condições normais, todos os picos apresentaram a mesma intensidade e a distância entre picos será a mesma, em qualquer angulação do sistema de suporte funcional ("gantry").

\subsubsection{ESTABILIDADE DA VELOCIDADE DAS LÂMINAS.}

Para cada sentido de movimento das lâminas (paralelo: $X$, ou perpendicular: Y) são realizadas duas irradiações no mesmo filme; em uma das irradiações, as seis intensidades de dose são geradas; na segunda irradiação são geradas sete etapas complementares às primeiras, resultando em um padrão de dose homogêneo simulando um campo aberto. Qualquer instabilidade no movimento das lâminas pode ser determinada se o filme resultante não apresenta um padrão homogêneo ou se a análise da irradiação parcial não apresenta as intensidades programadas: $(100 \%, 80 \%, 60 \%, 40 \%, 20 \%, 0 \%)$.

O resultado das duas irradiaçōes è mostrado na Figura 17 em vermelho. Foi realizada uma irradiação parcial e o padrão de intensidades apresenta as seis intensidades mencionadas. 


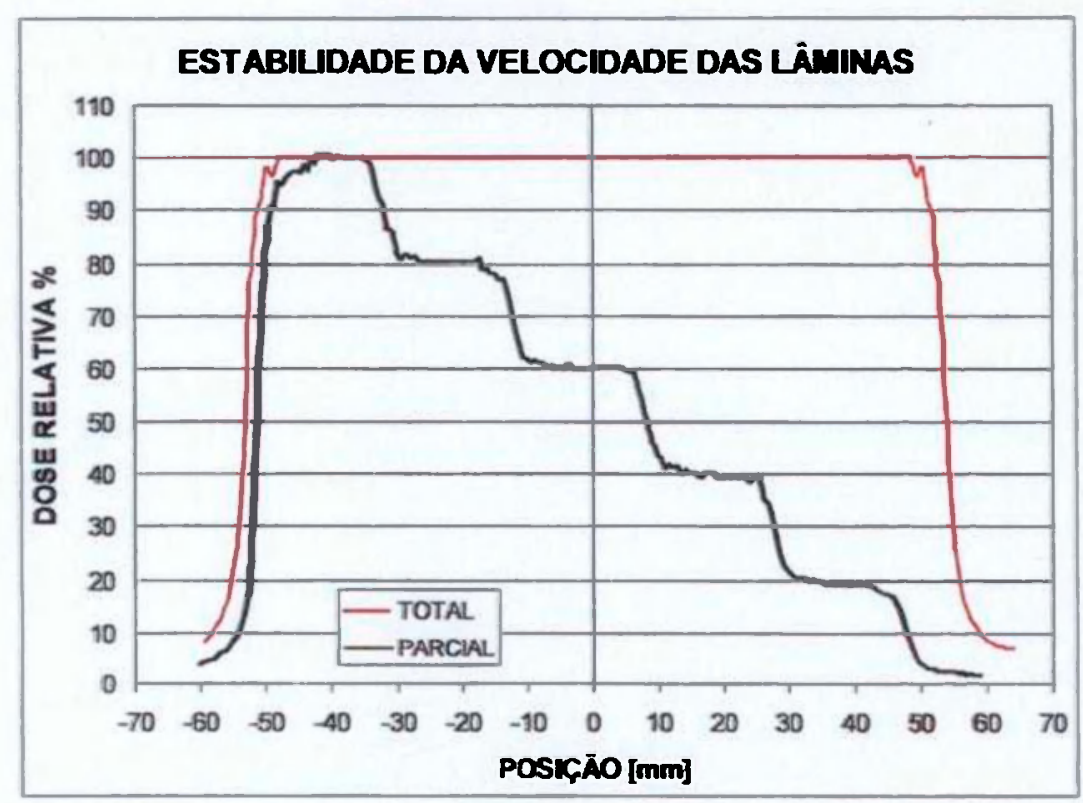

Figura 17. Resultados do teste de velocidade das láminas do MLC 120. Para o fabricante Varian, este teste é denominado X-WEDGE e Y-WEDGE.

\subsubsection{TESTES DOSIMÉTRICOS}

\subsubsection{SENSIBILIDADE À INTERRUPÇÃO DE TRATAMENTOS.}

A Figura 18 mostra o efeito da interrupção. Foi testado este parâmetro tanto em aceleração como em desaceleração para um campo de tratamento dinâmico de IMRT.

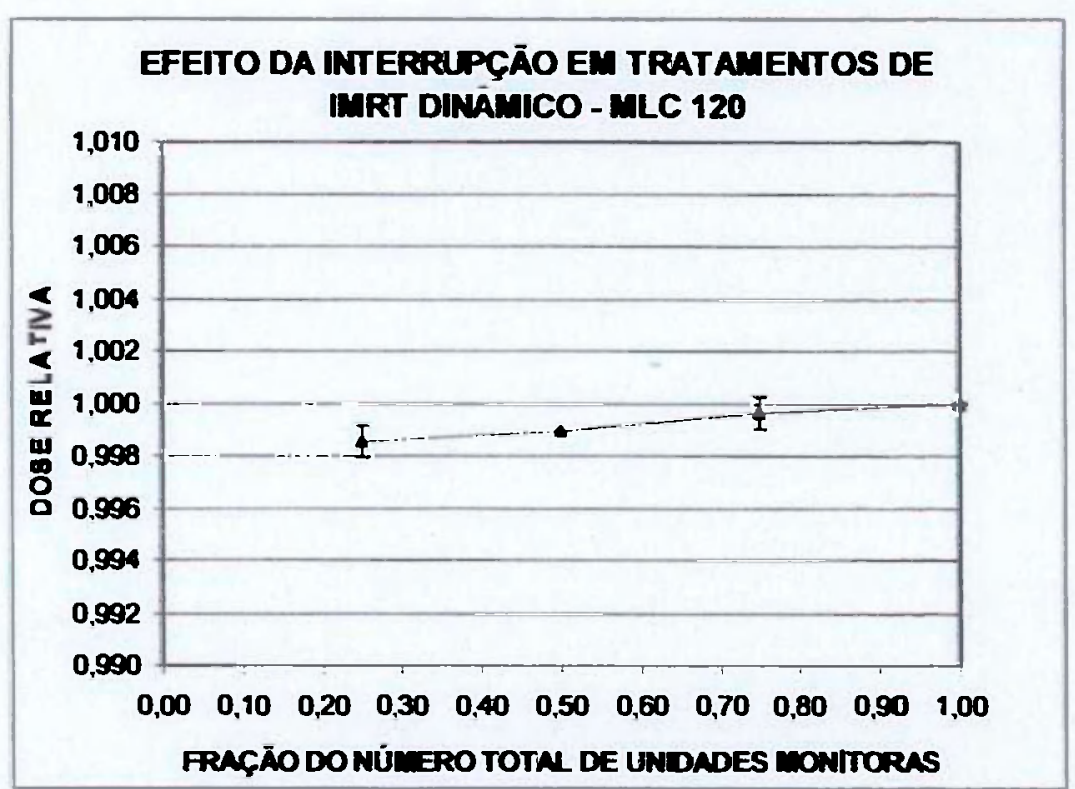

Figura 18. Efeito da interrupçāo do feixe durante um tratamento com o MLC 120 em modo dinámico (DMLC). 
Propositalmente o feixe foi interrompido em três instantes diferentes para obter a Figura 18. Os resultados obtidos mostram o maior desvio da dose na quarta parte do tratamento com um valor de $0,144 \%$.

\subsubsection{ESTABILIDADE DO FATOR DE RENDIMENTO COM O DMLC.}

Na Figura 19, estão os resultados dos testes de estabilidade do fator de rendimento medido a partir de um campo dinâmico padrão (abertura dinâmica de $1 \mathrm{~cm}$ de largura) em um objeto simulador cilindrico construído em acrilico. $O$ maior desvio com relação ao tratamento com o suporte funcional em $180^{\circ}$ foi de \pm $0,144 \%$. Este desvio pode representar um efeito da gravidade no movimento das lâminas enquanto elas estāo se movimentando para liberar o campo dinâmico de IMRT [15][16][18][35]. Os resultados do presente trabalho estão de acordo com os valores descritos na literatura. LoSasso [35] e LoSasso e colaboradores [16] citam variações de até $2 \%$, e Venencia e Besa [18] com uma incerteza menor que $\pm 2 \%$, Essers e colaboradores [14] obtiveram desvios na ordem de $\pm 1,4 \%$ para diferentes angulações do sistema de suporte funcional e, por fim. Van Esch e colaboradores [17] citam uma reprodutibilidade de "janela deslizante" dentro de limites de variação de $\pm 2 \%$.

FATOR DE RENOIMENTO CON DMLC - MLC 120

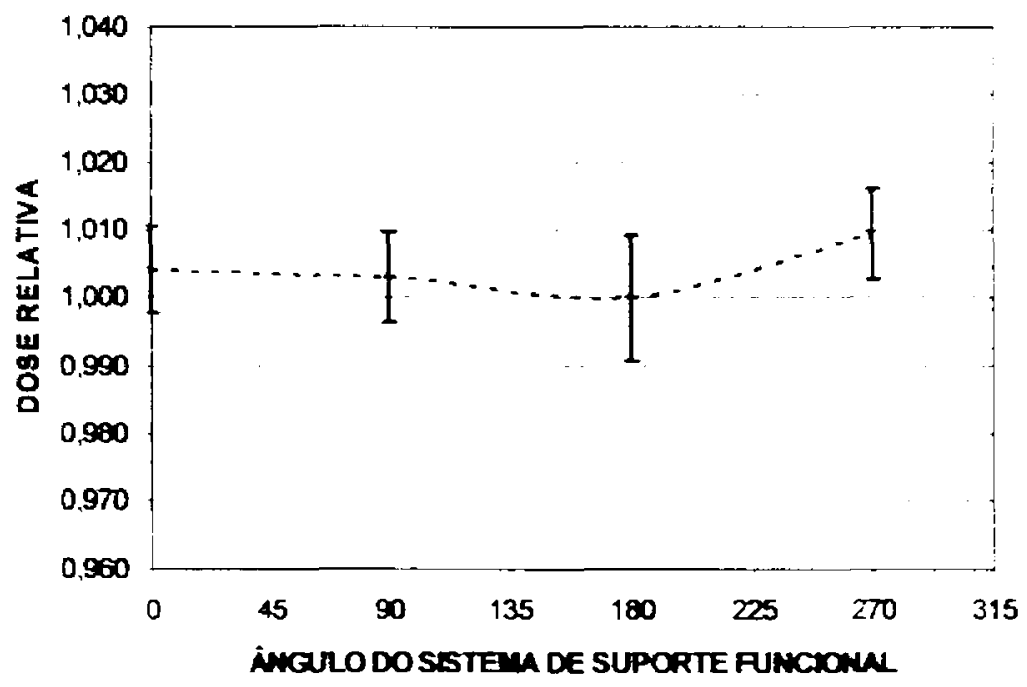

Figura 19. Resultados de mediçōes para verificar a estabilidade do fator de rendimento com o MLC 120 em modo dinâmico (DMLC). 


\subsubsection{LINEARIDADE DAS UNIDADES MONITORAS}

Os resultados obtidos são os esperados, o desvio de cada valor de unidade monitora com sua respectiva dose relativa está dentro da faixa de variação de $\pm 1 \%$ como pode ser visto na Figura 20 .

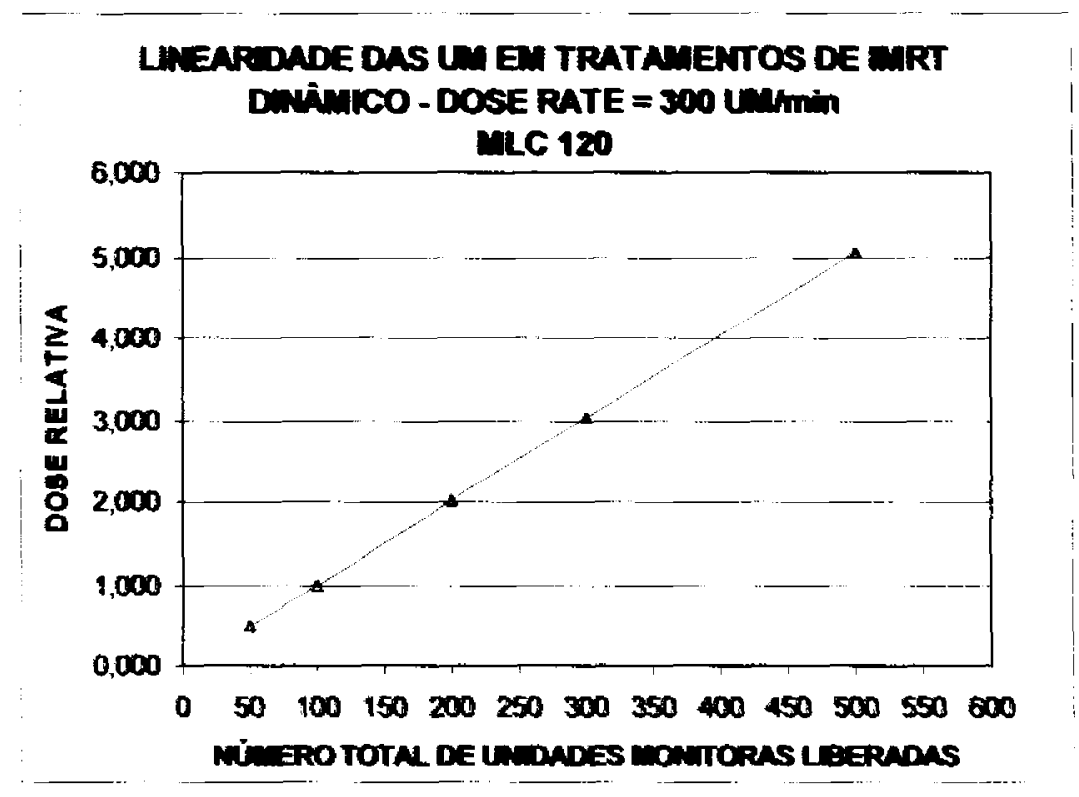

Figura 20. Resultados dos testes de linearidade das unidades monitoras para um tratamento de IMRT, liberado com o MLC 120, mantendo constante a taxa de dose.

As leituras seguiram o comportamento crescente quando o número de unidades monitoras aumentou. Se existir um desvio na reta da Figura 20, este pode ser interpretado como uma falha em um componente do sistema (motor das lâminas, taxa de dose, posição das lâminas, etc.) e deve ser rigorosamente analisado. As barras de erro foram omitidas já que sua magnitude é da ordem dos pontos da figura.

\subsubsection{LINEARIDADE DE DOSE EM FUNÇÃO DA TAXA DE DOSE}

Os resultados na Figura 21 mostram que a dose relativa ou fator de rendimento manteve-se constante dentro de $\pm 1 \%$ quando a taxa de dose variou nos tratamentos de IMRT com um número de unidades monitoras fixo [20][36].

O desvio observado para a menor taxa de dose difere do limite de variação de $\pm 1 \%$, que pode ser devido a uma situação de operação extrema dos motores das lâminas. Estas situações não são comuns na prática clínica rotineira, 
mas o comportamento do sistema deve estar bem caracterizado. até mesmo nestas situaçōes.

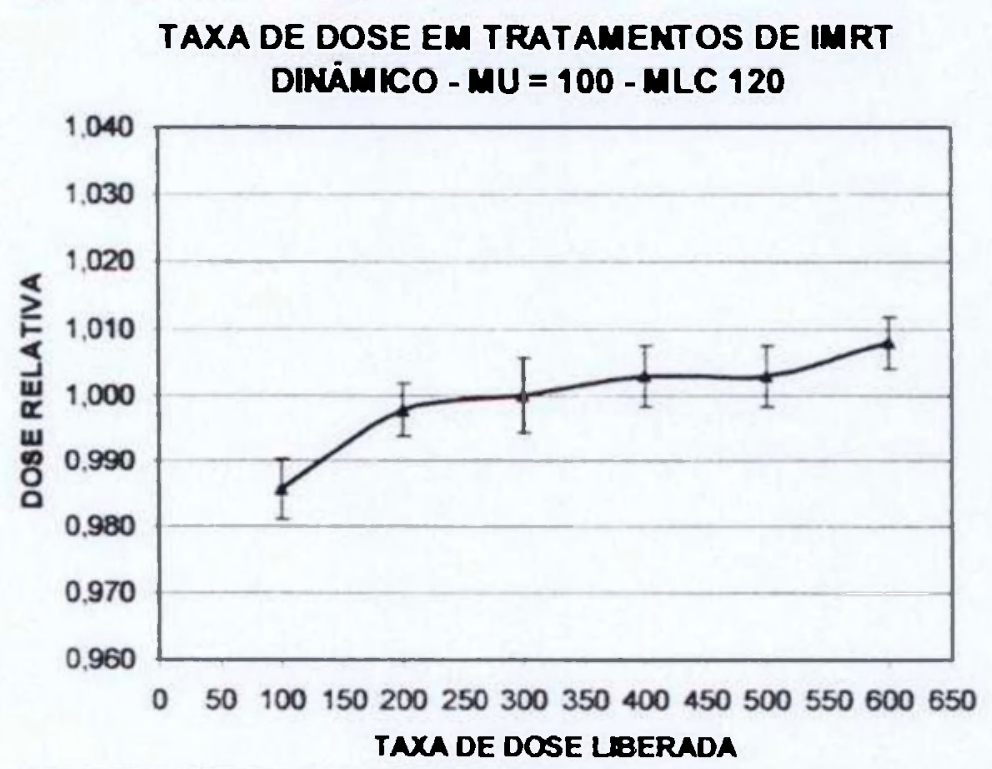

Figura 21. Resultados dos testes da constáncia da dose em funçăo da taxa de dose para um número fixo de unidades monitoras em um tratamento de IMRT.

\subsubsection{AVALIAÇÃO DE FIGURAS PADRÃO.}

As figuras padrāo disponibilizadas pelo fabricante permitem avaliar 0 funcionamento das lâminas, como o posicionamento, velocidade, efeito lingüeta e vāo, etc. Por exemplo, na Figura 22, a análise das fatias segmentadas (a) permite avaliar a operação apropriada do MLC através da intensidade dos segmentos irradiados e não irradiados, permite avaliar também o posicionamento das lâminas em posiçōes pré-definidas e que o fabricante disponibiliza no manual de operaçāo. Já o padrāo complexo permite avaliar o efeito lingüeta - vão das lâminas e os niveis de intensidade. Estes testes devem ser estudados antes e depois de realizados para se obter a maior quantidade de informaçāo deles e para se poder concluir com relação a um possivel mau funcionamento. Estes testes fazem parte dos procedimentos de aceitaçāo do MLC. 


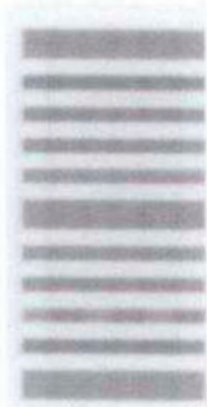

(a)

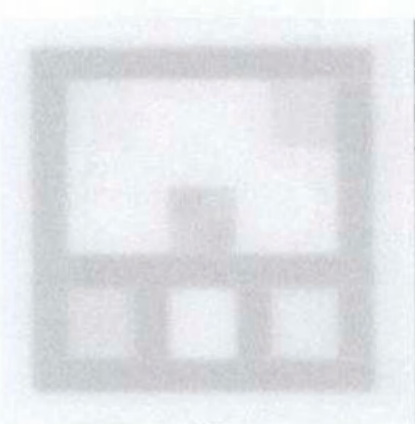

(b)

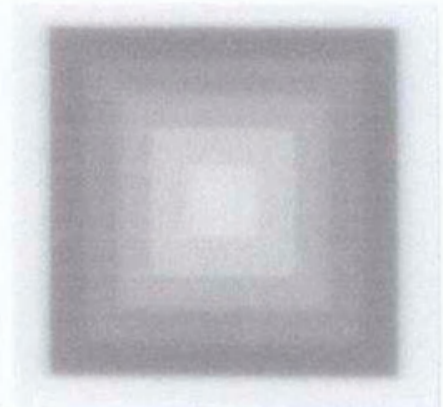

(c)

Figura 22 Figuras padrão disponibilizadas pelo fabricante. (a) Fatias segmentadas. (b) Padrāo complexo. (c) Pirâmide.

\subsubsection{TRANSMISSÃO}

\subsection{TRANSMISSÃO COM CÂMARA DE IONIZAÇÃO}

Foi medida a dependência da transmissão com o tamanho de campo em várias profundidades para as duas energias disponiveis (6 e $15 \mathrm{MV}$ ), em vários tamanhos de campo, tanto no eixo central (E.C.) como fora do eixo central (F.E.), como pode ser visto nas Figuras 23 e 24.

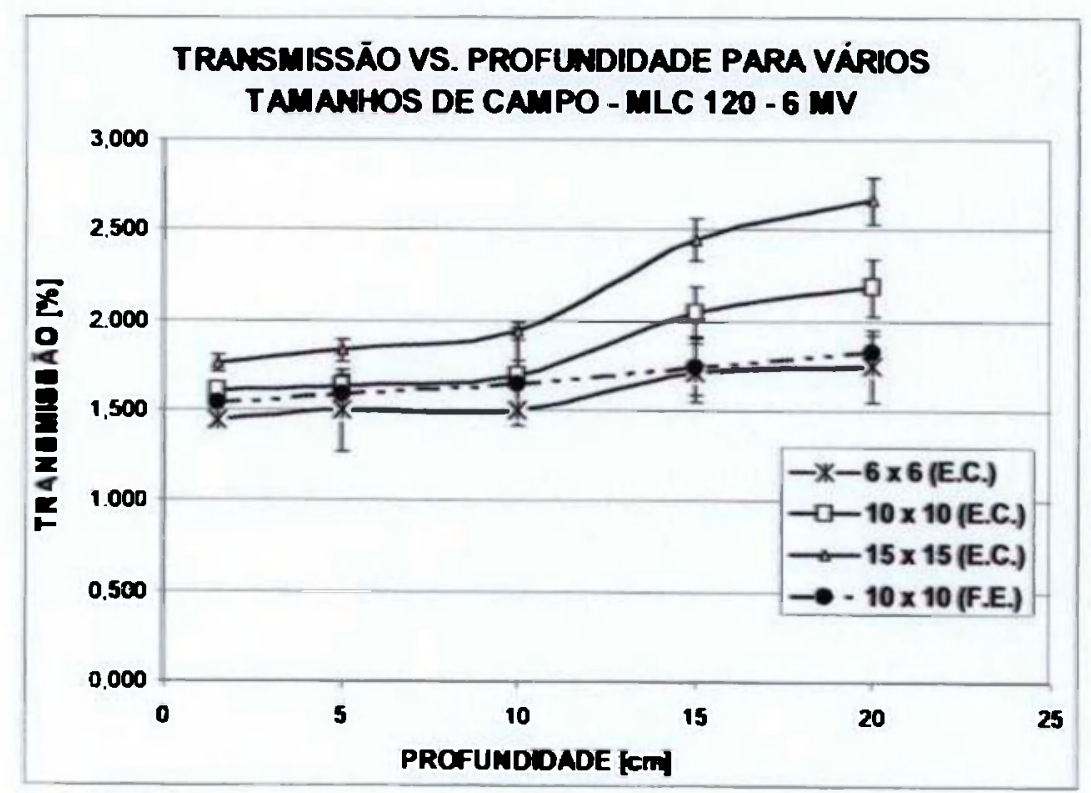

Figura 23. Transmissão do MLC 120 em função da profundidade para vários tamanhos de campo para um feixe de 6 MV. 


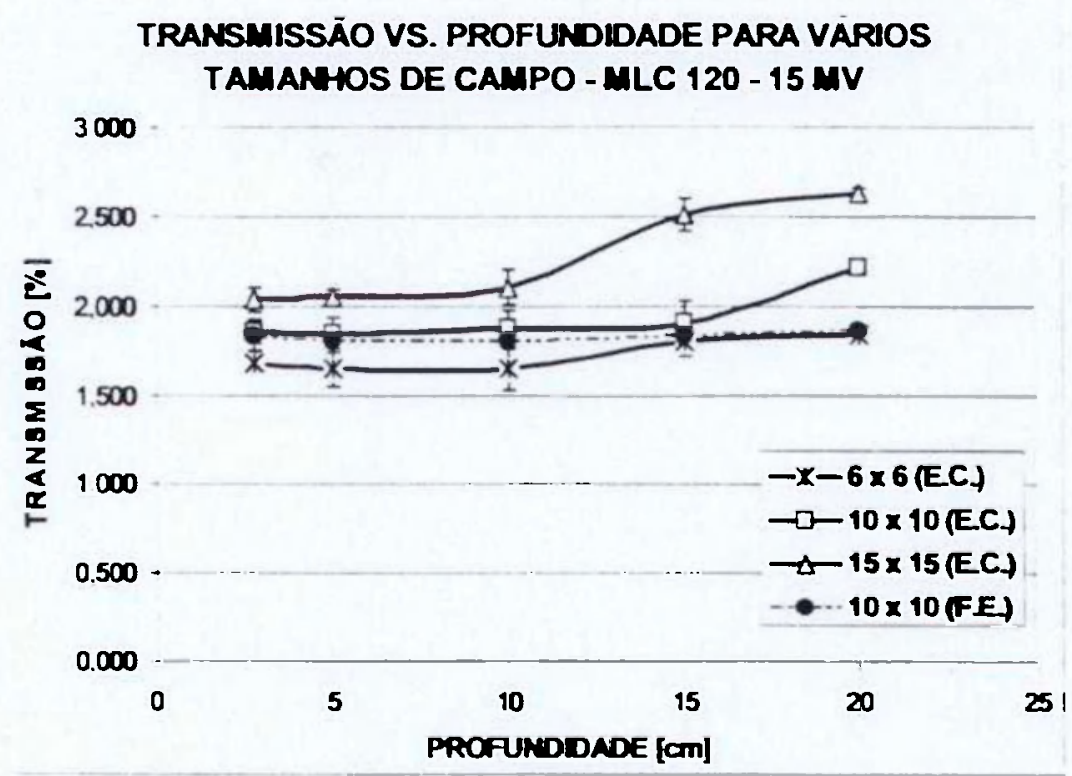

Figura 24. Transmissão do MLC 120 em funçāo da profundidade para vãrios tamanhos de campo para um feixe de 15 MV.

Os sistemas de planejamento computadorizados precisam do valor médio da transmissão para um tamanho de campo e profundidade clinicamente relevante. Uma boa escolha pode ser o valor de transmissão para o campo $10 \times$ $10 \mathrm{~cm}^{2}$, na profundidade de $5 \mathrm{~cm}$. Para o MLC - 120, o valor obtido para $6 \mathrm{MV}$ obtido foi $(1,630 \pm 0,018) \%$ e de $(1,838 \pm 0,016) \%$ para $15 \mathrm{MV}$ respectivamente.

A transmissão aumenta com o tamanho de campo pelo incremento do espalhamento produzido pelo MLC, já que os colimadores secundários estão em uma posição fixa. A tendência da transmissão aumentar para $6 \mathrm{MV}$ é causada pelo endurecimento do feixe. No feixe de $15 \mathrm{MV}$ este efeito não é visivel pela produção de pares nessa faixa de energia.

No modo dinâmico, o comportamento da transmissão muda, em razão do maior tempo que o ponto de medida (câmara de ionização) está bloqueado e é maior que o tempo exposto.

Comparando estes resultados com os da literatura, Venencia e Besa [18] obtiveram um valor médio para ser inserido no sistema de planejamento de $1,5 \%$. para o mesmo modelo de MLC.

Na publicação de Van Esch e colaboradores [17] estão descritos os resultados de 5 centros de Radioterapia, sendo que desses dois possuem MLC Millenium 120. Os valores de transmissão para um desses centros é 1,5 e 1,6\% 
para $6 \mathrm{MV}$ e $18 \mathrm{MV}$ respectivamente. Para outro centro com Millenium 120, o valor médio reportado é $1,7 \%$ para 6 e $18 \mathrm{MV}$.

Chauvet e colaboradores [37] descrevem um valor médio de transmissão de $1,8 \%$ para um MLC Millenium $120 \mathrm{em}$ um feixe de $20 \mathrm{MV}$.

\subsection{TRANSMISSÃO COM FILME}

Os resultados da transmissão estão mostrados nas Figuras 25 e 26.

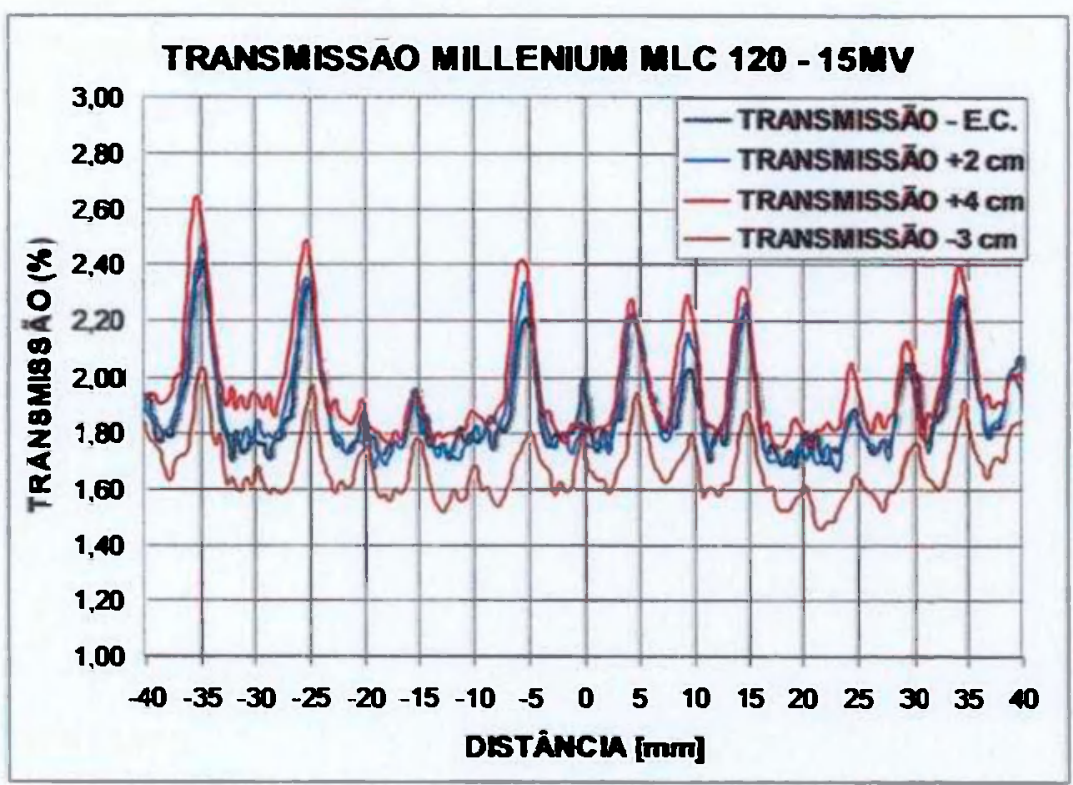

Figura 25. Transmissăo entre as láminas e intraláminas para um feixe de 15 MV no MLC 120.

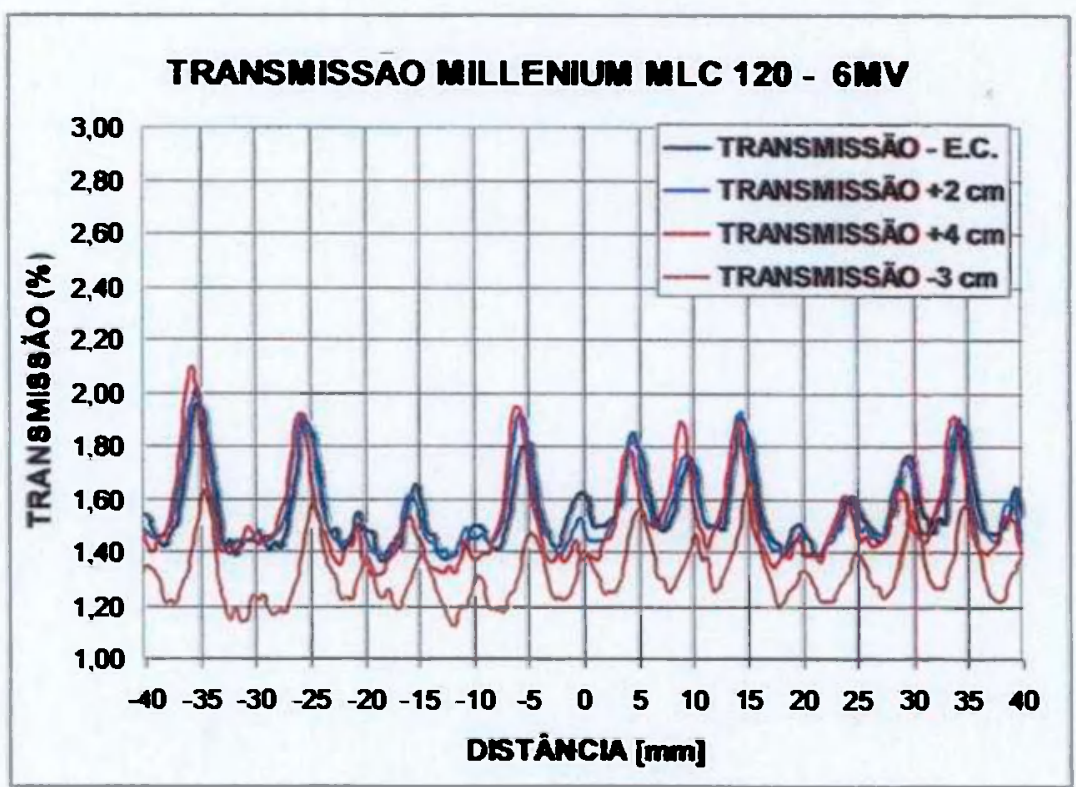

Figura 26. Transmissăo entre as láminas e intraláminas um feixe de 6 MV no MLC 120. 
A partir da análise das medições realizadas com filme para os feixes de $6 \mathrm{MV}$ e de $15 \mathrm{MV}$, foram obtidos os resultados apresentados na Tabela 1. Estes valores validam os obtidos com câmara de ionização. Para este teste as lâminas estiveram fechadas em um extremo do campo $10 \times 10 \mathrm{~cm}^{2}$; os dados obtidos próximos do outro extremo (posição $-3 \mathrm{~cm}$ ) são menores pelo projeto da lâmina.

Tabela 1. Resultados da transmissão medida com filme, analisados no eixo central.

\begin{tabular}{|c|c|c|}
\hline TRANSMISSĀO [\%] & $6 \mathrm{MV}$ & $15 \mathrm{MV}$ \\
\hline MÉDIA & 1,56 & 1,92 \\
\hline DESVIO PADRĀO & $\mathbf{0 , 1 5}$ & 0,20 \\
\hline ENTRE LÂMINAS & $\mathbf{2 , 0 3}$ & 2,73 \\
\hline INTRALÁMINAS & 1,36 & 1,68 \\
\hline
\end{tabular}

No trabalho de Arnfield e colaboradores [33] o valor médio de transmissäo obtido com filme para um feixe de $6 \mathrm{MV}$ foi $(1,34 \pm 0,03) \%$.

LoSasso [35] mostra um padrão de transmissão entre as lâminas e intralâminas que não supera 2,1\% para o MLC Millenium.

\subsubsection{ESPALHAMENTO DE RADIAÇÃO PRODUZIDO PELO MLC 120}

Foram realizadas as medições de transmissão para diferentes tamanhos de campo, mantendo fixo o comprimento do campo $(Y)$, os resultados obtidos para 6 e 15 MV estão ilustrados na Figura 27.

A partir das medições e valores apresentados na Figura 27, foram realizadas as respectivas extrapolações $e$ foi determinado $o$ valor de espalhamento produzido pelas lâminas do MLC para ambas as energias (6 e 15 MV), para um campo padrāo de $10 \times 10 \mathrm{~cm}^{2}$. Os resultados do espalhamento estão detalhados na Tabela 2. 


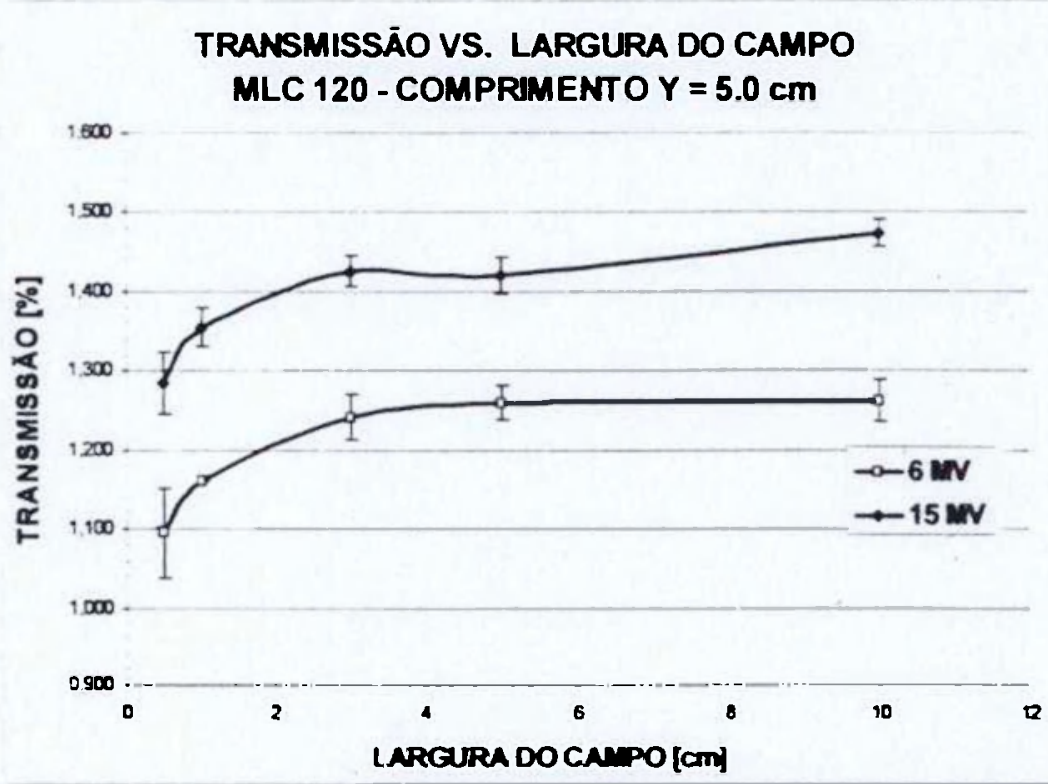

Figura 27. Transmissāo vs. largura do campo para o MLC Millenium 120 em um feixe de 6 e 15 MV.

Os resultados obtidos são satisfatórios quando comparados com o trabalho de Arnfield e colaboradores [33], no qual o espalhamento foi calculado para um sistema de colimador multi-lâminas do mesmo modelo. Varian Millenium 120, para a energia de $6 \mathrm{MV}$, sendo reportado o valor de $(0,21 \pm 0,03) \%$ medido através de filmes. $O$ valor calculado difere em $41 \%$ do valor mencionado na literatura, ele foi determinado seguindo o mesmo procedimento, mas com uma ferramenta dosimétrica diferente. A ordem de grandeza do resultado está de acordo com a do trabalho citado.

Tabela 2. Resultados do cálculo de espalhamento produzido pelas làminas do MLC Millenium 120 , para um campo de $10 \times 10 \mathrm{~cm}^{2}$.

\begin{tabular}{|c|c|}
\hline & ESPALHAMENTO - MLC 120 \\
& (\% DE DOSE DE UM CAMPO ABERTO $\left.10 \times 10 \mathrm{~cm}^{2}\right)$ \\
\hline $15 \mathrm{MV}$ & $(0,333 \pm 0,042) \%$ \\
\hline $6 \mathrm{MV}$ & $(0,297 \pm 0,024) \%$ \\
\hline
\end{tabular}

\subsubsection{EFEITO DA BORDA ARREDONDADA E ABERTURA DOSIMÉTRICA ENTRE PARES DE LÂMINAS.}

Para o MLC Millenium de 120 lâminas foi determinada a abertura dosimétrica entre pares de lâminas com câmara de ionização. sendo realizadas as correções detalhadas no item 2.8.8. Os resultados obtidos apresentam-se nas Figuras 28 e 29 respectivamente. As barras de erro nas duas figuras foram 
omitidas em virtude que sua magnitude é da ordem de grandeza dos pontos do gráfico.

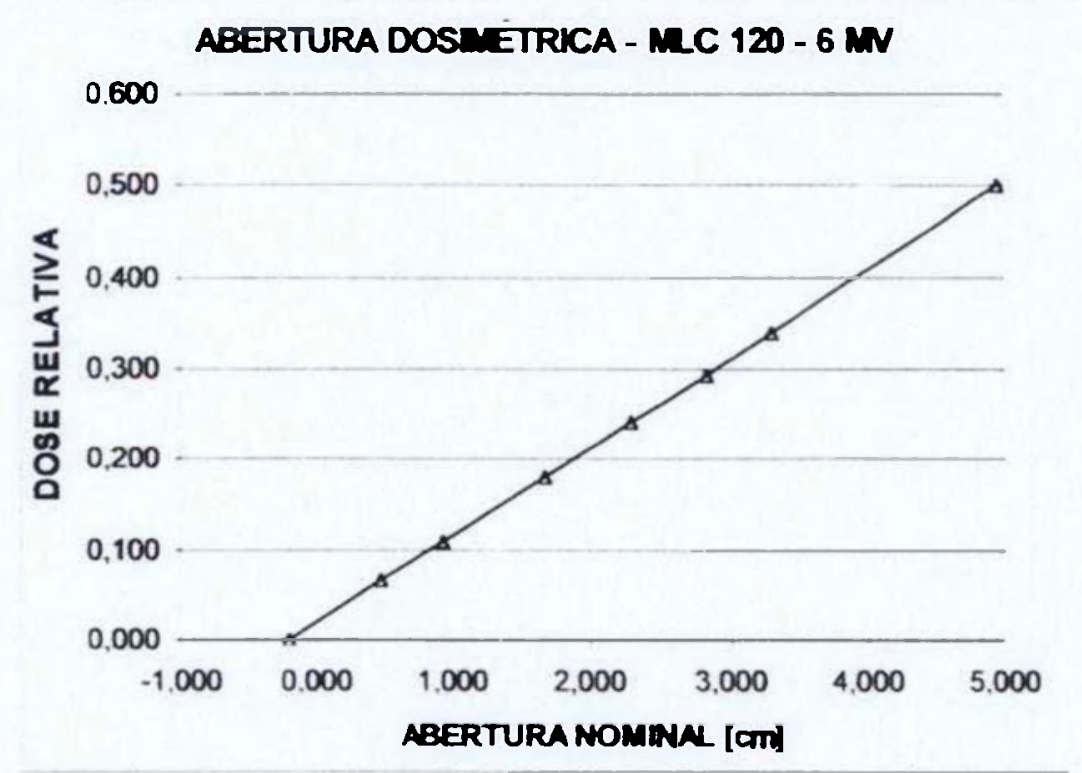

Figura 28. Gráfico da dose relativa em funçāo da abertura nominal para o MLC 120.

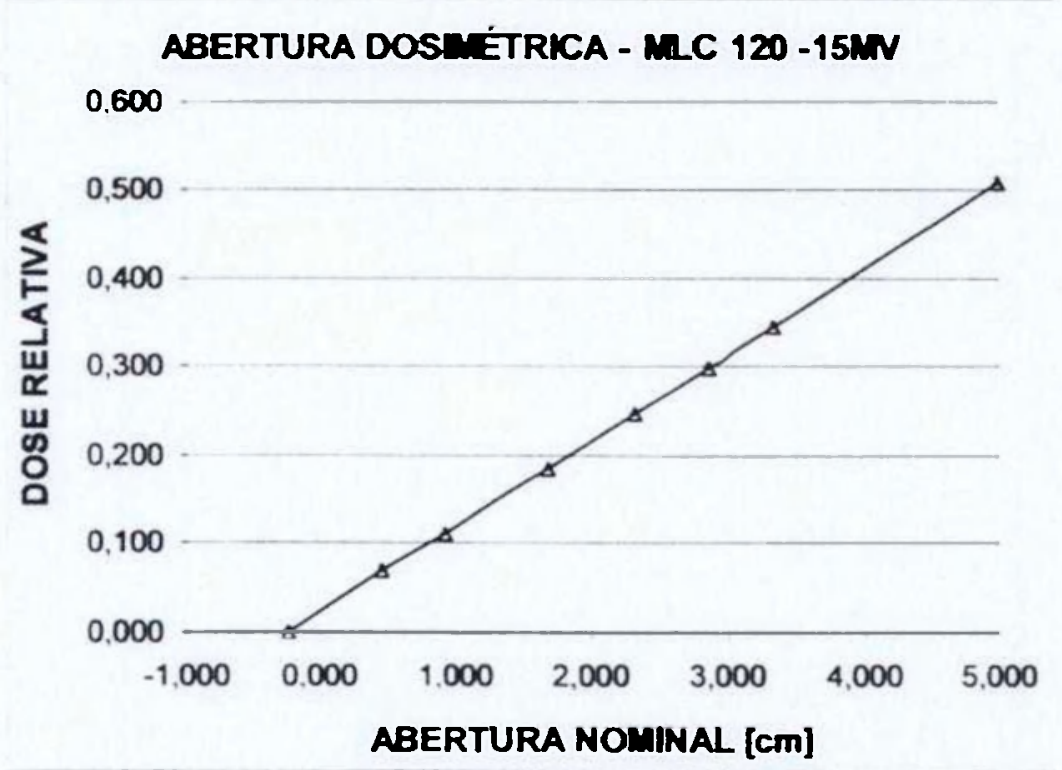

Figura 29. Gráfico da dose relativa em função da abertura nominal para o MLC 120.

Os valores obtidos da abertura dosimétrica entre pares de lâminas para o MLC Millenium foram $(0.202 \pm 0.054) \mathrm{cm}$ para $6 \mathrm{MV}$ e $(0.236 \pm 0.059) \mathrm{cm}$ para a energia de $15 \mathrm{MV}$. Na literatura. Venencia e Besa [18] obtiveram para o mesmo sistema de MLC um valor de $0,2 \mathrm{~cm}$ na energia de $6 \mathrm{MV}$. O valor recomendado pelo fabricante é $0.2 \mathrm{~cm}$ [33]. Já no trabalho apresentado por Van Esch e colaboradores [17] estão os valores da abertura dosimétrica utilizados em vários 
centros de Radioterapia; os valores dos MLC Millenium mencionados são 0.19 e $0,25 \mathrm{~cm}$.

\subsubsection{PENUMBRA}

\subsection{PENUMBRA EM FUNÇÃO DO DESLOCAMENTO FORA DO EIXO CENTRAL.}

$\mathrm{Na}$ Figura 30 , os valores negativos representam as posiçōes nas quais as lâminas estão estendidas sobre o eixo. Os valores positivos representam as posiçōes nas quais as lâminas estão retraidas. As barras de erro foram omitidas em virtude que sua magnitude è da ordem de grandeza dos pontos da figura.

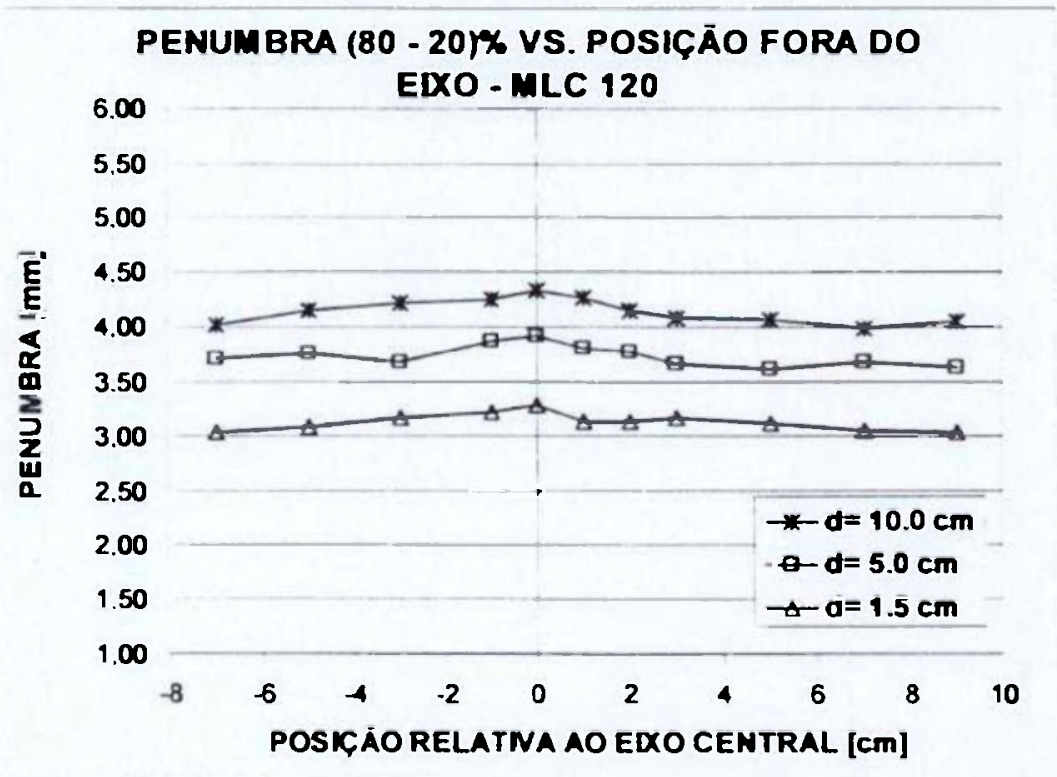

Figura 30. Penumbra (80-20\%) em função da posição das lâminas em relaçāo ao eixo central para o MLC 120.

Tanto para as lâminas estendidas sobre o eixo central como para as lâminas retraidas, pode ser observado que não existe uma variação significativa da penumbra com a posição das lâminas, sendo que os valores obtidos em nenhum dos casos ultrapassou $5 \mathrm{~mm}$, sendo menores do que o esperado. No trabalho de Huq e colaboradores [38], os resultados para um MLC Varian mostram um comportamento similar ao obtido neste trabalho. onde o valor de penumbra no eixo central é maior do que em posiçōes mais extremas. Isto pode ser explicado pelo fato das bordas estarem projetadas para minimizar a divergência do feixe. No presente trabalho, para a profundidade de $1,5 \mathrm{~cm}$ o valor 
no eixo central é $8,17 \%$ maior do que nas posiçōes extremas; para a profundidade de 5.0 esta diferença é de $6.33 \%$ e, para $10,0 \mathrm{~cm}$ de profundidade o valor no eixo central è $8,31 \%$ maior do que nas posiçōes extremas.

\subsection{PENUMBRA EM FUNÇÃO DO TAMANHO DE CAMPO.}

Os resultados obtidos por dosimetria com filme a $5 \mathrm{~cm}$ de profundidade para o MLC Millenium estão apresentados na Figura 31.

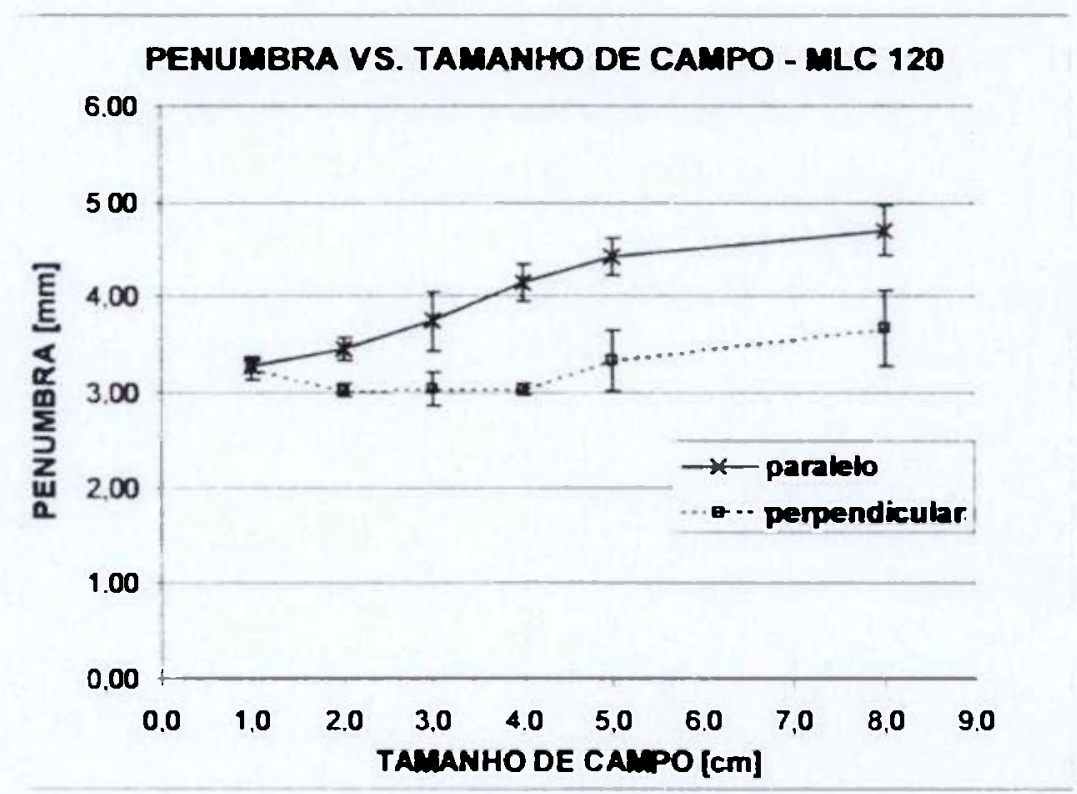

Figura 31. Variação da penumbra em funçāo do tamanho de campo nos sentidos paralelo e perpendicular ao movimento do MLC 120.

O comportamento da penumbra é o esperado, incrementando-se a medida que o tamanho de campo aumenta. sendo sempre maior o valor no sentido paralelo ao movimento das lâminas do que no sentido perpendicular.

\subsection{PENUMBRA EM FUNÇÃO DA PROFUNDIDADE.}

Os resultados obtidos (Figura 32) foram comparados com os descritos na literatura por Boyer e colaboradores [39] para 1,5 e $10 \mathrm{~cm}$ de profundidade (Tabeia 3). sendo que o sistema descrito pelo autor citado está conformado de lâminas de $1 \mathrm{~cm}$ de largura. 


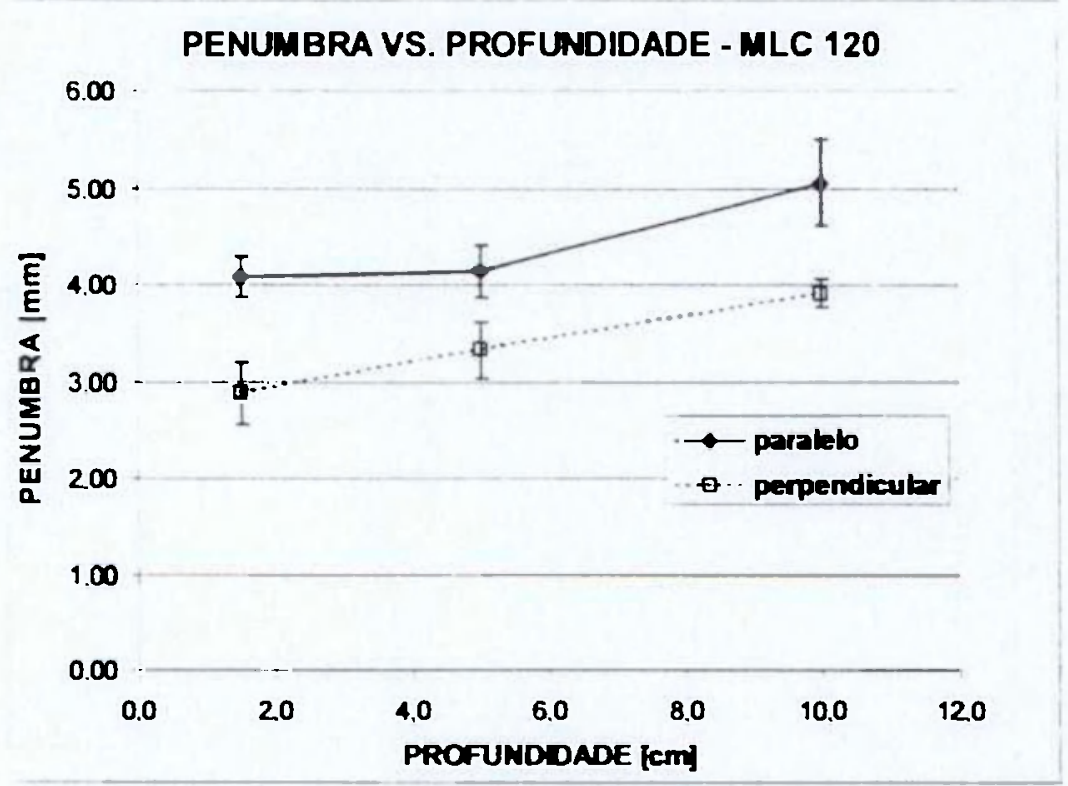

Figura 32. Variaçāo da penumbra em funçāo da profundidade para campos de referência $10 \times 10 \mathrm{~cm}^{2}$ definidos pelo MLC Millenium para 6 MV.

Tabela 3. Resultados obtidos da penumbra em funçāo da profundidade comparada com os descritos na literatura.

\begin{tabular}{|c|c|c|c|c|}
\cline { 2 - 5 } \multicolumn{1}{c|}{} & \multicolumn{2}{c|}{ SENTIDO PARALELO } & \multicolumn{2}{c|}{ SENTIDO PERPENDICULAR } \\
\hline $\begin{array}{c}\text { PROFUNDIDADE } \\
{[\mathrm{cm}]}\end{array}$ & $\begin{array}{c}\text { PENUMBRA 80- } \\
20 \% \mathrm{em} \mathrm{mm}\end{array}$ & $\begin{array}{c}\text { Boyer e } \\
\text { colaboradores } \\
{[39] \mathrm{em} \mathrm{mm}}\end{array}$ & $\begin{array}{c}\text { PENUMBRA 80-20\% } \\
\text { em mm }\end{array}$ & $\begin{array}{c}\text { Boyer e } \\
\text { colaboradores } \\
{[39] \mathrm{em} \text { mm }}\end{array}$ \\
\hline 1,5 & $4,08 \pm 0,21$ & 4,0 & $2,88 \pm 0,33$ & 3,00 \\
\hline 10,0 & $5,05 \pm 0,45$ & 6,8 & $3,91 \pm 0,15$ & 5,40 \\
\hline
\end{tabular}

Na literatura, Galvin e colaboradores [40] citam valores de penumbra para o feixe de $6 \mathrm{MV}$ de $2,96 \mathrm{~mm}$ no $\mathrm{d}_{\max }$ e $6,15 \mathrm{~mm}$ na profundidade de $10,0 \mathrm{~cm}$. Para $15 \mathrm{MV}$, a penumbra na profundidade de $10 \mathrm{~cm}$ é $7 \mathrm{~mm}$, no mesmo trabalho citado.

\subsection{PENUMBRA EM FUNÇÃO DO ÂNGULO COM AS BORDAS.}

Os resultados obtidos (Tabela 4) a partir dos filmes irradiados na profundidade de $1.5 \mathrm{~cm}(6 \mathrm{MV})$ apresentam concordância com o citado por Huq e colaboradores [38], no qual foi feito este teste somente para o ângulo de $45^{\circ}$ e 0 valor citado foi de $6 \mathrm{~mm}$ e na mesma profundidade. No trabalho publicado por Galvin e colaboradores [40], este teste foi realizado à profundidade de $10 \mathrm{~cm}$ e para ângulos de $45^{\circ}$ e $15^{\circ}$, obtendo penumbras de 0,8 e $1,0 \mathrm{~cm}$ respectivamente. 
Os sistemas citados, nesta comparação, possuem $1 \mathrm{~cm}$ de largura projetada no isocentro.

Tabela 4. Resultados da penumbra $80-20 \%$ em funçăo do ângulo que formam as bordas do MLC

\begin{tabular}{|c|c|c|c|c|c|c|}
\hline ANGULO ['] & 80 & 75 & 60 & 45 & 30 & 15 \\
\hline PENUMBRA [mm] & 6,51 & 5,69 & 4,86 & 5,02 & 4,95 & 4,89 \\
\hline DESVIO PADRĀO [mm] & 0,30 & 0,21 & 0,25 & 0,33 & 0,40 & 1,58 \\
\hline
\end{tabular}

\subsubsection{ANÁLISE DOS ARQUIVOS "DYNALOG".}

Os arquivos "dynalog" fornecem informação de extrema importância dos tratamentos dinâmicos, e são a ferramenta de "diagnóstico" de possíveis erros no posicionamento das lâminas. Para cada campo tratado em modo dinâmico, o histograma (Figura 33) é considerado aceitável se $95 \%$ ou mais das contagens de erro (número de desvios das posiçōes das lâminas) tiverem desvios menores do que $0,1 \mathrm{~cm}$ e não há contagem de erro com desvios superiores ao valor da tolerância definido pelo sistema.

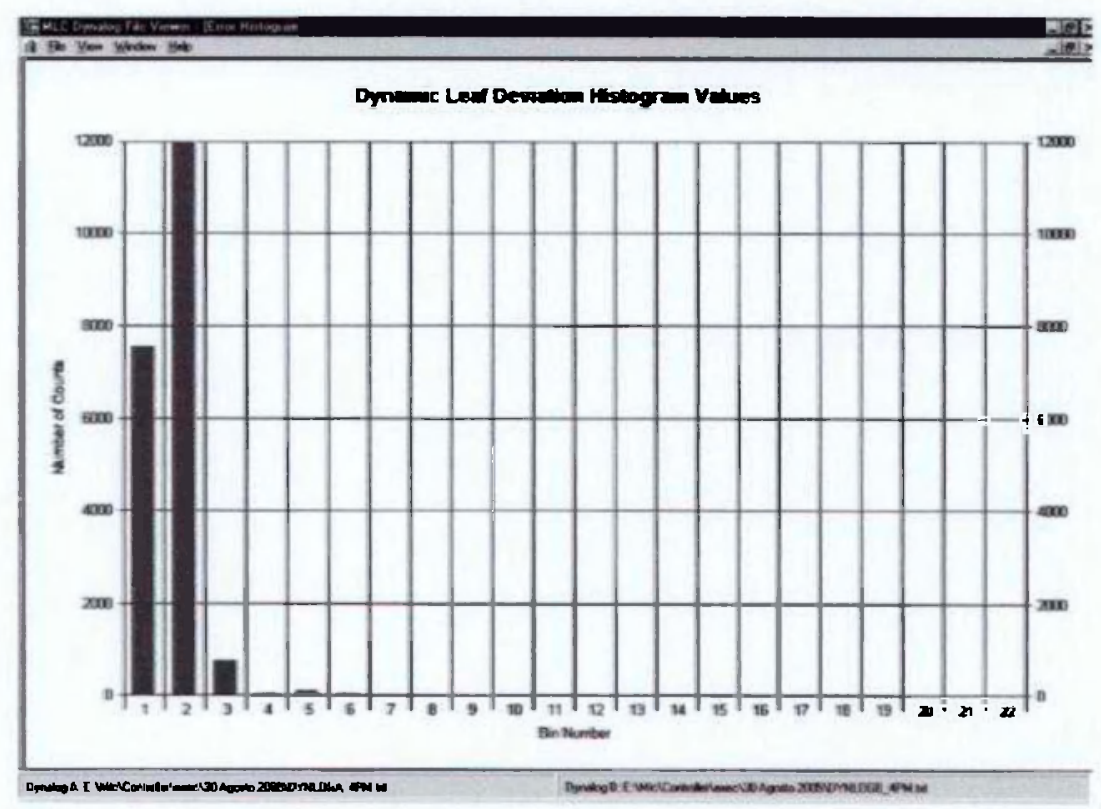

Figura 33. Histograma fornecido pelo arquivo "dynalog" com o número de desvios das posiçōes das láminas durante um tratamento dinámico no MLC 120.

O maior valor quadrático médio do erro é de $0,05 \mathrm{~cm}$. $\mathrm{O}$ número máximo de paradas do feixe aceito é igual a 2. O histograma dos desvios e o valor quadrático médio dos desvios são armazenados para cada campo de intensidade modulada. Os dados obtidos são utilizados para prever falhas iniciais nos motores e determinar a necessidade de substitui-los de forma preventiva 
[18][34]. São gerados gráficos do feixe em função do tempo de tratamento para avaliar se o feixe foi desligado (Figuras 34 e 35 ) e, em forma complementar, existe a possibilidade de análise através de um gráfico do desvio quadrático médio para cada uma das 120 lâminas.

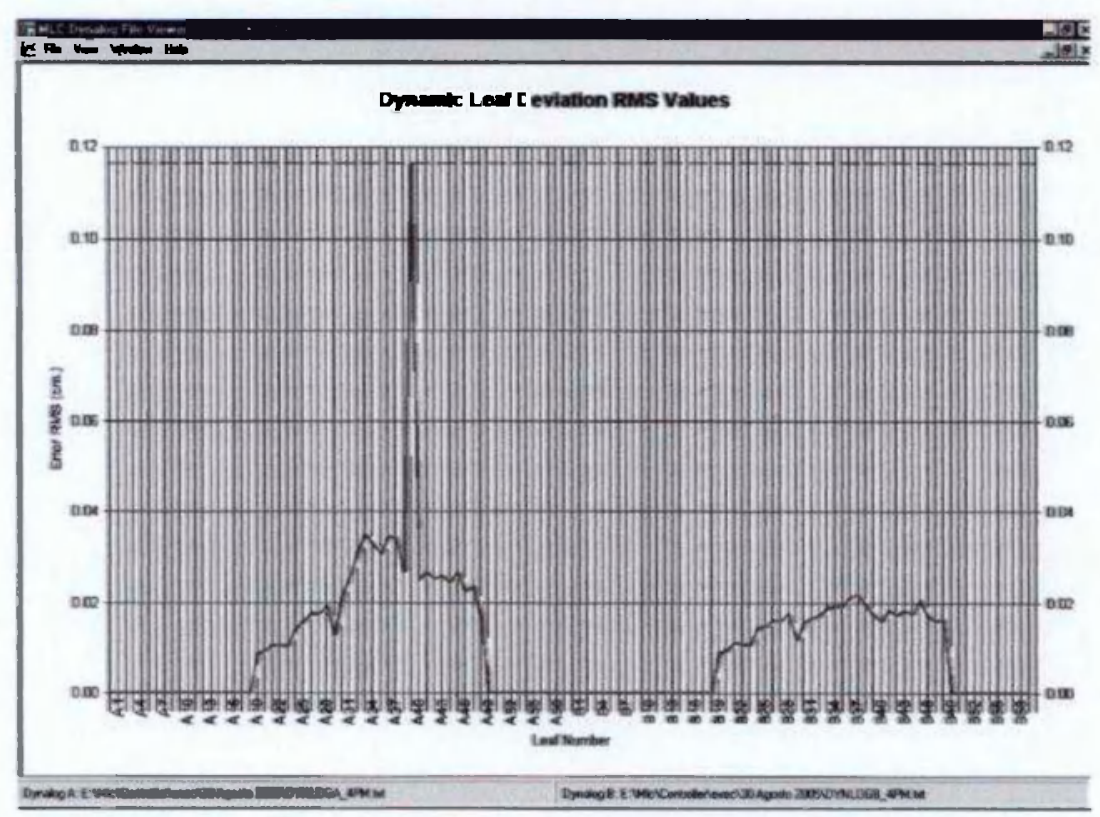

Figura 34. Gráfico do erro quadrático médio para cada uma das 120 lâminas do MLC. O maior pico indica um erro acima da tolerância do sistema para a lâmina $\mathbf{4 3 9}$ diagnosticado com o arquivo "dynalog".

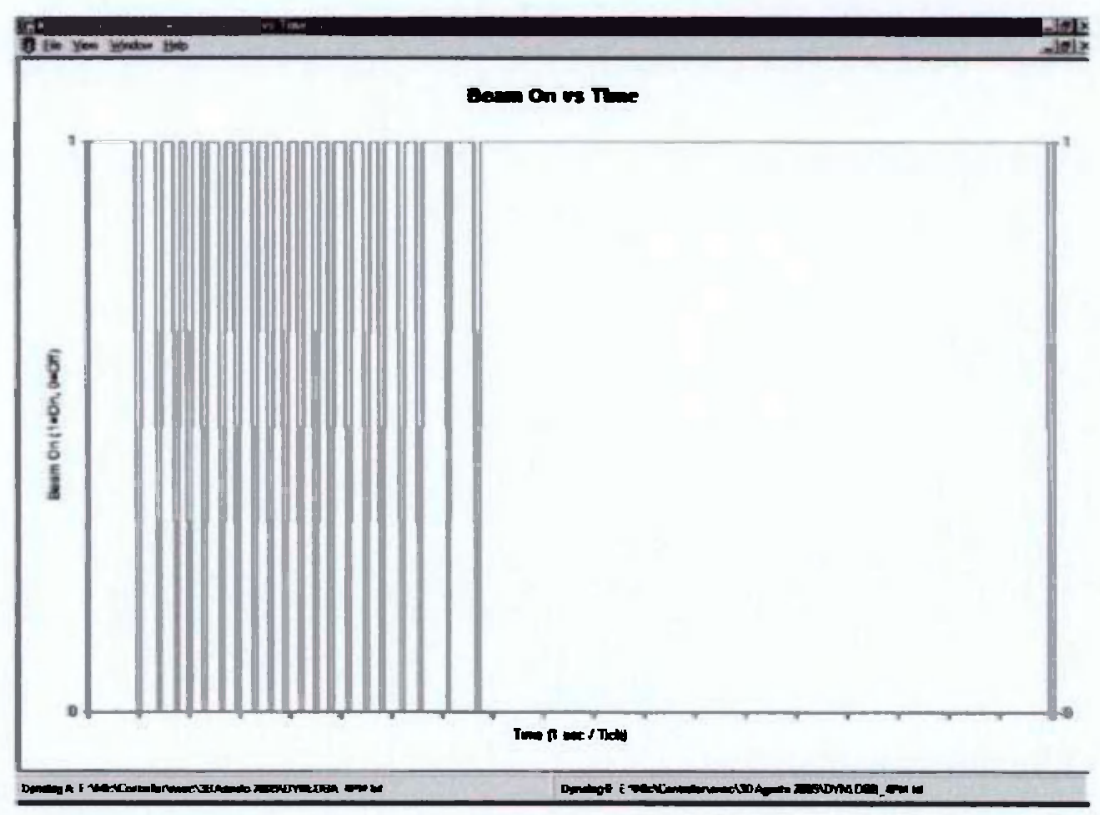

Figura 35. Gráfico do estado do feixe (ligado ou desligado) em funçāo do tempo de tratamento para um tratamento dinâmico liberado com o MLC 120. A existéncia de vários picos indica que o feixe foi desligado várias vezes durante o tratamento quando as lâminas nāo atingiram a posição programada. 


\subsection{MICRO COLIMADOR MULTI-LAMMINAS BRAINLAB m3.}

\subsubsection{TESTES MECÂNICOS}

Foi testado o efeito do parâmetro de tolerância entre a posiçāo programada e a posiçāo real das lâminas do mMLC. Determinou-se que existe um aumento no tempo de tratamento quando a tolerância diminuiu: a dose relativa apresentou variações quando a tolerância foi mudada nos arquivos dinâmicos, os resultados sāo apresentados nas Figuras 36 e 37.

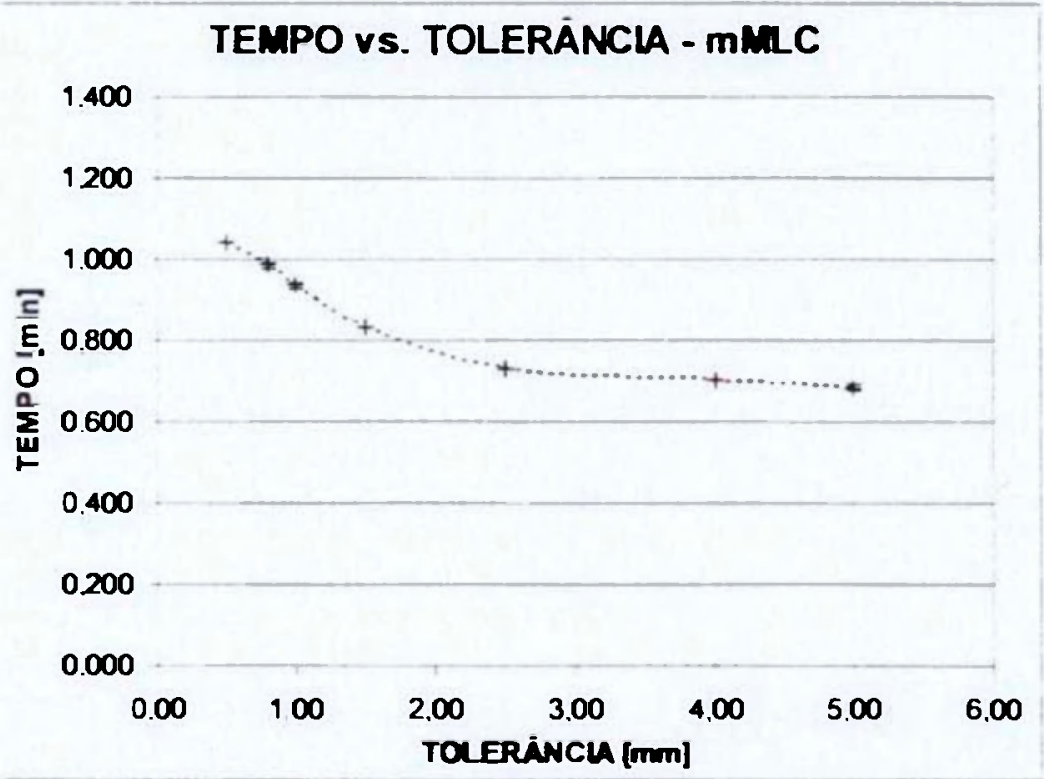

Figura 36. Variação do tempo de tratamento de um campo dinámico em funçāo da toleráncia entre as posiçōes programadas e reais das láminas em modo dinámico para o mMLC.

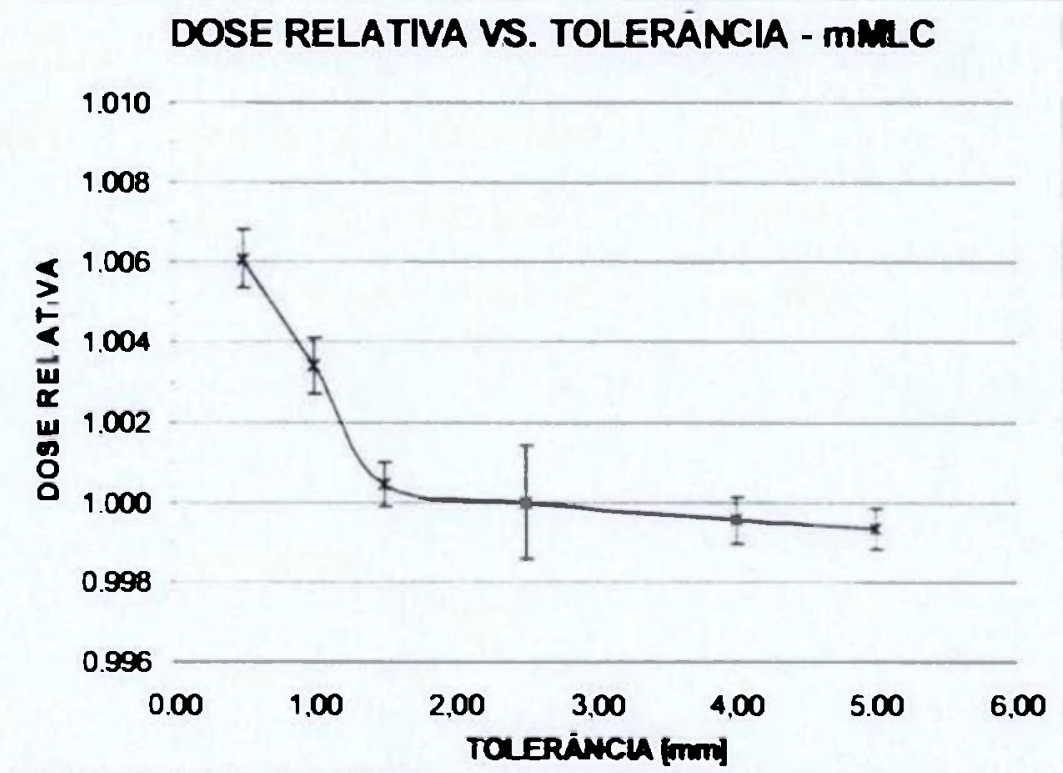

Figura 37. Efeito da toleráncia na posiçāo das láminas na dose relativa para um campo de tratamento dinámico para o mMLC. 
A ordem de grandeza $(\sim 0,6 \%)$ do aumento da dose relativa concorda com o resultado obtido neste mesmo trabalho para o MLC Millenium 120 e com o descrito por LoSasso e colaboradores [15].

\subsubsection{TESTE DE WINSTON - LUTZ}

Pode-se observar na Figura 38 , os resultados obtidos para 0 deslocamento do isocentro em função do ângulo de rotação do sistema de suporte funcional.

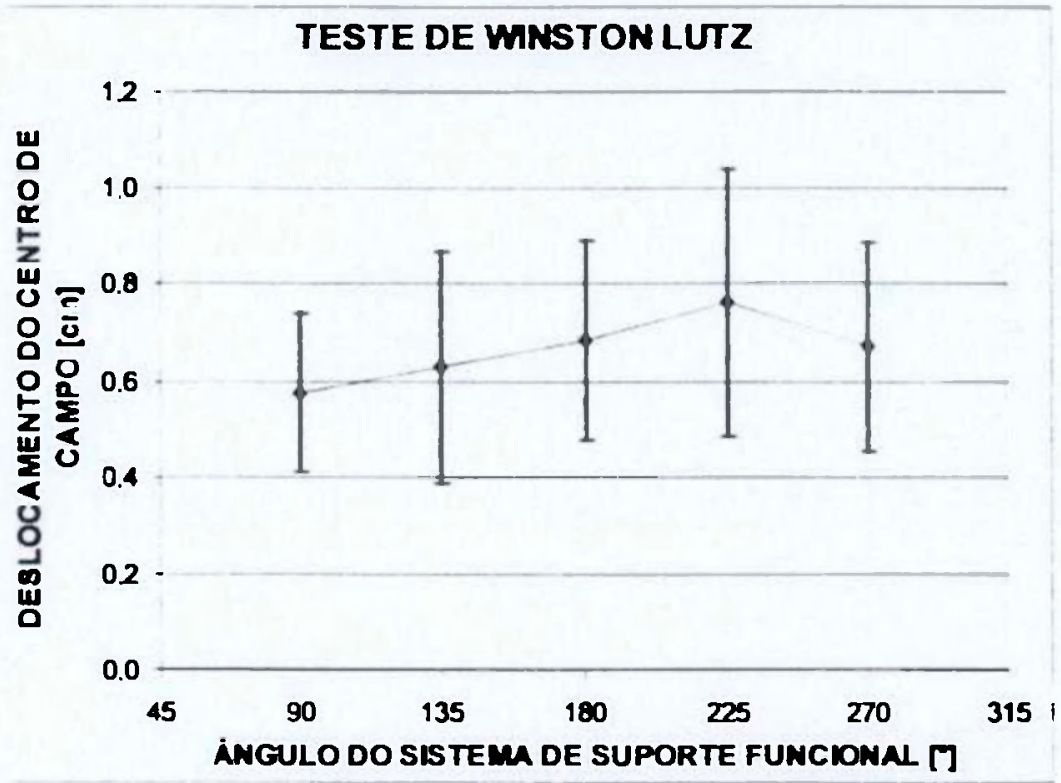

Figura 38. Gràfico do deslocamento do isocentro em função do ângulo de rotação do sistema de suporte funcional, realizado pelo método de Winston - Lutz no mMLC.

Os deslocamentos que o mMLC produz no centro de campo, quando acoplado ao sistema de suporte funcional ("gantry") do acelerador, são corrigidos a cada dia depois de realizado o teste se o deslocamento ultrapassa a incerteza deste parâmetro citada na literatura de $1 \mathrm{~mm}$ [41].

\subsubsection{POSIÇÃO DAS LÂMINAS NO ISOCENTRO}

Os valores encontrados estão de acordo com resultados publicados por LoSasso e colaboradores [15][35] para um sistema de MLC de 52 lâminas marca Varian, modelo Mark II. 
Na Figura 39 é possivel quantificar o erro na liberação da dose quando existe uma diferença no posicionamento das lâminas na abertura dinâmica. Por exemplo, para uma abertura nominal de $2 \mathrm{~cm}$, um erro no posicionamento das lâminas de $2 \mathrm{~mm}$ representa um desvio de $10,8 \%$ na dose com respeito à abertura de $2 \mathrm{~cm}$ sem erro na posição das lâminas.

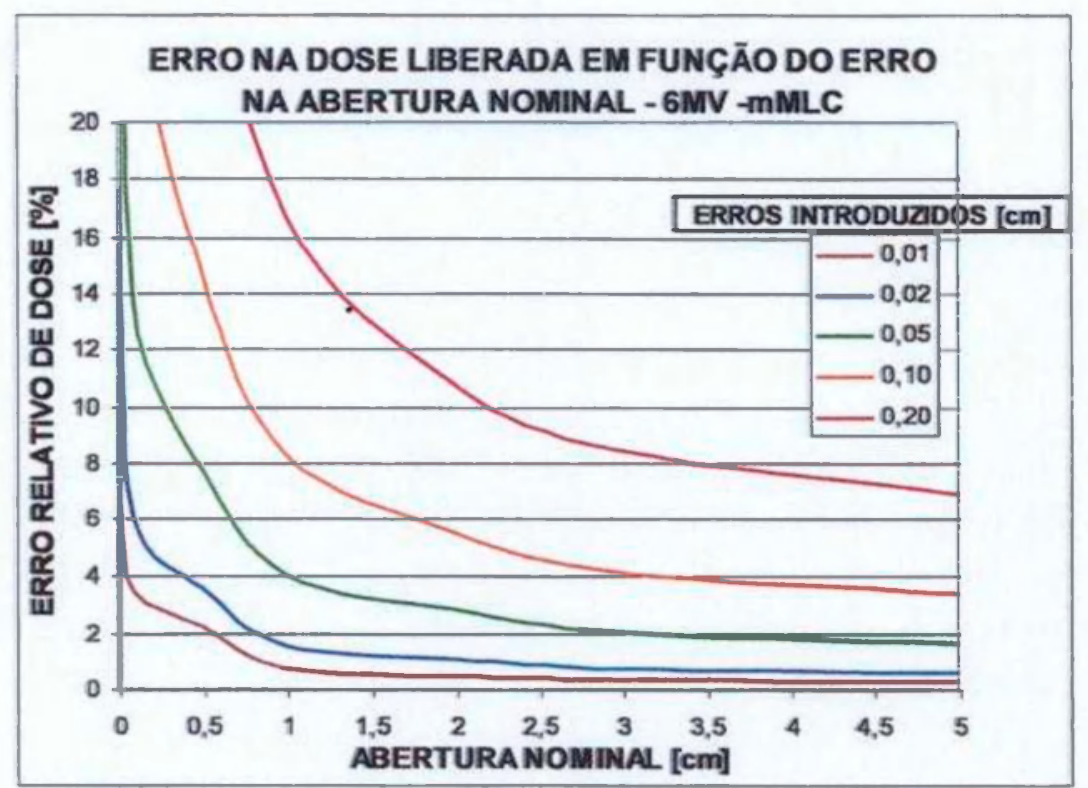

Figura 39. Resultados que relacionam o erro na dose liberada com o erro na abertura deslizante para GMV no $M M L C$.

\subsubsection{ESTABILIDADE DO SISTEMA mMLC EM MODO DINÂMICO.}

Para o sistema mMLC é realizado o teste da jardineira do mesmo modo que para MLC Millenium 120. A interpretação é realizada também através da análise de perfis paralelos ao movimento das lâminas e dos picos gerados. Os resultados são qualitativos.

\subsubsection{ESTABILIDADE DA VELOCIDADE DAS LÂMINAS.}

A estabilidade da velocidade das lâminas é testada com um arquivo dinâmico que irradia um campo em duas etapas da mesma forma que para o MLC Millenium 120. A análise é realizada da mesma maneira que a descrita na seç̧ão 3.1.1.3. Os resultados são também qualitativos. 


\subsubsection{TESTES DOSIMÉTRICOS}

\subsubsection{SENSIBILIDADE À INTERRUPÇÃO DE TRATAMENTOS.}

Foi testado este parâmetro tanto em aceleração como em desaceleração para um campo de tratamento dinâmico de IMRT liberado com o mMLC. Os resultados obtidos e apresentados na Figura 40 mostram que a interrupção dos tratamentos produz uma diferença máxima de $(0.4 \pm 0,2) \%$.

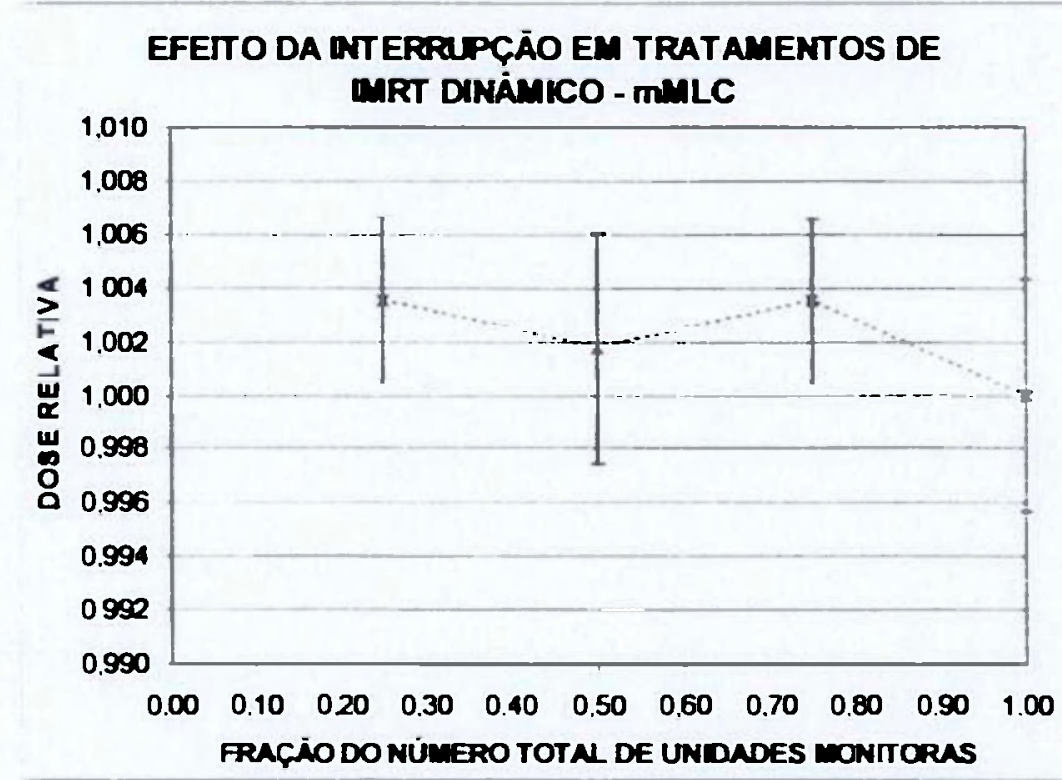

Figura 40. Efeito da interrupçăo do feixe durante um tratamento dinàmico com o mMLC.

\subsubsection{ESTABILIDADE DO FATOR DE RENDIMENTO COM O mMLC EM MODO DINÂMICO.}

Os resultados dos testes de estabilidade do fator de rendimento medido a partir de um campo dinâmico padrāo (abertura dinâmica de $1 \mathrm{~cm}$ de largura) em um objeto simulador cilindrico construido em acrilico estão na Figura 41.

A comparação dos resultados apresentados neste teste não pode ser feita com valores descritos na literatura devido à falta de publicaçōes do comportamento do $\mathrm{mMLC}$ modelo $\mathrm{m}_{3}$ da Brainlab em modo dinâmico e pela novidade das técnicas que podem ser tratadas com este equipamento. 
FATOR DE RENDIMENTO COM DMLC - mMLC

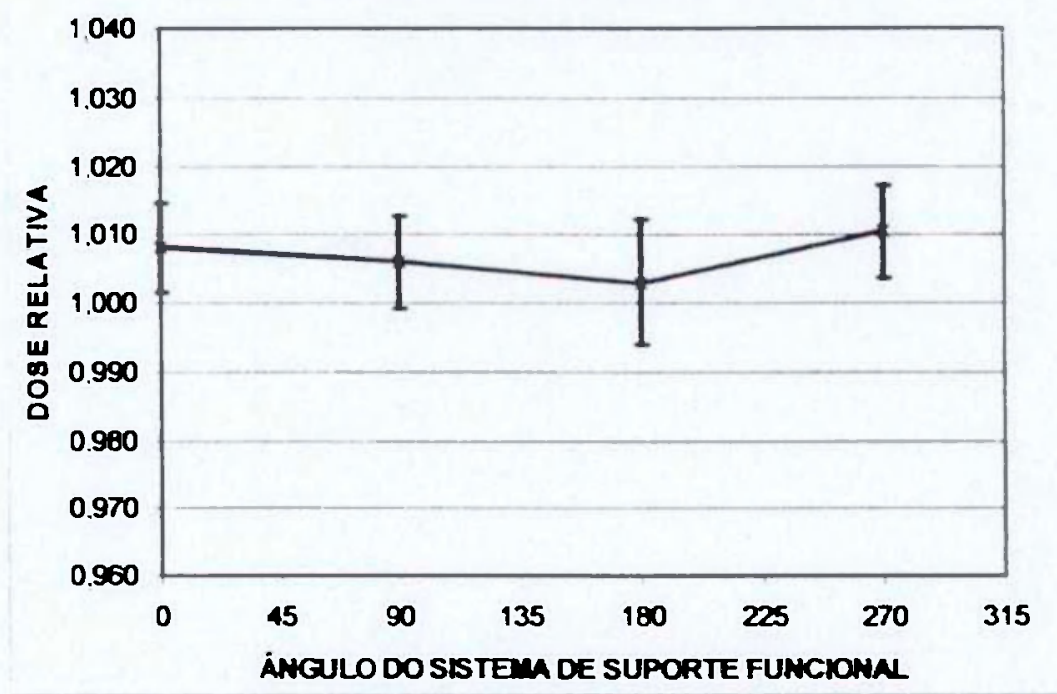

Figura 41. Resultados de mediçōes para verificar a estabilidade do fator de rendimento em modo dinámico do $\mathrm{mMLC}$

O maior desvio com relação ao tratamento com o suporte funcional em $180^{\circ}$ foi de $\pm 1,0 \%$. Este desvio pode representar um efeito da gravidade no movimento das lâminas enquanto elas estão se movimentando para liberar o campo dinâmico de IMRT [15][16][18][35].

\subsubsection{LINEARIDADE COM AS UNIDADES MONITORAS.}

O desvio de cada valor de unidade monitora com sua respectiva dose relativa está dentro da faixa de variação de $\pm 3 \%$. As leituras seguiram o comportamento crescente quando o número de unidades monitoras aumentou, conforme se pode verificar na Figura 42. As barras de erro foram omitidas em virtude que sua magnitude é da ordem de grandeza dos pontos da figura. 


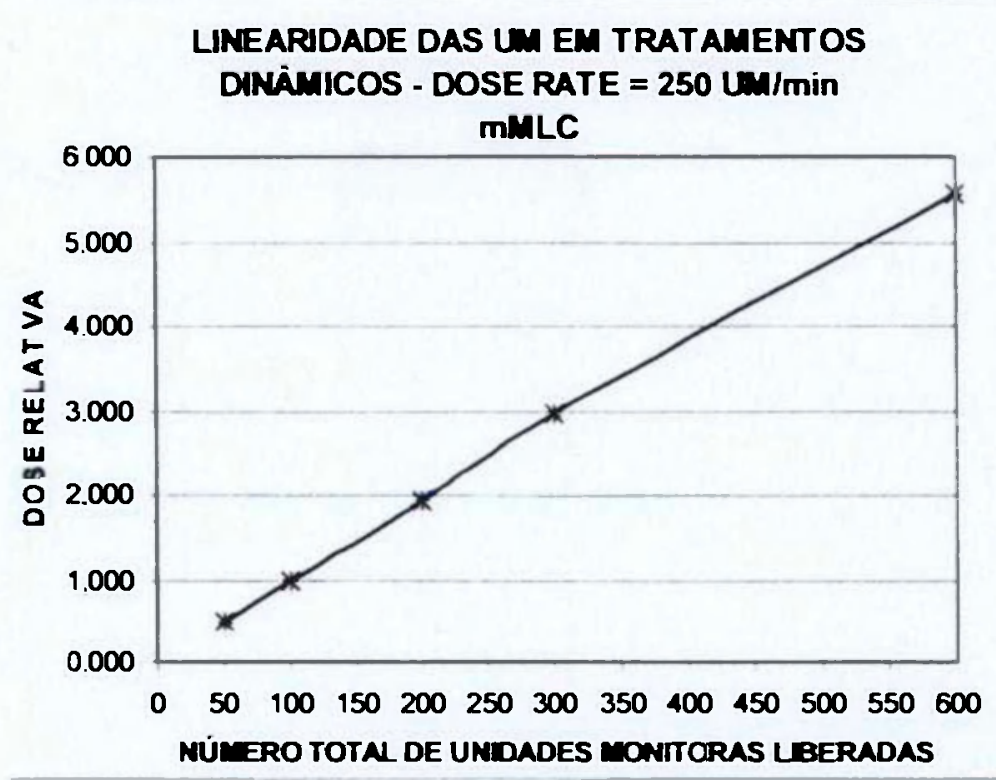

Figura 42. Resuitados dos testes de linearidade das unidades monitoras para um tratamento de IMRT liberado como o mMLC, mantendo constante a taxa de dose.

\subsubsection{LINEARIDADE DE DOSE EM FUNÇÃO DA TAXA DE DOSE.}

Os resultados da Figura $\mathbf{4 3}$ mostram que a dose relativa ou fator de rendimento se manteve constante dentro de $\pm 2 \%$ quando a taxa de dose variou nos tratamentos de IMRT com um número de unidades monitoras fixo [20][36].

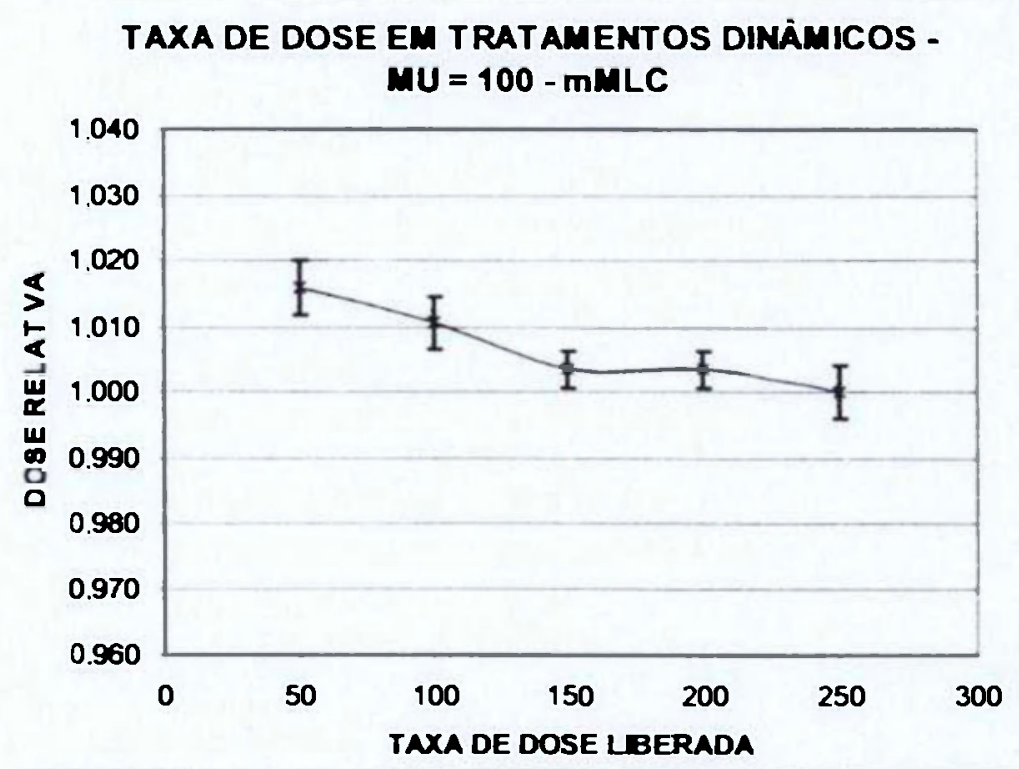

Figura 43. Resultados dos testes da constância da dose em funçāo da taxa de dose para um número fixo de unidades monitoras em um tratamento de IMRT liberado como o mMLC. 
O desvio observado para a menor taxa de dose foi $(1,585 \pm 0,289) \%$; pode ter ocorrido por causa de uma situação de operação extrema dos motores das lâminas. Este comportamento do sistema deve estar bem caracterizado, até mesmo nestas situações.

\subsubsection{AVALIAÇÃO DE FIGURAS PADRÃO.}

Existem testes com figuras padrão que procuram uma análise qualitativa da exatidão na posição das lâminas, propriedades cinéticas do sistema de multi-lâminas e uma avaliação dosimétrica da fração de dose liberada [32].

Todos estes testes foram desenvolvidos irradiando-se filmes e analisando-se os padrões de dose. Estes testes fornecem informação qualitativa da constância no posicionamento das lâminas, na velocidade das lâminas e uma avaliação dosimétrica da fração de dose liberada, como mostrado na Figura 44.

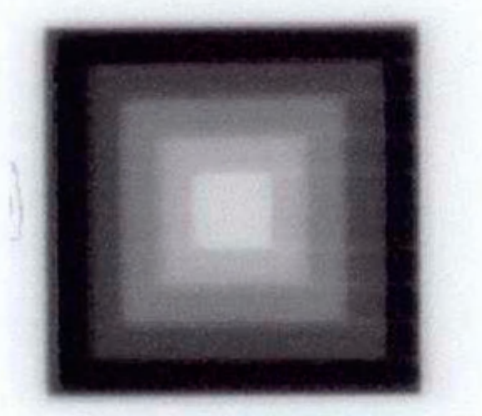

Figura 44. Figura padrāo (PIRAMIDE) que fornece informaçāo qualitativa da posiçāo das İ́minas e do movimento das Iáminas.

Estes testes devem ser realizados em suspeita de funcionamento incorreto para obter a maior quantidade de informação deles e poder concluir com relação a um possivel mau funcionamento $e$, se for preciso, a realização dos procedimentos de manutenção preventiva ou corretiva. Estes testes fazem parte dos procedimentos de aceitação do mMLC.

\subsubsection{TRANSMISSÃO}

\subsection{TRANSMISSÃO COM CÂMARA DE IONIZAÇÃO}

A transmissão média no eixo central do $\mathrm{mMLC} \mathrm{m} 3$ medida com câmara de ionização (Farmer $0,6 \mathrm{~cm}^{3}$ ) foi $(1,291 \pm 0,085) \%$. Este valor encontra-se de 
acordo com os descritos na literatura [28][42] e com as especificações técnicas oferecidas pelo fabricante [43].

Foi determinada a dependência da transmissão com a profundidade, para vários tamanhos de campo. Os resultados obtidos mostram o comportamento esperado: incremento da transmissão em função da profundidade e do tamanho de campo, vide Figura 45 abaixo.

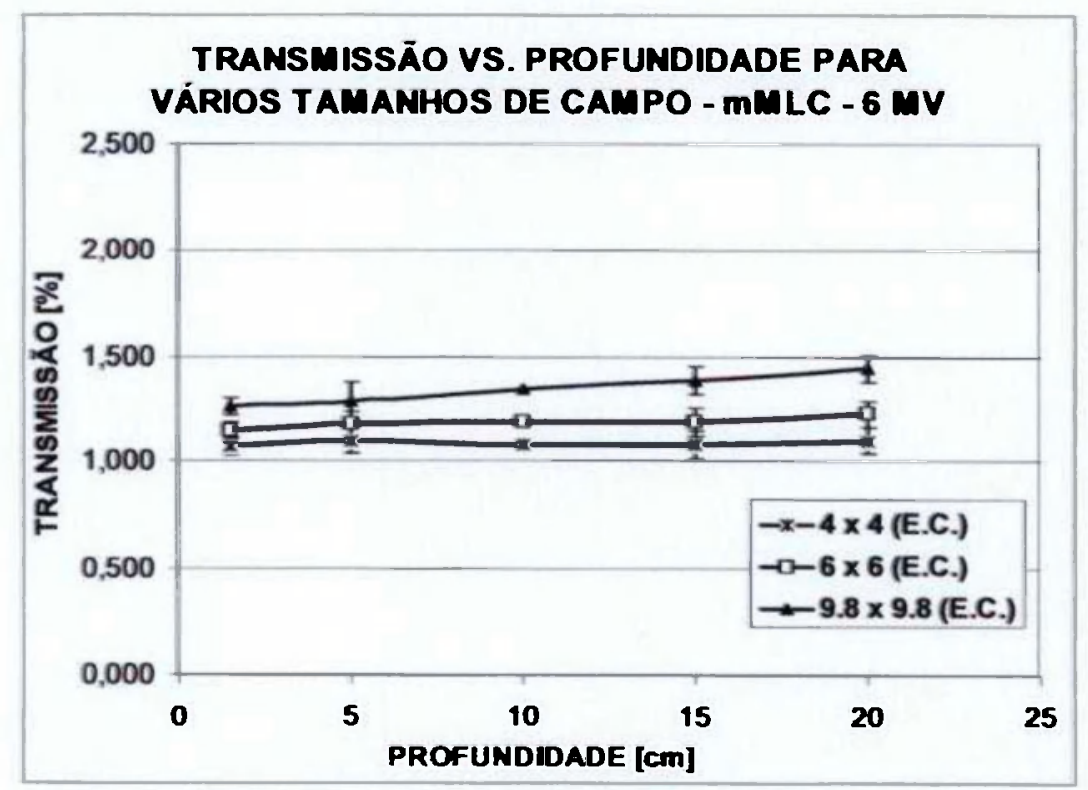

Figura 45. Transmissão em função da profundidade para vários tamanhos de campo definidos pelo mMLC para um feixe de 6 MV.

\subsection{TRANSMISSÃO COM FILME}

$\mathrm{Na}$ Figura 46 encontra-se um exemplo de um filme de verificação dosimétrica testando a transmissão. 
Na Figura 47 pode-se observar que a transmissão varia com a posição, sendo maior quanto mais longe do eixo central. $O$ valor de transmissão máxima no eixo central é $1,62 \%$ (entre lâminas) e o minimo é $1,03 \%$ (intralâminas). A transmissão média obtida com filme é $(1,28 \pm 0,12) \%$, valor que difere em $0,85 \%$ do valor obtido com câmara de ionização $(1,291 \pm 0,085) \%$. Estes resultados são coerentes com os descritos na literatura [28][42].

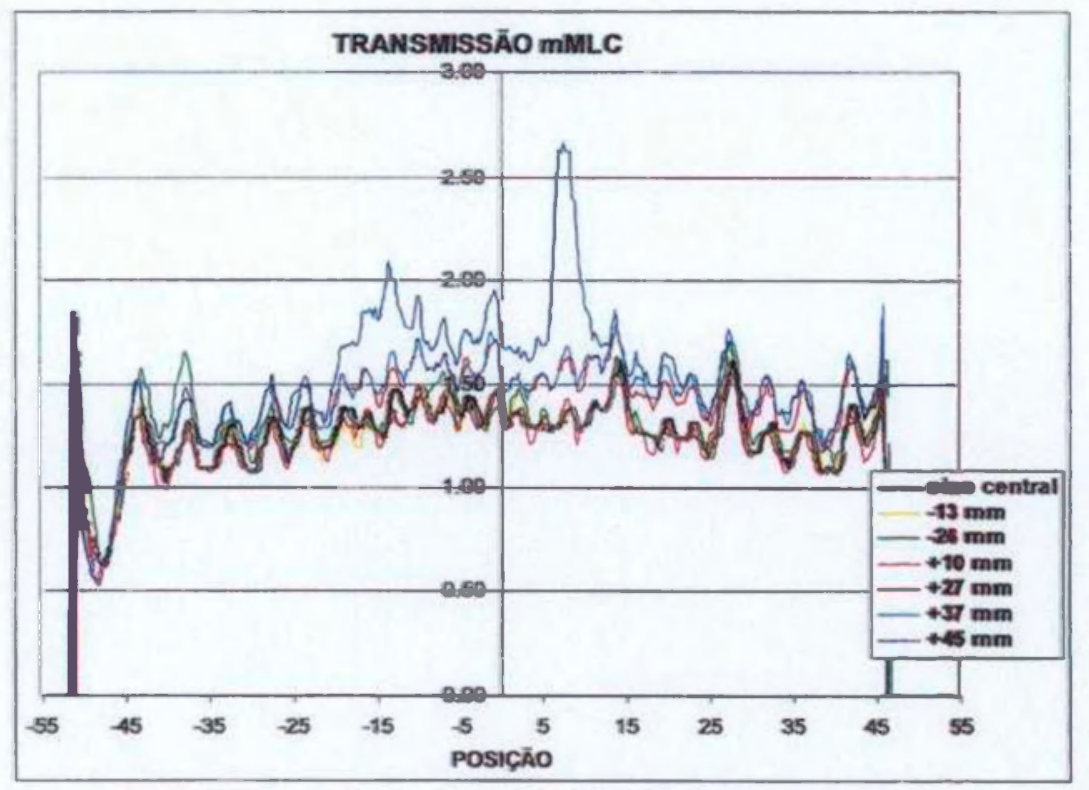

Figura 47. Transmissão entre as láminas e intraláminas obtida através de filme de verificação dosimétrica.

\subsubsection{ESPALHAMENTO DE RADIAÇÃO PRODUZIDO PELO mMLC}

A partir das medições e valores apresentados na Figura 48, foi realizada a respectiva extrapolação e foi determinado o valor de espalhamento produzido pelas lâminas do MLC para a energia do Clinac $600 \mathrm{C}$, para um campo de referência de $9,8 \times 9,8 \mathrm{~cm}^{2}$. 


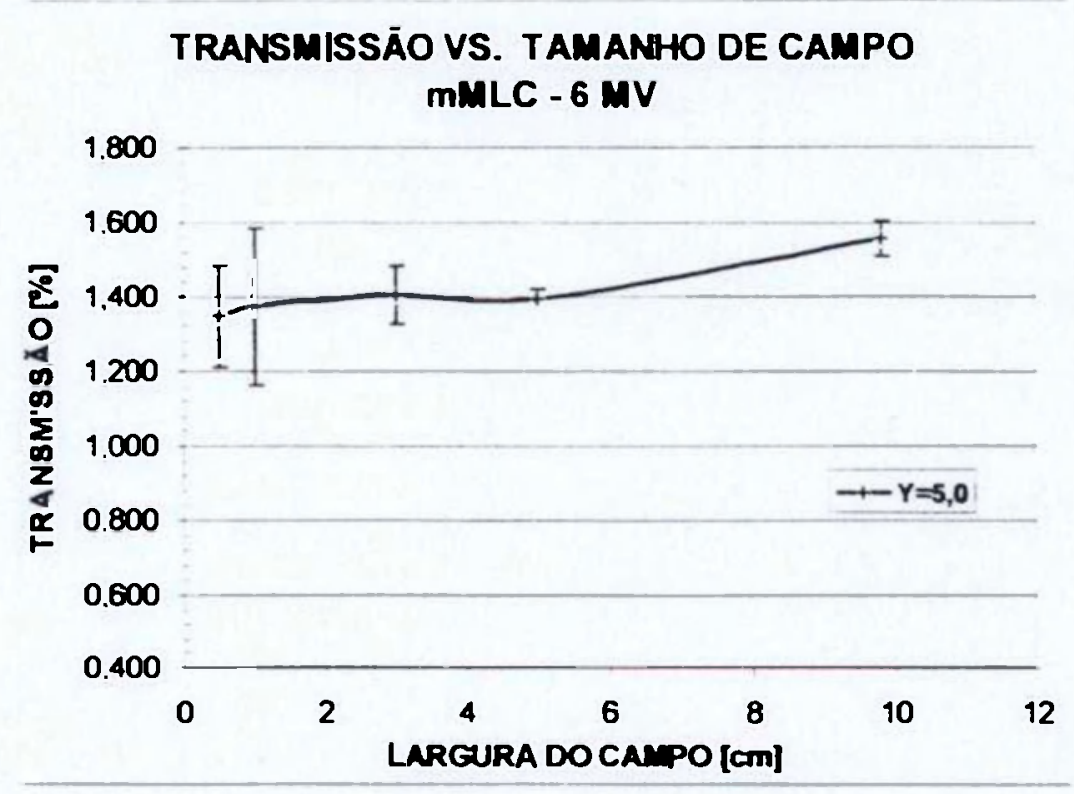

Figura 48. Transmissāo vs. largura do campo para o mMLC em um feixe de $6 M V$.

Os resultados mostrados na Tabela 5 são satisfatórios quando comparados com o trabalho de Arnfield e colaboradores [33], no qual o espalhamento foi calculado para um sistema de colimador multi-lâminas Varian Millenium 120, para a energia de $6 \mathrm{MV}$, sendo reportado o valor de $(0,21 \pm 0,03) \%$, medido através de filmes.

Tabela 5. Resultados do cálculo de espalhamento produzido pelas láminas do mMLC $\mathrm{m}_{3}$, para um campo de $9,8 \times 9,8 \mathrm{~cm}^{2}$.

\begin{tabular}{|c|c|}
\hline \multicolumn{2}{|c|}{ ESPALHAMENTO - $m M L C$} \\
$\left(\%\right.$ DE DOSE DE UM CAMPO ABERTO $\left.9,8 \times 9,8 \mathrm{~cm}^{2}\right)$ \\
\hline $6 \mathrm{MV}$ & $(0,239 \pm 0,052) \%$ \\
\hline
\end{tabular}

$\mathrm{Na}$ literatura não existem registros deste parâmetro para este sistema de MLC; foi seguida a metodologia descrita por Arnfeld e colaboradores [33]. O valor calculado no presente trabalho difere em $13,80 \%$ do valor calculado para o Millenium 120 no trabalho mencionado.

\subsubsection{EFEITO DA BORDA ARREDONDADA E ABERTURA DOSIMÉTRICA ENTRE PARES DE LÂMINAS.}

O valor calculado a partir da Figura 49, da abertura dosimétrica entre as lâminas, para o modo dinâmico. é de $(0,157 \pm 0,070) \mathrm{cm}$. Este valor foi obtido através de mediçōes com a câmara de ionização Scanditronix modelo RK083 com 
volume sensivel de $0,120 \mathrm{~cm}^{3}$. Na literatura, não existe um valor para ser comparado com este parâmetro no mMLC. As barras de erro foram omitidas em virtude que sua magnitude é da ordem de grandeza dos pontos do gráfico.

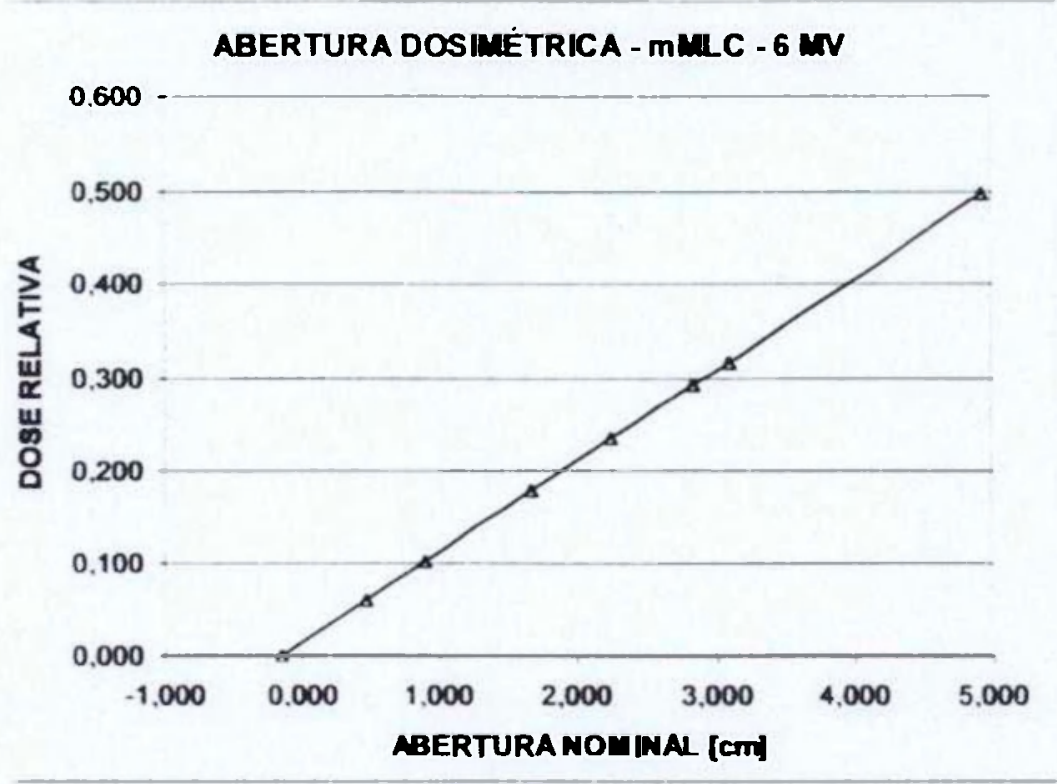

Figura 49. Gráfico da abertura dosimétrica entre pares de lâminas obtida com cámara de ionizaçāo para o $\mathrm{mMLC}$.

\subsubsection{PENUMBRA}

\subsection{PENUMBRA EM FUNÇÃO DO DESLOCAMENTO FORA DO EIXO CENTRAL.}

$\mathrm{Na}$ Figura 50, os valores negativos representam as posições nas quais as lâminas estăo estendidas sobre o eixo. Os valores positivos representam as posições nas quais as lâminas estão retraidas. As barras de erro foram omitidas em virtude que sua magnitude é da ordem de grandeza dos pontos da figura.

Pode-se observar que existe variaçăo da penumbra com a posiçăo das lâminas fora do eixo, aumentando quando a lâmina está estendida sobre o campo de tratamento, não existindo variaçōes significativas quando a lâmina está retraida. Os valores obtidos estão de acordo com o trabalho reportado por Cosgrove e colaboradores [28] para o mMLC m3 de Brainlab 


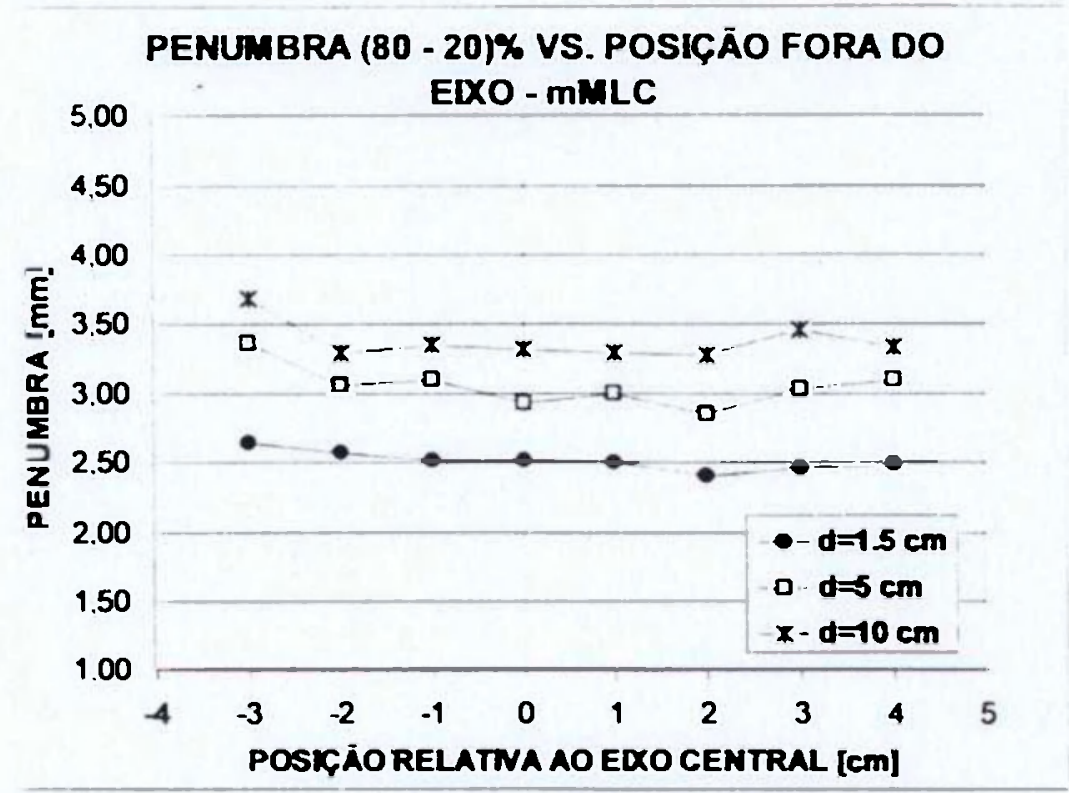

Figura 50. Penumbra (80-20\%) em função da posiçāo das láminas com respeito ao eixo central para o IMLC.

\subsection{PENUMBRA EM FUNÇÃO DO TAMANHO DE CAMPO.}

$\mathrm{Na}$ Figura 51, pode-se observar que a penumbra para campos quadrados não apresentou variações importantes, tanto nos sentidos perpendicular como paralelo ao movimento das lâminas para o mMLC, sendo sempre a penumbra no sentido paralelo ao movimento das lâminas maior do que no sentido perpendicular. Na literatura, Cosgrove e colaboradores [28] relatam que os valores de penumbra não variaram campo com significância estatistica em função do tamanho de campo. Nesse trabalho, o valor médio no sentido perpendicular é $(2,45 \pm 0,10) \mathrm{mm}$; e $(2,6 \pm 0,1) \mathrm{mm}$ no sentido paralelo ao movimento das lâminas. 


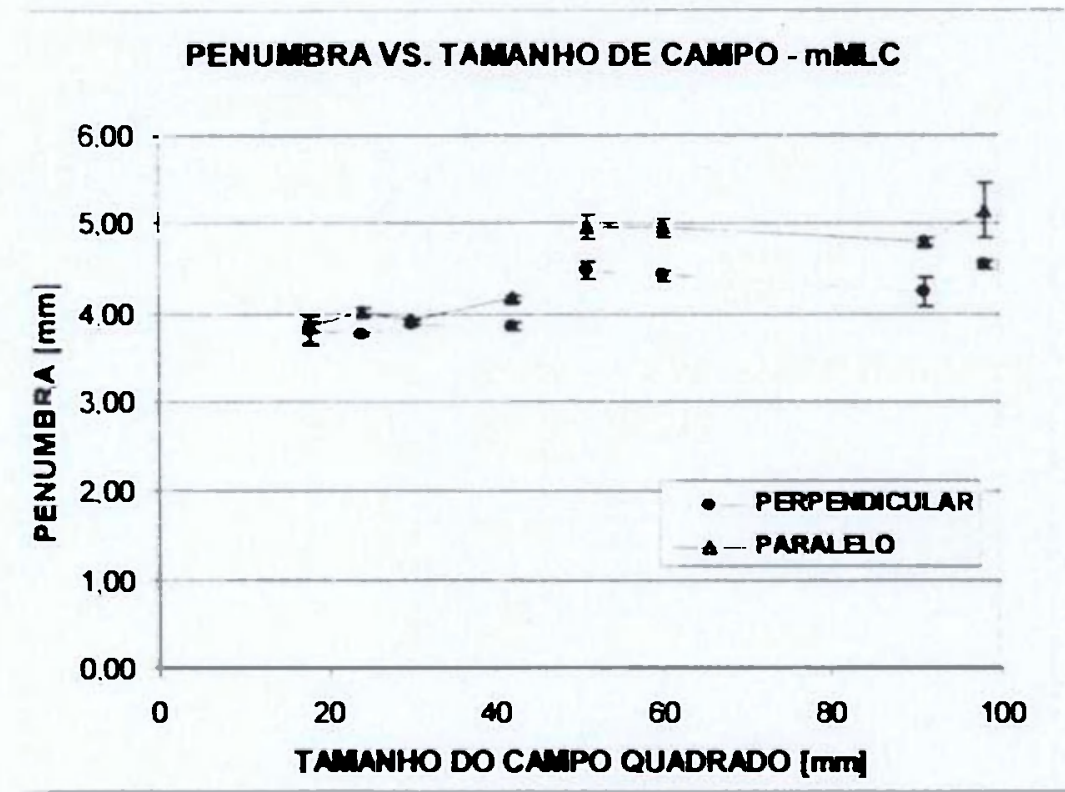

Figura 51. Gráfico da penumbra vs. Tamanho de campo para campos definidos pelo mMLC em sentido paralelo e perpendicular ao movimento das láminas.

\subsection{PENUMBRA EM FUNÇÃO DA PROFUNDIDADE.}

O valor médio da penumbra varia com a profundidade, crescendo à medida que a profundidade aumenta; como pode ser observado na Figura 52.

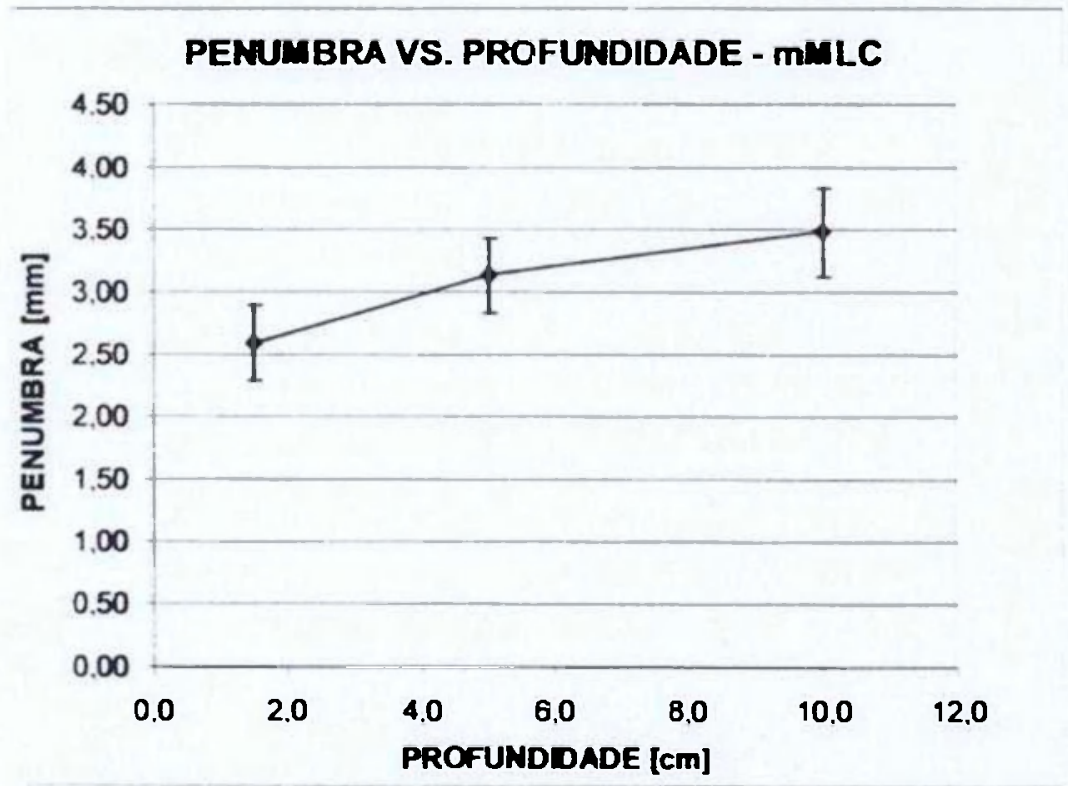

Figura 52. Variaçāo da penumbra em funçāo da profundidade para campos de referència $10 \times 10 \mathrm{~cm}^{2}$ definidos pelas lâminas do mMLC.

Esta tendência e os resultados obtidos são comparáveis aos descritos na literatura [28]. Yin e colaboradores [44] no seu trabalho acharam a mesma 
tendência crescente da penumbra quando a profundidade também aumentou, e valores que concordam com os obtidos neste estudo.

\subsection{PENUMBRA EM FUNÇĀO DO ÂNGULO COM AS BORDAS.}

A penumbra não apresenta variaçōes significativas com o ângulo formado pelas lâminas com relação ao seu eixo de movimento. Os valores obtidos estão apresentados na Tabela 6 . No trabalho de Cosgrove e colaboradores [28], obtiveram valores de $2,8 \mathrm{~mm}$ para a angulação de $10^{\circ}$ e de $5,0 \mathrm{~mm}$ para $70^{\circ}$. Para o ângulo de $45^{\circ}$, que é um parâmetro e comparação nos diferentes sistemas de MLCs, no trabalho mencionado os autores obtiveram um valor máximos de 5,0 mm e minimo de $3,75 \mathrm{~mm}$, que estão em concordância com o valor obtido para o mMLC de $4,56 \mathrm{~mm}$.

Tabela 6. Resultados da dependência da penumbra em função do ângulo que formam as lāminas com seu eixo de movimento.

\begin{tabular}{|c|c|c|c|c|c|c|c|}
\hline ÂNGULO & 70 & 60 & 50 & 45 & 40 & 30 & 10 \\
\hline PENUMBRA [mm] & 4,67 & 4,54 & 4,60 & 4,56 & 4,44 & 4,46 & 3,74 \\
\hline DESVIO & 2,16 & 2,13 & 2,14 & 2,14 & 2,11 & 2,11 & 1,93 \\
\hline
\end{tabular}

Outros trabalhos [45] realizados com outros modelos de sistemas de mMLC (Moduleaf MLC, MRC Systems GmbH, Heidelberg, Germany) cujas lâminas tem $2.5 \mathrm{~mm}$ de largura, relataram um valor próximo a $3,5 \mathrm{~mm}$ para o ângulo de $45^{\circ}$.

\subsubsection{ANÁLISE DOS ARQUIVOS “DYNALOG".}

A análise dos arquivos "dynalog" é realizada da mesma maneira que foi detalhada na secção 3.1.2.10 do presente trabalho para o MLC Millenium 120. 


\subsection{COLIMADOR MULTI-LÂMINAS VARIAN MODELO MARK II.}

\subsubsection{TESTES DOSIMÉTRICOS}

\subsubsection{TRANSMISSĀO}

\subsection{TRANSMISSĀO COM CÂMARA DE IONIZAÇĀO}

Foi medida a dependência da transmissão com o tamanho de campo em várias profundidades para as duas energias disponiveis com este sistema de MLC (6 e $18 \mathrm{MV}$ ), em vários tamanhos de campo no eixo central (E.C.). Os resultados são mostrados nas Figuras 53 e 54.

Para o campo $10 \times 10 \mathrm{~cm}^{2}$, na profundidade de $5 \mathrm{~cm}$, para o MLC Mark II, o valor obtido para $6 \mathrm{MV}$ obtido foi $(1,638 \pm 0,001) \%$ e de $(1,668 \pm$ $0,036) \%$ para $18 \mathrm{MV}$.

A transmissão aumenta com o tamanho de campo pelo incremento do espalhamento produzido pelo MLC, já que os colimadores secundários estão em uma posição fixa. A tendência de a transmissão aumentar para $6 \mathrm{MV}$ é causada pelo endurecimento do feixe. No feixe de $18 \mathrm{MV}$ este efeito não é visivel pela produção de pares nessa faixa de energia.

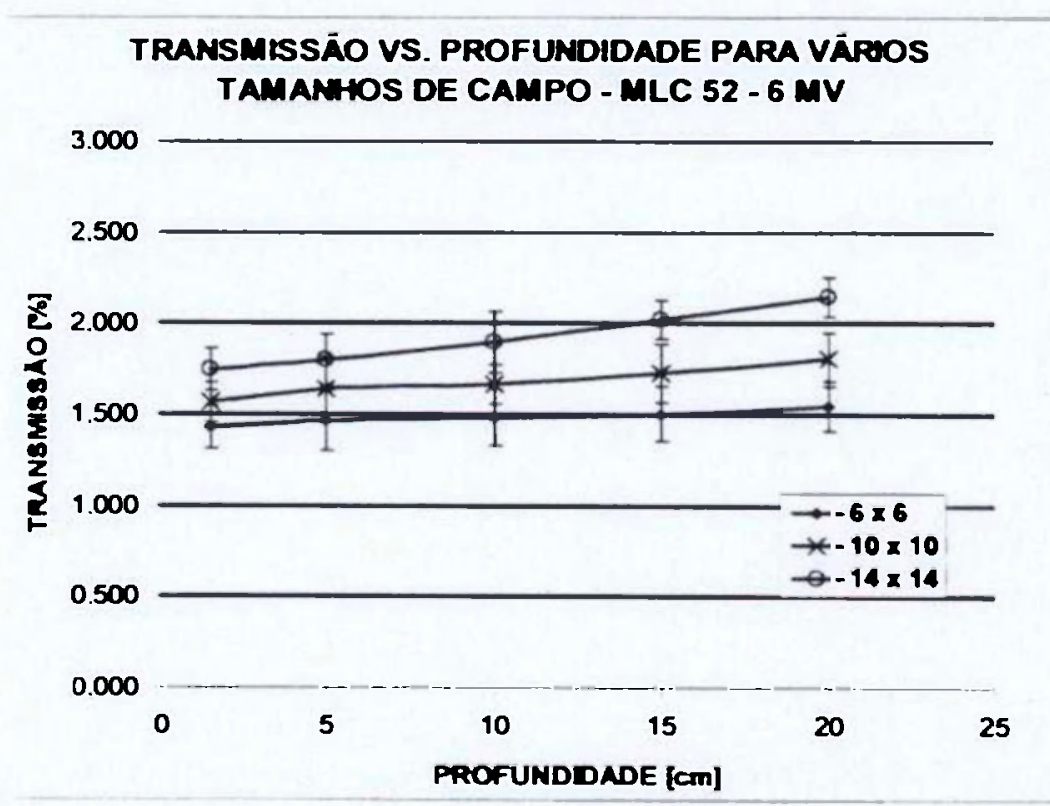

Figura 53. Transmissão do MLC 52 em funçāo da profundidade para varios tamanhos de campo para um feixe de $6 \mathrm{MV}$. 


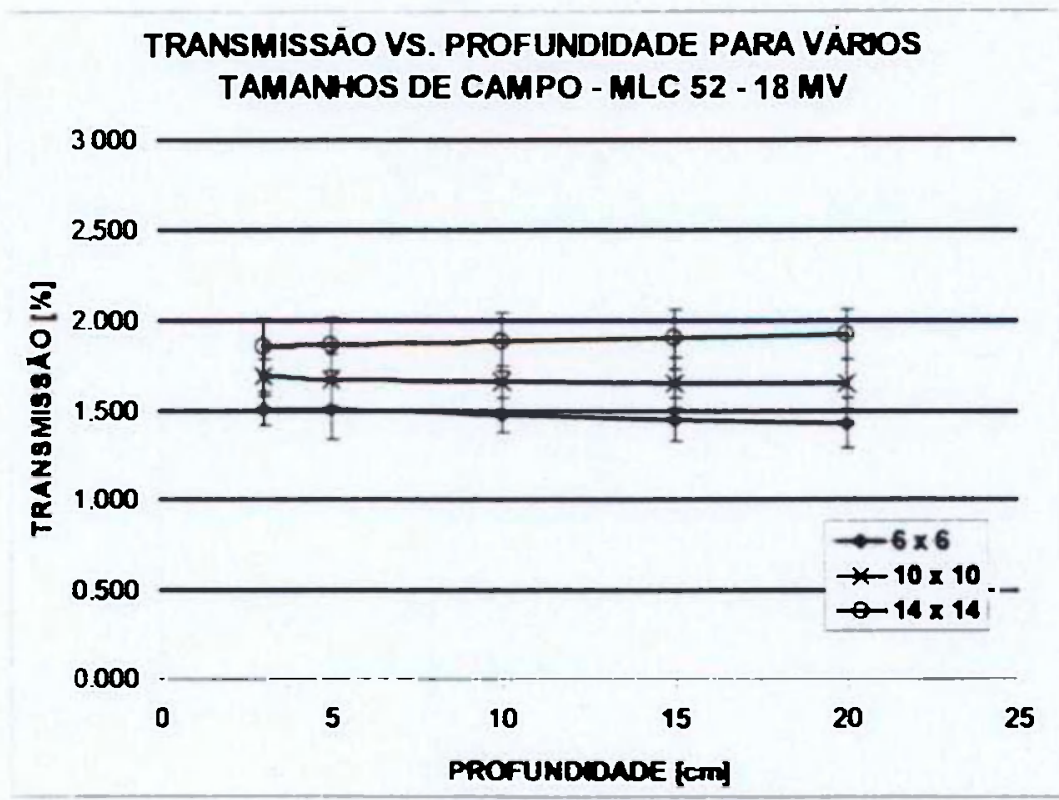

Figura 54. Transmissảo do MLC 52 em funçảo da profundidade para vários tamanhos de campo para um feixe de $18 \mathrm{MV}$.

Na publicação de Van Esch e colaboradores [17] está descrito o valor de 1,8\% para um MLC Mark II para ser inserido no sistema de planejamento, para feixes de 6 e $20 \mathrm{MV}$. Essers e colaboradores [14] descrevem um valor médio de transmissão de 1,6\% para um MLC - Mark II em feixes de 6 e 18MV. LoSasso e colaboradores [15] obtiveram valores com câmara de ionização a $5 \mathrm{~cm}$ de profundidade de $1,85 \%$ para $6 \mathrm{MV}$ e $2,10 \%$ para $15 \mathrm{MV}$.

\subsection{TRANSMISSÃO COM FILME}

A partir da análise das medições realizadas com filme (Figuras 55 e 56) para os feixes de $6 \mathrm{MV}$ e de $18 \mathrm{MV}$. foram obtidos os resultados apresentados na Tabela 7.

Tabela 7. Resultados da transmissäo medida com filme, analisados no eixo central para o MLC 52.

\begin{tabular}{|c|c|c|}
\hline TRANSMISSAO [\%] & $6 \mathrm{MV}$ & $18 \mathrm{MV}$ \\
\hline MEDIA & 1,375 & 1,428 \\
\hline DESVIO PADRAOO & 0,222 & 0,284 \\
\hline ENTRE LÁMINAS & 1,944 & 2,173 \\
\hline INTRALAMINAS & 1,103 & 1,091 \\
\hline
\end{tabular}

$\mathrm{Na}$ literatura, LoSasso e colaboradores [15] citam o valor de transmissão média entre as lâminas do MLC Mark \| de 1,7\%. Em outro trabalho. 
LoSasso [35] mostra um padrão de transmissão entre as lâminas e intralâminas que varia entre 1,7 e 2,9\% para o MLC Mark II. Huq e colaboradores [38] mostram também um padrão de transmissăo entre as lâminas e intralâminas entre 1,3 e $2,0 \%$. No trabalho de Galvin e colaboradores [40] o padrão apresentado está entre 1,5 e $2,2 \%$.

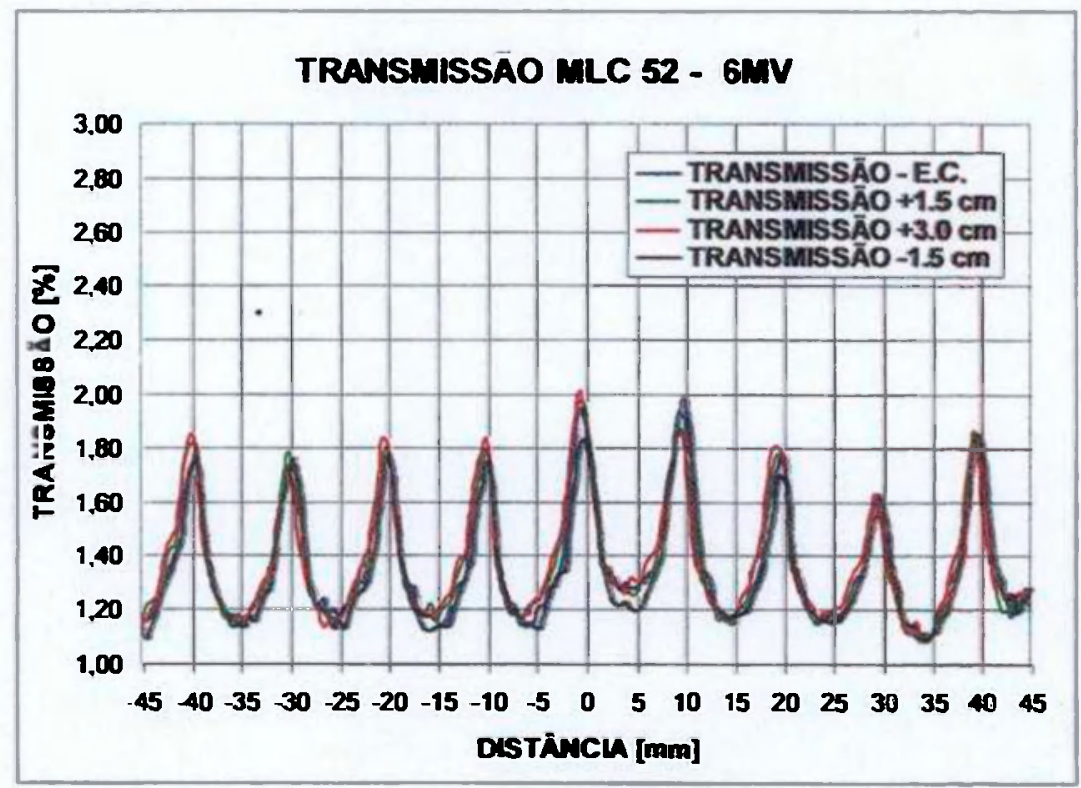

Figura 55. Transmissão entre as láminas e intraláminas para a energia de 6 MV no MLC Mark II de 52 lâminas.

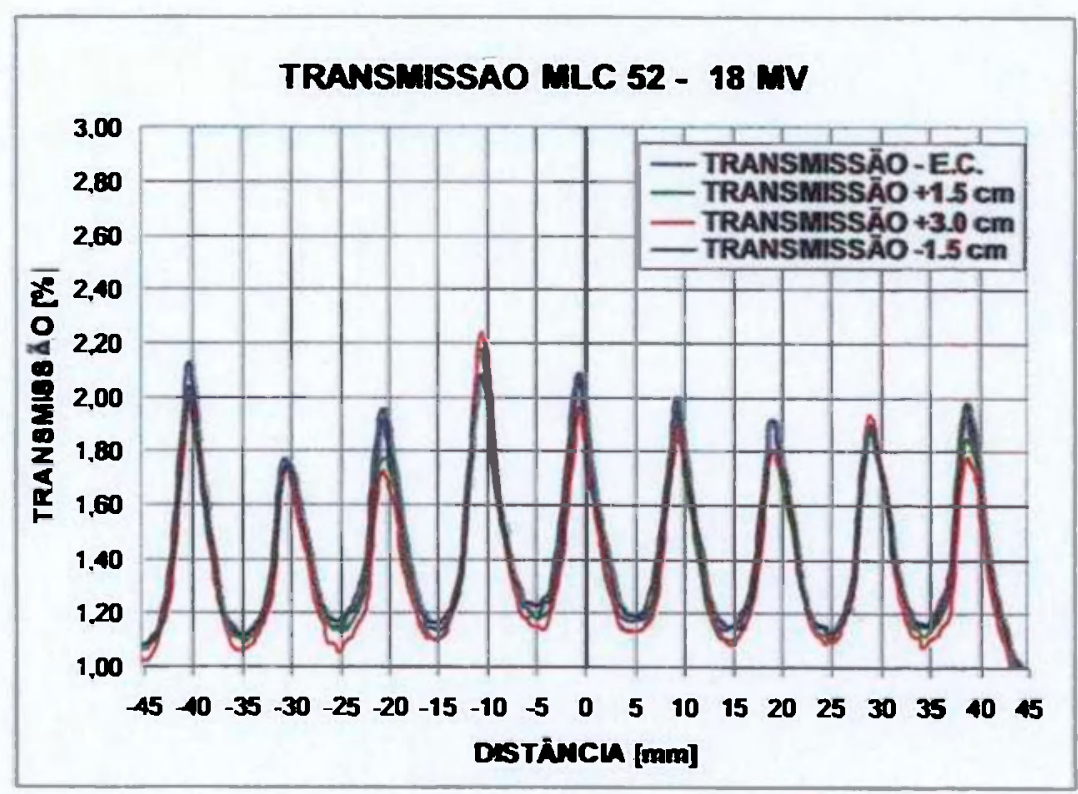

Figura 56. Transmissão entre as láminas e intraláminas para a energia de 18 MV no MLC Mark II de 52 Iáminas. 


\subsubsection{ESPALHAMENTO PRODUZIDO PELO MLC 52 - MARK II}

Foram realizadas as mediçōes de transmissão para diferentes tamanhos de campo, mantendo fixo o comprimento do campo $(\mathrm{Y})$; os resultados obtidos para 6 e $18 \mathrm{MV}$ estão apresentados na Figura 57.

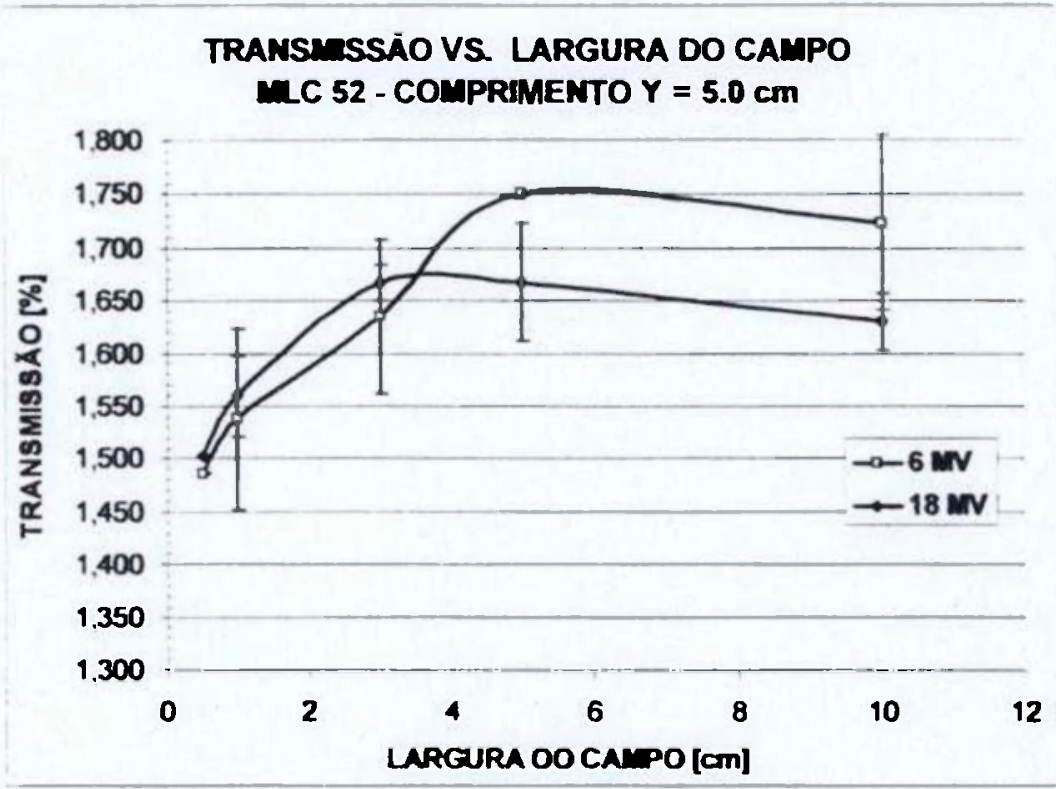

Figura 57. Transmissão vs. largura do campo para o MLC Mark II em feixes de 6 e 18 MV.

A partir das medições e valores apresentados, foram realizadas as respectivas extrapolações e foi determinado o valor de espalhamento produzido pelas lâminas do MLC para ambas energias (6 e $18 \mathrm{MV}$ ), para um campo padrão de $10 \times 10 \mathrm{~cm}^{2}$, obtendo-se os valores da Tabela 8 .

Tabela 8. Resultados do cálculo de espalhamento produzido pelas làminas do MLC 52, para um campo de $10 \times 10 \mathrm{~cm}^{2}$.

\begin{tabular}{|c|c|}
\hline & $\begin{array}{c}\text { ESPALHAMENTO - MLC } 52 \\
\text { (\% DE DOSE DE UM CAMPO ABERTO } 10 \times 10 \mathrm{~cm} 2)\end{array}$ \\
\hline $18 \mathrm{MV}$ & $(0,221 \pm 0,035) \%$ \\
\hline $6 \mathrm{MV}$ & $(0,202 \pm 0,028) \%$ \\
\hline
\end{tabular}

O resultado obtido no presente trabalho para $6 \mathrm{MV}$, apresenta um desvio de $1 \%$, quando comparados com o trabalho de Arnfield e colaboradores [33], no qual o espalhamento foi calculado para um sistema de MLC Varian com lâminas de $1 \mathrm{~cm}$ de largura, medido através de filmes. Os mesmos autores 
calcularam o espalhamento para o mencionado sistema de MLC, através de simulaçāo de Monte Cario, obtendo um valor de $(0,185 \pm 0,002) \%$

\subsubsection{EFEITO DA BORDA ARREDONDADA E ABERTURA DOSIMETRICA ENTRE PARES DE LÂMINAS.}

A partir dos dados da Figura 58, o valor obtido da abertura dosimétrica entre as làminas, através de medições com filme de verificação dosimétrica, como descrito por LoSasso e colaboradores [15], é de $(0,189 \pm 0,081) \mathrm{cm}$. O valor recomendado pelo fabricante è $0,2 \mathrm{~cm}$.

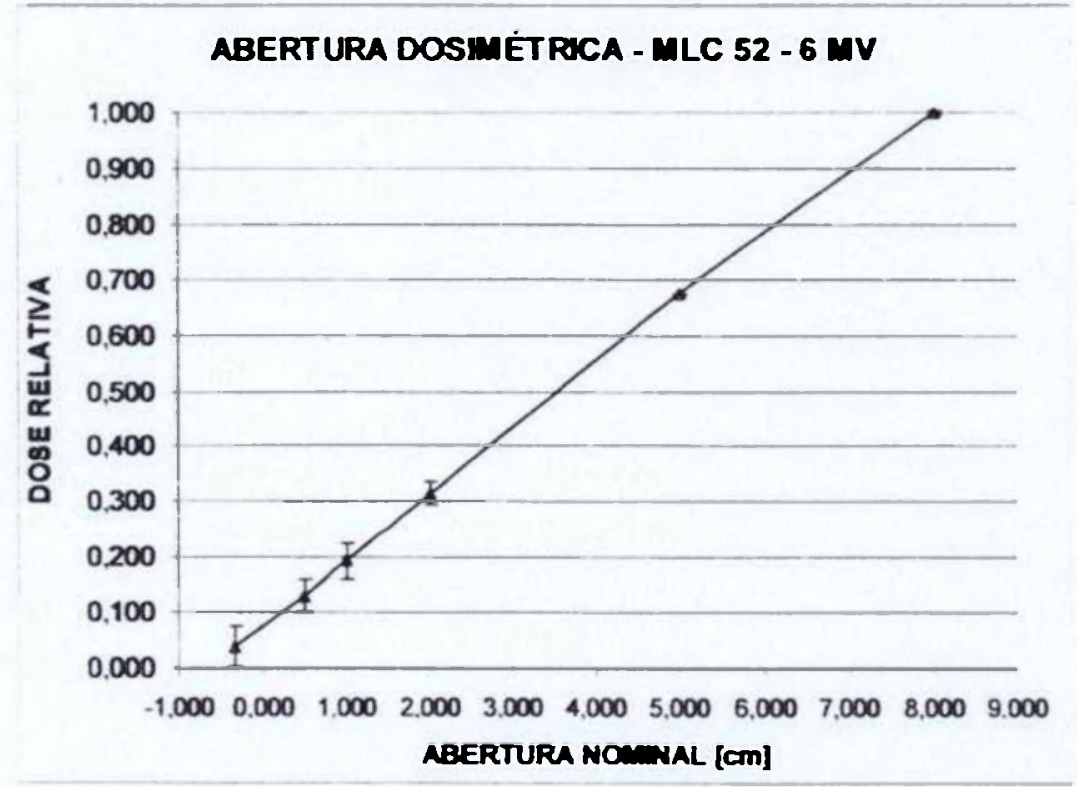

Figura 58. Gráfico da abertura dosimètrica entre pares de lâminas obtida com câmara de ionizaçāo para o MLC 52.

$\mathrm{Na}$ literatura LoSasso e colaboradores [15] acharam um valor de $(0,2 \pm 0,1) \mathrm{cm}$ para $15 \mathrm{MV}$ e de $(1,7 \pm 0,1) \mathrm{mm}$ para $6 \mathrm{MV}$. Van Esch e colaboradores [17] relataram um valor de $2.6 \mathrm{~mm}$ em um sistema Mark II de 52 làminas. No trabalho de LoSasso [35], para a energia de $6 \mathrm{MV}$ o valor citado è $1,80 \mathrm{~mm}$.

Os valores obtidos no modo estático no presente trabalho apresentam boa concordância com os citados na literatura. 


\subsubsection{PENUMBRA}

\subsection{PENUMBRA EM FUNÇĀO DO DESLOCAMENTO FORA DO EIXO CENTRAL.}

$\mathrm{Na}$ Figura 59 , os valores negativos representam as posiçōes nas quais as lâminas estão estendidas sobre o eixo. Os valores positivos representam as posiçōes nas quais as lâminas estão retraídas. As barras de erro foram omitidas em virtude que sua magnitude é da ordem de grandeza dos pontos da figura.

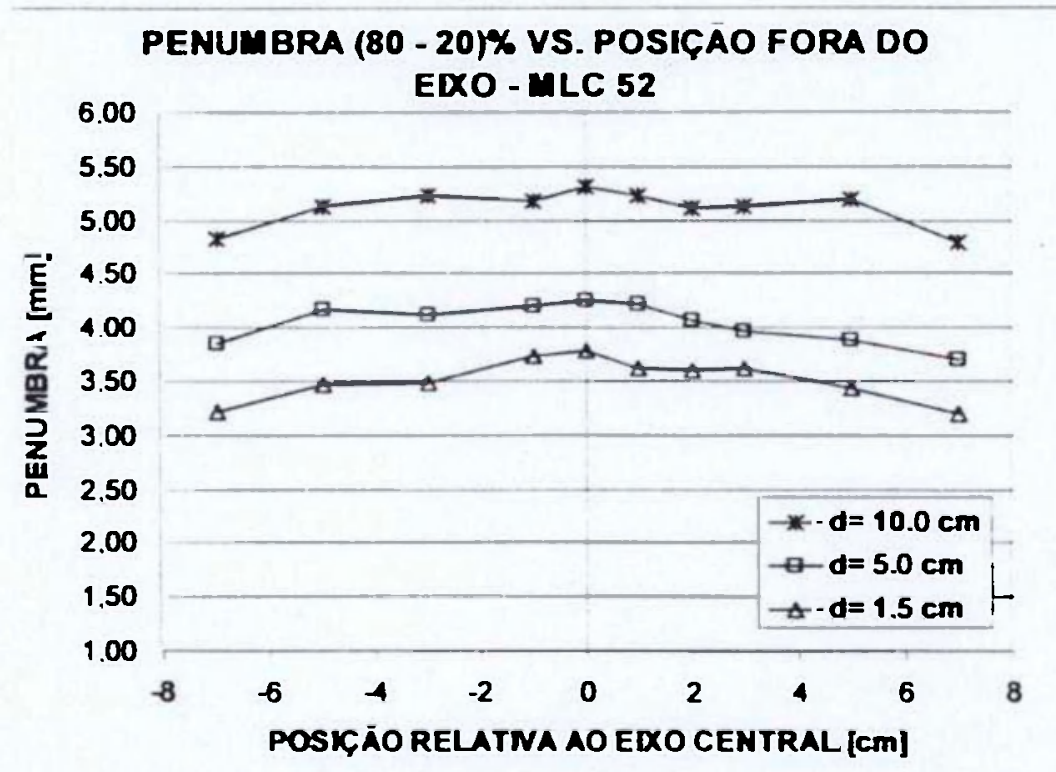

Figura 59. Penumbra (80-20\%) em função da posição das lâminas com respeito ao eixo central para o MLC Mark II.

Tanto para as lâminas estendidas sobre o eixo central como para as lâminas retraidas, o valor da penumbra não ultrapassou $5,5 \mathrm{~mm}$. No trabalho de Huq e colaboradores [38], os resultados para um MLC Varian mostram um comportamento similar ao obtido neste trabalho, onde o valor de penumbra no eixo central é mais alto do que em posiçōes mais extremas; isto pode ser explicado pelo fato das bordas estarem projetadas para minimizar a divergência do feixe. No presente trabalho, as diferenças entre a penumbra no eixo central e a penumbra a $5 \mathrm{~cm}$ o eixo central, são $9,55 \%$ na profundidade de $1,5 \mathrm{~cm} ; 6,04 \%$ a 5 $\mathrm{cm}$ de profundidade e, $2.82 \%$ na profundidade de $10 \mathrm{~cm}$.

No trabalho de Galvin e colaboradores [40], os valores de penumbra tanto para as lâminas retraidas como estendidas não apresentaram variações significativas. Mostrou-se também um valor máximo no eixo central. Para a 
energia de $6 \mathrm{MV}$, na qual foi realizado este teste no presente trabalho, na profundidade de $1,5 \mathrm{~cm}$ os valores citados por Galvin e colaboradores [40] são menores de $5 \mathrm{~mm}$; na profundidade de $10 \mathrm{~cm}$ os valores de penumbra são apenas mais altos dos $5 \mathrm{~mm}$.

Esta situação se repete também no trabalho de Boyer e colaboradores [39], nas mesmas profundidades.

\subsection{PENUMBRA EM FUNÇÃO DO TAMANHO DE CAMPO.}

Os resultados de penumbra em função do tamanho de campo definido pelo MLC a $5 \mathrm{~cm}$ de profundidade estão apresentados na Figura 60.

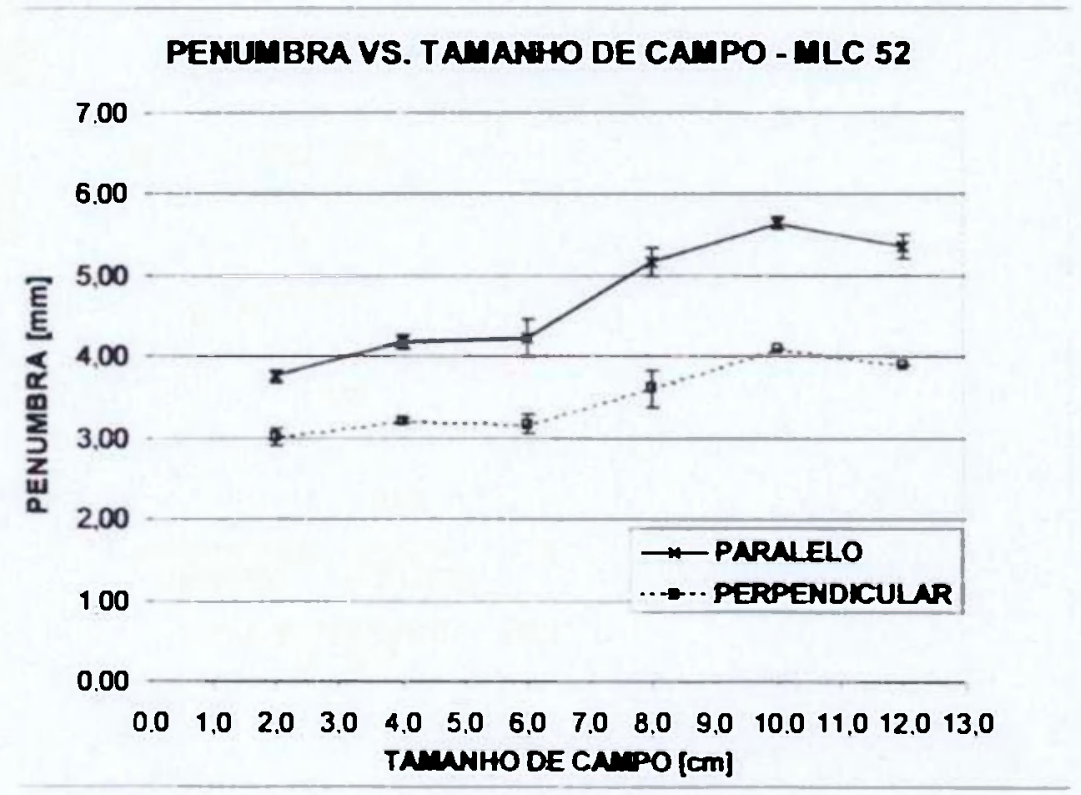

Figura 60. Gráfico da penumbra vs. tamanho de campo para campos definidos pelo MLC Mark II em sentidos paralelo e perpendicular ao movimento das lâminas.

A penumbra incrementou-se à medida que o tamanho de campo aumenta. sendo sempre maior o valor no sentido paralelo ao movimento das lâminas (borda arredondada) do que no sentido perpendicular (lado da lâmina).

\subsection{PENUMBRA EM FUNÇÃO DA PROFUNDIDADE.}

Os resultados obtidos estão apresentados na Figura 61 e foram comparados na Tabela 9 com os descritos na literatura por Boyer e colaboradores [39] para 1.5 e $10 \mathrm{~cm}$ de profundidade, mostrando excelente concordância. 


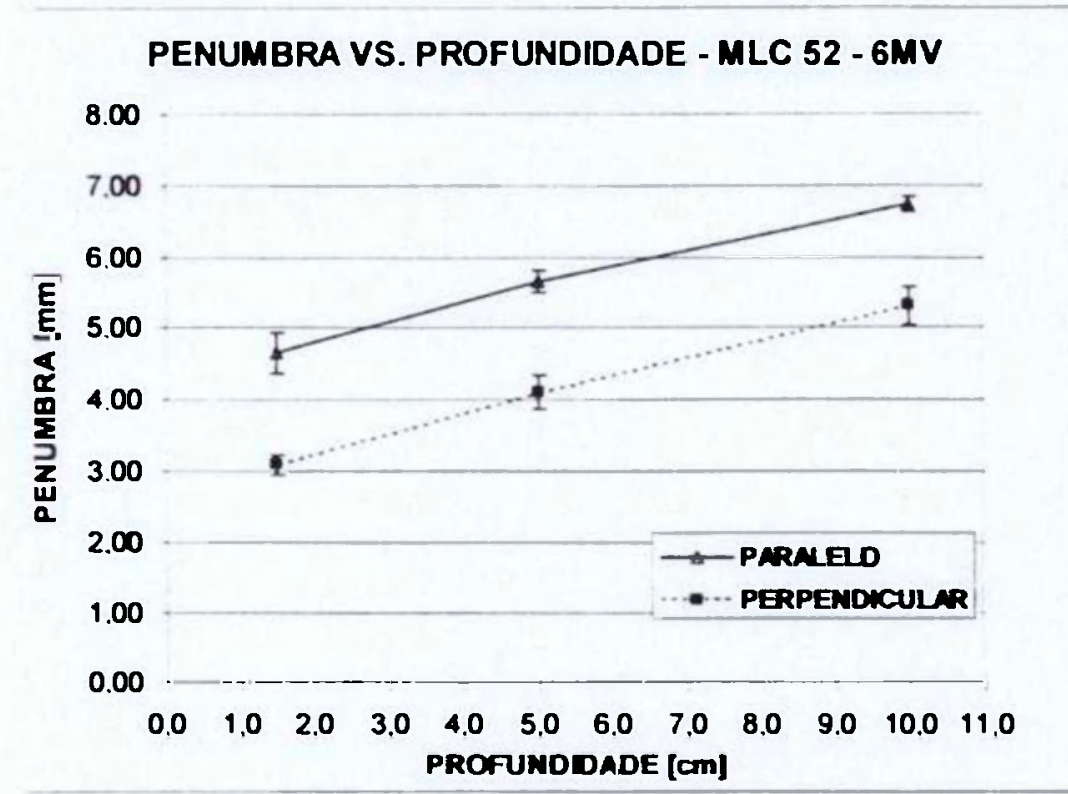

Figura 61. Variaçāo da penumbra em funçāo da profundidade para campos de referência $10 \times 10 \mathrm{~cm}^{2}$ definidos pelas lâminas do MLC Mark II.

Tabela 9. Resultados obtidos da penumbra em funçāo da profundidade comparados com os descritos na literatura.

\begin{tabular}{|c|c|c|c|c|}
\cline { 2 - 5 } \multicolumn{1}{c|}{} & \multicolumn{2}{c|}{ SENTIDO PARALELO } & \multicolumn{2}{c|}{ SENTIDO PERPENDICULAR } \\
\hline $\begin{array}{c}\text { PROFUNDIDADE } \\
\text { [cm] }\end{array}$ & $\begin{array}{c}\text { PENUMBRA 80-20\% } \\
\text { em mm }\end{array}$ & $\begin{array}{c}\text { Boyer e } \\
\text { colaboradores } \\
{[39] \mathrm{em} \mathrm{mm}}\end{array}$ & $\begin{array}{c}\text { PENUMBRA 80-20\% } \\
\text { em mm }\end{array}$ & $\begin{array}{c}\text { Boyer e } \\
\text { colaboradores } \\
{[39] \text { em mm }}\end{array}$ \\
\hline 1,5 & $4,65 \pm 0,28$ & 4,0 & $3,09 \pm 0,15$ & 3,00 \\
\hline 10,0 & $6,74 \pm 0,10$ & 6,8 & $5,31 \pm 0,27$ & 5,40 \\
\hline
\end{tabular}

$\mathrm{Na}$ análise feita no trabalho de Galvin e colaboradores [40] foi considerada a dependência com a profundidade encontrada neste trabalho, aumentando a penumbra quando a profundidade também aumenta.

\subsection{PENUMBRA EM FUNÇÃO DO ÂNGULO COM AS BORDAS.}

Os resultados obtidos a partir dos filmes irradiados na profundidade de $1,5 \mathrm{~cm}$ (6 MV) mostrados na Tabela 10, apresentam concordância com o citado por Huq e colaboradores [38], no qual foi feito este teste somente para o ângulo de $45^{\circ}$ e o valor citado foi de $6 \mathrm{~mm}$ e na mesma profundidade. No trabalho publicado por Galvin e colaboradores [40], este teste foi realizado à profundidade de $10 \mathrm{~cm}$ e para ângulos de $45^{\circ}$ e $15^{\circ}$, obtendo penumbras de 8 e $10 \mathrm{~mm}$ 
respectivamente. Os sistemas citados, nesta comparaçāo, possuem $1 \mathrm{~cm}$ de largura projetada no isocentro.

Tabela 10. Resultados da dependēncia da penumbra em função do ângulo que formam as lâminas do MLC Mark II com seu eixo de movimento.

\begin{tabular}{|c|c|c|c|c|c|c|}
\hline ÂNGULO & 10 & 15 & $\mathbf{3 0}$ & $\mathbf{4 5}$ & $\mathbf{6 0}$ & $\mathbf{7 5}$ \\
\hline PENUMBRA [mm] & $\mathbf{5 , 0 8}$ & $\mathbf{5 , 2 1}$ & $\mathbf{5 , 3 1}$ & $\mathbf{5 , 3 9}$ & $\mathbf{5 , 4 2}$ & $\mathbf{5 , 5 2}$ \\
\hline DESVIO & $\mathbf{0 , 4 2}$ & $\mathbf{0 , 6 1}$ & $\mathbf{0 , 4 9}$ & $\mathbf{0 , 2 7}$ & $\mathbf{0 , 8 3}$ & $\mathbf{0 , 8 3}$ \\
\hline
\end{tabular}




\section{INTERCOMPARAÇÃO}

No capitulo 3 foram descritos os resultados dos diversos testes para cada um dos três sistemas de colimador multi-lâminas que possui o Serviço de Radioterapia do Hospital Israelita Albert Einstein:

- O MLC marca Varian modelo Millenium de 120 lâminas, que permite a liberação do feixe para técnicas convencionais, para Radioterapia Conformada, Arco dinâmico, e Radioterapia de Intensidade Modulada (IMRT) em modo dinâmico e estático.

- O micro colimador multi-lâminas, mMLC marca Brainlab, modelo m3, que permite a liberação do feixe para Radioterapia Conformada, Arco dinâmico, e Radioterapia de Intensidade Modulada (IMRT) em modo dinâmico e estático e Radiocirurgia Estereotáxica tanto de dose única como fracionada.

- O colimador multi-lâminas marca Varian, modelo Mark II de 52 lâminas, que permite a liberação de feixe para técnicas convencionais e Radioterapia Conformada.

Os testes que visaram avaliar as condiçōes de liberaçăo do feixe no modo dinâmico foram feitos com o MLC 120 e com o mMLC e os testes dirigidos a analisar as caracteristicas aplicáveis às técnicas conformadas estáticas foram feitos com os três sistemas.

$\mathrm{Na}$ literatura existe informação do comissionamento de cada um dos sistemas estudados por separado [14][15][18][22][27][28][39][40][42][44][45]]. Existem publicações que comparam sistemas de MLC de diferentes fabricantes e com diferentes projetos desde o ponto de vista dos dados dosimétricos que são levantados para sua implementação clínica [38]. Mas são poucos os trabalhos que comparam vários sistemas visando a implementação clínica de IMRT [17].

A intercomparação realizada neste trabalho abrange tanto testes mecânicos, como dados dosimétricos para uso clinico (perfis, fatores de rendimento) e testes dosimétricos. 


\subsection{TESTES MECÂNICOS}

\subsubsection{POSICIONAMENTO DAS LÂMINAS}

Nas seções que descrevem o teste de POSIÇĀO DAS LÂMINAS NO ISOCENTRO (3.1.1.1 e 3.2.1.2), estão as familias de curvas levantadas para quantificar os erros em abertura de janela deslizante nominais, tanto para o MLC Millenium 120 como para o mMLC. Nos três casos (MLC 120: 6 e 15 MV; mMLC: $6 \mathrm{MV}$ ), as curvas seguem o mesmo padrão que as familias de curvas citadas nos trabalhos de LoSasso [35] e de LoSasso e colaboradores [15], ou seja, o desvio na liberação da dose é inversamente proporcional ao erro na abertura. Os resultados do MLC 120 concordam com os citados por Venencia e Besa [18], no qual é citado um valor de variação na dose de 1,5\% corresponde a um erro de 0,2 $\mathrm{mm}$ em uma abertura deslizante de $1 \mathrm{~cm}$.

No modo dinâmico, o impacto da calibração das lâminas está ilustrado nas Figuras 15 e 16. Os desvios na dose para janelas deslizantes de abertura constante são inversamente proporcionais aos erros introduzidos nas aberturas.

Em campos clínicos de DMLC, nem a largura da abertura nominal nem as velocidades das lâminas são fixas; não obstante, o desvio médio da dose é inversamente proporcional à abertura média. As aberturas foram consideradas "clínicas" entre 1 e $5 \mathrm{~cm}$.

Um erro na calibraçäo da posição das lâminas no mesmo sentido não produzirá um erro na dose no sentido usual, mas sim causará um deslocamento na distribuição de dose produzida por esse par de lâminas. Os problemas potenciais são visiveis quando os feixes modulados se combinam dependendo da magnitude do deslocamento. Isto demonstra uma pequena, mas importante diferença entre os erros no posicionamento das lâminas que podem ser compensados e os erros na abertura da janela deslizante.

É por isto que os testes de controle de qualidade a serem realizados, quando o serviço trata pacientes com IMRT dinâmico, devem visar a precisão na estabilidade da abertura nominal deslizante, como melhor indicador da dose liberada em modo dinâmico do que a posição das lâminas. No obstante, a verificação rotineira da posição das lâminas e da constância da abertura nominal devem ser realizadas na faixa de "janelas deslizantes" utilizadas clinicamente. 
Alguns destes testes devem ser realizados em diferentes angulações do sistema de suporte funcional ("gantry"), de colimador, para avaliar os efeitos da gravidade e fricção no posicionamento das lâminas e a velocidade.

O posicionamento das lâminas propriamente dito é testado através da verificação deste parâmetro no isocentro com papel milimetrado de forma rotineira.

\subsection{DADOS DOSIMÉTRICOS PARA USO CLÍNICO}

\subsubsection{PERFIS}

Pode ser observado na Figura 62, que os perfis gerados na mesma profundidade $(5 \mathrm{~cm})$, com a mesma ferramenta dosimétrica (filme), a mesma energia $(6 \mathrm{MV})$ e o mesmo tamanho de campo $\left(8 \times 8 \mathrm{~cm}^{2}\right)$, para cada um dos sistemas de colimador multi-lâminas, diferem na região de penumbra. Quantitativamente, o MLC 120 nesse perfil apresenta um valor de penumbra (80$20) \%$ de $4,144 \mathrm{~mm}$; para o MLC Mark II esse valor é 4,249 mm e para o mMLC a penumbra é de $3,535 \mathrm{~mm}$.

Quando comparados os perfis gerados por cada um dos sistemas de MLC estudados no presente trabalho; observa-se que a inclinação do perfil na região de alto gradiente de dose ( 80 - 20\%) para o mMLC é maior do que para os outros dois sistemas de MLC.

Isto pode ser explicado no fato do mMLC estar mais próximo do paciente ou do objeto simulador do que os outros sistemas, porque ele está montado como acessório ao cabeçote do acelerador, produzindo maior espalhamento e gerando em conseqüência maior dose na superfície. Outra razão que pode explicar estas diferenças é o fato da energia utilizada no teste ter sido a mesma, mas em três aceleradores distintos, sendo que cada um deles possui suas caracteristicas próprias na geração de feixe (alvo, filtro aplainador. etc.), o que faz com que os espectros de energia de cada um sejam distintos. 


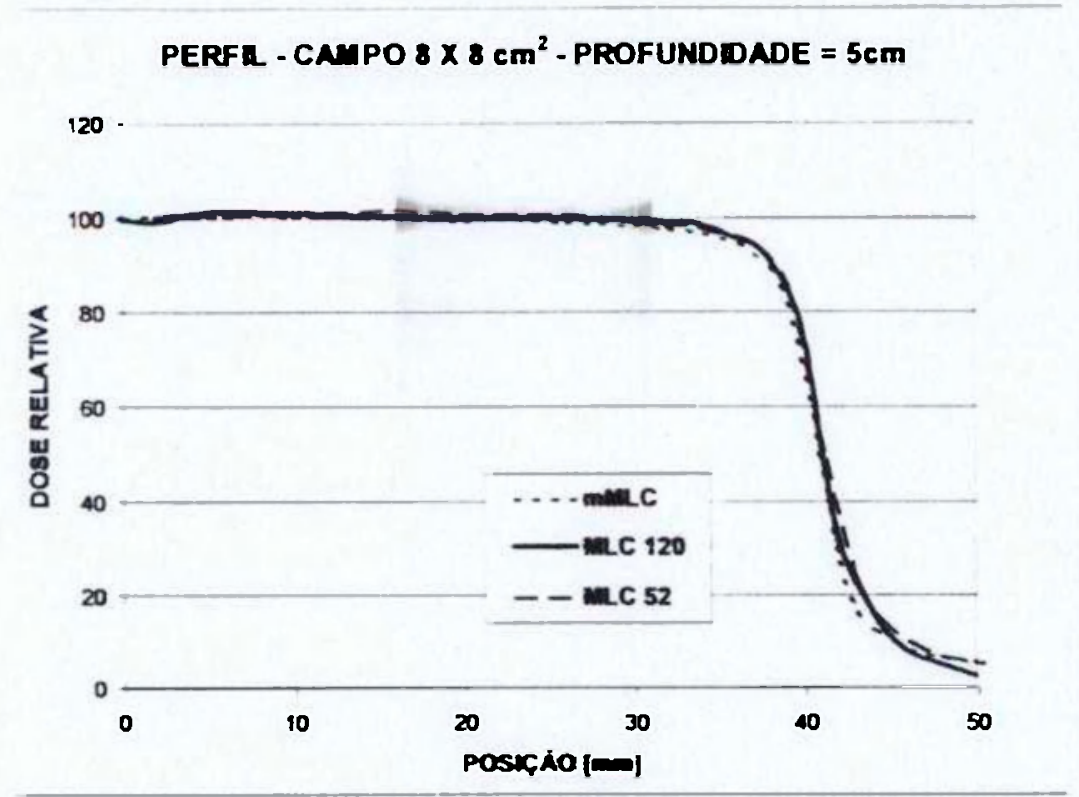

Figura 62. Comparação de perfis para campos $8 \times 8 \mathrm{~cm}^{2}$ definidos pelos três sistemas de $M L C$ estudados.

\subsubsection{FATORES DE RENDIMENTO}

As curvas de rendimento dos campos delimitados com os MLCs, nos três casos seguem a tendência esperada (Figura 63). Quando comparados entre eles, observa-se que para o mMLC os valores para campos pequenos estảo acima dos outros dois sistemas. A justificativa é a mesma que para os perfis, o fato do mMLC estar posicionado mais próximo ao paciente e produzir mais espalhamento e em conseqüência maior dose superficial faz com que os valores para um mesmo tamanho de campo sejam maiores para o mMLC que para os outros dois sistemas. Estes valores foram obtidos com a mesma energia, na mesma profundidade, razão pela qual também podem ser justificadas estas diferenças nos espectros de energia de cada um dos aceleradores. 


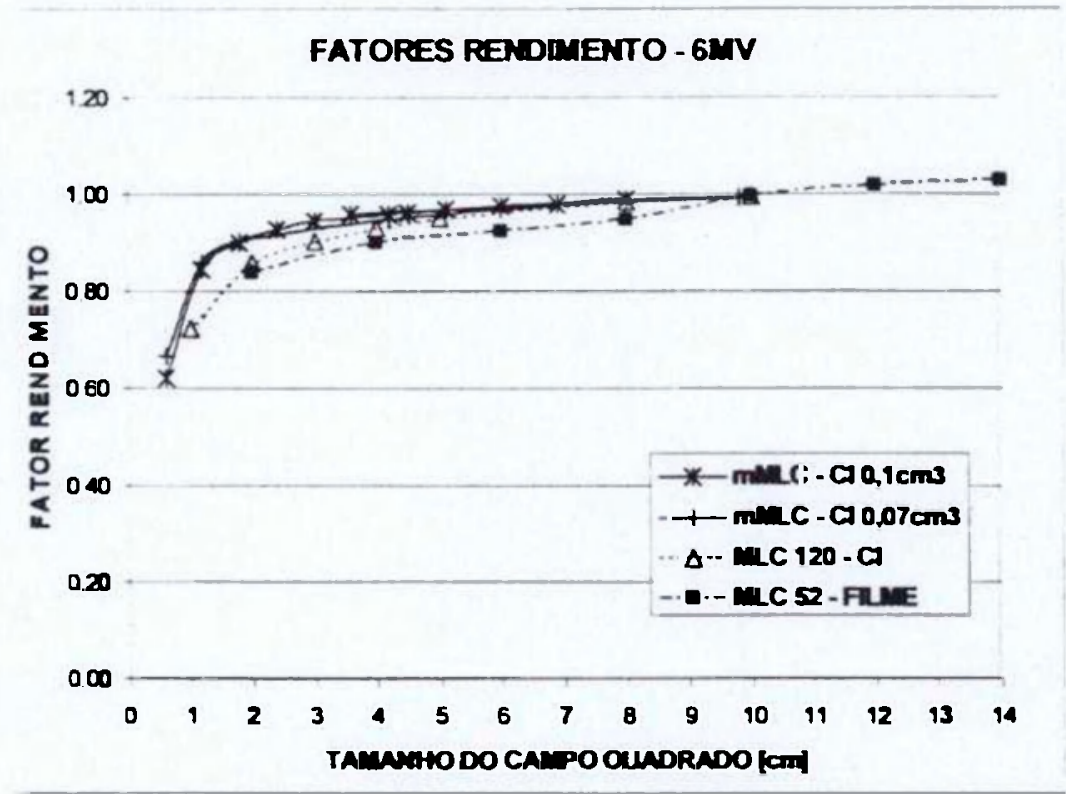

Figura 63. Resultados comparativos dos fatores de rendimento para campos quadrados definidos pelos MLC's.

Foram comparados os valores com três técnicas dosimétricas, para poder avaliar a conveniência de cada uma. Os resultados são mostrados na Figura 64.

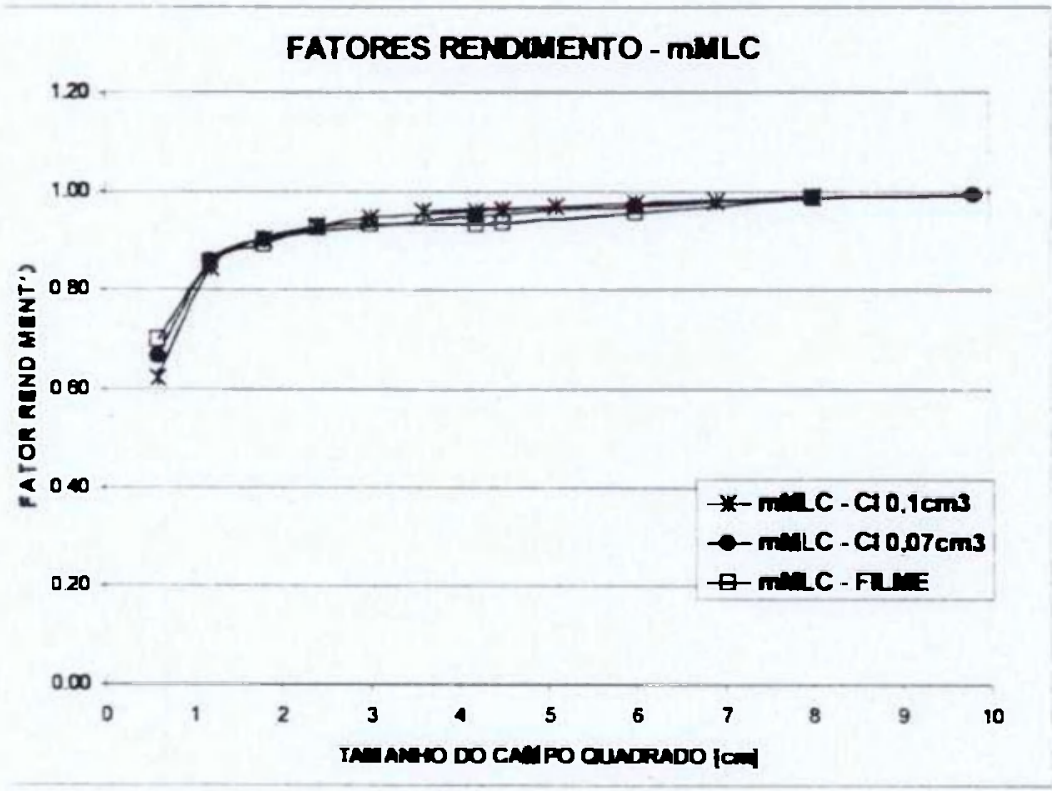

Figura 64. Fatores de rendimento para o mMLC realizados com diferentes ferramentas dosimétricas.

Na Figura 64 pode ser observado que as maiores diferenças entre uma ferramenta e outra estão nos campos pequenos, devido às caracteristicas de cada um dos dosimetros. A diferença no fator rendimento para o menor campo $\left(0,6 \times 0,6 \mathrm{~cm}^{2}\right)$ entre a câmara de ionizaçāo de $0,1 \mathrm{~cm}^{3}$ e a de $0,07 \mathrm{~cm}^{3}$ è $6,51 \%$. Quando comparados os valores para esse tamanho de campo, entre a câmara de 
$0,07 \mathrm{~cm}^{3}$ e o filme a diferença é $5,21 \%$. Quando estas medidas são realizadas com câmara de ionizaçāo, deve estar garantido o equilibrio eletrônico para a medição de campos pequenos, e esta deve ter o menor volume sensivel possivel. O filme apresenta um desvio maior. Esta comparaçāo pode ser realizada com TLD e diodo, porém sempre garantindo o equilibrio eletrônico. É recomendável nos serviços que o possuam a utilização de um detector com a melhor resolução espacial disponivel para os campos de pequenas dimensões. Nas Figuras 63 e 64 foram omitidas as barras de erro.

\subsection{TESTES DOSIMÉTRICOS}

\subsubsection{LINEARIDADE DE DOSE EM FUNÇÃO DA TAXA DE DOSE}

No modo dinâmico, se a velocidade da lâmina excede os valores máximos, a taxa de dose é modulada. Nesta situação a dose é liberada em pulsos de forma que o desvio de cada lâmina varie com cada um deles. $O$ movimento das lâminas é continuo, mas a distribuição de dose terá certa ondulação. Para situações clínicas típicas, nas quais poucas UMs por campo e UMs por segmento são evitadas para SMLC, ou quando os parâmetros de seqüencia das lâminas são apropriados (taxa de dose, tolerância no posicionamento das lâminas, velocidade máxima das lâminas) para o DMLC, os atrasos ocasionados pelo desligamento do feixe durante a liberação não nos levam a erros grosseiros na dose liberada. Pode existir preocupação quando essas seqüências sāo utilizadas para controle de qualidade, onde o filme ou o sistema de imagem portal eletrônico requerem um número pequeno de UM; nesses casos, a taxa de dose será reduzida para que a velocidade máxima não ultrapasse seu limite. Em conclusão é melhor evitar a utilizaçăo de taxas de dose pequenas para O MLC no modo dinâmico, situação refletida na Figura 65 para os dois sistemas estudados. Deve ser também evitado $\circ$ uso de taxas de dose diferentes das planejadas clinicamente, já que a velocidade das lâminas se ajusta as UM e um aumento ou diminuição na taxa de dose fará que as lâminas se movimentem mais rápido ou mais lento, ocasionando os efeitos já descritos. 


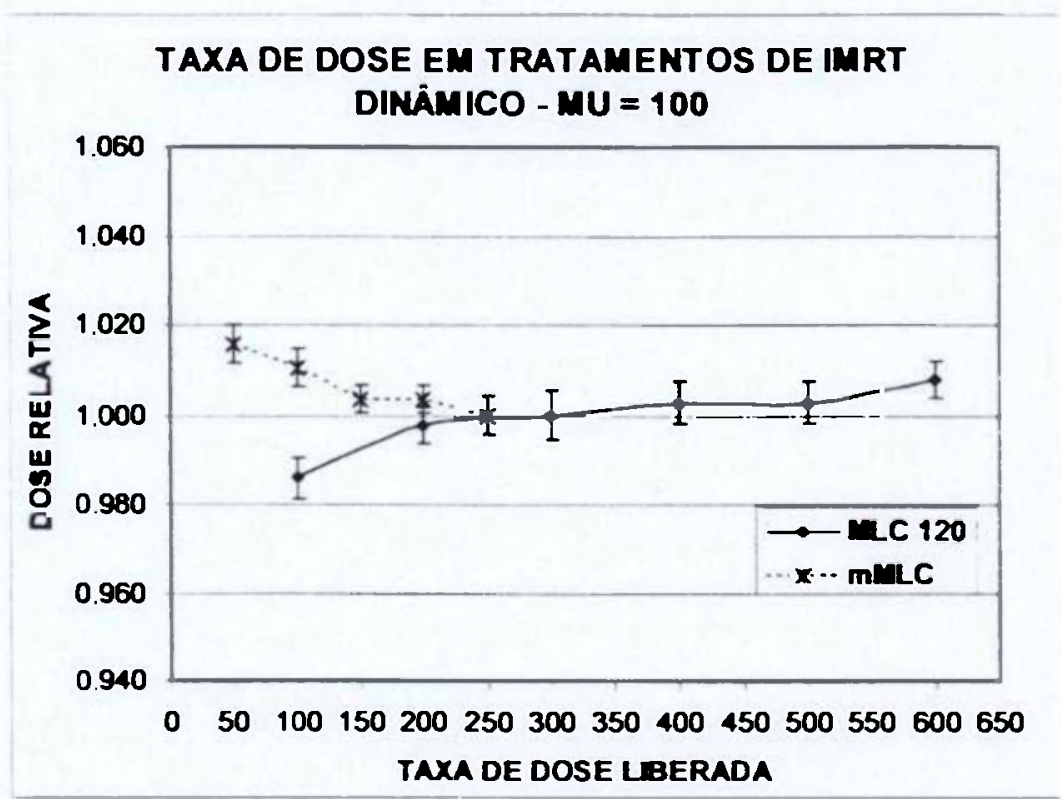

Figura 65. Comportamento da dose relativa nos sistemas com capacidade de liberação de feixes modulados dinamicamente quando a taxa de dose varia.

\subsubsection{SENSIBILIDADE Ȧ INTERRUPÇÃO DE TRATAMENTOS}

Como foi discutido ras seç̧ões 3.1.2.1 e 3.2.2.1 do presente trabalho, as diferenças na interrupção dos tratamentos nos dois sistemas que liberam feixes dinâmicos não foi significativa. As interrupções programadas testaram as lâminas em aceleração e em desaceleração (Figura 66).

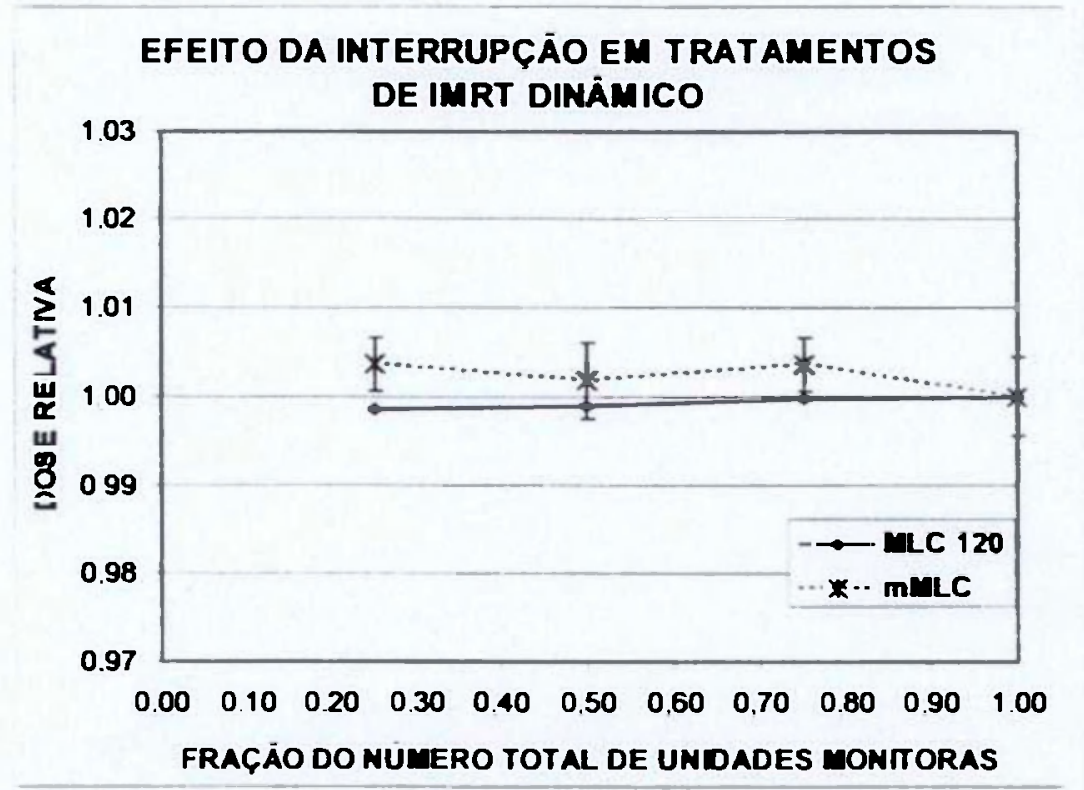

Figura 66. Comparação do efeito de interrupção em tratamentos de IMRT dinámico liberado pelos dois sistemas de MLC habilitados para esta técnica. 
$\mathrm{Na}$ literatura. Essers e colaboradores [14] mostram resultados comparativos entre campos dinâmicos liberados com e sem interrupção durante 0 tratamento, achando diferenças não significativas.

\subsubsection{ESTABILIDADE DO FATOR DE RENDIMENTO COM O DMLC}

Este teste pode ser incorporado na rotina de controle de qualidade dos serviços que dispõem desta tecnologia para testar a constância da dose relativa liberada dinamicamente em cada uma das energias disponibilizadas no acelerador. Pode ser utilizada uma abertura nominal de 1 ou $2 \mathrm{~cm}$, já que os erros no posicionamento das lâminas são quantificáveis e perceptiveis por uma câmara de ionização cilindrica padrão. Baseados nas familias de curvas levantadas nas seçōes 3.1.1.1 e 3.2.1.2, pode-se selecionar esta abertura nominal como referència.

A realização periódica deste teste em várias angulações do sistema de suporte funcional (Figura 67) permite também estabelecer se ocorre algum desvio por efeito da gravidade, enquanto as lâminas estão se movimentando para liberar o campo dinâmico de IMRT.

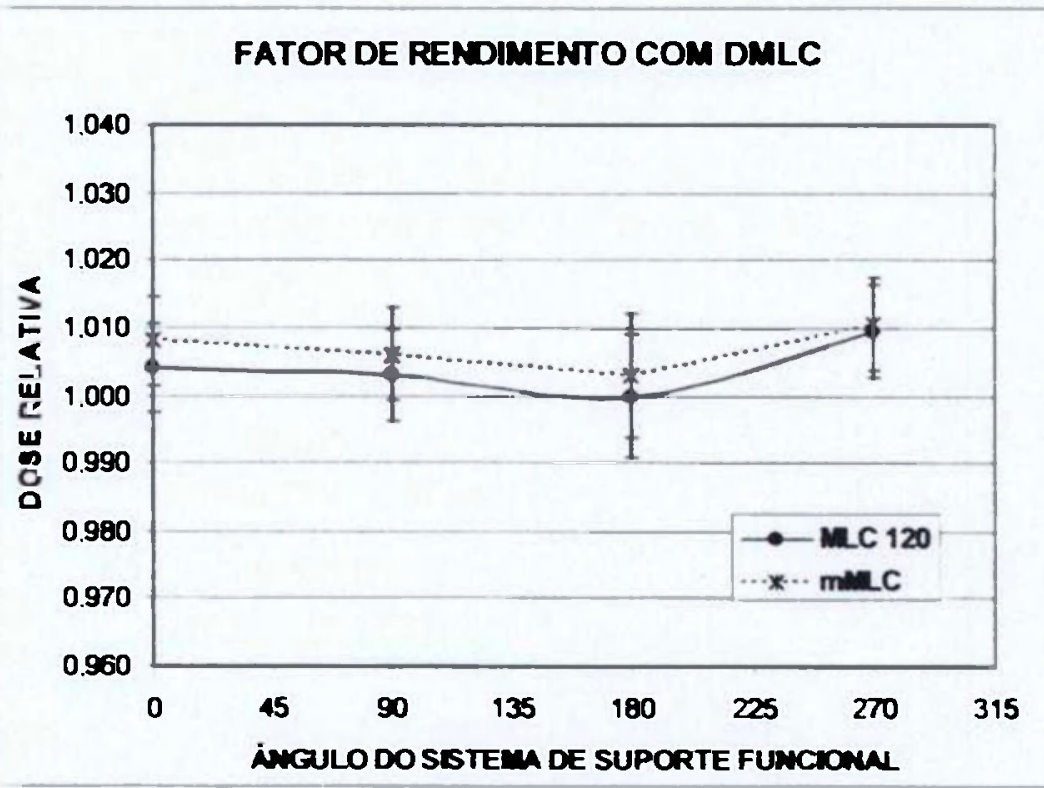

Figura 67. Comparaçāo do fator de rendimento em modo dinàmico em funçào do àngulo do sistema de suporte funcional nos dois sistemas que permitem a liberaçāo de feixes modulados. 


\subsubsection{TRANSMISSÃO MÉDIA COM CÂMARA DE IONIZAÇÃO.}

Da comparação descrita na Tabela 11, para uma mesma energia (6 MV) a menor transmissão é a do mMLC modelo $m_{3}$ da Brainlab. Em todos os casos a transmissão foi determinada com a câmara de ionização de $0,6 \mathrm{~cm}^{3}$ de volume, posicionada perpendicularmente ao movimento das lâminas para garantir dessa forma uma melhor estatistica na medição.

Tabela 11. Comparação dos valores de transmissão medidos com câmara de ionização.

\begin{tabular}{|c|c|c|c|}
\hline $\begin{array}{c}\text { FEIXE } \\
{[M V]}\end{array}$ & $\begin{array}{c}\text { SISTEMA } \\
\text { DE MLC }\end{array}$ & $\begin{array}{c}\text { TRANSMISSÃO } \\
\text { COM CI [\%] }\end{array}$ & $\begin{array}{c}\text { DESVIO } \\
\text { PADRÃO } \\
{[\%]}\end{array}$ \\
\hline 6 & MLC 120 & 1,630 & 0,018 \\
\hline 6 & mMLC & 1,291 & 0,029 \\
\hline 6 & MLC 52 & 1,638 & 0,010 \\
\hline 15 & MLC 120 & 1,838 & 0,016 \\
\hline 18 & MLC 52 & 1,668 & 0,036 \\
\hline
\end{tabular}

Quando foi determinada a dependência da transmissão com o tamanho de campo e a profundidade, como detalhado nas secçōes 3.1.2.6.1, 3.2.2.6.1 e 3.3.1.1.1, observou-se que a transmissão aumentou com o tamanho de campo.

Quando analisada a dependência da transmissão com a profundidade, este parâmetro aumentou para a energia de $6 \mathrm{MV}$ nos três sistemas de MLC, mantendo-se quase constante para $15 \mathrm{MV}$. Este fato pode ser atribuido ao endurecimento do feixe na energia de $6 \mathrm{MV}$, resultando em um feixe mais penetrante. $O$ aumento na produção de pares nas energias mais altas pode ser a razāo para anular o efeito do endurecimento

\subsubsection{EFEITO LINGÜETA - VÃO}

Uma informação complementar à transmissão é a quantificação do efeito lingüeta - vāo ("tongue and groove"). Este efeito é produto do projeto da lâmina, para conseguir se movimentar uma junto com a outra minimizando a transmissão entre as lâminas, otimizando a altura das lâminas e como resultado deste fato minimizando o peso do sistema. Os resultados obtidos sāo ilustrados na Figura 68. 


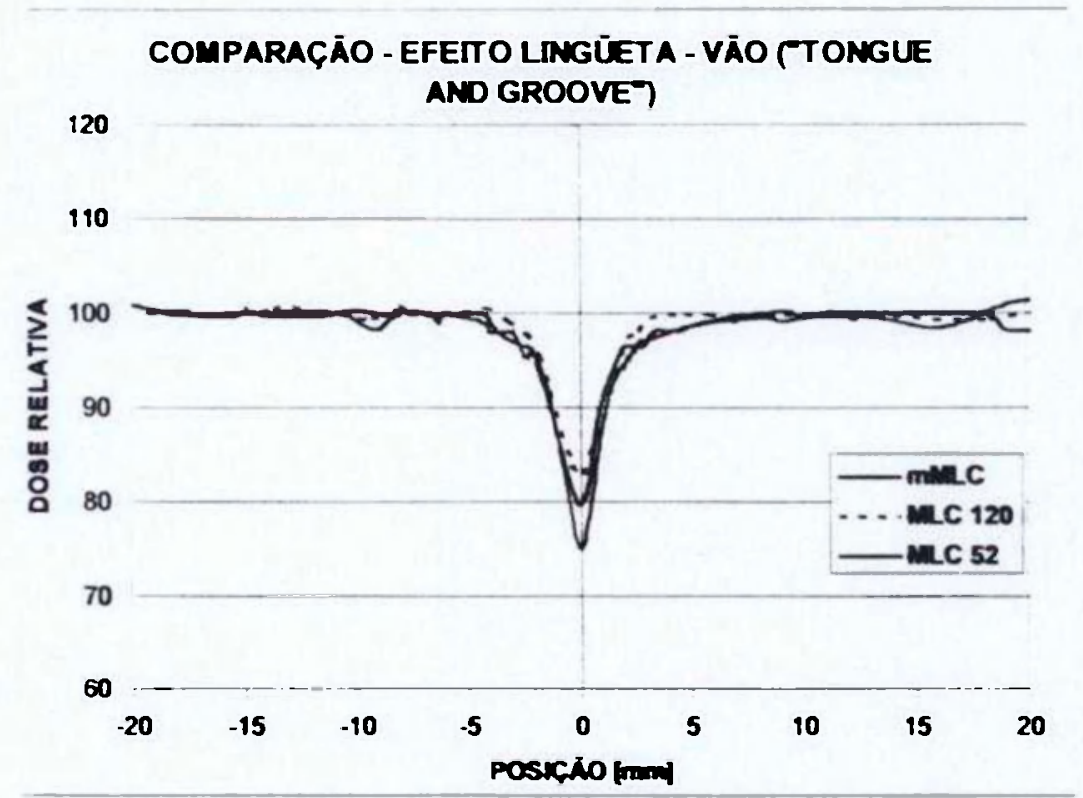

Figura 68. Resultados comparativos do efeito lingüeta - vão dos trés sistemas de MLC estudados.

$\mathrm{Na}$ literatura, Huq e colaboradores [38] fizeram uma comparação deste parâmetro entre vários fabricantes de MLC, para o sistema da Varian com lâminas de $1 \mathrm{~cm}$ de largura projetada no isocentro, o valor obtido por eles está próximo do $80 \%$ da dose, concordando com o valor determinado no presente trabalho para o MLC Mark II. Galvin e colaboradores [40] fizeram este teste para um MLC com lâminas de $1 \mathrm{~cm}$ de largura, e para as lâminas centrais foi obtido um valor que concorda com o resultado do presente trabalho.

Intercomparando os três sistemas; é possivel verificar que este parâmetro é menor para o $\mathrm{mMLC} \mathrm{m}_{3}$ da Brainlab. As diferenças entre um sistema e outro se justificam nos diferentes projetos de lâminas, explicando-se assim o maior valor para MLC Mark II de 52 lâminas.

\subsubsection{TRANSMISSÃO ENTRE AS LÂMINAS E INTRALÂMINAS}

Nas Figuras 69 e 70 pode-se observar uma comparação da transmissão no eixo central e a très centimetros do eixo central para uma mesma energia nos très sistemas de MLC. 


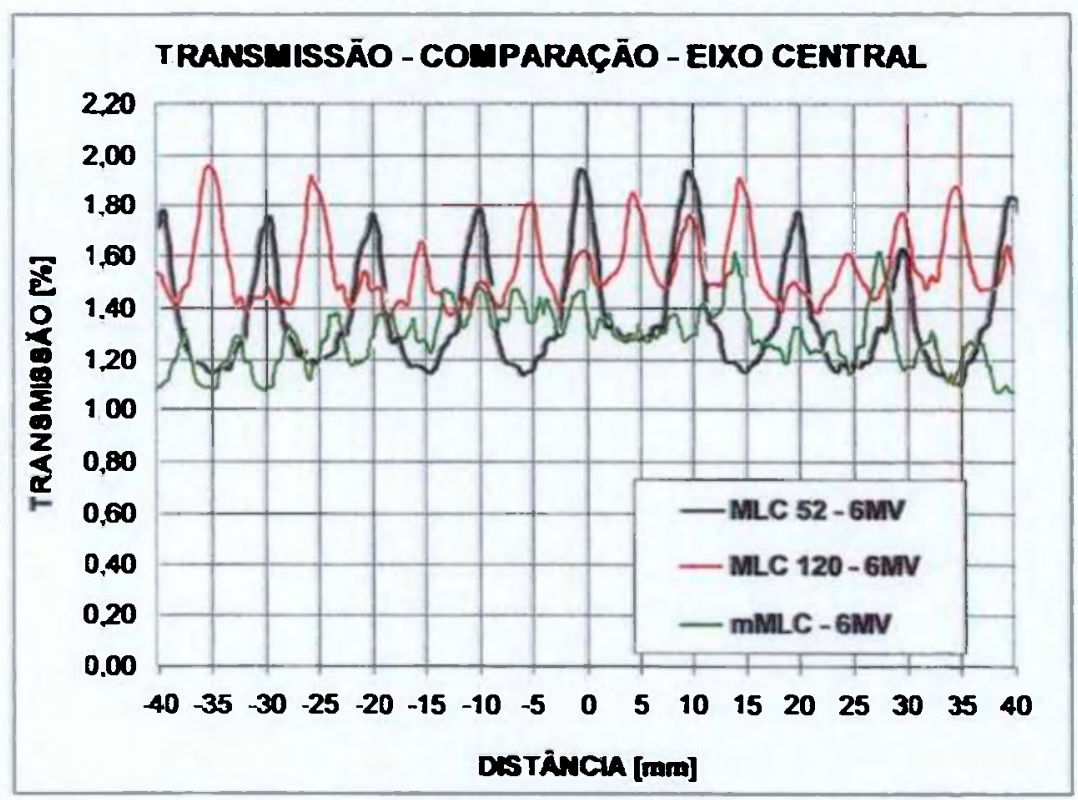

Figura 69. Comparação da transmissāo para 6 MV dos três sistemas de MLC do HIAE, no eixo central.

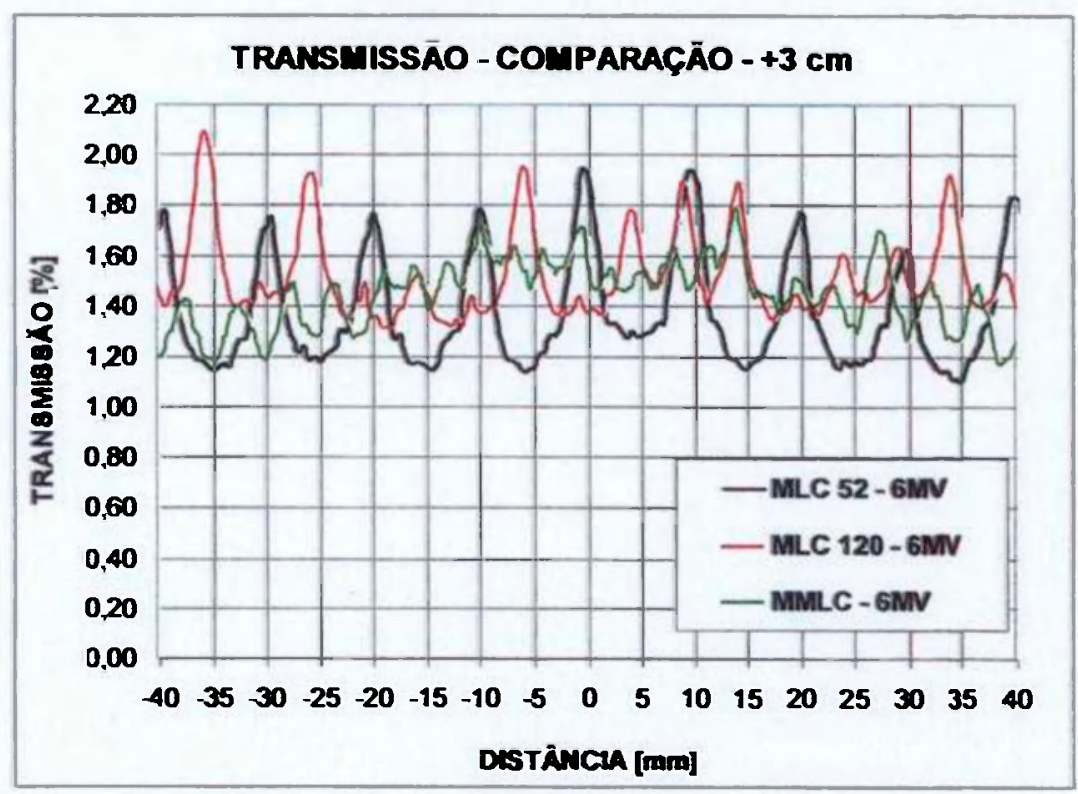

Figura 70. Comparação da transmissão para 6 MV dos três sistemas de MLC do HIAE, os perfis foram obtidos a $3 \mathrm{~cm}$ de deslocamento do eixo central em sentido oposto à junçăo das láminas opostas.

Os padrões de transmissão; determinados com filme nas secções 3.1.2.6.2 e 3.2.2.6.2 deste trabalho, mostraram tanto para o MLC Millenium 120 como para o mMLC diferenças deste parâmetro quando o perfil medido com filme foi determinado no eixo central e fora do eixo (em sentido oposto à junção das lâminas opostas). Este comportamento não foi observado no MLC Mark II (Secção 3.3.1.1.2), onde os perfis foram muito próximos nas diferentes posições no campo de radiação testado. 
As diferenças encontradas na transmissão dependendo da posição com relação ao eixo central devem ser estimadas, mas não podem ser levadas em consideração nos sistemas de planejamento computadorizados, já que estes requerem a entrada de um único valor em uma profundidade e para um tamanho de campo relevantes clinicamente.

Possivelmente no futuro, com a disponibilidade comercial dos sistemas de planejamento baseados em simulações de Monte Carlo, estas diferenças possam ser levadas em conta.

A transmissão e o efeito lingüeta - vão têm uma influência maior nos tratamentos de IMRT do que nos tratamentos conformados porque as UMs sāo maiores no IMRT e porque as làminas cobrem o campo durante um periodo significativo do tratamento. Por isto, a faixa de transmissão entre as lâminas deve ser determinada para todas as lâminas durante o comissionamento; as variações podem ser observadas em angulaçōes diferentes do sistema de suporte funcional e do colimador. Estas diferenças podem explicar as discrepâncias entre as doses calculadas e medidas para campos individuais, durante o controle de qualidade rotineiro pré-tratamento de IMRT. Na composição de campos nos tratamentos completos, tanto a transmissão entre as lâminas como a transmissão adicional pelo efeito lingüeta - vão tendem a ser compensadas uma com outra.

\subsubsection{ESPALHAMENTO}

Os resultados do espalhamento para os três sistemas de MLC em todos os feixes disponiveis estäo na Tabela 12.

Tabela 12. Resultados comparativos do espalhamento produzido pelos três sistemas de MLC estudados.

\begin{tabular}{|c|c|c|c|}
\hline $\begin{array}{c}\text { FEIXE } \\
\text { [MV] }\end{array}$ & $\begin{array}{c}\text { SISTEMA } \\
\text { DE MLC }\end{array}$ & $\begin{array}{c}\text { ESPALHAMENTO } \\
\text { (\% DE DOSE DO CAMPO } \\
\text { ABERTO DE REFERENCIA) }\end{array}$ & $\begin{array}{c}\text { DESVIO } \\
\text { PADRĀO } \\
{[\%]}\end{array}$ \\
\hline 6 & MLC 120 & 0,297 & 0,024 \\
\hline 6 & MMLC & 0,239 & 0,052 \\
\hline 6 & MLC 52 & 0,202 & 0,028 \\
\hline 15 & MLC 120 & 0,333 & 0,042 \\
\hline 18 & MLC 52 & 0,221 & 0,035 \\
\hline
\end{tabular}


Os resultados obtidos são satisfatórios quando comparados com 0 trabalho de Arnfield e colaboradores [33], no qual o espalhamento foi calculado para um sistema de MLC Varian com lâminas de $1 \mathrm{~cm}$ de largura, para o feixe de $6 \mathrm{MV}$, sendo relatado o valor de $(0,20 \pm 0,01) \%$ medido através de filmes. Os mesmos autores calcularam o espalhamento para o sistema mencionado de MLC, através da simulação de Monte Carlo, obtendo um valor de $(0,185 \pm 0,002) \%$. No trabalho mencionado, foi calculado para um sistema de colimador multi-lâminas Varian Millenium 120, para o feixe de $6 \mathrm{MV}$; sendo relatado o vator de $(0,21 \pm 0,03) \%$ medido também através de filmes.

$\mathrm{Na}$ literatura não existem registros deste parâmetro para o mMLC e, por isto, foi seguida a metodologia descrita por Arnfield e colaboradores [33].

\subsubsection{ABERTURA DOSIMÉTRICA ENTRE PARES DE LÂMINAS}

Os valores de abertura dosimétrica entre pares de lâminas foram obtidos utilizando metodologias diferentes, os resultados estão apresentados na Tabela 13. No caso do MLC Millenium e do mMLC, a abertura dosimétrica foi determinada através da dose integral medida com câmara de ionização. Para o MLC Mark II, este parâmetro foi determinado com filme como descrito por LoSasso e colaboradores [15] e Venencia e Besa [18].

Os valores obtidos concordam satisfatoriamente com os citados na literatura e com a recomendação do fabricante para este parâmetro de $0,2 \mathrm{~cm}$. Estes fatos validam as metodologias utilizadas para a determinação da abertura dosimétrica entre pares de lâminas.

Tabela 13. Resultados comparativos da abertura dosimétrica entre pares de lâminas nos três sistemas de MLC estudados.

\begin{tabular}{|c|c|c|c|}
\hline FEIXE [MV] & $\begin{array}{c}\text { SISTEMA DE } \\
\text { MLC }\end{array}$ & $\begin{array}{c}\text { ABERTURA DOSIMÉTRICA } \\
\text { ENTRE PARES DE LÂMINAS [cm] }\end{array}$ & $\begin{array}{c}\text { DESVIO } \\
\text { PADRÄO [cm] }\end{array}$ \\
\hline 6 & MLC 120 & 0,202 & 0,054 \\
\hline 6 & MMLC & 0,157 & 0,070 \\
\hline 6 & MLC 52 & 0,189 & 0,081 \\
\hline 15 & MLC 120 & 0,236 & 0,059 \\
\hline
\end{tabular}


É importante mencionar que este paràmetro é muito importante no cálculo e no sequeênciamento das lâminas no IMRT liberado em modo dinâmico. O valor obtido deve ser inserido no sistema de planejamento computadorizado, e ele será utilizado nessa fase do planejamento. Este é um dos parâmetros dos quais depende que a fluência real liberada pelo acelerador seja o mais próxima possivel da fluência calculada no sistema de planejamento.

A transmissão devida à borda arredondada nos MLCs é equivalente a aumentar o tamanho de campo em uma quantidade igual à abertura dosimétrica entre pares de lâminas $(\sim 2 \mathrm{~mm})$.

\subsubsection{PENUMBRA}

\subsubsection{PENUMBRA EM FUNÇÃO DA PROFUNDIDADE}

Os resultados obtidos (Tabela 14) permitem fazer a seguinte análise com relaçăo à aplicabilidade de cada um dos sistemas estudados em diferentes técnicas de tratamento:

Se um dos sistemas for utilizado para Radiocirurgia estereotáxica, é pertinente lembrar, que segundo o Grupo de Trabalho da Associação Americana de Físicos em Medicina que elaborou o Relatório \#54 (AAPM Task Group Report 54 ,) é recomendado para esta técnica em dose única, na região de gradiente, que a penumbra $(80-20) \%$ deve ser de até $3 \mathrm{~mm}$ (gradiente de $60 \% / 3 \mathrm{~mm}$ no máximo) [41]. Isto restringe a escolha de um sistema de MLC a ser utilizado em Radiocirurgia de Dose Única para aquele que apresenta penumbra menor do que $3 \mathrm{~mm}$. Nos casos estudados nesta intercomparaçāo o escolhido é o mMLC, aproveitando que volumes pequenos a serem irradiados (volumes indicados para esta técnica de tratamento devem ser menores de $3 \mathrm{~cm}$ ) vão ser conformados pelas lâminas menos largas $(3 \mathrm{~mm})$, reduzindo assim este parâmetro.

Tabela 14. Resultados comparativos da penumbra ( $80-20) \%$ em funçāo da profundidade nos três sistemas de MLC para $6 M V$.

\begin{tabular}{|c|c|c|c|}
\cline { 2 - 4 } & \multicolumn{3}{|c|}{ PENUMBRA $(80-20) \%[\mathrm{~mm}]$} \\
\hline $\begin{array}{c}\text { PROFUNDIDADE } \\
{[\mathrm{cm}]}\end{array}$ & mMLC & MLC 120 & MLC 52 \\
\hline 1,50 & $2,59 \pm 0,30$ & $4,08 \pm 0,21$ & $4,65 \pm 0,28$ \\
\hline 5,00 & $3,13 \pm 0,30$ & $4,14 \pm 0,27$ & $5,65 \pm 0,15$ \\
\hline 10,00 & $3,48 \pm 0,36$ & $5,05 \pm 0,45$ & $6,74 \pm 0,10$ \\
\hline
\end{tabular}


Para volumes maiores, nos quais o seu desenho será coberto pelas lâminas maiores do $\mathrm{mMLC}(4,5$ e $5,5 \mathrm{~mm})$ a penumbra è maior, mas estes volumes podem ser tratados com as técnicas de Radiocirurgia fraccionada, tratados com Arco Dinâmico ou com feixes de intensidade modulada, o requerimento do valor de penumbra não é tão restrito.

Os valores de penumbra do MLC Millenium 120 e do Mark II concordam com os citados na literatura, sendo sempre maiores do que $4 \mathrm{~mm} e$ não ultrapassando os $10 \mathrm{~mm}$ conforme estabelece o fabricante. Os resultados para o Millenium 120 possibilitam a utilização deste sistema nas técnicas de Tratamento Conformada, Arco Dinâmico e de IMRT.

A variação da penumbra com a profundidade deve ser considerada na hora do planejamento, e como esta variação irá influenciar o cálculo no sistema de planejamento computadorizado. A determinação desta variação pode ser feita com a análise dos dados que vāo ser inseridos no sistema de planejamento computadorizado.

\subsubsection{PENUMBRA EM FUNÇÃO DA POSIÇÃO FORA DO EIXO}

A partir dos resultados das Figuras 71, 72 e 73, pode-se concluir que 0 mMLC apresenta um menor valor de penumbra quando as lâminas se apresentam estendidas sobre o eixo central e também quando estão retraidas, nas três profundidades testadas. É importante citar que nenhum dos três sistemas de MLC apresenta variações significativas quando as lâminas se retraem ou estendem com relação ao eixo central, como foi descrito nas secçōes 3.1.2.9.1, 3.2.2.9.1 e 3.3.1.4.1 para cada um dos sistemas. Pode ser analisado também que, tanto no MLC 120 como no MLC 52, a penumbra apresenta um mesmo padrão, sendo maior sobre o eixo central e menor quando a lâmina se encontra estendida ou retraida. Isto se deve ao projeto da lâmina que com a borda arredondada pretende minimizar a penumbra. Este comportamento também foi citado na literatura [38][39][40]

O comportamento da penumbra quando as lâminas estão estendidas e retraídas, deve ser bem entendido para os casos de tratamentos conformados em 
que o isocentro do volume alvo está coberto pelas lâminas por alguma mudança no planejamento com relação à simulação.

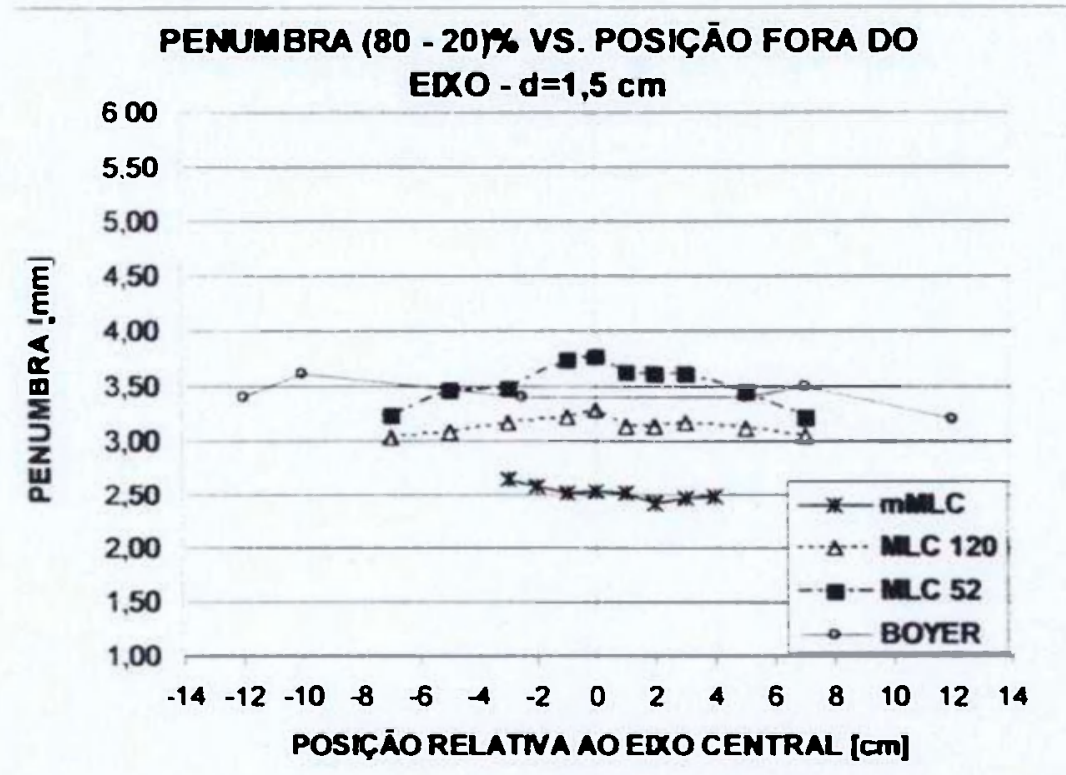

Figura 71. Resultados comparativos da penumbra $(80-20) \%$ em função do deslocamento fora do eixo central na profundidade de $1,5 \mathrm{~cm}$.

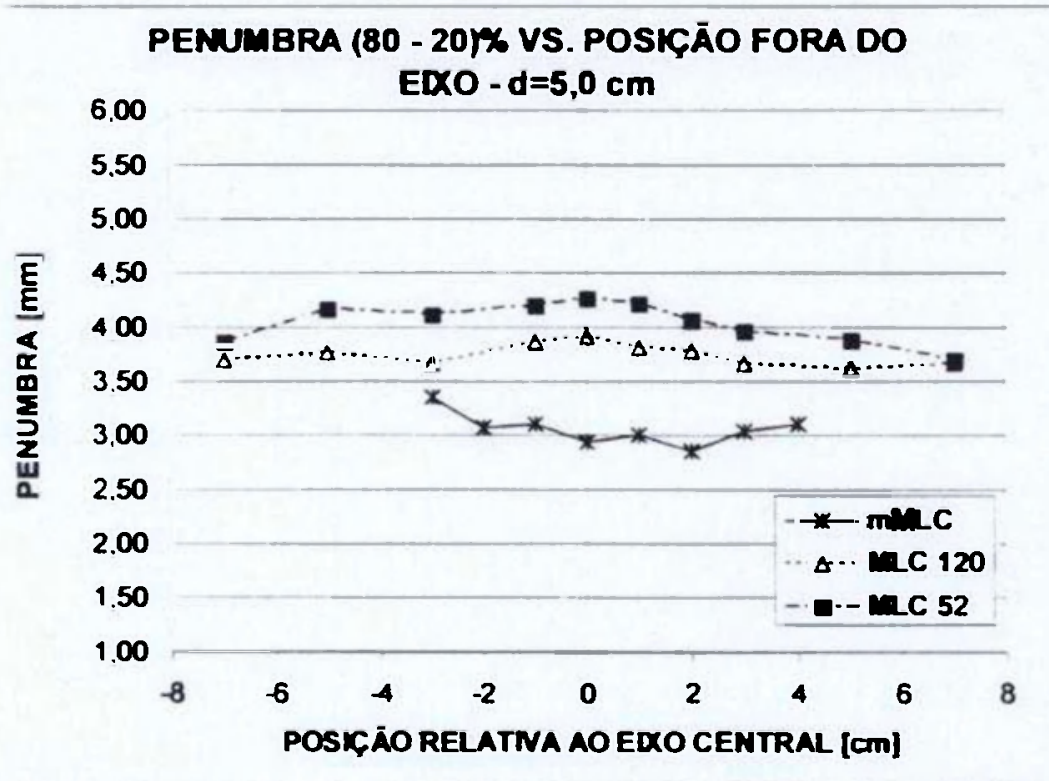

Figura 72. Resultados comparativos da penumbra $(80-20) \%$ em função do deslocamento fora do eixo central na profundidade de $5,0 \mathrm{~cm}$. 


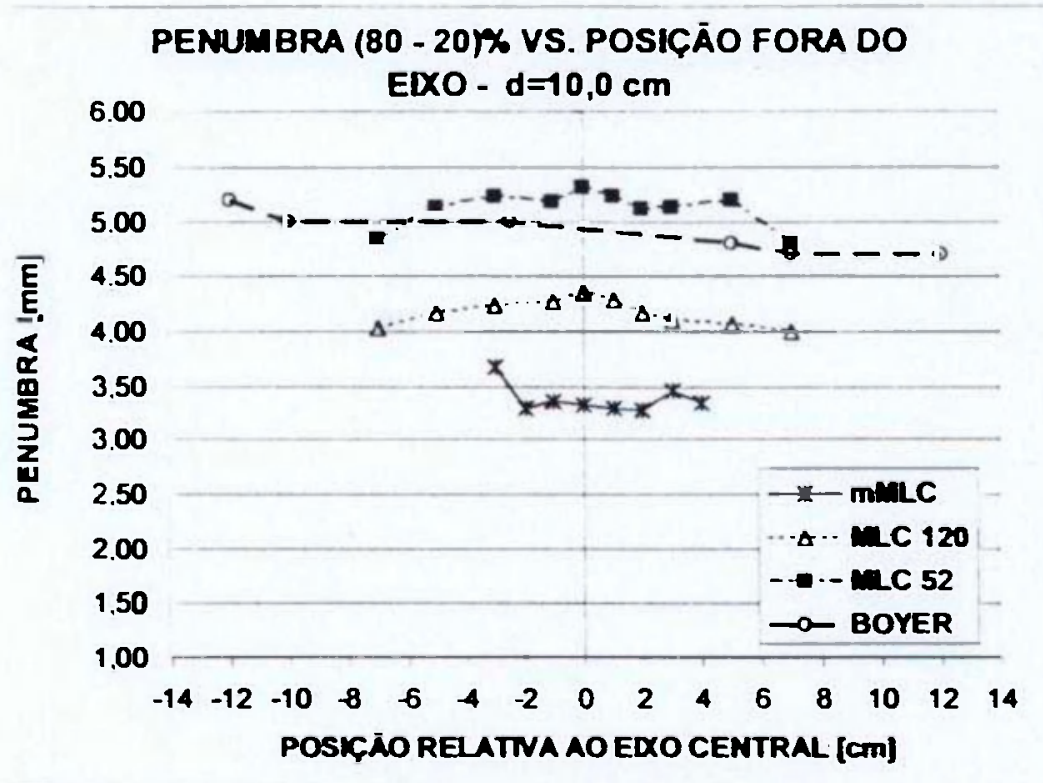

Figura 73. Resultados comparativos da penumbra $(80-20) \%$ em funçāo do deslocamento fora do eixo central na profundidade de $10,0 \mathrm{~cm}$.

Nos casos de IMRT em modo dinâmico, este fato é comum nos campos de tratamento, porque eles começam com um banco de lâminas estendido sobre o eixo central. Por isto, é importante o levantamento desta dependência para compreender o comportamento e para ser levado em consideração na hora da análise dos testes de controle da qualidade dos planos de tratamento de IMRT. Os testes de penumbra são de utilidade para ter conhecimento detalhado do comportamento deste parâmetro em situaçōes que são reais na prática clinica, e durante o planejamento dos tratamentos conformados e de intensidade modulada.

\subsubsection{PENUMBRA EM FUNÇĀO DO TAMANHO DE CAMPO}

Nos três casos estudados, a penumbra aumenta quando o tamanho de campo cresce, tanto no sentido paralelo ao movimento das lâminas (Figura 74), como no sentido perpendicular ao movimento das lâminas (Figura 75). Este comportamento encontra-se descrito na literatura para os diversos sistemas estudados e para outros similares [28][39][42][44][45]. 


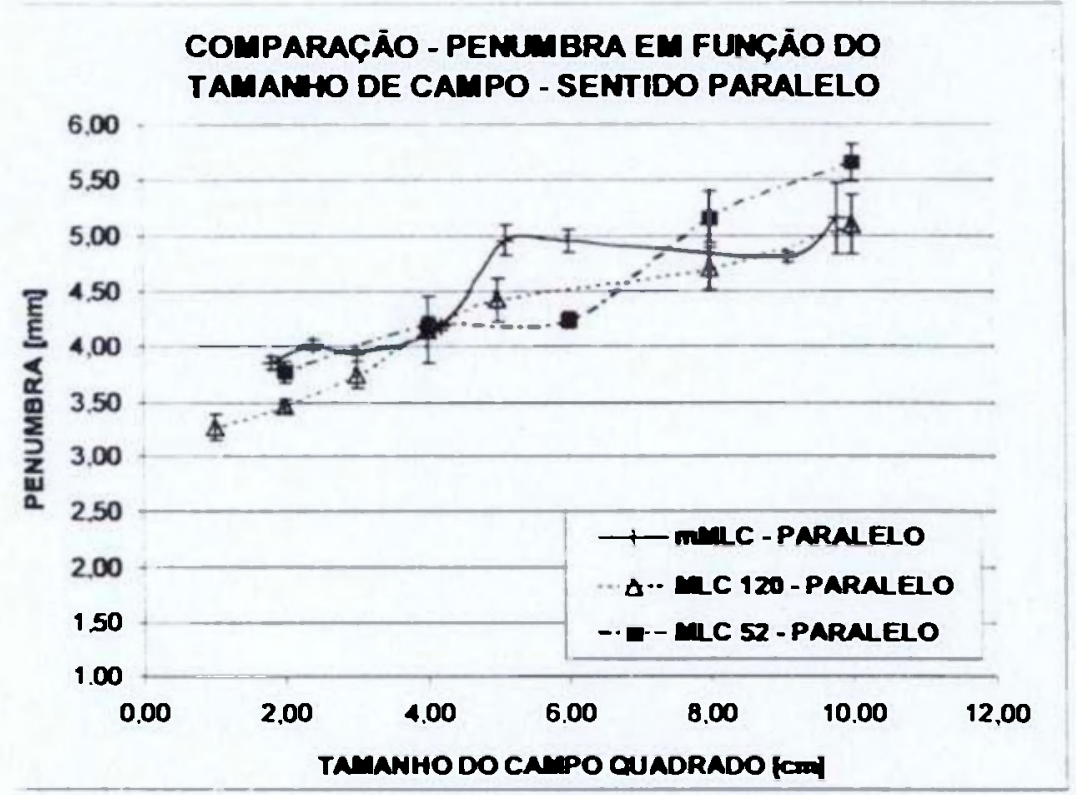

Figura 74. Resultados comparativos da penumbra (80 - 20)\% em funçāo do tamanho de campo definido pelos trés sistemas de MLC no sentido paralelo ao movimento das lâminas.

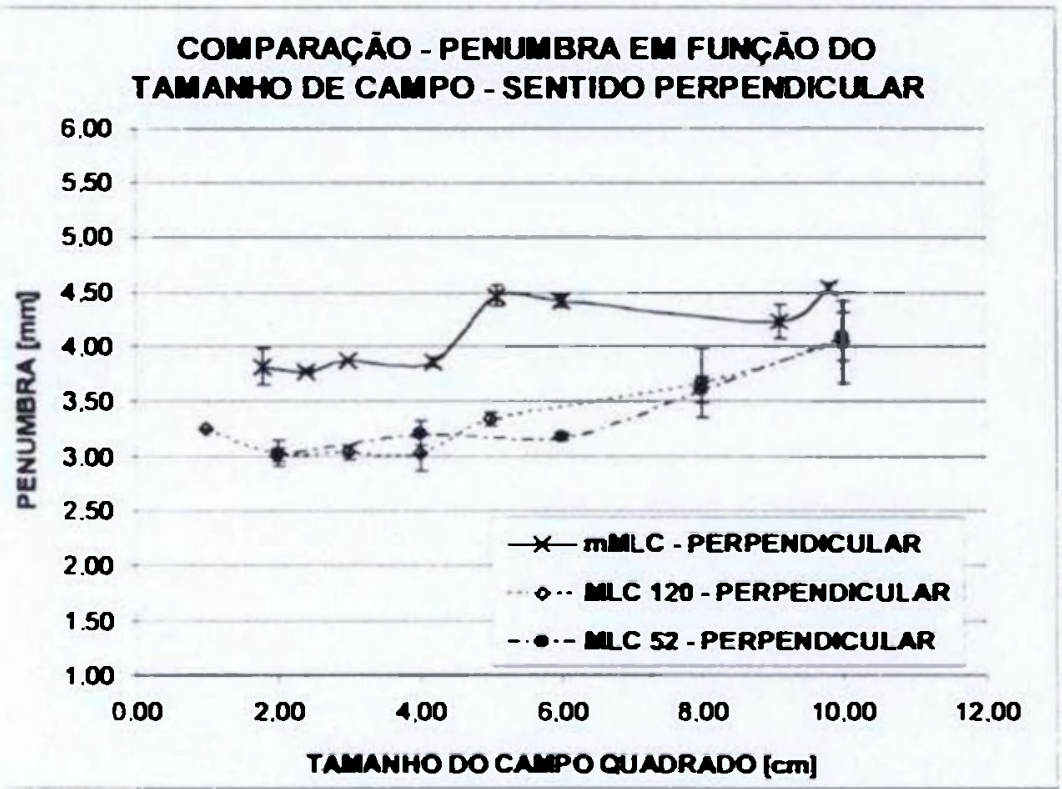

Figura 75. Resultados comparativos da penumbra $(80$ - 20)\% em função do tamanho de campo definido pelos trés sistemas de MLC no sentido perpendicular ao movimento das lâminas.

\subsubsection{PENUMBRA EM FUNÇÃO DO ÃNGULO QUE FORMA COM O EIXO DE MOVIMENTO DAS LÂMINAS}

Nas Figuras 76 e 77, estăo comparados os resultados dos três sistemas com os dados descritos por Cosgrove e colaboradores [28] e por Monk e colaboradores [46] 


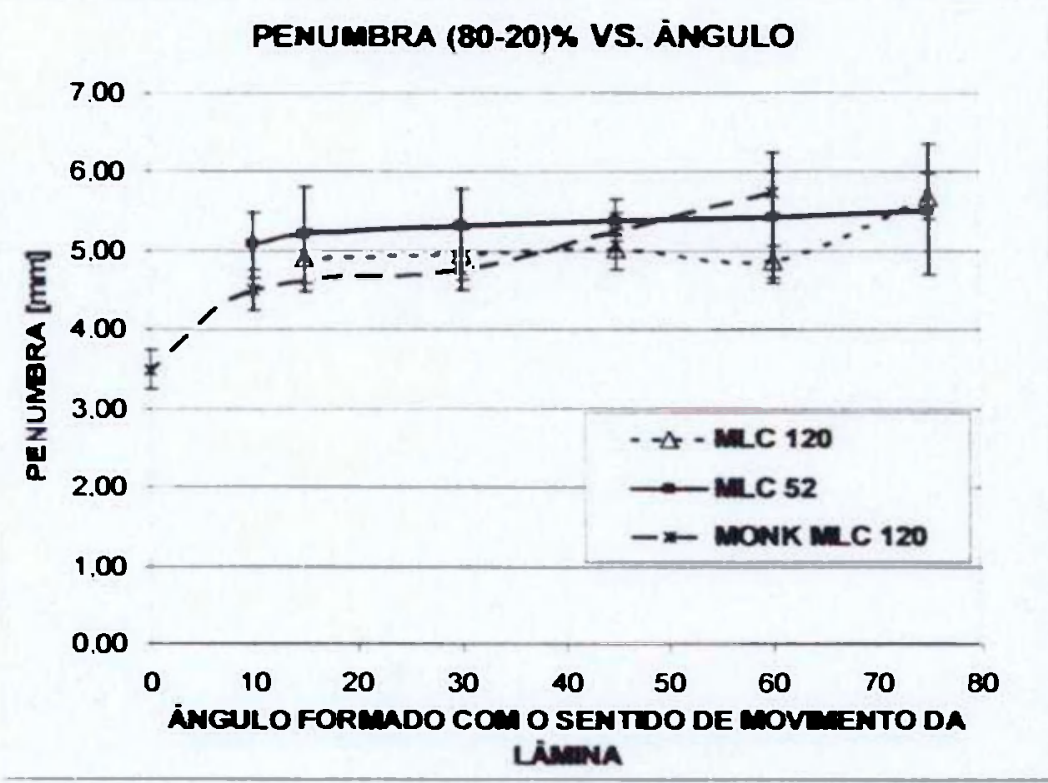

Figura 76. Resu/tados comparativos da dependéncia da penumbra 80 - $20 \%$ em função do ângulo que formam as lâminas com seu eixo de movimento.

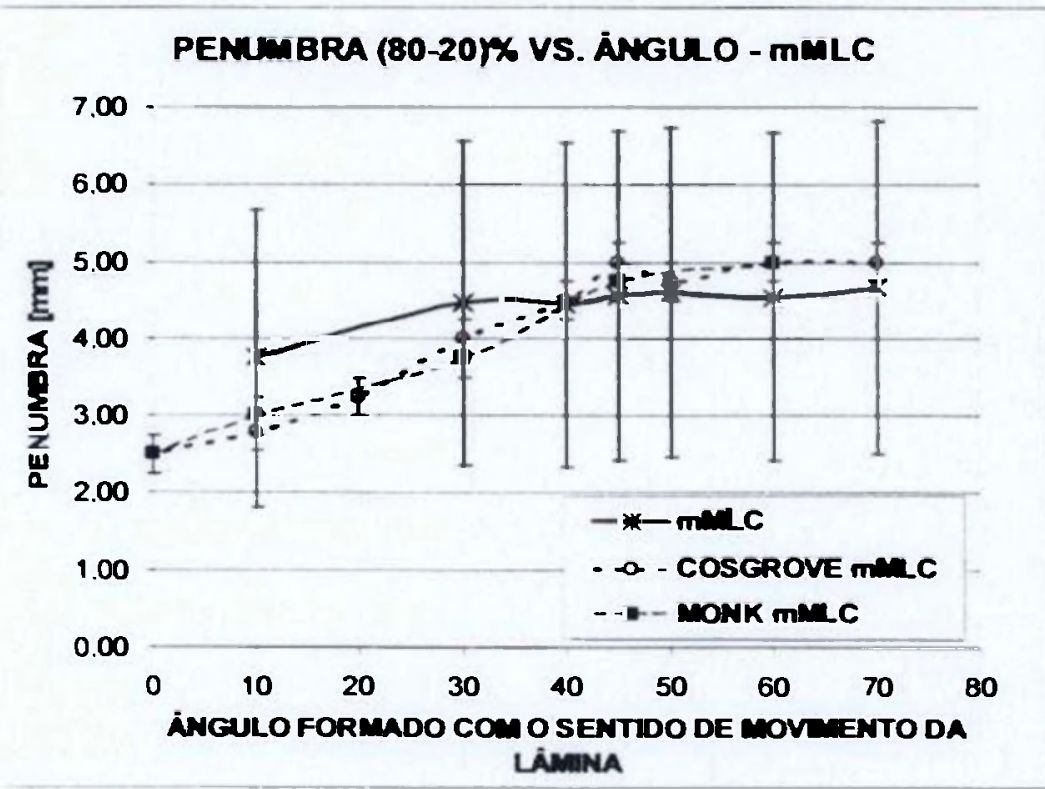

Figura 77. Resultados comparativos da dependéncia da penumbra (80 - 20)\% em funçāo do ângulo que formam as lâminas com seu eixo de movimento para o mMLC.

A menor penumbra para todos os ângulos testados é a apresentada pelo mMLC. Nos três casos, a tendência da penumbra é aumentar quando o ângulo aumenta com o eixo de movimento; isto significa que a menor penumbra é a dos campos que possuem as suas lâminas completamente opostas (p.ex. campos quadrados). Nos campos com as lâminas formando ângulos maiores, a penumbra e a incerteza associada aumentam devido às curvas de isodoses apresentarem ondulações maiores do que nos casos de ângulos menores. $\mathrm{Na}$ 
determinação da margem do volume clinico a irradiar para gerar o volume alvo de planejamento (PTV), este fato deve ser considerado nos casos clínicos, nos quais os volumes a serem irradiados apresentam concavidades no seu contorno.

No caso dos testes de penumbra, a sua maior utilidade é o conhecimento detalhado do comportamento deste parâmetro em situaçōes que são reais na prática clínica, e sua utilidade durante o planejamento dos tratamentos conformados e de intensidade modulada. 


\section{CONCLUSÕES E RECOMENDAÇÔES.}

A comparação de alguns resultados apresentados neste trabalho não pode ser feita com valores descritos na literatura devido à falta de publicaçōes do comportamento do $\mathrm{mMLC}$ modelo $\mathrm{m}_{3}$ da Brainlab em modo dinâmico e pela novidade das técnicas que podem ser tratadas com este equipamento.

Os testes mecânicos e dosimétricos apresentados no presente trabalho avaliam de forma correta o funcionamento do sistema de colimador multi-lâminas, permitindo assim achar desvios e possiveis fontes de erro nos parâmetros testados.

Os testes que envolvem a penumbra, a variação da transmissão com a profundidade e com a distância fora do eixo, abertura dosimétrica, foram realizados para se ter um levantamento de informação aplicável na rotina de planejamento. O tratamento de IMRT em modo dinâmico implica posições extremas das lâminas durante a liberação do feixe. O comportamento desses paràmetros bem como as conseqüencias deles devem ser muito bem conhecidas na hora da avaliação dos planos de tratamentos.

Os sistemas de planejamento computadorizados utilizam um único valor de transmissão e abertura dosimétrica para ser empregado em todos os cálculos, sem diferençar a energia que está sendo considerada. A decisāo do valor a ser utilizado requer uma avaliação exaustiva do comportamento destes parâmetros juntamente com o conhecimento da rotina clinica que está sendo implementada.

A transmissão devida à borda arredondada nos MLCs é equivalente a aumentar o tamanho de campo em uma quantidade igual à abertura dosimétrica entre pares de lâminas $(\sim 2 \mathrm{~mm})$.

A transmissão entre as lâminas e o efeito lingüeta - vão têm uma influência maior nos tratamentos de IMRT do que nos tratamentos conformados, porque as UMs são maiores no IMRT e porque as lâminas cobrem o campo durante um periodo significativo do tratamento. Por isto, a faixa de transmissão entre as lâminas deve ser determinada para todas as lâminas durante o 
comissionamento; as variaçōes podem ser observadas em diferentes angulaçōes do sistema de suporte funcional e do colimador. Posteriormente, estas diferenças podem explicar as discrepancias entre as doses calculadas e medidas para campos individuais, durante o controle de qualidade rotineiro pré-tratamento de IMRT. Na composiçăo de campos em tratamento completo, tanto a transmissão entre as lâminas como a transmissão adicional pelo efeito lingüeta - vão tendem a ser compensadas uma com outra.

As diferenças nos perfis gerados por cada um dos sistemas não são significativas, mas existe uma inclinação maior na regiāo de alto gradiente de dose $(80-20 \%)$ do perfil. Existem pequenos desvios nas curvas de fator de rendimento para campos delimitados com cada um dos MLCs, sendo os valores mais altos os provenientes do $\mathrm{mMLC}$.

Os arquivos "dynalog" são a ferramenta de "diagnóstico" de possiveis erros no posicionamento das lâminas. A partir da análise dos dados obtidos nestes arquivos, eles devem ser utilizados para prever falhas iniciais nos motores e determinar a necessidade de substituí-los de forma preventiva.

O sistema de MLC Millenium 120 da Varian Medical Systems, e o mMLC $m_{3}$ da Brainlab sāo dispositivos funcionais que apresentam reprodutibilidade e confiabilidade nos parâmetros testados, para a implementação de IMRT, desde as perspectivas do planejamento e da liberação de tratamento.

O MLC Mark II - 52 da Varian apresentou caracteristicas que garantem sua utilização em tratamentos conformados $e$, se estiver habilitado, para tratamentos de IMRT.

Dos resultados obtidos da análise do comportamento da penumbra nos três sistemas e seguindo as recomendações da literatura, pode ser concluido que somente o mMLC é confiável para o tratamento de Radiocirurgia Estereotáxica de dose única. Para as técnicas de Radiocirurgia Fracionada, tanto o mMLC como o Millenium 120, são aptos.

Os resultados descritos permitem caracterizar cada um dos sistemas de MLC estudados. Não é possivel dizer que um sistema é melhor que outro, mas é possivel a partir da escolha de um deles identificar as possiveis vantagens e desvantagens que cada um vai apresentar. Não existe um sistema de MLC 
completo nem perfeito, o importante é que o sistema escolhido preencha os requisitos necessários na prática clínica de acordo com a realidade do Serviço de Radioterapia.

As recomendações futuras de pesquisa são a caracterização e quantificaçāo da influência dos parâmetros levantados no comissionamento no planejamento clínico, isto é, quanto vai influenciar no planejamento clínico as diferenças encontradas no comissionamento do sistema de MLC. 


\section{REFERÊNCIAS BIBLIOGRÁFICAS}

[1] BOYER A.; BUTLER B.; DIPETRILLO T.; ENGLER, M.; FRAASS, B.; GRANT, W.; LING, C.; LOW, D.; MACKIE, T.R.; MOHAN, R.; PURDY, J.; ROACH, M.; ROSENMAN, J.; VERHEY, L.; WONG, J.; CUMBERLIN, R.; STONE, H.; PALTA, J. Intensity Modulated Radiation Therapy Collaborative Group. Intensity Modulated Radiotherapy: Current Status and Issues of Interest. Int. J. Radiat. Oncol. Biol. Phys. v. 51, n. 4, p. 880-914. 2001.

[2] PURDY J, GRANT W. III; PALTA J.; BUTLER E.; PEREZ C.; editors. 3-D Conformal and Intensity Modulated Radiation Therapy: Physics and Clinical Applications. Madison, WI: Advanced Medical Publishing; 2001.

[3] EZZEL G.; GALVIN J.; LOW, D.; PALTA J.; ROSEN, I.; XIA, P.; XIAO, Y.; $X I N G, L$. Guidance document on delivery, treatment planning, and clinical implementation of IMRT: Report of the IMRT subcommittee of the AAPM Radiation Therapy Committee. Med. Phys. v. 30, n. 8, p. $2089-2115$ 2003.

[4] GALVIN, J.; EZZELL, G.; EISBRAUCH, A.; YU, C.; BUTLER, B.; XIAO, Y.; ROSEN, I.; ROSENMAN, J.; SHARPE, M.; XING, L.; XIA, P.; LOMAX, T.; LOW, D.; PALTA, J. Implementing IMRT in Clinical Practice: A joint document of the American Society for Therapeutic Radiology and Oncology and the American Association of Physicists in Medicine. Int. J. Radiat. Oncol. Biol. Phys. v.58, n. 5, p. $1616-1634,2004$.

[5] INTERNATIONAL COMMISSSION ON RADIATION UNITS AND MEASUREMENTS, (ICRU), "Prescribing, recording and reporting photon beam therapy". International Commission on Radiation Units and Measurements. ICRU Report 50, ICRU, Bethesda, Maryland, USA (1993).

[6] INTERNATIONAL COMMISSSION ON RADIATION UNITS AND MEASUREMENTS, (ICRU), "Prescribing, recording and reporting photon beam therapy (Supplement to ICRU Report 50)", ICRU Report 62, ICRU, Bethesda, Maryland, USA (1999). 
[7] PODGORSAK, E.; editor. Review of Radiation Oncology Physics: A Handbook for Teachers and Students. Vienna, Austria. International Atomic Energy Agency. Educational Reports Series, 2003.

[8] ALMOND, P.; BIGGS, P.; COURSEY, B.; HANSON, W.; HUQ, S.; NATH, R.; ROGERS, D. AAPM's TG-51 protocol for clinical reference dosimetry of high-energy photon and electron beams. Med. Phys. v. 26, n. 9, 1847 $1870,1999$.

[9] INTERNATIONAL ATOMIC ENERGY AGENCY. ABSORBED DOSE DETERMINATION IN EXTERNAL BEAM RADIOTHERAPY: An International Code of Practice for Dosimetry Based on Standards of Absorbed Dose to Water. IAEA Technical Reports Series No. 398), Vienna, 2000.

[10] KHAN, F.M. The Physics of radiation therapy. Williams and Wilkins, Second Edition,Baltimore, Maryland, USA (1994).

[11] BUCCIOLINI, M.; BUONAMICI, F.B.; CASATI, M. Verification of IMRT fields by film dosimetry. Med. Phys. v. 31, n. 1, p. $161-168,2004$.

[12] DANCIU, C.; PROIMOS, B.; ROSENWALD, J.C.; MIJNHEER, B. Variation of sensitometric curves of radiographic films in high energy photon beams. Med. Phys. v. 28, n. 6, p. $966-975,2001$.

[13] WILLIAMSON, J.; KHAN, F; SHARMA, S. Film dosimetry of megavoltage photon beams: A practical method of isodensity-to-isodose curve conversion. Med. Phys. v. 8, n. 1, p. $94-98,1981$.

[14] ESSERS, M.; DE LANGEN, M.; DIRKX, M. ; HEIJMEN, B. Commissioning of a commercially available system for intensity - modulated radiotherapy dose delivery with dynamic multileaf collimation. Radiother. Oncol. v. 60 , n. 2, p. $215-224,2001$.

[15] LOSASSO. T.; CHUI, C.; LING, C. Physical and dosimetric aspects of a multileaf collimation system used in the dynamic mode for implementing intensity modulated radiotherapy. Med. Phys. v. 25, n. 10, p. $1919-1927$, 1998. 
[16] LOSASSO, T.; CHUI, C.S.; LING, C.C. Comprehensive quality assurance for the delivery of intensity modulated radiotherapy with a multileaf collimator used in the dynamic mode. Med. Phys. v. 28, n. 11, p. 2209$2219,2001$.

[17] VAN ESCH, A.; BOHSUNG, J.; SORVARI, P.; TENHUNEN, M.; PAIUSCO, M.; IORI, M.; ENGSTRÖM, P; NYSTRÖM, H.; HUYSKENS, D.P. Acceptance tests and quality control quality (QC) procedures for the clinical implementation of intensity modulated radiotherapy (IMRT) using inverse planning and the sliding window technique: experience from five radiotherapy departments. Radiother. Oncol. v. 65, n. 1, p. 53-70, 2002.

[18] VENENCIA, C.; BESA, P. Commissioning and quality assurance for intensity-modulated radiotherapy with dynamic multileaf collimator: Experience of the Pontificia Universidad Católica de Chile. Journal of Applied Clinical Medical Physics. v. 5, n. 3, p. $37-54,2004$.

[19] FRAASS, B.; DOPPKE, K.; HUNT, M.; KUTCHER, G.; STARKSCHALL, G.; STERN, R.; VAN DYKE, J. American Association of Physicists in Medicine Radiation Therapy committee Task Group 53: Quality assurance for clinical radiotherapy treatment planning. Med. Phys. v. 25, n. 10, p. $1773-1828$, 1998.

[20] INTERNATIONAL ATOMIC ENERGY AGENCY. Aspectos fisicos de la garantia de calidad en radioterapia: Protocolo de control de calidad. IAEA Technical Document No. 1151, Vienna, 2000.

[21] INTERNATIONAL ATOMIC ENERGY AGENCY. Commissioning and quality assurance of computerized planning systems for radiation treatment of cancer. IAEA Technical Reports Series No. 430, Vienna, 2004.

[22] LOSASSO, T.; KUTCHER, G. Multileaf collimation versus alloy blocks: Analyis of geometric accuracy. Int. J. Radiat. Oncol. Biol. Phys. v. 32, n. 2, p. $499-506,1995$.

[23] HOUNSELL, A. R.; JORDAN, T. Quality control aspects of the Philips multileaf collimator. Radiother. Oncol. v. 45, n. 3, p.225-233, 1997. 
[24] KLEIN, E.; LOW, D.; MAAG, D.; PURDY, J. A quality assurance program for ancillary high technology devices on a dual-energy accelerator. Radiother. Oncol. v. 38, n. 1, p. $51-60,1996$.

[25] MUBATA, C.; CHILDS, P.; BIDMEAD, M. A quality assurance procedure for the Varian multi-leaf collimator. Phys. Med. Biol. v. 42, n.2, p. 423 - 431 , 1997.

[26] BOYER, A., BIGGS, P.; GALVIN, J.; KLEIN, E.; LOSASSO. T.; LOW, D.; MAH, K. AND YU, C. Basic Applications of Multileaf Collimators: Report of the AAPM Radiation Therapy Committee Task Group No. 50. AAPM Report No. 72. Madison, WI: Medical Physics Publishing, 2001.

[27] LINTHOUT, N. Tese de Doutorado: Evaluation of Conformal Radiation Therapy Techniques using various multileaf collimators. Vrije Universiteit Brussel. Faculteit Geneeskunde en Farmacie. 2003.

[28] COSGROVE, V.; JAHN, U.; PHAENDER, M.; BAUER, S.; BUDACH, V.; WURM, R.E. Commissioning of a micro multi-leaf collimator and planning system for stereotactic radiosurgery. Radiother. Oncol. v. 50, n. 3, p. $325-$ 336, 1999.

[29] LINTHOUT, N.; VERELLEN, D.; VAN ACKER, S.; STORME, G. A simple theoretical verification of monitor unit calculation for intensity modulated beams using dynamic mini-multileaf collimation. Radiother. Oncol. v. 71, $\mathrm{n}$. 2, p. $235-241,2004$

[30] DEPUYDT, T.; VAN ESCH, A.; HUYSKENS, D.P. A quantitative evaluation of IMRT dose distributions: refinement and clinical assessment of the gamma evaluation. Radiother. Oncol. v. 62, n. 3, p. $309-319,2002$.

[31] CRUZ, J.C.; SEGRETO, R.A.; SEGRETO, H.R.C. Estudo dosimetrico de campos circulares pequenos de raios $X$ utilizados em radiocirurgia com um acelerador linear de 6 MV. Rev. Imagem. v. 25, n. 4, p. $257-267,2003$.

[32] QA test patterns and procedures (P/N 100012878-01). Varian Medical Systems, Inc., Palo Alto, CA.

[33] ARNFIELD, M. R.; SIEBERS, J.V.; KIM, J.O.; WU, Q.; KEALL, P.J.; MOHAN, R. "A method for determining multileaf collimator transmission and 
scatter for dynamic intensity modulated radiotherapy." Med. Phys. v. $27, \mathrm{n}$. 10, p. 2231-2241, 2000.

[34] LITZENBERG, D.; MORAN, J.; FRAAS, B. Verification of dynamic and segmental IMRT delivery by dynamic log file analysis. Journal of Applied Clinical Medical Physics. v. 3, n. 2, p. $63-73,2002$.

[35] LOSASSO, T. IMRT Delivery System QA. In: PALTA, J.; MACKIE, R., editors. Intensity Modulated Radiation Therapy: The State of the Art. Medical Physics Monograph 29. 2003 AAPM Summer School Proceedings. Colorado Springs; p. $561-591,2003$.

[36] AMERICAN ASSOCIATION OF PHYSICISTS IN MEDICINE. Comprehensive QA for radiation oncology: Report of AAPM Radiation Therapy Committee Task Group - 40. Med. Phys. v. 21, n. 4, p. 518 - 618, 1994.

[37] CHAUVET, I.; PETITFILS, A.; LEHOBEY, C.; KRISTNER, J.Y. ; BRUNET, Y.; LEMBREZ, R. ; GABORIAUD, G.; MAZAL, A.; ZEFKILI, S.; ROSENWALD, J.C. The sliding test for dynamic IMRT: a useful tool for adjustment of MLC related parameters. Phys. Med. Biol. v. 50, n. 4, p. 563 $-580,2005$.

[38] HUQ, S.; DAS, I.; STEINBERG, T.; GALVIN, J. A dosimetric comparison of various mutileaf colimators. Phys. Med. Biol. v. 47, n. 12 , p. N159-N170, 2002.

[39] BOYER A.L; OCHRAN T.G.; NYERICK C.E.; WALDRON T.J. Clinical Dosimetry for implementation of a multi-leaf collimator. Med Phys.. v.19, n. 5 , p. $1255-1261,1992$.

[40] GALVIN, J.; SMITH, A.; LALLY, B. Characterization of a Multileaf Collimator System. Int. J. Radiat. Oncol. Biol. Phys. v. 25, n. 2, p. 181 - 192, 1993.

[41] SCHELL, M.; BOVA, F.; LARSON, D.; LEAVITT, D.; LUTZ, W.; PODGORSAK, E.; WU, A. Stereotactic Radiosurgery. Report of the AAPM Radiation Therapy Committee Task Group No. 42. AAPM Report No. 54. New York: American Institute of Physics, 1995. 
[42] XIA, P.; GEIS, P.; MA, C.; FINDLEY, D.; FORSTER, K.; BOYER, A. Physical characteristics of a miniature multileaf collimator. Med. Phys. v. 26 , n. 1, p. $65-70,1999$.

[43] Informaçōes técnicas e especificaçōes do micro colimador multi-lâminas $m_{3}$ BrainLab, Disponivel em <http:llwww.brainlab.com>. Acceso em: 08 abril, 2005.

[44] YIN, F.F.; ZHU, J.; YAN, H.; GAUN, H.; HAMMOUD, R.; RYU, S.; KIM, J. Dosimetric characteristics of Novalis shaped beam surgery unit. Med. Phys. v. 29, n. 8, p. $1729-1738,2002$.

[45] HARTMANN, G.H.; FÖHLISCH, F. Dosimetric characterization of a new miniature multileaf collimator. Phys. Med. Biol. v. 47, n. 12 , p. N171-N177, 2002.

[46] MONK, J.E.; PERKS, J.R.; DOUGHTY, D.; PLOWMAN, P.N.; Comparison of a micro-multileaf collimator with a $5 \mathrm{~mm}$ - leaf width collimator for intracranial Stereotactic Radiotherapy. Int. J. Radiat. Oncol. Biol. Phys. v. 57, n. 5, p. $1443-1449,2003$. 

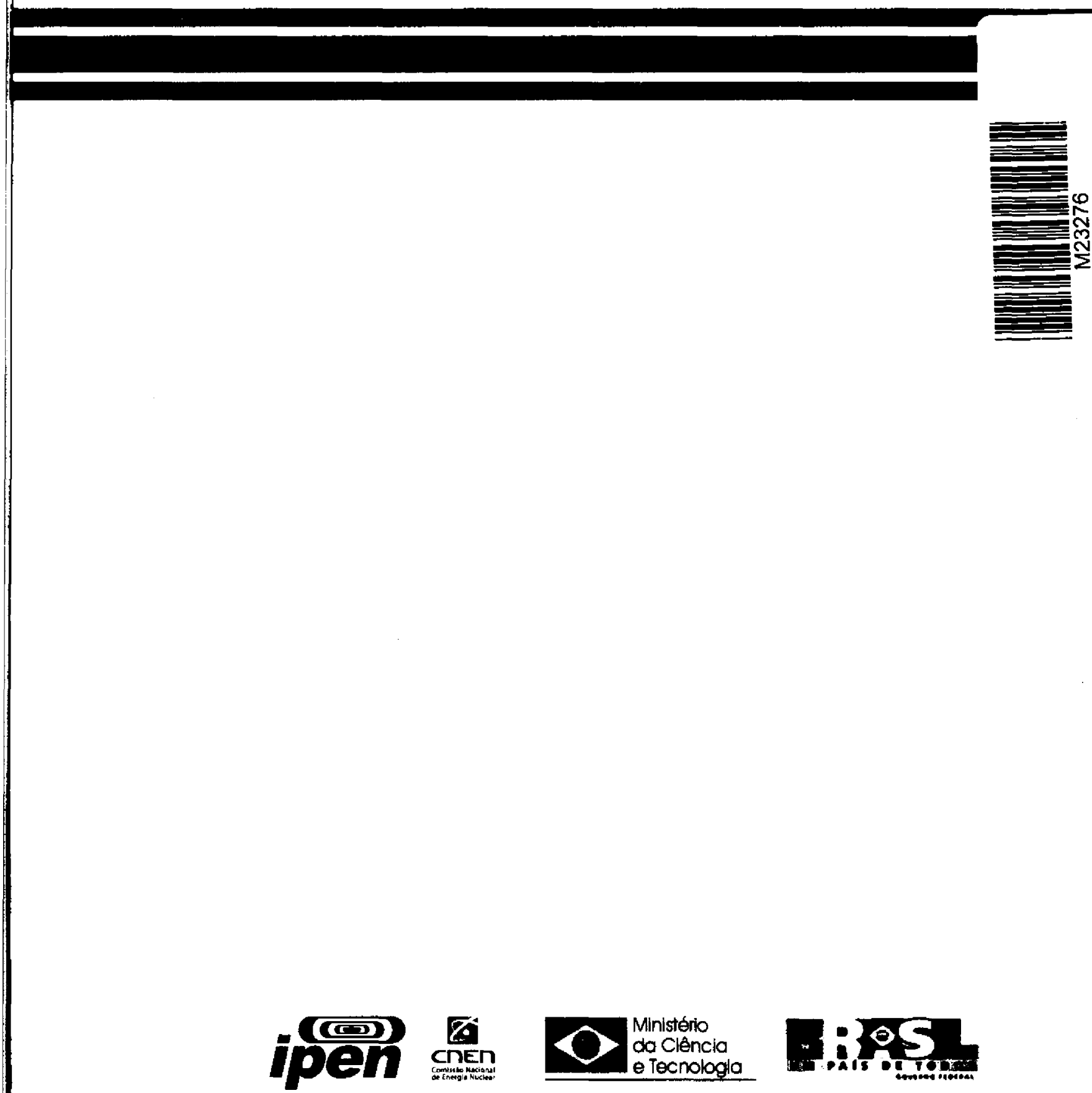

Instituto de Pesquisas Energéticas e Nucleares

Diretoria de Ensino \& Informaça Científica e Tecnológica

Av. Prof. Lineu Prestea, 2242 Cldade Universltarla CEP: 05508-000

Fone/Fax(0XX11) $3816-8148$

SÁO PAULO - Sto Paulo - Brasil

http: /tumw.ipen.br

O Ipen 6 uma autarquia vinculada \& Secretarla de Clencla, Tecnologla $\bullet$ Desenvolvimento Economico

- Turismo do Eatado de \$10 Paulo, gerida thcnics, adminiotrattiva financelramente pela

Comissto Nacional de Enorgla Nuclear, orgtio do Ministorio da Clancla e

Tecnologla, aseociada I Universidade de Slo Paulo. 